\title{
Gender, ritual \\ and social formation \\ in West Papua
}

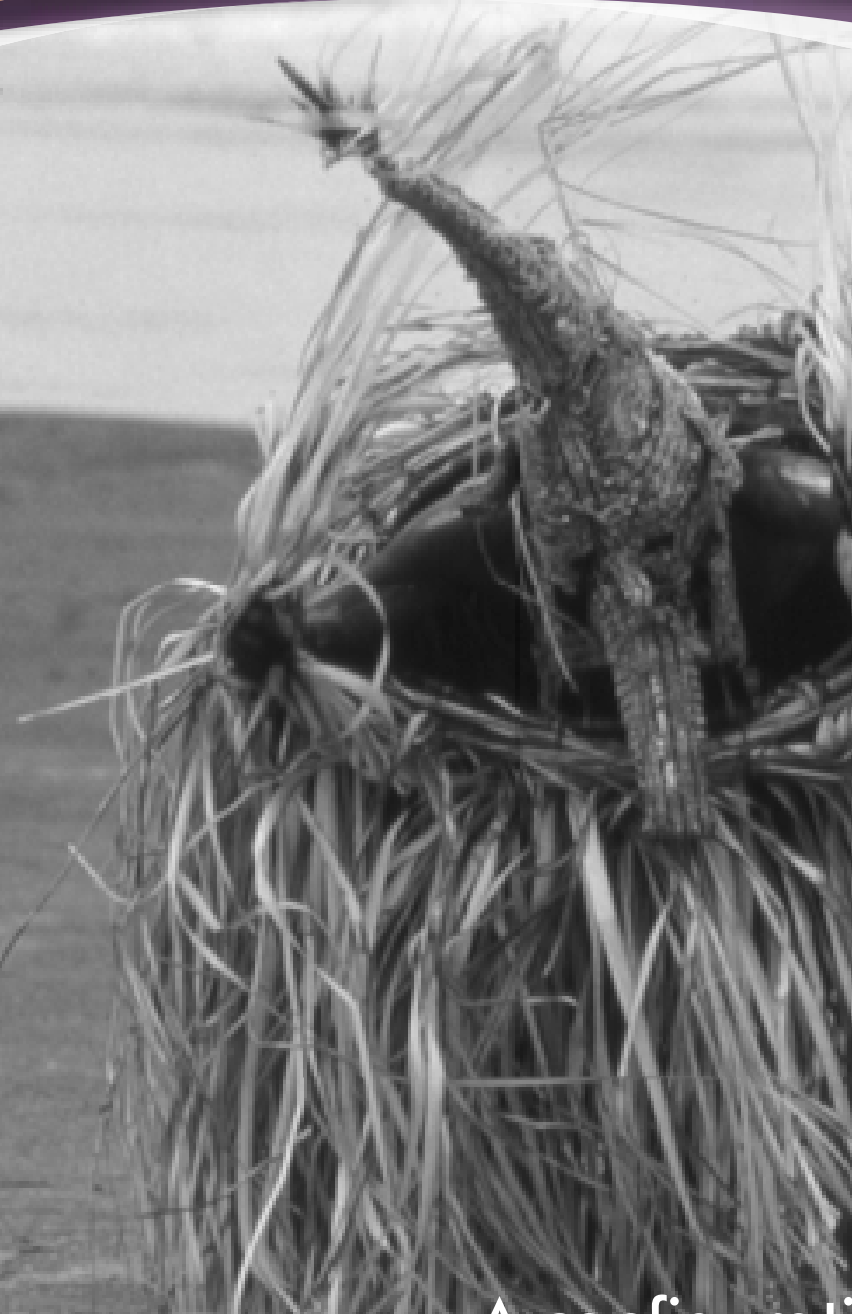

A configurational analysis comparing Kamoro and Asmat 
GENDER, RITUAL AND SOCIAL FORMATION IN WEST PAPUA 


\section{In memory of Ingrid, my courageous companion in Papua}

Cover: The dignitary Galus Mauria enacts the final stage of the Kaware ritual: while throwing lime-powder to mark the accasion he stabs an evil spirit with his ceremonial lance (apoko) in the sand of Paripia beach, West Mimika. From Pickell 2002: front cover. Photograph by Kal Muller. 
V E R H A N D E L I N G E N

VAN HET KONINKLIJK INSTITUUT

VOOR TAAL-, LAND- EN VOLKENKUNDE

$$
258
$$

JAN POUWER

\section{GENDER, RITUAL AND SOCIAL FORMATION IN WEST PAPUA}

A configurational analysis comparing

Kamoro and Asmat

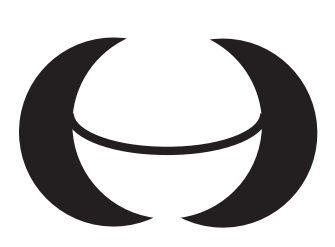

KITLV Press

Leiden

2010 
Published by:

KITLV Press

Koninklijk Instituut voor Taal-, Land- en Volkenkunde

(Royal Netherlands Institute of Southeast Asian and Caribbean Studies)

P.O. Box 9515

2300 RA Leiden

The Netherlands

website: www.kitlv.nl

e-mail: kitlvpress@kitlv.nl

KITLV is an institute of the Royal Netherlands Academy of Arts and Sciences (KNAW)

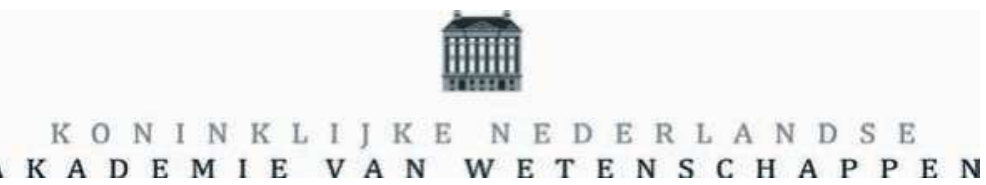

Cover: Creja ontwerpen, Leiderdorp

ISBN 9789067183253

(C) 2010 Koninklijk Instituut voor Taal-, Land- en Volkenkunde

No part of this publication may be reproduced or transmitted in any form or by any means, electronic or mechanical, including photocopy, recording, or any information storage and retrieval system, without permission from the copyright owner.

Printed in the Netherlands 


\section{Contents}

Acknowledgements $\quad$ ix

Notes on spelling $\quad x i$

Abbreviations xiii

Part One Gender and the ritual cycle in Mimika

I Prologue

The structure of this book 7

Duality and reciprocity: two core concepts of Kamoro culture 11

General rituals and ceremonies of the individual life cycle 15

II The 'female' contribution to life

Ema Kame rituals

Occurrence and main functions 19

The structure of the ceremonial house 20

Prelude: the python ceremony 22

Erecting the ceremonial house 25

The framework 25

The rattan ceremony 26

Ore and Tama ceremonies 28

Carved attributes: ceremonial shields 31

Carved attributes: sacred oval boards 32

The ancestress ritual 34

Unveiling ceremonial shields and ceremonial boards 35

Secluding initiates: move and counter-move in gender antagonism 36

The bat ritual 38

The glorious return of the initiates: the hornbill ceremony 40

Postlude 44

III The 'male' contribution to life

Kaware ritual

Kaware ritual and myth 47

Myth 1: Muanuru-from-above and Muanuru-from-below 48

Myth 2: The culture hero Mamirima 49

Myth 3: A widower and his daughters 49 
Male secrets versus female power 50

Clearing the ground 51

Erecting roof support poles 51

Erecting the poles 52

Enacting the death and resurrection of the mythical hero 52

The house-building ceremony 53

Making and erecting spirit poles 54

The sago grub ritual 55

The festival of canoes 56

The grand finale of Kaware 57

IV The initiation of male adolescents

Making and erecting spirit poles; collecting the food 65

Sago magic 67

Pig ritual and hunt 68

Tree lizard ritual 70

Shellfish for the initiation ceremony 71

Sago supply for the initiation ceremony 72

The sun dance 73

The final ceremony: nose piercing 74

The initiation of male adolescents into adulthood 76

The first stage: parting from childhood 76

The second stage: demonstrating skills 77

The third stage: providing the insignia of manhood 77

V Marking death

Critical illness, passing away and mourning 79

Disposal of the dead and bereavement 81

Ceremony marking the end of mourning 83

Ritual cleansing and cancellation of food taboos 84

House of the corpse ceremony 85

Spirit platform ritual 88

Lifting the head-covering 93

Part Two The Kamoro in relation to the Asmat

VI The theory of comparison and the context of the rituals

The theory 97

Languages 102

Sago stands, riverine, marine and horticultural resources 103

Types of kinship and descent 105

Residential aggregates and political affiliations 106

Pervasiveness of dual organization 119

Cosmology 124 
VII Ema Kame and Emak Cem

Ema Kame/Emak Cem and myth 129

Ema Kame/Emak Cem and ritual 142

Comparison 157

VIII Honouring the dead

Display and performance

The myth 167

The ritual 169

The masquerade 175

Donning the armbands 176

IX Male to female

Social opposition versus communal solidarity

The myths 179

The rituals 185

Conclusions 191

$\mathrm{X} \quad$ Initiating young males and commemorating the dead

On nose piercing and spirit poles

The myths: a summary 194

The story of Seitakap 194

The story of Mbish, the ideal wife 195

Comments 197

The rituals 200

Comments 202

XI Asmat headhunting and the initiation of male adolescents

The myths 207

The ritual 217

Prelude 217

The raid 223

The initiation 225

Identifying with the dead: the first stage of male initiation 227

The ritual recognition of adolescence 229

XII Conclusions

XIII Epilogue

Continuity in discontinuity: the current situation 241

Contemporary Kamoro ceremonies 256

Glossary

Bibliography

Index 



\section{Acknowledgements}

I wish to extend my sincere thanks to the following persons:

- Dr Kal Muller, Freeport Mine, Timika, for making available his reports about the recent celebration by Kamoro of ceremonies, attended by him, and a selection of his magnificent photographs, free of charge, and also to his assistant Mrs Luluk Intarti, for being very helpful in dispatching photographs;

- David Pickell for allowing me to use photographs, illustrations and a map published in his highly commendable travelogue (2002) with photographs by Kal Muller;

- Dr Karen Jacobs, University of East Anglia, UK for allowing me to quote liberally from her valuable $\mathrm{PhD}$ thesis Collecting Kamoro;

- Dr Chris Ballard, Research School of Pacific and Asian Studies, Australian National University, for allowing me to quote from his reports and forthcoming papers;

- Drs. Dirk Smidt, retired Curator of the Department of Oceania at the Rijksmuseum voor Volkenkunde, Leiden, and Mrs Monique Koek of the Museum Archives, for assisting in selecting and publishing a number of his and other valuable photographs, free of charge;

- Ursula and Gunter Konrad, Asmat Art Gallery, Mönchengladbach, Germany, for allowing me free of charge to include a selection of their outstanding photographs;

- Mary E. Braun, American Museum of Asmat Art, Saint Paul, Minnesota, USA, for being very helpful in providing me with copies of issues of Asmat sketch book;

- Dr Stuart Robson, retired Associate Professor of Indonesian at Monash University, Australia, for his rapid yet painstaking and creative correction of the English text which required a thorough treatment;

- Drs. Han F. Vermeulen, Leiden, for his careful formatting and typing of the first draft presented to KITLV;

- Dr Toon van Meyl and Drs. René van der Haar, Centre for Pacific and Asian Studies, Radboud University, Nijmegen, for their generous offer to prepare the final format. René van der Haar put many hours of painstaking 
and enthusiastic work into typing the final draft. We exchanged dozens of emails;

- Rita DeCoursey, of KITLV Press, for further revision of terminology, clarity, punctuation, consistency, and sentence structure. Her efforts have rendered the text more accessible;

- Dr Klarijn Anderson-Loven, for her precision and clarity in furthering consistency in spelling native terms and in efficiency of phrasing;

- Finally I wish to express my respect for the dedication of the late Fathers Gerard Zegwaard, MSC, and Julianus Coenen, OFM, to their missionary duties in Mimika and Asmat, often under trying circumstances. They put much effort into gaining a deeper understanding of Kamoro and Asmat lifeways. I owe a lot to them. This publication bears witness to this. 


\section{Notes on spelling}

The following conventions on spelling are used in this book. Indonesian, Asmat and Kamoro expressions are in modern spelling except when in quotations from printed sources. Asmat and Kamoro terms are rendered in the main text without diacritical marks (for instance, mbaowooko), whereas in the Glossary diacritical marks are shown on these words (mbaowòòò). Names of Asmat and Kamoro rituals and ceremonial plays are capitalized. Indonesian words listed in the Concise Oxford dictionary as borrowings into English are treated as English words and spelled as they appear in that dictionary (for instance, raja). In addition, a number of Kamoro words that appear frequently in this book but are not listed in the Concise Oxford dictionary are treated as borrowed words and not italicized (for instance, yew). Geographical names are rendered according to current usage. 



\section{Abbreviations}

ANU Australian National University, Canberra

COW Contract of Work, Freeport Indonesia Mining Company

COWB Second Contract of Work, Freeport Indonesia Mining Company

FUNDWI Fund of the United Nations for the Development of West Irian

KDC Katholiek Documentatie Centrum, Radboud Universiteit, Nijmegen

KIT Koninklijk Instituut voor de Tropen, Amsterdam

KITLV Koninklijk Instituut voor de Taal-, Land- en Volkenkunde, Leiden

LEMASKO Lembaga Masyarakat Adat Kamoro (Indonesian; Kamoro Adat Council)

MSC Missionarii Sacratissimi Cordis Iesu

OFM Ordo Fratrum Minorum

OSC Ordo Sanctae Crucis

RMV Rijksmuseum voor Volkenkunde, Leiden

UNCEN Universitas Cenderawasih, Jayapura 
Figures, tables and photographes 


\section{PART ONE}

Gender and the ritual cycle in Mimika 


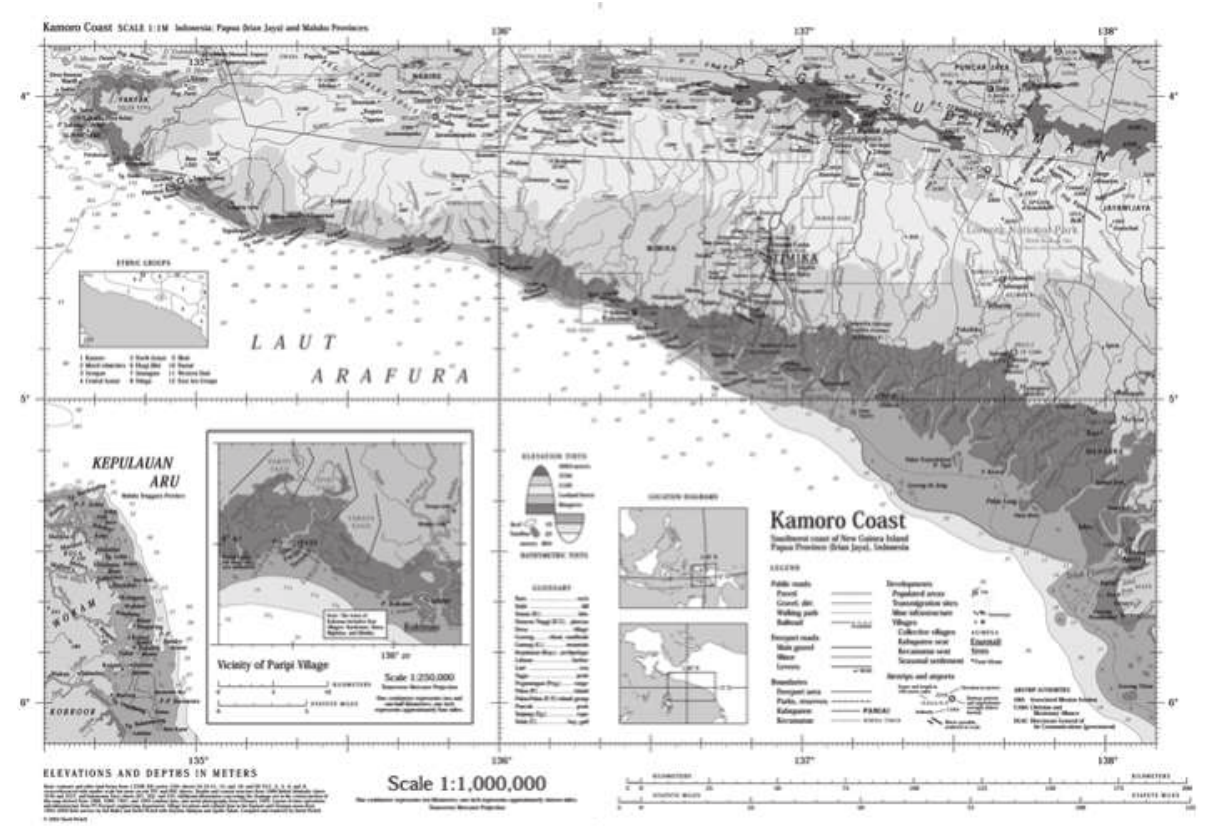

Map 1. Kamoro Coast in 2001. From Pickell 2002: Appendix.

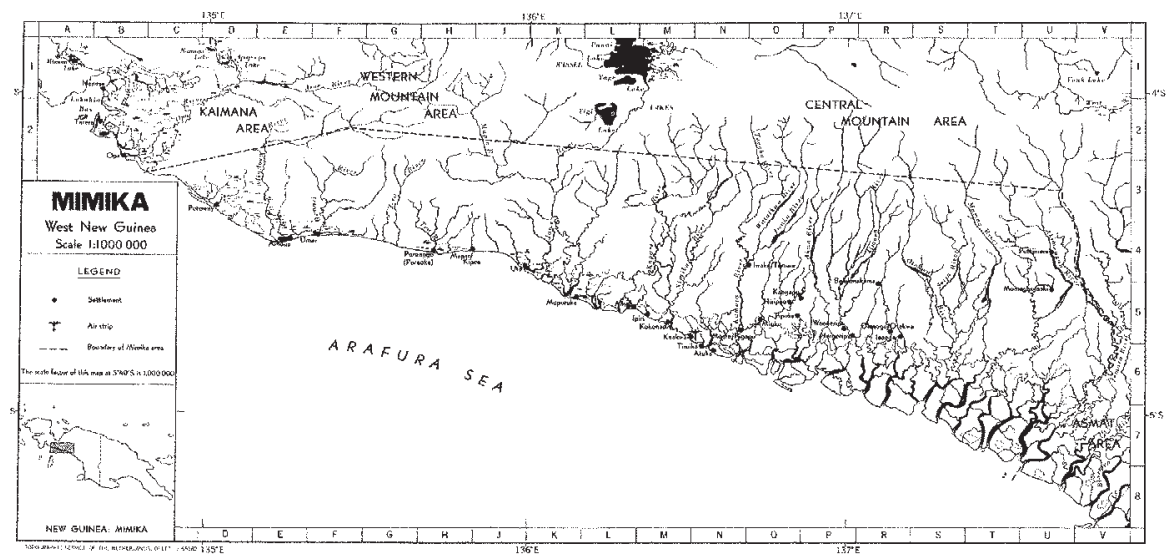

Map 2. Mimika in the 1960s. From Pouwer 1955a: Appendix. 


\section{Chapter I}

\section{Prologue}

The culture of the Kamoro - previously known as the Mimika people - is to be found on the northwestern border of the non-Austronesian linguistic and cultural areas that extend along the south coast of New Guinea from Etna Bay in West Papua to Orokolo in the Gulf District of Papua New Guinea (maps 1 and 2). This huge coastal area is the subject of a comparative study by Bruce Knauft (1993), which is penetrating as well as theoretically and methodologically innovative. However, while the Kamoros' eastern neighbours, the Asmat, are reasonably well covered in Knauft's study (although limited by the paucity of ethnographic data), the Kamoro are dealt with only in passing. For example, there is no mention of ritual homosexuality, the complementarity of female and male cult life, sister exchange marriage, or early trading through rajas in West Mimika. This is despite the availability of systematic ethnographic descriptions. ${ }^{1}$ In addition, extensive fieldwork reports from the 1950s on such subjects as the social and ritual commemoration of death and the participants' view of history are available, although not in print. Among these sources Knauft refers only to Pouwer 1956, 1975 and 1991. This omission may be partly due to lack of a reading knowledge of Dutch. For example, my doctoral dissertation (Pouwer 1955a), which deals mainly - in a configurative fashion - with socio-economic structure, reciprocity as a total social fact, history and social change, was written in Dutch. In Part Two of the present publication I attempt to make up for Knauft's omission by comparing the Kamoro with the Asmat along the lines that he sets out.

Recent years have seen a welcome accumulation of data and interpretations on the Kamoro that is internationally accessible. This includes information about the massive changes that have occurred since the late 1960s. To put this in perspective, the 1961 census of the entire Mimika district showed that the Kamoro $(9,300)$ then constituted $96.5 \%$ of the total population, with Chinese and other Indonesians representing 3\%, and Europeans $0.5 \%$ (Kamoro baseline study 1998:36). In 1998, however, this position was almost reversed: the 


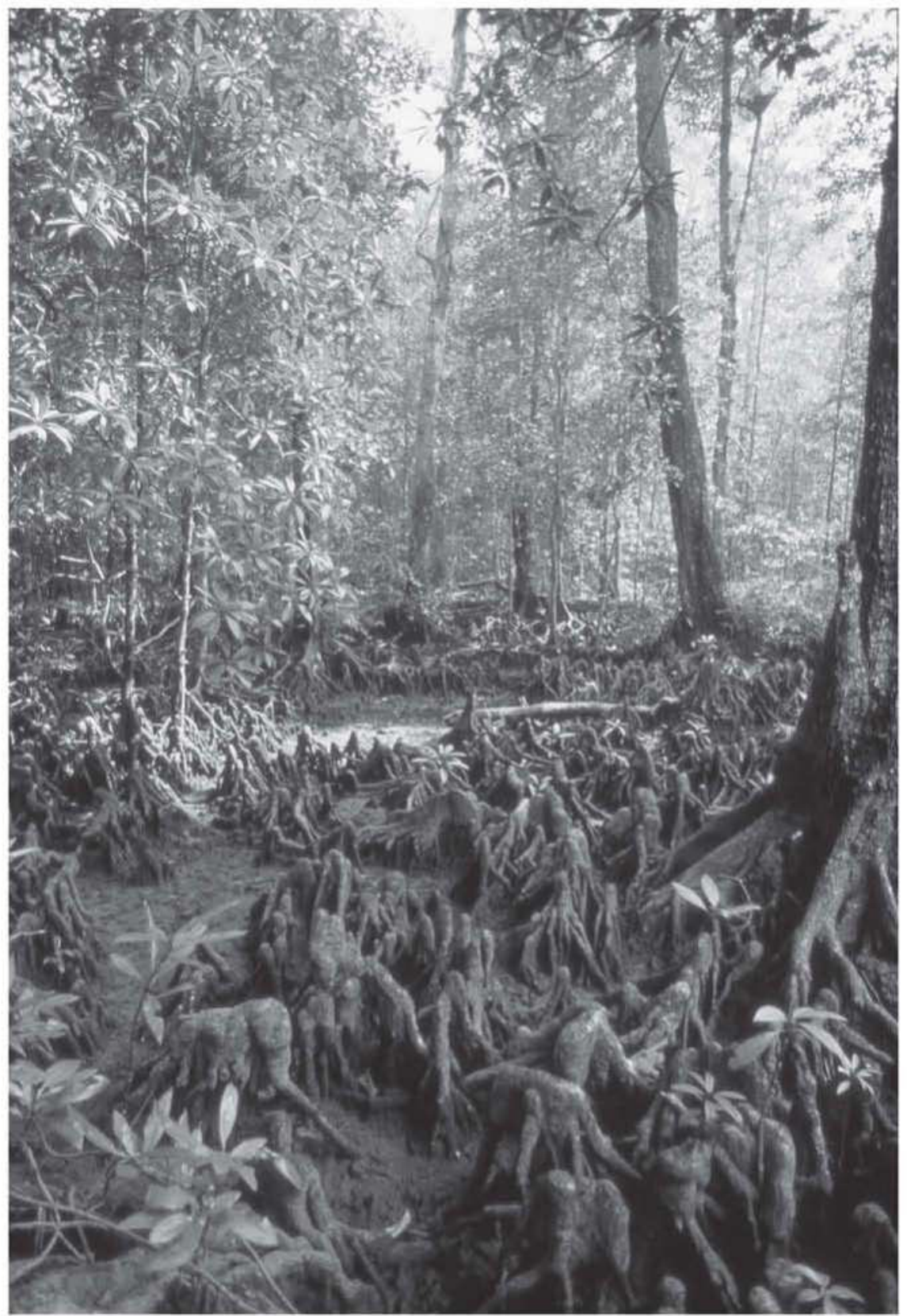

Mangrove, inland from Paripi, Mimika, 1997. Growing in regularly flooded soil, the Bruguiera tree has 'knees' so that its roots will have access to air. From Pickell 2002:30. Photograph by Kal Muller. 
Kamoro were then estimated to represent only $15 \%$ of the total population, a minority in their own country (Kamoro baseline study 1998:5). The main cause of this change was the immigration of very large numbers of Indonesians from various parts of Indonesia after the former Netherlands New Guinea was handed over to Indonesia in 1963. The majority of these immigrants settled in the eastern part of the district, attracted by the arrival of the Freeport Indonesia Mining Company (abbreviated as Freeport Mine) in 1967. Moreover, in this process the Indonesian transmigration department also targeted the township of Timika and its surroundings. By 1985 at least nine transmigration settlements had been established in this area (Kamoro baseline study 1998:36). In 1955 the coastal village of Timika or Timuka had about 578 inhabitants (Pouwer 1955a:283). Its present namesake and modern successor, located inland on a different site, has about 40,000 inhabitants, including about 7,500 Kamoro, roughly half of the total Kamoro population of the entire district (Harple 2000:196). This new Timika has become an icon of inequity, human rights abuse, and environmental destruction, as Harple (2000:190) asserts. The total population of the Freeport Contract of Work (COW) area, ranging over 90 kilometres from the coast to the mountains, is estimated at more than 120,000. This includes government-sponsored transmigrants, mine employees and their families, members of Kamoro and Highland Amungme or related tribal groups from outside the COW area, and spontaneous migrants from other parts of West Papua and Indonesia (Ballard and Banks 2007:21).

Yet in spite of drastic political change, modernization, and mass immigration, the Australian National University $\mathrm{PhD}$ thesis by the American Todd Harple, based on 20 months of fieldwork between 1996 and 1998 and taking my 1955 thesis as a baseline, bears ample testimony to cultural and social continuity (Harple 2000). His ethno-historical analysis of social engagement gives further striking evidence, already documented in my thesis and in other publications, of an incorporation by the Kamoro of foreign elements and their reformulation in terms of the exploits of suprahistorical culture heroes to whom the origin of major social institutions and critical features of the environment are ascribed. The Kamoro clearly interpret their history as being propelled by the ageless and dynamic principle of reciprocity, rather than by 'progress' (see for instance Pouwer 1975). The negation by foreigners of kata - the Kamoro term for ritual secrets and individual characteristics and, by extension, modern wealth and abilities - emerges as a dominant theme in Kamoro narratives. It is interpreted as theft, ultimately establishing relationships of negative reciprocity between the Kamoro and powerful outsiders (see Harple 2000:vii).

In the light of this remarkable continuity it is a happy coincidence that in 2002 an anthology of 22 Asmat and 23 Kamoro narratives was published, with emphasis on the Kamoro (Offenberg and Pouwer 2002). The majority of the stories in this anthology were collected by the late Father Gerard Zegwaard, 


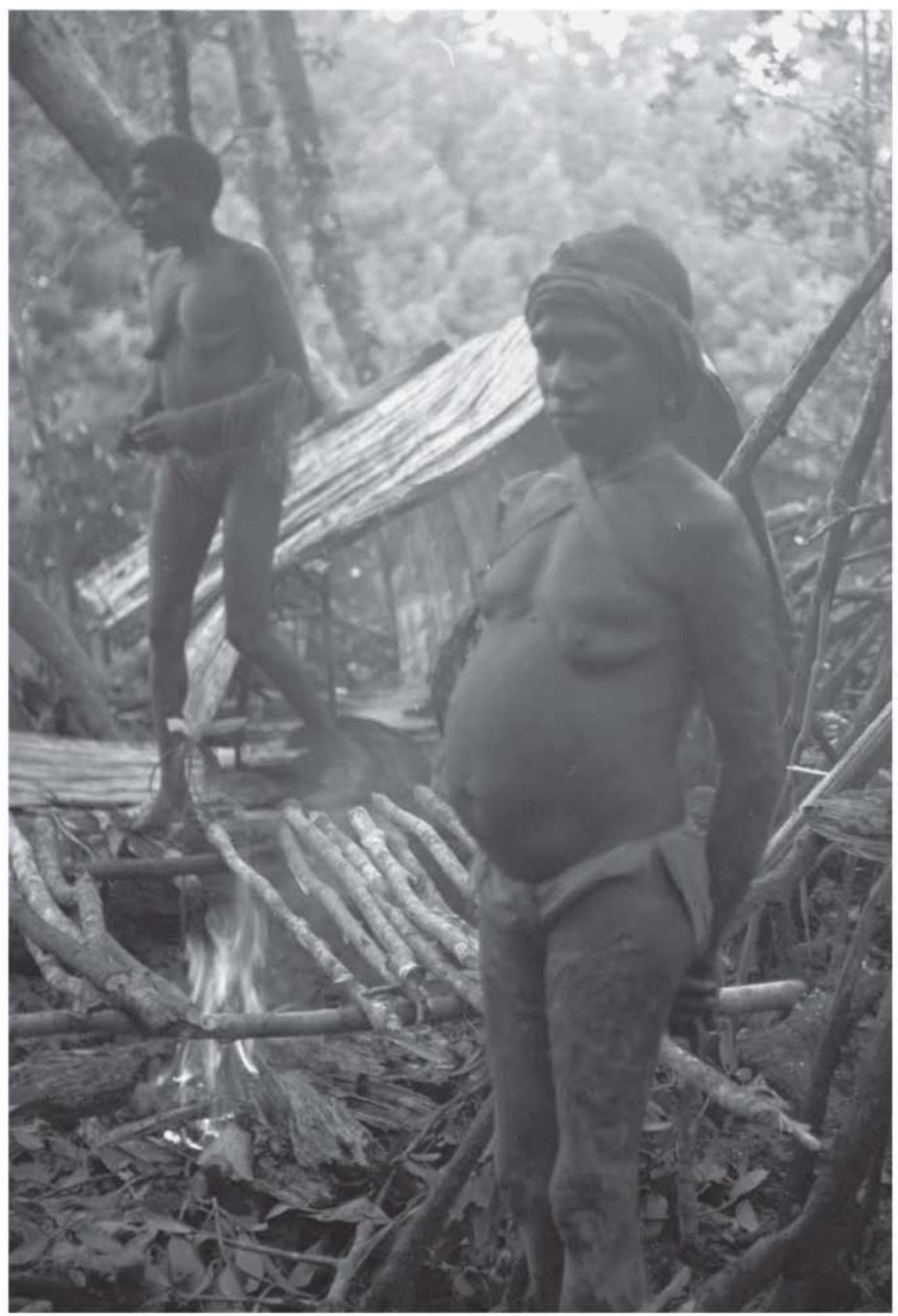

A couple and their temporary shelter near a fishing weir in a mangrove creek, Ipiri, Mimika, 1954. RMV: 10809-54-78. Photograph by Jan Pouwer. 
MSC (1919-1996), a missionary to both Kamoro and Asmat. The anthology in his honour was supplemented by narratives assembled by the late Father Julianus Coenen, OFM (1924-1984) and myself. Sjel Coenen, who was largely based in the eastern Kamoro villages from 1953 to 1963, spent more time among the Kamoro than any other Kamoro ethnographer. His lengthy essay (Coenen 1963), written as a complement to my doctoral thesis (Pouwer 1955a), was unfortunately never published. It is a principal source of knowledge of and insight into Kamoro cosmology and worldview. It takes the work of Zegwaard and myself as a baseline in a critical, highly informed way.

The most recent contribution to Kamoro ethnography was provided on the occasion of a comprehensive exhibition of Kamoro art staged by Dirk Smidt at the National Museum of Ethnology, in Leiden, from February to August 2003. At a certain point Kamoro woodcarvers even enlivened the exhibition. The museum holds a unique collection of about 1,300 objects, the largest Kamoro collection in the world, assembled from as early as 1828 up to the present time. The latest acquisitions date from the 2002 Kamoro Arts Festival organized by Freeport Mine official Kal Muller (Jacobs 2003b). The lavishly illustrated catalogue (Smidt 2003) includes a lengthy essay on Kamoro rituals (Pouwer 2003). Part One of the present book is a revised and expanded version of this essay. Harple, as well as contributing to this catalogue in conjunction with the Kamoro author Mamapuku (Mamapuku and Harple 2003), also wrote a case study about the outward appearance and deeper reality of the first Kamoro Arts Festival in 1998, as a prologue to Offenberg and Pouwer (2002:xxii-xxvi).

\section{The structure of this book}

This book consists of two parts. Part One is a revised version of an essay published in Dirk Smidt's Kamoro art; Tradition and innovation in a New Guinea culture (Pouwer 2003:24-57). It looks at Kamoro culture through the window of its ritual cycle, the material culture is clearly dependent on the ritual. The socio-economic, political and mytho-cosmological setting of the ritual cycle is referred to only briefly in this part. Part Two takes the spectator to the terrace at the top of the cultural edifice. This offers a wider, more extensive view of the setting, while continuing to concentrate on the rituals. Moreover, it does so from a cross-cultural perspective, by means of a configurational-comparative analysis of Kamoro with the adjacent Asmat culture. ${ }^{2}$ By 'configuration' I mean a process that turns elements into components arranged and imbued with 


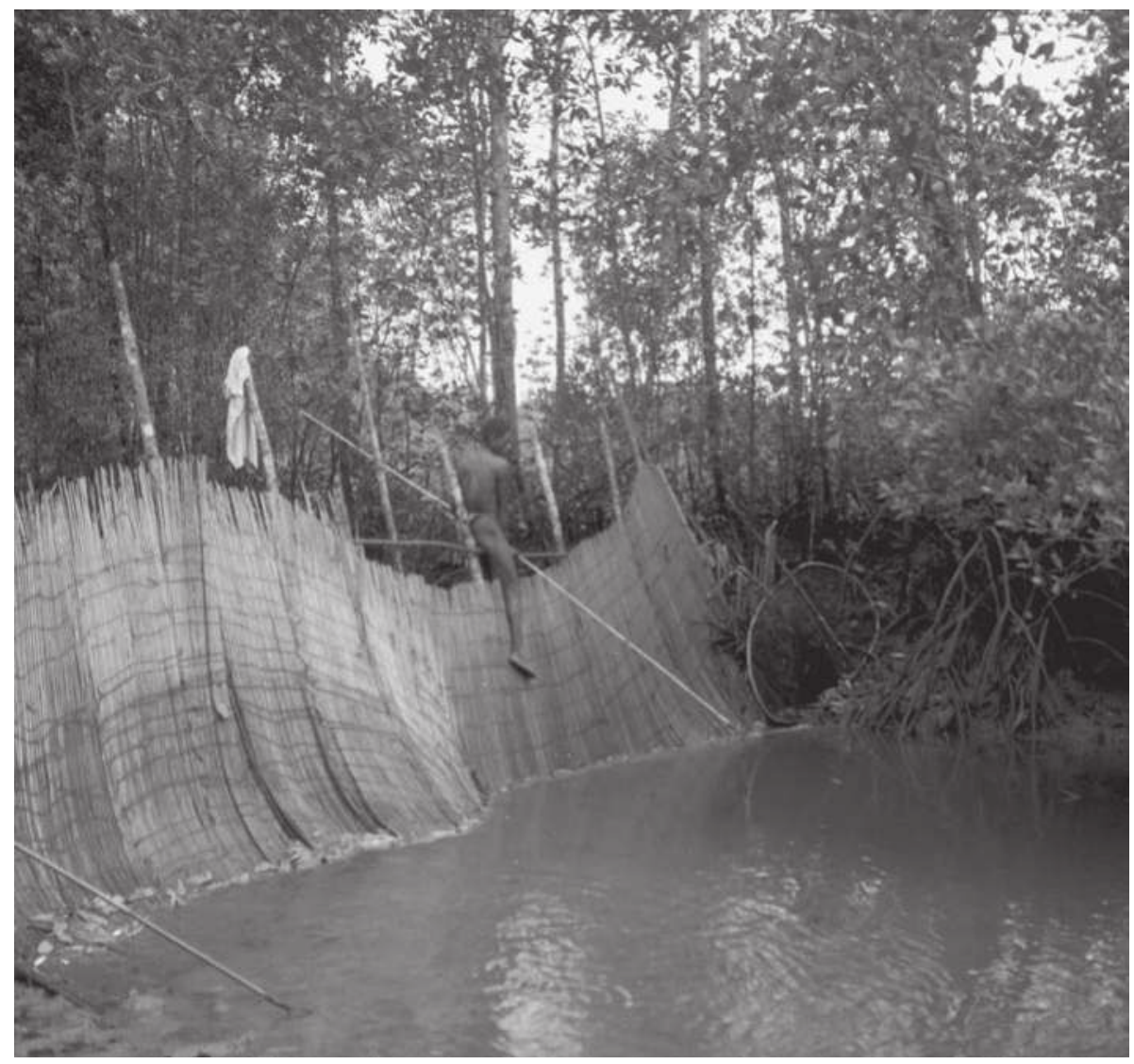

Fishing weir in tidal creek, downstream Ipiri River, February 1954. RMV: NG-54-75. Photograph by Jan Pouwer.

meaning by a central orientation. Similar or even identical elements in different configurations may have different meanings or functions. Both configuration and orientation are conceived of as always being on the move, never closed, always open to change, ambivalence and contradiction. A configurational approach assumes a central orientation that permeates a particular society and culture. Put differently, an arrangement is more than the sum of its parts. Hence, similar or even identical phenomena occurring in differently oriented configurations may have different meanings. Configuration is conceived of as a process, and this is why it is always open to alteration. It does not exclude variations and contradictions. The two cultures are sufficiently similar to justify a comparison, and at the same time they are sufficiently different to make 
a comparison useful for a deeper understanding of the cultures concerned.

Part One is written in the ethnographic present of 1951-1955, when I was in the field for about two years. The inhabitants of the area were then known by the exonym Mimikans, named after the Mimika River in the central district, where the Dutch colonial government opened its first station in 1926. After Netherlands New Guinea was transferred to Indonesia in the early 1960s, the exonym Kamoro, introduced by the linguist Father Petrus Drabbe, MSC to indicate their language (Drabbe 1953), was extended to denote its speakers as well. 'Kamoro' actually means 'living person' as opposed to 'spirit'. The exonyms were used because there was no native term for the entire population of the district. As we nata, 'real human beings', they contrasted themselves with we awayte (literally: further people, 'not-really human persons'), such as the Asmat and the Kapauko (meaning 'inland people').

Oral traditions trace the origins of the Kamoro to four groups in the lowlands, east of the Otakwa River, which constitutes the boundary between the Kamoro and their eastern neighbours, the Asmat. It is likely that a historical exodus, caused in part by a conflict over rich sago groves in the far eastern part of the island, triggered a chain reaction, reaching at least as far as Etna Bay, the boundary of Mimika to the west.

Early contacts with Indonesian and Chinese traders and Dutch explorers date back to about 1600 . In the first half of the twentieth century there was another rush from east to west, this time for ironware, textiles, earrings, betel nuts, and beads. These products were exchanged for resin, birds of paradise, crocodile skins, and slaves. The initial trading centre was Etna Bay. Dignitaries from areas west of Etna Bay, who represented trading interests of the Sultans of Ceram, Ternate and Tidore, in their turn appointed rajas in West Mimika as far as the Mimika River. There was some superficial Islamization.

From about 1926 the Roman Catholic Mission and the colonial government established central and sub-district stations. Attitudes towards these various sorts of foreigners, including Chinese traders, passed through a number of stages, from enmity, to cautious rapprochement, to strong enthusiasm inspired by a fervent desire for commodities, to disappointment and passive acceptance of their power and their permanent presence. After the Dutch were forced to leave in the 1960s, the establishment of the American-Indonesian Freeport copper and goldmine, excavating in the central highlands west of the Carstensz glaciers, meant a new invasion, this time of industrial civilization. It led to large shifts of residence and a move of Kamoro from west to east. Also, it turned the Kamoro into a minority.

The swampy lowlands where the Kamoro live are bounded on the north by the highlands, the mountain range of which descends towards Etna Bay in the southwest. From there an ever-widening coastal plain extends to the northeast, to the upper reaches of Otakwa River, some 90 kilometres from 


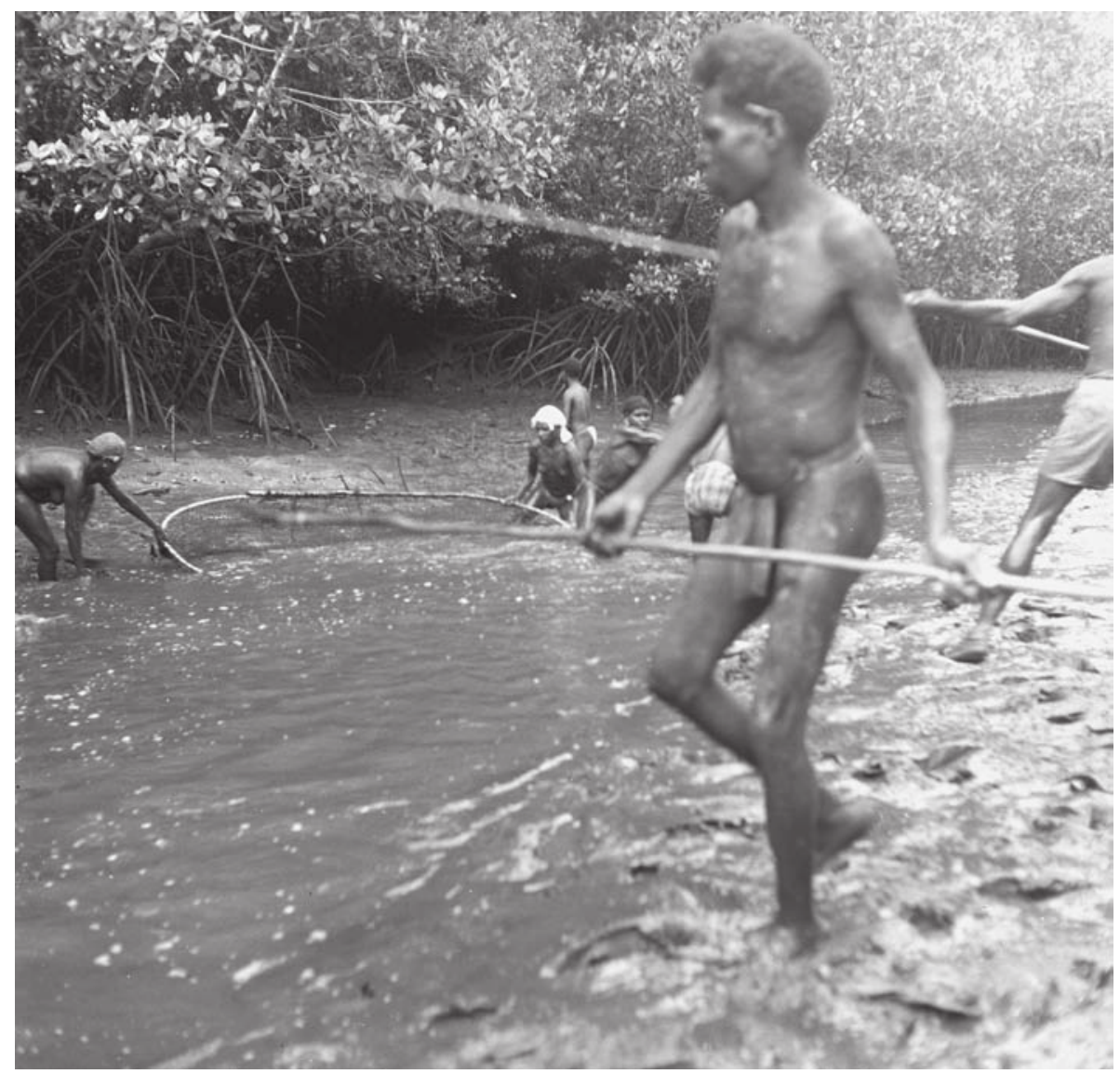

Man spearing, women scooping fish near fishing weir, downstream Ipiri River, February 1954. RMV: NG-54-82. Photograph by Jan Pouwer.

the sea. This geographical southwest-northeast orientation is expressed in the important Kamoro distinction imuu-kapao (coast, downstream vs inland, upstream). Some 60 swamp and mountain rivers and tributaries and countless creeks traverse the lowlands. Behind a rather small sandy beach confined to West and Central Mimika are tidal woods and, further inland, dense swamp forests. Everyday life consisted, and still consists, of moving up and down between the sago forests upstream and the main fishing grounds downstream and in the estuaries. Hence transport is by river-going shallow dugouts $(k u)$ and seagoing canoes with high sharp bows (torepa). The latter were introduced from an area west of Etna Bay. The two types of canoe and their associated songs are sharply distinguished in Kamoro culture. 
Food production is traditionally part of a cycle of festivities and rituals. Labour derives its incentive from the performance of ceremonies. This traditional rhythm of life and work was interrupted by the advent of trade, the Mission, the colonial government, and modern money-oriented work. Leadership traditionally is informal and diffuse; it depends on a combination of age and personal qualities. In times of strife, we ayku, literally 'big men', acted as leaders for the occasion.

Localized descent groups (taparu) claim a territory (tapare) of their own. A descent group consists of putatively linked, exogamous units comprising three generations. Although matrilineally oriented, these groups and units stress horizontal rather than vertical ties. Intermarriage between members of these units does occur, if the persons concerned are not considered closely related kin. Hence a taparu consisting of a relatively large number of constituent units may be non-exogamous, whereas a taparu with a small number of units tends to be exogamous.

There are also complementary grounds for kinship and descent that tend to blur the matrilines. The numerous individual entitlements to rituals are inherited mainly along patrilines. The preferred matrilocal or uxorilocal type of marriage is one of exchange of real or putative sisters. In actual practice, however, alongside 'right' marriages there are many 'left' marriages that involve payment of a brideprice.

There are about 50 ethnic units consisting of a variable number of taparu, which claim and inhabit particular territories along the main rivers. They used to live in and move between more permanent longhouses and temporary settlements near the fishing and sago grounds. Since the coming of the Mission and colonial rule, these ethnic units have lived in villages, usually two or more ethnic groups to a village. The number of inhabitants of a village ranges from 100 to 600 . Due to the greater abundance of sago in the eastern regions, the larger villages are found there. Their eastern neighbours, the Asmat, still outnumber the Kamoro. The Asmat live in settlements ranging from 800 to 2,000 and have control over large sago and fishing grounds. They are more powerful; in pre-colonial times the Kamoro feared attacks by them and cannibalism, which was not practised by the Kamoro. Some communities in the far eastern part of Mimika were indeed subject to attacks by Asmat.

\section{Duality and reciprocity: two core concepts of Kamoro culture}

Duality permeates Kamoro society, culture and cosmology. There is a dual counting system. Dual distinctions abound in kinship and affinity. Marriages are either 'right' (superior) or 'left' (inferior). There is a clear terminological and behavioural distinction between superior bride-givers and inferior bride- 


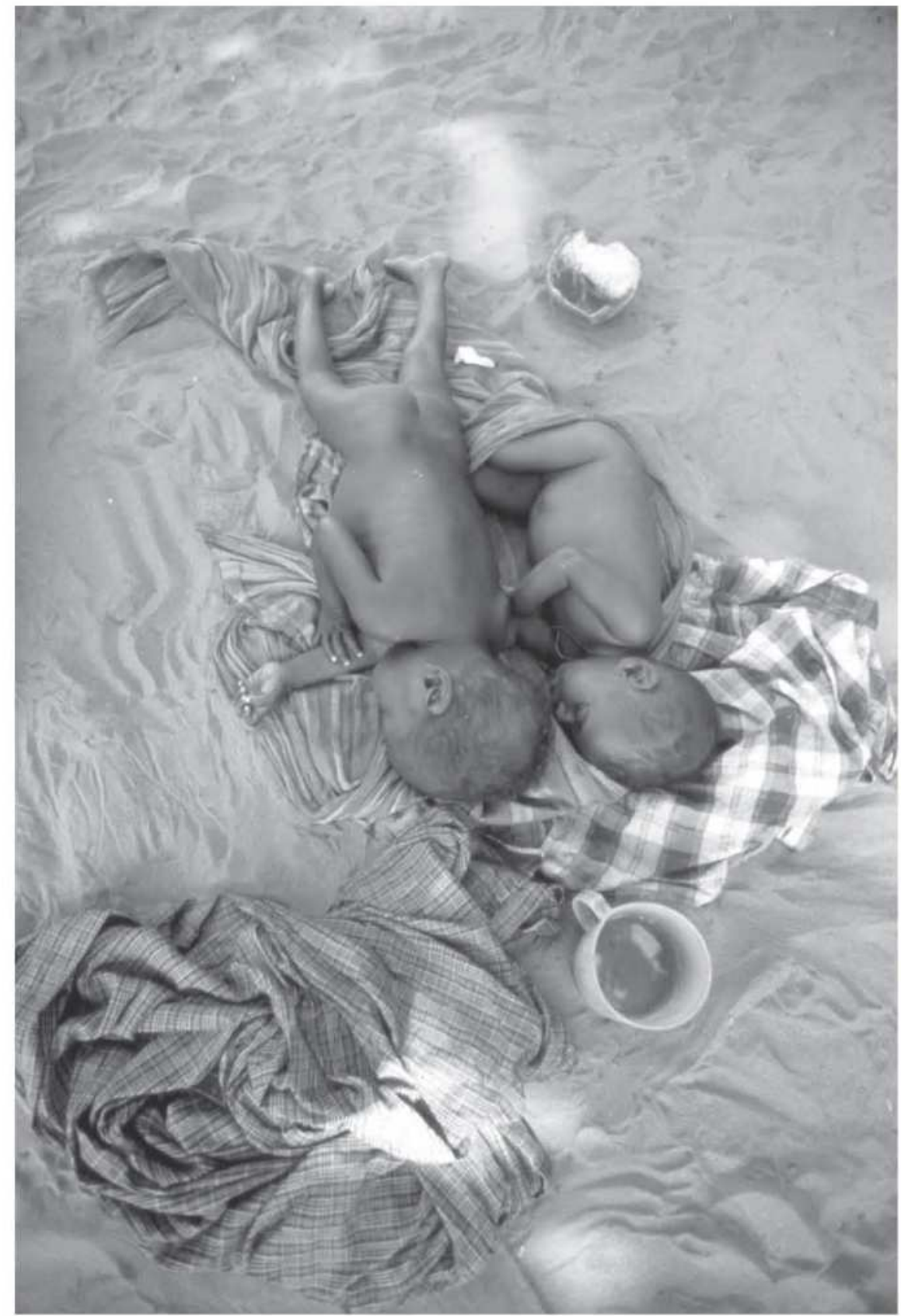

Children sleeping on the beach, Yapakopa, Ayndua, Mimika, 1997. From Pickell 2002:176. Photograph by Kal Muller. 
receivers, expressed in work, social obligations, joking relationships, and ceremonial roles. Settlements have a spatially expressed dual division of two or more taparu descent groups. All rituals, ceremonies, acts of singing, drumming and recited narratives proceed along alternating lines of duality. Cosmology distinguishes between an upper and a lower world; the world of humans lies between these, it forms the middle way. The participants' conception of history is one of ongoing reciprocity, not of unilinear or multilateral 'progress'. Consequently, Kamoro do not distinguish a zero point of development and evolution. The upper and lower worlds and the human sphere in between are eternally coexistent and co-active. There is coexisting surface (ipere, 'top') and deep reality (mapere, 'bottom, root'). Basic reality is progressively revealed and unveiled in surface reality. For instance, the canoes of the culture heroes were propelled by frogs, and the present ones by outboard motors, which pre-existed but were not yet visible. The latter were unveiled by Europeans, originating from Kamoro ancestresses. As a consequence of this basic concept, myth are very flexible and innovative (whereas rituals are fixed, relatively speaking). Culture heroes did not create human ancestors; these pre-existed. What the culture heroes did do was to generate groups of people by way of division or articulation. Apart from this, oral history has it that the dispersal of Kamoro ethnic groups from east to west was set in motion by an attack led by two hero 'brothers', the older brother Aoweyao, literally 'son of a human mother', and the younger brother Mbiminareyao, literally 'son of an underworld spirit woman'. They rose to the status of fearsome warlords as revenge (aopao) for being humiliated by their kin and affines who refused to pierce their noses as a sign of reaching maturity - a major affront. ${ }^{3}$

The human body is conceived as a doubly dual entity. It consists of a superior female right half and an inferior male left half. Its surface, apparent reality, skin ( $k a o$ ), withers after death but its inner reality (ndata, 'real') goes upstream after death and joins the spirits (ipu). Spirits are substantial: they do walk, but humans can only see them on exceptional occasions.

The human world in between was 'furnished' by earth-based culture heroes who laid their hands on the 'furnishings' acquired from the upper and lower worlds, mainly by deceit and by violating the rule of reciprocity. Examples of this 'furnishing' are sun and moon, rain, thunderstorms, mosquitoes, sago palms, dogs, traditional tools and Western commodities, illness, death, and the major rituals. The dynamic force, the lynchpin of the multiple forms of duality and the propeller of history, is the golden principle of reciprocity, aopao, which stands for counter-service, counter-action, counter-gift, exchange or barter, response, revenge and retaliation. 


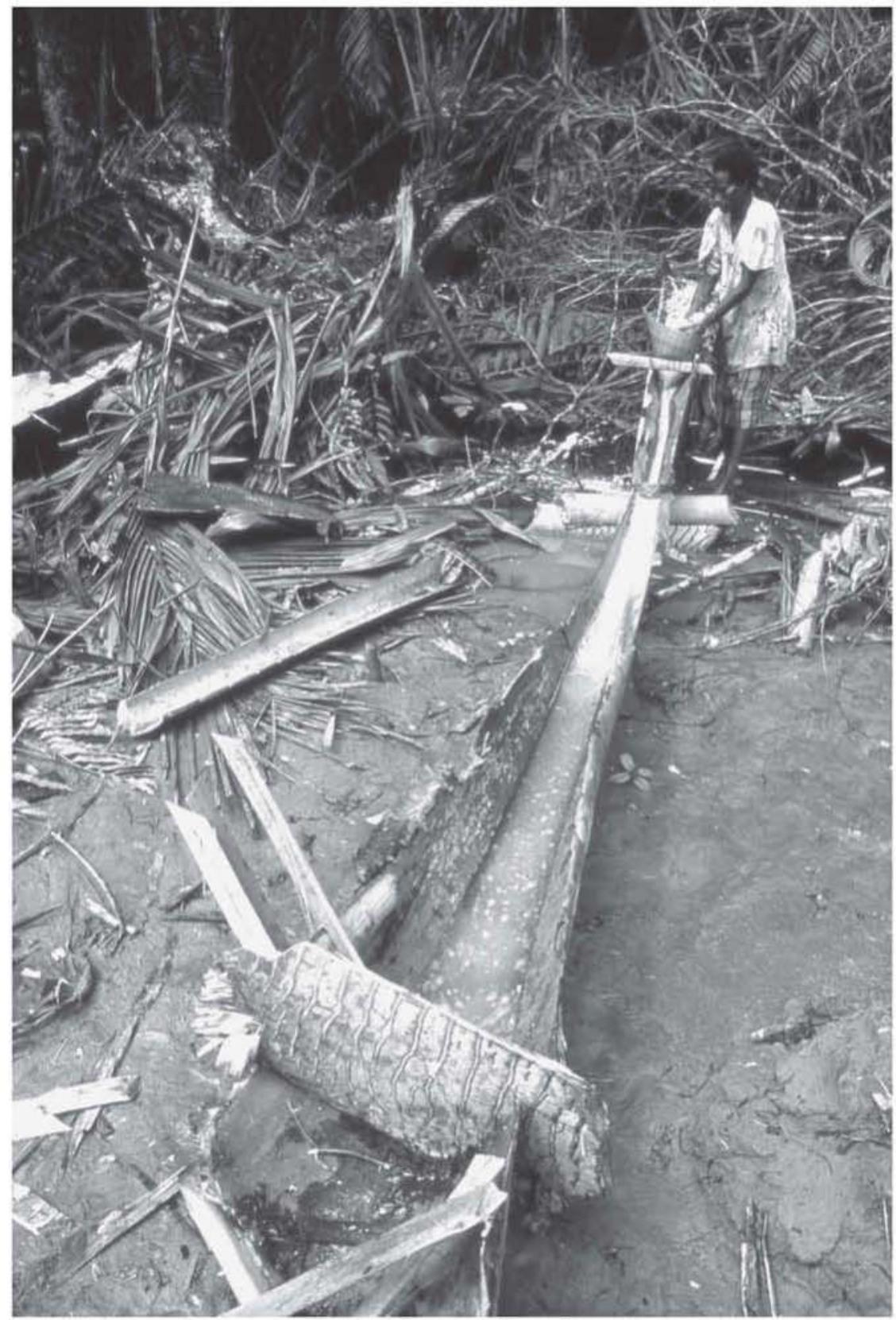

Squeezing and washing sago pith, a woman's job. Near east levee of Aikwa River at Nawaripi, Mimika, 1997. From Pickell 2002:135.

Photograph by Kal Muller. 


\section{General rituals and ceremonies of the individual life cycle}

Duality also has a bearing on the division of rituals. There are two major general rituals, Ema Kame and Kaware, which relate to each other as female/ right to male/left. The former promotes life, fertility, procreation, growth, multiplication and abundance. The latter concerns communication with the underworld and the upper world, including dealing with death, mainly the prerogative of males. It highlights the contribution of males to material culture: the making of canoes, tools and weapons. In addition it accounts for the underworldly origin of (exogenic) cultivars, mainly grown by males. The female-male distinction does not imply that 'female' rituals are exclusively performed by women and 'male' rituals by men, although women do play an important part in the former and men in the latter. The distinction is primarily a classificatory device (like the distinction of feminine and masculine nouns in French grammar). It also refers to the complementary contribution of females and males to economic, social, political and religious aspects of society. Although males are believed to contribute to procreation by shaping and feeding the foetus through repeated intercourse, the undeniable and socially stressed fact is that it is women who give birth. Moreover, women play a dominant and socially recognized role in the production of food; they are responsible for the cultivation and collection of sago, fish, clams, mussels, and, to some extent, garden produce. Men's contribution to curing a large variety of illnesses as well as their communication with the spirits of the dead, the ancestors, and the personalized forces which control natural phenomena, safety, the growth and abundance of sago, fish, cultivars and of human life, are recognized and expressed by their performance of rituals.

Alongside these general female and male rituals are the rituals and ceremonies of the life cycle. Again, there is a dual division. The initiation of boys, called Tawri Kame, literally 'apron house', and the initiation of male adolescents, called Mirimu Kame, literally 'nose house', together indicated by the term Karapao, on the one hand, and a series of separately named rituals on the other marking a gradual farewell to the dead, are opposed as female to male.

Also in the 'female' sphere of fertility and multiplication is the pig ritual, Oo Kame, literally 'pig house', which in fact is an essential part of Karapao. Just as much in the female sphere is the breadfruit ceremony or play, Opako Kata. This ceremony is performed exclusively in upstream settlements, since it is only there that the breadfruit tree grows. The purpose of the first ritual is to lure an abundance of wild pigs to a location where sago bait has been placed so that they can be stabbed on the occasion of a celebration. The second ritual aims at an abundant harvest of breadfruit.

In addition, there are two rituals in the 'male' sphere, Te Kata and Tiri Kata, literally 'mud play' and 'sand play'. In the first one male adolescents are 


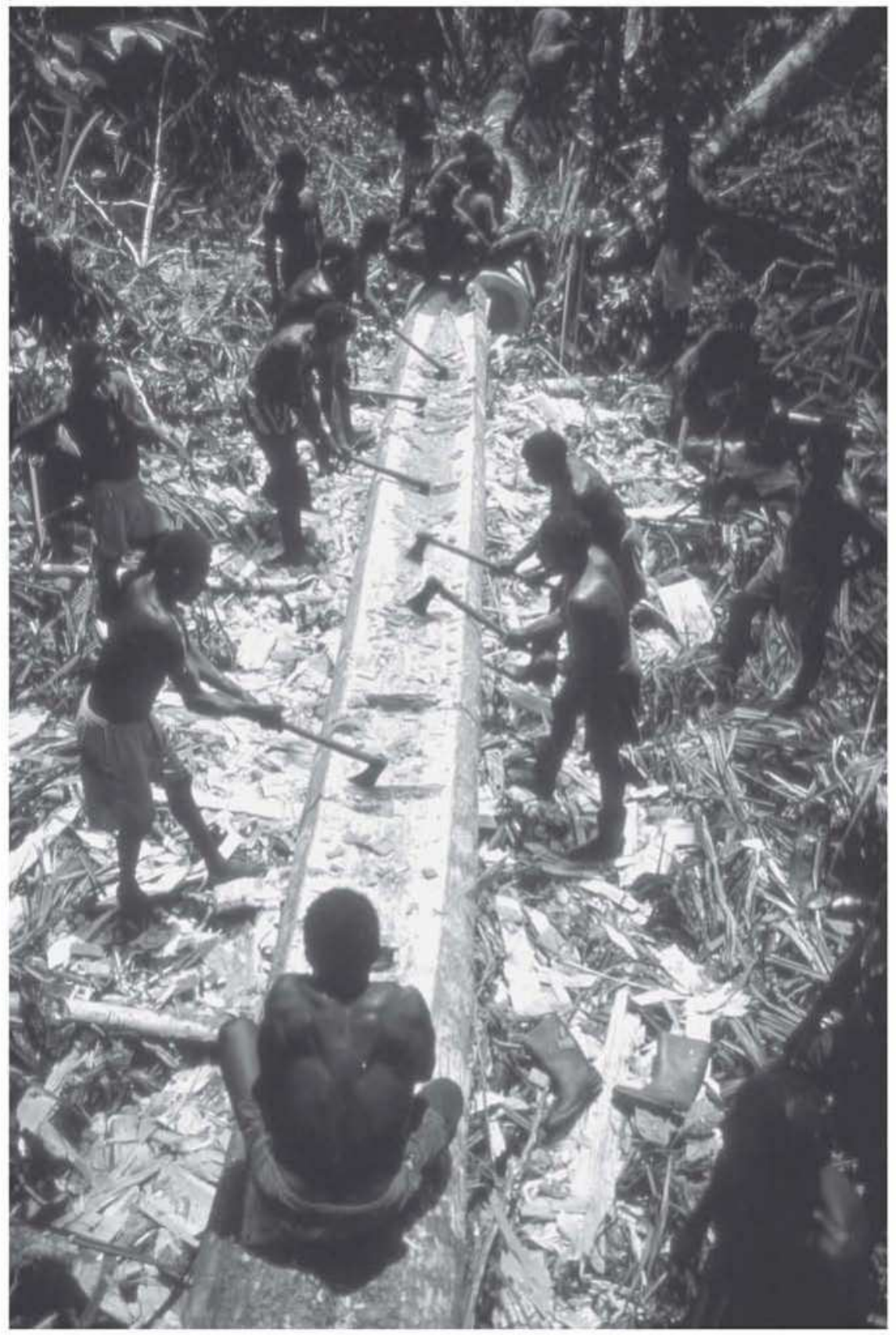

Hollowing out the canoe, near the Paripi sago groves. Mimika, 1997. From Pickell 2002:202. Photograph by Kal Muller. 
initiated into secrets of the underworld by showing them (dramatized) spirits emerging from a grove of trees. I attended this celebration in Mioko, on the Kamora River. In the second ritual the opposite occurs: male adolescents are initiated in driving an impersonation of the culture hero Mapurupiu into a grove of trees and watching him being stabbed by a spirit. His transgression of the rule of reciprocity is regarded as responsible for the fact that humans die. He is also the one who guards the entrance and access in the underworld to the realm of (Western) wealth. ${ }^{4}$ For more on the breadfruit, mud, and sand rituals, see Chapter XIII.

Finally, there is a separate ritual, Kamupu Kame, which is associated with the female sphere of Ema Kame. The purpose of Kamupu Kame is to neutralize the danger of men being turned into women carrying babies as a punishment for not properly looking after the well-being of a particular woman who died in labour with her baby. This was still considered a real threat in the 1950s, and the ritual was performed accordingly. Zegwaard observed it in Koperapoka, East Mimika, in the early 1950s. ${ }^{5}$

$4 \quad$ See Coenen 1963:101; confirmed by my own field observations in upstream villages along the Kamora River. For the myth see Offenberg and Pouwer 2002:162-8.

5 Gerard Zegwaard, personal communication, 1953. For details of the relevant myth and ritual see Coenen 1963:47; Pouwer 1987:36-8; Offenberg and Pouwer 2002:148-50. 



\section{Chapter i I}

\section{The 'female' contribution to life Ema Kame rituals}

\section{Occurrence and main functions}

The Ema Kame (literally 'bones house') ceremony was of universal occurrence throughout the Mimika district and its details are still very well known, although at present only parts of it are celebrated. ${ }^{1}$ In East Mimika it is known by a different name, Kiewa, the literal meaning of which is unknown. According to Zegwaard, the Nafuaripi or Sirao people living far inland and upstream from Akimuka River to at least Lorentz River, who are linguistically and culturally related to the Sempan Kamoro of the far eastern part of Mimika, also celebrate it. Not much is known of them. They live largely in isolation. Relations with other peoples are infrequent and hostile. The Asmat used to raid them. Zegwaard encountered Nafuaripi slaves in Asmat villages.

Upstream Asmat also celebrate Ema Kame, known as Emak Cem, but systematic information is limited. According to Zegwaard (1953-56, Kewa:1), downstream Asmat borrowed it from upstream villages, and some typical coastal Asmat villages like Ewer, Shuru and Ayam do not celebrate it at all. Data are sketchy.

Although the Ema Kame ceremony occurs throughout Mimika, it is ideologically related to the inland (kapao). In contrast, Kaware is not only ideologically associated with the coast or downstream (imuu), but is also in fact not celebrated in upstream Kamoro villages from the upper Kamora River to the far eastern part of Mimika.

Ema Kame's main functions are the commemoration of the dead, the promotion of new life, fertility, and reproduction, and the expression of gender antagonism; it has strong erotic features. These functions are clearly evident in peared. 
its rituals, ceremonies and general atmosphere. Its name, 'bones house', derives from the final ritual, when the excavated bones of the dead of recent years are thrown into the ceremonial house, after which it is abandoned. Its importance in promoting fertility was explicit in the complaints of older male inhabitants of various settlements at Etna Bay during my visit on 16 November 1952: 'We have been prevented from celebrating Ema Kame by the Protestant Mission and the Administration for years, hence the scarcity of children and adults. If our children and adolescents could celebrate it, they would be strong and healthy.'2 Some informants attributed the lack of offspring to the prohibition on producing and drinking palm wine. At the time of my visit the settlements were indeed small. There were not many children; there was a high mortality rate and a feeling of malaise and mental depression.

Ema Kame is famous throughout the district for its many plays (kakuru) and the splendour and spectacular variety of its carvings. A key informant in Umar, West Mimika, even called it 'the mother of all ceremonies'.

\section{The structure of the ceremonial house}

We are fortunate in being able to compare information gathered by Gerard Zegwaard, Julianus Coenen and myself, none of whom witnessed the construction of the ceremonial house, with a brief description of it by members of the British Wollaston expedition of 1910-1913 who did, though they were not aware of its name (Figure 1$).^{3}$ There is a surprisingly good fit:

The length of the house [in Timika or Nimae, a coastal settlement east of Kaokonao] from front to back was about 100 feet, the width about 25 feet, and it rested on poles which were about 8 feet in front, rising up to about 14 feet at the back. The sidewalls and the back were of 'atap' as was also the roof, which sloped from a long ridgepole running the whole length of the house (A). The ridgepole was remarkable as being made from a single tree trunk (Casuarine) shaved down very smoothly to a uniform thickness of about 10 inches; the ends of it, which projected about 8 feet both at the front and back of the house, were carved in very life-like representations of the head of a crocodile and were painted red. The weight of the beam must have been enormous and one wondered how it had been hoisted into position. Between the ridge of the roof and the eaves there projected both in front and at the back six other smaller poles (a-f) grotesquely carved to represent fish and reptiles and hideous human heads. The front of the house was open.

2 Etna Bay has never belonged to the administrative district of Mimika; it was not the Roman Catholic but the Protestant Mission which operated there and prohibited 'heathen' ceremonies.

3 See Wollaston 1912:143-4, cited by Kooijman 1984:36-7. 

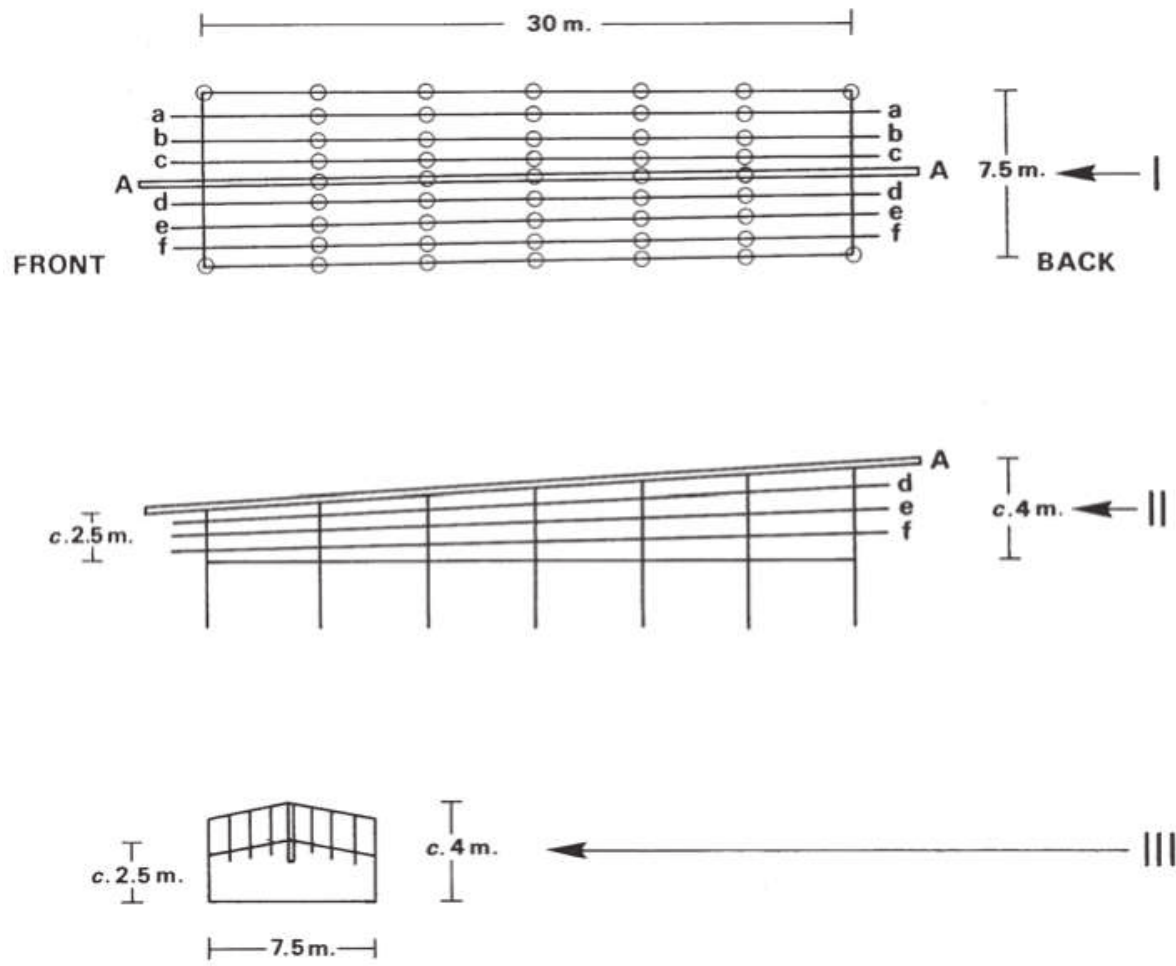

Figure 1. Kamoro ceremonial house. From Kooijman 1984:36.

The length and width of the house as described here correspond with my estimates based on information from informants in West and East Mimika. They also confirm that the roof sloped from front to back. Zegwaard observed such a sloping roof on an Emak Cem house in Erema, Asmat, on the Northwest River (Zegwaard 1953-56, Kewa:7). The Ema Kame ceremonial house differs from all other Kamoro ceremonial houses in that it has a small front, a double-edged roof, and is situated not parallel to the riverbank but at an angle. Other houses have a broad front with many openings and a single-sided roof. The higher rear (mipi, 'tail') of the house faces the river, and the lower front (upao, 'head') faces the land. The front has one entrance in the centre, or two entrances one on each side, according to some West Mimika informants. The entrance, at some distance from the bottom, is divided into an upper and a lower half by a threshold, a special horizontal ceremonial board (puru kani) decorated with carvings. Uninitiated men enter through the lower part, and initiated ones through the upper part (Zegwaard 1953-56, Kewa:6).

There is a small entrance on the riverbank for those who go fishing or want 
to relieve themselves. The house stands on the ground. Its full length from front to back is occupied by two platforms on short poles, divided by a corridor. The platforms are used for sitting, squatting and lying. The ridgepole rests on three sets of crossbeams supported by three pairs of poles, left and right of the platforms. In the centre of the house a sec-

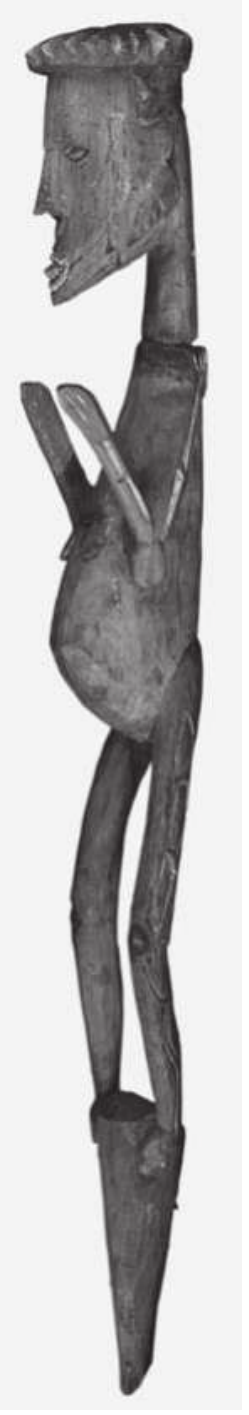
ond ceremonial board is attached between the two central crossbeams, ${ }^{4}$ the first one serving as a threshold for initiated men at the entrance.

In front of the ceremonial house, left and right of the central entrance, two spirit poles about two metres high, smaller than the mbitoro spirit poles and of a particular type called irane, dominate the scene. In the Sempan villages in the far eastern part of Mimika, only one pole was erected, called irahe. ${ }^{5}$ These poles depict ancestral mothers. The National Museum of Ethnology in Leiden is the only museum to have a number of these statues, collected by A.J. Gooszen, commander of the South New Guinea section of the Military Exploration Team in 1913. They have not existed in Mimika for many years now.

Outside, left and right of the centre of the house and connected to it by a path marked and covered by leaves, are two huts serving as a private place for male participants while they work, eat or sing. ${ }^{6}$

\section{Prelude: the python ceremony}

Ema Kame is famous for its many plays or dramatizations (kakuru). The python play is one of these. It is optional. In fact, according to many informants, it belongs to the 'male' Kaware complex. The python (miroko, Sempan: menewe) itself is associated with the inland, the 'female', and is

Statue of pregnant ancestress, placed in front of Kiewa (Ema Kame) ritual house, Otokwa. Collected by Military Exploration Team, 1913. RMV: 3600-7537. See Kooijman 1984:25-31, Fig. 22; Smidt 2003:123, Fig. 85.

$4 \quad$ For an illustration, see Kooijman 1984:75.

5 For illustrations, see Kooijman 1984:26-31.

6 Zegwaard 1953-56, Kewa:7; confirmed by my informants. 
of central mythological importance for Mimika as a whole. He, or rather she, is represented as lord of the land or tapar amako (Coenen 1963:79). In the eastern version of the central Ema Kame myth, all groups of humans, including foreigners, canoes and Western commodities, emerged from the bones and flesh of a python. ${ }^{7}$ In the western and more general version the name of the ancestral mother of all groups of men is Miroko, and her culture hero son is called Mirokoatayao, literally 'the son of Miroko'. He killed the monster monitor lizard that devoured all the inhabitants of a primeval settlement except the pregnant Miroko, who gave birth to him. All human groups emerged from the flesh and bones of the monster (Offenberg and Pouwer 2002:121-7). It is small wonder, then, that the python may not be consumed (except by the Sempan; Coenen 1963:79). The climax of the play is a head-on collision between the 'pythons' of the right party and of the left party of the group concerned. The 'pythons' are embodied in two trunks that are pushed over the ground in opposite directions. After a few turns the 'pythons' and the parties change sides, like in a soccer match. I attended the play in Mioko, upstream Kamoro River, on 12 September 1952. (I also attended one in Jeraja, West Mimika, on 2 October 1952.)

A description of the play in Mioko is as follows. The two village halves, formerly living in separate settlements, are called Iwekae (right) and Matiae (left). Each half consists of three taparu, each of these having a female ancestor of their own. ${ }^{8}$ Early in the morning at about seven o'clock the left party sets out on a canoe trip to their own territory on the right side of the river, the right party going to the left side. There are about ten men in each canoe. Women are taboo. Some older men select a tree, while the male adolescents, who have not been initiated into the secret, stay behind in the canoe. All initiated adult men clear the ground around the tree and hide it from sight by a camouflage of leaves. The trunk is of a soft variety also used for making canoes. The three men entitled to cut the tree (otemako, 'owners of the secret') squat near the tree, adorned with bird of paradise feathers, with lime on their faces and a green leaf through their pierced noses. The decoration is applied by their kaokapayti, or bride-receivers, more specifically their sisters' and daughters' husbands, as part of their duties to assist their bride-givers. The bride-receivers are then ordered to leave. The three dignitaries squat in a row close together, their backs turned to the tree, near one of its buttress roots, with their lime-lined axes in their hands. After ample deliberations, the exact spot on the trunk where it will be cut is indicated by a lime-powder ring. Lime is a ceremonial marker. The adults start a song (tao) in high-pitched voices appropriate to

7 For the full story, see Offenberg and Pouwer 2002:127-9.

8 For more details, see Pouwer 1955a:283. 
the ceremonial occasion, accompanied by drumming. Then the uninitiated adolescents, with lime on their faces, singing and drumming and beating a gong, rush to the camouflage and remove it after a sign from the adults. The three dignitaries are revealed, their heads slanting and their tongues protruding. After a sign from the main singer-drummer, the trio performs a squatting dance, their arms spread like the wings of a bird. They are in fact imitating birds. The leader of the trio, who relates to the other two as mapere to ipere (root to surface), suddenly turns to the tree and swings his axe with the utmost force into the trunk on the line marked with lime, while shouting the name of his mother's taparu. The other two men follow suit. Then the bride-receivers take over and do the real job. An old man starts weeping: the uninitiated adolescents are now in the know and are adults; it is an emotional moment. The tree sways and is pulled down with rattan canes. The trio start removing the branches; the work is taken over by the bride-receivers: the trio merely mark the occasion. The work is left to their bride-receivers. Shouts of 'Wuu-wuu' punctuate the fall. The second man of the trio throws lime over the trunk. The leader then slips the first roller of wood under the trunk. All the others follow and the trunk is rolled and dragged to the riverside. It is said that formerly the men painted their faces with sago mixed with the red sap of a tree and made a reddish track in order to give women the impression that a python had attacked and swallowed people. Before dragging the trunk to the shore, its bark is removed. Headed by the chief drummer and the leader of the trio, the trunk is escorted to the riverside by the yelling crowd and thrown into the river. One branch is not removed; this will function as the tail of the python. Another canoe arrives and the trunk is hidden behind the two canoes. Suddenly a canoe carrying women happens to appear on the opposite shore, causing consternation. The leader shouts to the women not only in his own language, but also in authoritarian Malay, to make themselves scarce. The trunk is hidden even better. Then the canoe with the second trunk of the right party arrives on the scene. The trunks are transported to the village between the canoes. All the men have covered themselves with lime. Near every turn in the river there is shouting and drumming and gonging in order to chase off and impress the women. At about 12:30 p.m. the group arrive at the village. The trunks are transported to an open site in front of the two rows of houses, corresponding with the right and the left village halves. Fishing nets and leaves conceal the site and the trunks facing each other. In the afternoon the woodcarving specialist belonging to the right half starts carving out a face and a neck; the eyes correspond to the sun symbol often found on canoes. The neck, a groove in the wood, is marked by charcoal and white lime dots, which also adorn the body. He takes turns with a younger brother. After him the carver of the left half works on the left trunk. Older men watch them closely and make critical remarks. Adolescents scour the trunks carefully with leaves. 
When the 'pythons' are ready there is a competition. The initiated participants, instructed by the leaders of the right and the left, take hold of the trunks and move these forcefully over rollers in opposite directions. At the very moment that the heads of the 'pythons' are about to collide, the leaders heading the two rows insert leaves between the heads, after which there is a head-on collision. Immediately behind the leaders are their sons and sisters' sons. The participants imitate the hissing of snakes. Then the uninitiated adolescents are invited. They remove the nets and rush to the scene; their bodies are decorated with lime and they throw clouds of lime powder. They remove the leaves between the pythons' heads, unveiling the secret. Then they join the others in fastening the 'snakes' and having them collide with much force and hullabaloo. After the collision all participants fall on the 'python' and perform the ritual bird dance (Kata Ndi). Tongues are poked out. After a number of collisions the position of the parties is reversed. The play goes on and on until older dignitaries tell the parties to stop. The three leading dignitaries on both sides then initiate the splitting of the trunks with axes and wedges. The adolescents finish the job and split the trunks into pieces. All the remaining pieces and rolls are thrown into the river or the woods, lest women find out about them. The ceremonial house should be built on the very spot of the python ritual. In my opinion this game can be considered a ritualized mock battle between two autonomous settlements or village halves, which each have their own ancestry and territory.

\section{Erecting the ceremonial house}

\section{The framework}

The preparations are announced and are preceded by passing around a pole which is to be erected, while those attending are singing and dancing. Men dance in the inner circle, women in the outer one, accompanied by the guild of drummers. This goes on from sunset till dawn. The next day men from the right and men from the left depart for their own territory to cut the timber for the right and left platforms (mbeamo). Pegs are inserted; the platforms, consisting of sticks and trunks cut in half, are placed on the pegs. Large pieces of bark, which will cover the platform at a later stage, are landed ceremonially by the two parties and put on the ground with a loud bang to impress the women. These activities take a couple of days. Then the right and left parties of men leave again to cut the three pairs of poles and crossbeams. The poles are erected in holes with rhythmic ceremonial movements accompanied by singing and drumming. The poles are named after important, recently deceased men and women. These have been cut by their relatives, with 
assistance from their bride-receivers. The heavy ridgepole ( $m b u)$ (sometimes two ridgepoles are used), which is also named after an important deceased man or woman, is then hoisted and installed. This is a crucial and highly emotional moment, punctuated by singing, drumming, dancing, and a lot of noise. Two ceremonial announcers (imakatiri), a right one and a left one, line up in front of the ridgepole and formally announce the event. Some informants in Timare (upper Kamoro River) told me that women are driven off on the pretext that the village is going to be attacked. On their return they show (or feign) excitement and amazement at the male achievement of putting the heavy ridgepole into position.

According to different informants, the carved front end projecting about two metres represents a king parrot, mopoko (Inawka, Sempan, upstream); in Kawkapu, Wania River, upstream, a spoonbill, kaymo; in Timuka, a coastal village, a crocodile, timako; in Mikiwia, a coastal village, a hornbill, komay. Apparently the animals depicted vary, some being associated with the coast (crocodile, spoonbill), and some with the inland (king parrot, hornbill). The king parrot in particular is associated with the secret (otepe) of sago and of pigs (Coenen 1963:78). Zegwaard (1953-56, Kewa:7) suggests that the name for ridgepole, $m b u$, meaning 'turtle' in Asmat, is because of its curved line. Informants confirm Alexander Wollaston's statement that the carvings on the ends of the crossbeams depict various kinds of fish, reptiles and human heads. The crossbeams are also named after deceased persons. The carvers (maramo amako) are paid mainly with prepared food, presented in large quantities by relatives of the deceased persons being honoured.

Finally, the framework of the sidewalls and of the back wall, consisting of crossed sticks and branches, is installed.

\section{The rattan ceremony}

Rattan has not only practical functions but also ceremonial ones. There is a right and a left rattan dignitary (keme amako). Informants in Timare (upper Kamora River) give the following description. In the early morning the two dignitaries secretly enter the woods. While walking, they hit trees and roots. They remove rattan vines from the trees - a demanding job usually done by male adolescents - and carve out at one end the head and protruding tongue of a land snake, miroko, identical with the python of the python ritual; they make a right one and a left one. They take these snakes and the rattan canes to the rear of the ceremonial house. Women are not allowed to be present, and pretend not to know what is going on. Men rub their bodies with a mixture of lime and red sap from trees to give the impression that they have been attacked by a snake or are snakes themselves. Again, this is reminiscent of 
the primeval lords of the land. At night men frighten women and children by hitting the roofs of the huts and behaving like spirits (mbi). In Kawkapu I was told that a rattan dignitary steps forwards and backwards, zigzagging over the rattan snake, which is decorated with flowers. He dances and sings and ends by yelling Ieyeva, I ya ihuyo. I asked him: Is this sound the equivalent of Kiewa (the eastern name for Ema Kame)? He nodded, but I am not sure whether to interpret this as a confirmation of my suggestion.

In Umar, West Mimika, it is male adolescents who collect rattan canes, adorn them with rattan fruit and leaves, sing the rattan song, and take the canes to the back of the house. The next day they put the rattan in rolls in front of the ceremonial house. Three groups of three rattan dignitaries stand to the side of the right and the left roll, in front, in the middle and at the back (the position of these groups is similar to that in the python ceremony described earlier). They sing the Keme Tao, the rattan song. The bride-givers of the adolescents and the adults who cut the rattan are then presented with lots of food by way of a return gift (aopao) for their hard labour. There is singing and dancing from dusk to dawn. The next morning the rattan is split up to use for binding. The rattan dignitaries start splitting; the work is taken over by their bride-receivers (compare this with the python ceremony). In Umar it was said that the model of a crocodile with a wide-open mouth is made out of scraps of rattan and is placed in a tree near the river. My impression is that in the coastal settlements the crocodile takes the place of the python of the upstream settlements as the lord of the land. According to some informants in Mikiwia (a village of the Kaokonao agglomeration), the crocodile is secretly destroyed by men in order to give women the impression that the crocodile has gone away.

Ceremonial shield representing a deceased member of the community. From Cape Steenboom, near the mouth of the Mukumuga River, Mimika. Collected by W. de Jong, 1903. RMV: 1416-9 zw-w. See Kooijman 1984:xv; Smidt 2003:76, Fig. 7.

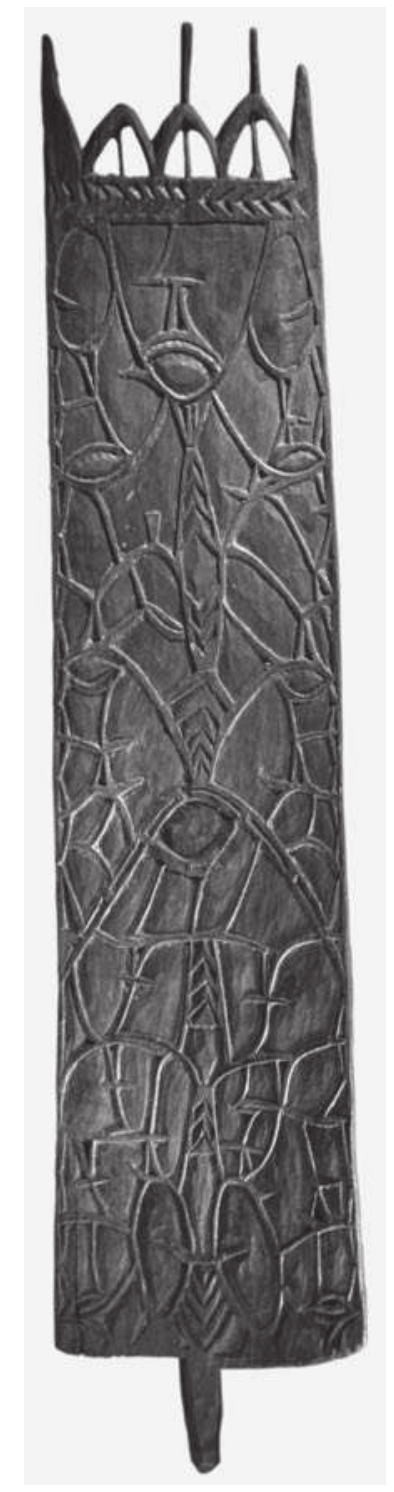




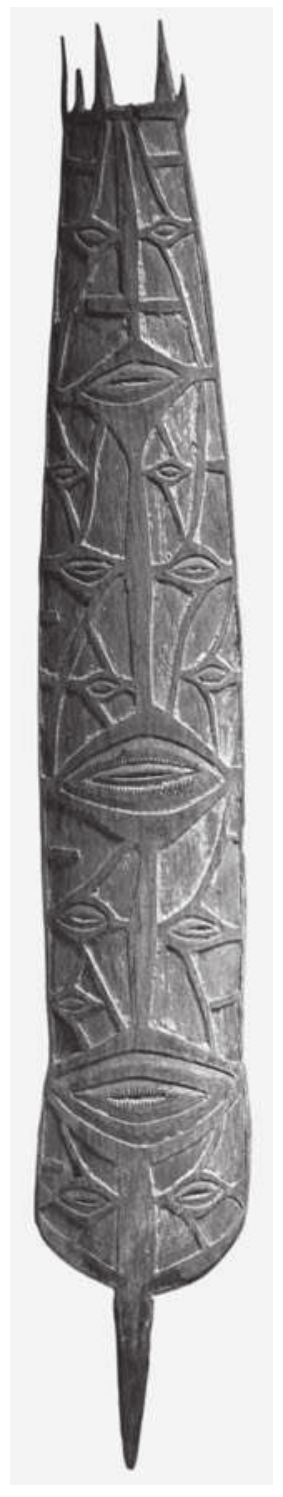

Ceremonial shield representing a deceased member of the community, Mimika. Collected by Ch.L.J. Palmer van den Broek during visits to Mimika, before 1908. RMV: 1670-60 zw-w. See Kooijman 1984:xv, 61, Fig. 54.

In Umar and Potoway (in the far western part of Mimika) part of the rattan is used to make rings, each one named after a deceased person. Their relatives cast the rings round a stick in the ground while solemnly pronouncing the name of the deceased. After the ceremony the rings are laid down in the houses of those who collected the rattan. I wonder whether this ceremony has replaced the making and naming of individual ceremonial shields (yamate). Most of the ceremonial shields in museum collections were collected in Central and East Mimika. During my visits to villages in West Mimika, ceremonial shields were not often mentioned spontaneously when I inquired about Ema Kame. Is there a link with a strong exposure of the far western part of Mimika to commercial trading and to eastern Indonesian and Western power and influences radiating from Etna Bay? The quality of carving also tends to be inferior to that of Central and East Mimika. In the latter areas the open and elaborate style of carving abounds, while in West Mimika the closed, less elaborate style dominates (see also Kooijman 1984:63).

\section{Ore and Tama ceremonies}

Ore is the Kamoro term for what is called atap in some Indonesian communities. Collecting the atap (sago leaves) for covering roofs and walls is a male job. Women provide the elastic strips for stitching the leaves together; these are made out of pandanus fibre. Work and play and gender antagonism again go together at this stage of activities. Men and women depart separately for their territories; they are not supposed to see each other. There is a story about an older and a younger brother, called Omo and Tere, who spied on naked women collecting pandanus strips (tama). The story has it that the enraged women killed the men. In the course of the Tama song chanted by women 
returning from collecting pandanus strips, this event is narrated as a warning to men to stay away from women's secrets. The men arrive at the Ema Kame site in canoes lined up in battle array, dancing and singing with the sago leaves swaying in their hands. They sing the Ore song. They put down the sago leaves with a loud noise and a display of power near the framework of the house. Meanwhile the women are at work in the woods. They lie down naked near the pandanus trees with the strips in their hands and sing the Tama song. This is their secret (Coenen 1963:45). By lying down near the pandanus trees they identify with them, just as the male snake dignitaries do when cutting down trees. A similar action by three dignitaries takes place while cutting the tree for making a drum (Coenen 1963:44). This is reminiscent of the three rattan dignitaries standing beside the rattan canes. In all these cases one senior dignitary relates to the other two as mapere to ipere. Coenen's informants explicitly called this identification ipu enakoa, meaning 'of one soul'. In this way cross-links are laid between a great variety of animals, plants, objects, natural phenomena, and rituals. These links constitute the very basis of Kamoro cosmological classification. Coenen assembled a great quantity of crucial and detailed information about this (Coenen 1963:35-9, 43-8). In this particular way the women's tama secret is associated with the Ema Kame bat ritual (Coenen 1963:45). The bat ritual (see below) is so crucial for Ema Kame that people who celebrate Ema Kame are called bat people (Coenen 1963:37).

The women carry the pandanus strips to the back of their houses. Meanwhile - at least in West Mimika; this is not a custom in Central and East Mimika - men suspend a coconut from a cord in front of the ceremonial house. Some of the women cut the coconut in half with much ado and eat its contents: by doing so they declare war on the men. In Potoway I wrote down the following description of the start of this mock war: Women and men standing or sitting in their canoes line up opposite each other, on either side of the river. Women wear male clothing and attributes. They dance and sing, holding plates of prepared sago and fish in their hands. They cross the river and offer the food to the men, who have gone ashore. However, when the women arrive the men withdraw in their canoes and eat the food separately. Roles are then reversed: men (in female clothing) now offer food to the women (in male dress). This mutual gift giving between men and women is meant as ceremonial mockery, a reversal of gender roles. Then - and this applies to all areas of Mimika - the women attack the men with their pandanus strips, functioning as spears (potako paata, literally 'mock spears'). They rush at the men brandishing bows, arrows, axes and machetes. The men make no attempt to defend themselves, and take to their heels. Zegwaard witnessed this part of Ema Kame performed separately in Atuka, Timuka, and the Koperapoka villages (Zegwaard 1953-56, Kewa:8). He observes that the women launch the attack as soon as the men start singing the Kuru song. 


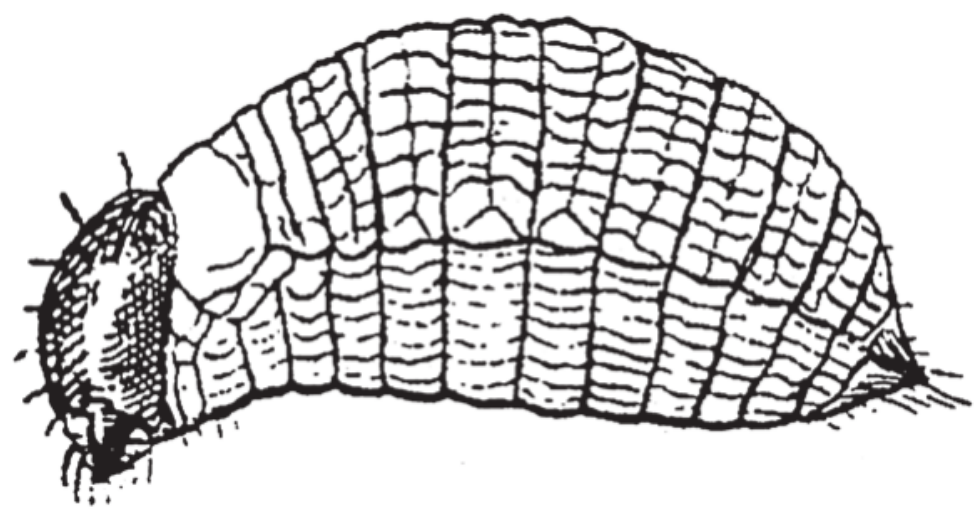

Figure 2. Sago grub (actual length of grub is $4.5 \mathrm{~cm}$ ). From Pickell 2002:138.

In this song a small kind of bat, called maora, warns 'wild' women (wamoko kaoka), women of the hinterland, women depicted as animals of the woods, that a man from the coast is about. The sex-driven women are anxious to meet him. In the myth, universally known in Mimika and strongly associated with Ema Kame, these women replace the culture hero women (amoko kaoka) who have left their husbands who cheated them. These powerful superwomen waged war with men and killed many of them. The losers, left to their own resources, engaged randomly in homosexual relations with male adolescents who played the part of women. However, when they found out about the bushwomen, they took them as their wives. The latter, being less powerful and less perfect, gave birth to the present race, which no longer has the attributes and power of the culture hero women. ${ }^{9}$ The mock battle between women and men thus alludes to a well-known myth. However, the relation between the myth and the ritual is not one-to-one. The mock battle has erotic and aggressive features. Zegwaard's informants, while attending the mock battle, told him on the spot that in the early days men and women performed a joint dance after the battle, in which their legs were entwined in an erotic way. The end of the battle is marked by a dance around the post in which everybody, young and old, participates. During the dance men offer women young sago-palm shoots; women offer men sago and sago grubs $(k o)$. These larvae of the capricorn beetle (see Figure 2) are considered a delicacy with

9 For the full story and details, see Zegwaard 1953-56, Kewa:8, and Offenberg and Pouwer 2002:22. 
erotic overtones. In Wanihiripao I was told that sisters snatch the sago shoots from their brothers. The gender relationships here indeed seem ambivalent.

The delivery of the sago leaves is also marked by a ceremony. The men from the right, followed by the men from the left, walk towards the ceremonial house in a long line, sago-palm branches in their hands. Walking in a circle, they first pretend to lay the branches against the frame of the house, but then walk on and deliver them suddenly with a loud bang. The women simply deposit the pandanus strips on the ground in front of the house.

The next day the sago leaves are stitched together and fastened to the framework of the roof and the wall. The right men cover the right half of the root, the left men the left half. The tempo is high and the work strenuous, the more so since progress on both sides is kept strictly even: no opening near the ridgepole is allowed lest people fall ill or even die. The workforce is lavishly rewarded with food prepared by their bride-receivers.

\section{Carved attributes: ceremonial shields}

In Otakwa I witnessed the making of a ceremonial shield or yamate, called yamahe in the local dialect. It was in the local clubhouse for men, which is lacking elsewhere in Mimika but is present in the adjacent Asmat area. There was a strong feeling of togetherness. Two woodcarvers were sitting in the centre of a group of men and boys who were standing, sitting or lying down. An oval-shaped board, already roughly cut with an axe and a chisel (maramo), was situated between the two men. With fine-grained chisels the two carvers worked at the same time, one on the right and one on the left side of the board. They worked together so closely that the vertical and horizontal patterns they simultaneously carved fitted perfectly. The carvers represented the right and the left halves of the village. The main vertical pattern represented a particular kind of fish (irako). The men's chisels almost touched each other in the middle. The space between the central pattern and the edges of the shield was filled with a grid of notches that looked like footprints of birds or crabs. One of the carvers, while working carefully, was joking, and made several funny remarks about Father Zegwaard and the Keiese village teacher. There were roars of laughter from the onlookers. Meanwhile, young and old spectators watched the progress of the carving critically. Two older carvers offered unsolicited advice on their younger colleagues' carving. Meanwhile, a number of adolescent boys mixed red sap from the mangi-mangi trees in the swamps with charcoal and lime. The two carvers, assisted by an older man, applied white lime dots, each to his own side of the board. They took turns dipping their finger into a shell-container of lime. The boys joined them in applying white, red and black dots according to a pattern pointed out by three older 
men. Everybody was in high spirits. More refined and special work, such as painting the edges of the shield and smoothing the back, was left to the carvers. The board, shaped like a shield, but not intended for actual use, had no handle. It was to be fastened horizontally to one of the walls inside the Kiawa house. At that time there was no ceremonial house in the village.

The carving method of ceremonial shields is of two types, an openwork type and a bas-relief type. Outstandingly ornamented shields of the openwork type are sometimes used as screens to close off the front entrance, one at the top and one at the bottom. Boards (baka), distinct from ceremonial shields and only depicting human figures that presumably represent the ancestress (and her husband) of a village half, are also sometimes used to close off the entrance. I saw such boards in Naygeripi in the far eastern part of Mimika. A striking feature of all ceremonial shields is a navel-shaped motif called mopere; this motif is repeated all over the surface of the shield. The grid of notches starts from there. Mopere, meaning navel or vagina, is regarded as the essence of life and is present in all types of carving. In addition, one often finds representations of hornbills or cassowaries. In Wanihiripao, ceremonial shields serving as screens depicted a combination of these two birds. When Zegwaard held up a copy of a ceremonial shield from Iwaka and Kawkapu (Wania River) that was used as a screen, in the shape of a hornbill, his informants identified fourteen body parts depicted in the carving (Zegwaard 195356, Kewa:6). Other motifs found on shields are lizards, eggs of a bush hen, scissors of a crab, bones of birds, and sawfish. Pythons are represented as zigzag lines. All these animals are associated with Ema Kame ceremonies.

\section{Carved attributes: sacred oval boards}

In 2003, when comparing and combining my field data from three villages in East Mimika (Waoneripi, Naygeripi and Inawka) with information from Wollaston (1912), Zegwaard (1953-56), and Coenen (1963), it dawned on me what these mysterious carved oval boards mean: they are considered as sacred objects. This is in line with Zegwaard's statement that these attributes are called the 'sacred two', literally puru (sacred, taboo) mane (two). Coenen supplies us with the crucial information that the two sacred oval boards represent the (putative) ancestress of a neighbourhood or parish and her husband (Coenen 1963:94-5). The neighbourhood consists of one or more localized descent groups, which in their turn comprise a number of putatively related subgroups called peraeko, literally 'vagina share one'. Each peraeko subgroup consists of the traceable matrilateral or matrilineal descendants of 


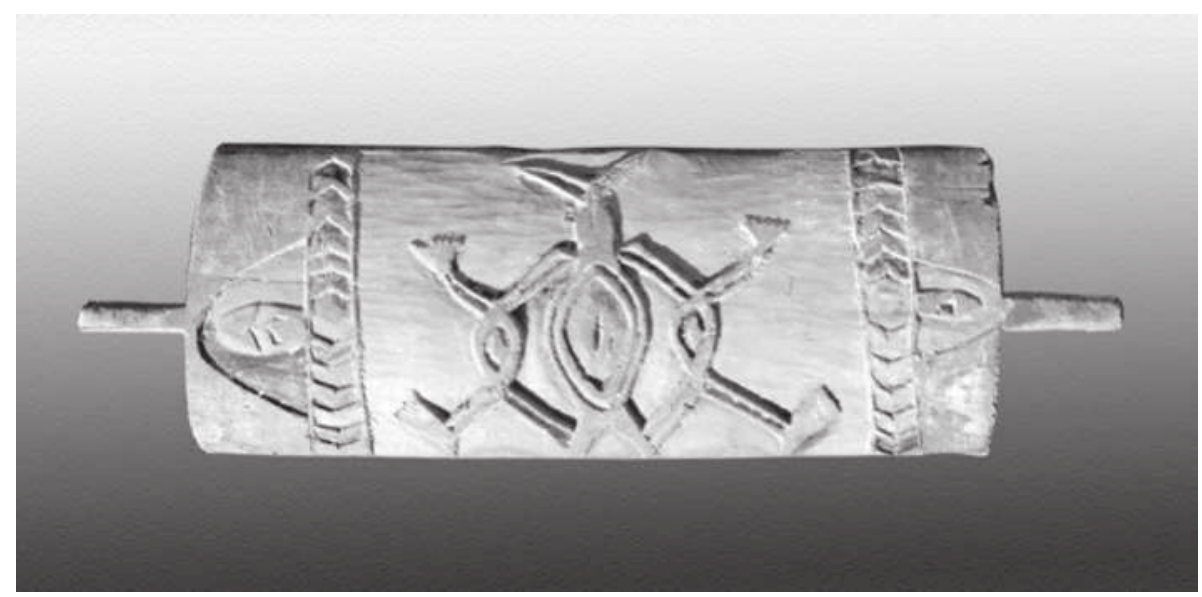

Female part of two sacred shield-like boards representing the ancestress and her husband, suspended between two central poles in the Ema Kame ceremonial house; the 'male' board serves as threshold at the entrance. Collected by Sacred Heart missionaries in the 1950s or earlier. Collection of the Volkenkundig Museum, Tilburg, The Netherlands: ET 53.7.12; at present Volkenkundige Collectie, Department of Anthropology, Radboud University: ET 53.7.12. Photograph by Thijn van de Ven. See also Kooijman 1984:75, Fig. 70.

one grandmother or great-grandmother. ${ }^{10}$ According to Zegwaard, one of the two boards is placed horizontally in the middle of the central entrance, and one between the central poles inside the house (Zegwaard 1953-56, Kewa:6, 10). Coenen (1963:95), however, writes that the two boards are suspended above the double entrance of the ceremonial house. Zegwaard's information, according to which one of the boards is attached between the central poles inside, seems to be borne out by a photograph of a ceremonial board in Kooijman (1984:75, Fig. 70). This board, part of the collection of the former Tilburg MSC museum, was erroneously ascribed to the Asmat, but is clearly a Kamoro carving. Unlike a ceremonial shield, it has two pointed horizontal ends that apparently are meant to be inserted into holes in the two central poles. Its centrally placed abstract motif seems to represent the ancestress, in the middle of which a vagina shows up very clearly. Left and right of the mopere-like vagina, two other mopere are situated in the centre of bent elbows and knees: the essence of life. It is this board that, according to my field data, functions as the centre of the ancestress ritual, as described below. Zegwaard's and my information are confirmed by Wollaston's description of the interior 
of the ceremonial house, quoted earlier:

and exactly in the middle of the hall, fixed to the floor were two posts about 3 feet apart and tied between them, at about half the height of a man, was an elaborately carved and painted board about 12 inches wide. In the middle of this board was carved the eye, which is a familiar feature of the ornamental carving on the canoes and drums, and it appeared that this eye is the centre of the ceremonies which take place in the house. ${ }^{11}$

The second board, functioning as the threshold for initiated men, who enter the house through the middle of the front entrance, is thus likely to represent the husband of the founding ancestress. It is decorated with representations of pigs and the eggs of a bush hen (Zegwaard 1953-56, Kewa:6).

Coenen points out a pertinent connection between these two sacred boards and the sacred rattles or bullroarers (wayiri) used throughout the Mimika area in the course of all sorts of ceremonies, including Ema Kame (Coenen 1963:934). Their whirring noise when swung around fastened to a string represents in the Ema Kame context respectively the voices of the ancestress, her husband, and her 'children', the peraeko. The three rattles correspond to three particular ceremonial shields, present in the ceremonial house. The latter vary in size from large to small, depicting the ancestress, her husband, and her peraeko children. They are stuck in the ground..$^{12}$ So there is a clear analogy between the boards, the rattles, and the special ancestral ceremonial shields. The three ancestral representations are kata puru, sacred/taboo secrets (kata).

\section{The ancestress ritual}

This ceremony was described to me in Naygeripi, East Mimika on 7 October 1952. I did not observe it myself. Neither did Zegwaard and Coenen, who do not mention it at all. It is performed after the completion of the ceremonial house. Women do not attend. One of the older men of the village, called Aneti, who was still alive during my visit, lies down on the sacred board between the poles while reciting the name of his mother. Then bystanders assist him in coming down. His (classificatory) sisters' sons (fatako) and his own and his classificatory sons (kamarima), literally his 'anus children' and his 'penis children', in that order, follow his example; the anus corresponds with female parts. After this, another senior man lies down on the board, followed by his (classificatory) sisters' sons, his sons and his (classificatory) brothers' sons.

11 Wollaston 1912:142, cited in Eyde 1967:128.

12 For more details, see Coenen 1963:94. 
Boys of school age also participate. Bearing in mind Coenen's information about sacred rattles and boards, what is happening here seems clear: the senior and the junior members of the various peraeko groups present themselves to the community. They are acting out their birth from the vagina (pera) of the neighbourhood's founding ancestress and from the various mothers (and mothers' mothers) of the peraeko; the vagina is carved out on the very board they are lying on. It is interesting that alongside maternal relatives, paternal relatives also participate.

My field notes correspond strikingly well with a description by Wollaston (1912:144) of a ceremony he observed in Timuka in what apparently was an Ema Kame house, though he was not aware of the fact: 'The people who participated in them [the ceremonies] dance slowly upwards from the front of the house, and each one in turn touches the eye [central mopere in the central area], while all the people shout together.' These people were probably acting out the tie with their real and putative ancestress. Ceremonially touching a person or an object in various contexts demonstrates the emotional tie with that person or object. In Inawka (Sempan, East Mimika) I was told that adolescent boys climb onto a ceremonial shield standing upright near the central poles, assisted by their bride-receivers. They perch on top of the ceremonial shield for a few moments and then jump down, again assisted by their bride-receivers. They repeat the climbing, alternatively facing and not facing the central entrance. They all call out the names of their mothers while jumping down.

This crucial ritual was described to me only in the East Mimika villages referred to, not elsewhere. However, Wollaston's description of the events in Timuka (Central Mimika) makes it seem likely that this ritual was performed in both Central and East Mimika. Peraeko are demonstrably present in the East Mimika settlements, which are larger than the villages in the other parts of Mimika. In West and Central Mimika taparu and their constituents are more numerous and less clearly localized, and thus more mixed up.

The Kamoro term puru mane for the two sacred shield-like boards representing the ancestress and her husband apparently corresponds to Asmat wuramun or uramun (spirit canoe). For a description of the latter and a comparison with the former, see Chapter VII. There are similarities but also striking differences.

\section{Unveiling ceremonial shields and ceremonial boards}

Two men, one of the 'right' and one of the 'left', face each other on opposite ends of the settlement. They draw closer, shouting and abusing each other under the pretext that one has given inferior food, and so on. They launch a mock attack, each of them supported by men of his own party. Women and 
children flock together from all sides to see what is going on. In this way men divert attention from the ceremonial house. At that moment other men hiding in the ceremonial house come forward singing, dancing and drumming. They remove the nets and leaves covering the ceremonial shields and boards mounted in front of the house, and turn the carved side of the objects to the centre of the settlement. They also remove the boards closing off the entrance. Women, adolescents, and children rush to the scene and admire the carvings, outside and inside the house, yet keeping their distance. Men point to the carvings on the ceremonial shields and boards while enumerating the names of the deceased, who are honoured and remembered separately by each ceremonial shield or board: 'Look, this is your brother [or sister, and so on, the name being stated].' There is loud weeping, mourning, and admiring the work of the carvers, who are lavishly rewarded with prepared food. In Naygeripi two female dignitaries, one from the right and one from the left, enter the house dancing and singing. They offer shellfish of the umu variety, prepared and wrapped in leaves, to their sisters' and daughters' husbands (their bride-receivers). Everywhere I was told that carved or uncarved boards, used to close off the entrance and differing from the 'sacred two' (puru mane, puru kani), are taken to the woods after the unveiling and left near their fishing and sago grounds. These are set up and shot at with arrows by men while calling out the names of their mothers and of their taparu. This act is meant as a way of communicating with the dead. By doing this they hope that the spirits of the dead will promote the growth of sago and the catch of fish.

\section{Secluding initiates: move and counter-move in gender antagonism}

Informants in Umar, West Mimika, described the seclusion of the young male initiates (tapena we, 'armband people'), corresponding by and large with descriptions in other villages and with Zegwaard's data, as follows. At dusk, when darkness sets in, the imakatiri draws people's attention by flinging smouldering pieces of wood; this announces the ceremony. Limecovered and lime-dotted mock spirits (mbi pata) rush out and beat on the roofs of the temporary shelters of women and children. Behind the shelters they round up the initiates and drag them to the ceremonial house, holding the sago balls they had been given. When it is pitch dark, the offenders pinch and sting the initiates and eat their sago balls. Mothers and other women watch near the entrance, crying and weeping. The initiates flee in terror to the rear of the ceremonial house. They have to spend the night there and are told to keep their mouths shut and not to cry. This horseplay, called umuria, also includes threatening women with muffled shouting and funny noises, and slinging around two types of rattles, a small penis-like board attached 
to a string, and a folded pandanus leaf. Other instruments used to produce frightening noises are bamboo flutes and bottles that are blown on (the anaipo game, Zegwaard 1953-56, Kewa:8-9, 14-5). Behaviour intended to frighten the women and initiates goes on for hours. At dawn the women take food they have prepared to the initiates. They are told that the initiates are not allowed to leave the ceremonial house, but in actual fact the initiates do secretly leave through the rear entrance to go fishing and have fun.

A counter-move by the women by way of revenge (aopao) is bound to come. It is called Miminaro (in Atuka) or Niniwaro (in Tipuka) and was briefly witnessed and described by Zegwaard (1953-56, Kewa:10) in Atuka as follows. Miminaro is a small bat with broad wings. Female dignitaries play, according to very confidential information from the mother of one of them, the role of an apoko snake. They imitate its high-pitched mbrrr noise that can be heard at night. These women represent particular groups or wards of the settlement. They are decorated with lime, red earth, soot, and cassowary or bird of paradise feathers. They are the dignified counter-actors (aopao) of the men with their horseplay. One of them enters the ceremonial house doing a bird dance in a bent-over pose. She carries a burning torch, which she presses against the vagina motif on the sacred board attached to poles in the centre of the ceremonial house. The torch may also be pressed against the private parts of a carved hornbill. She and other women threaten the men with torches, shouting ' $U, u^{\prime}$. Men flee to all corners of the house. The performance is repeated by other women carrying a torch. According to Coenen (1963:39), this ceremony is named apoko, after the snake that they imitate. The hornbill stands for love, erotica and reproduction. Zegwaard reports that the women in Mioko do not use a torch but a stick, with which they touch the shoulders of terrified men. This act clearly connotes the Kamupu Kame myth and ritual referred to above, concerning a woman who died while delivering a baby. As a punishment for neglecting her, men were transformed into women who have to put up with having a baby. Everywhere men sing the Kuru song while being threatened, a clear reminder of the rebellion of the amoko superwomen of the myth that is acted out in the Tama ritual.

What is the purpose of the torch ceremony, apart from terrifying men? My assumption is that by doing so the ancestral mother whose vagina is touched is symbolically brought to life. It demonstrates the unique reproductive power of the ancestress and of all women. It is common practice that a woman fainting in labour is revived by touching her body with a smouldering piece of wood. In the Kaware myth and ritual (see Chapter III) the drowned culture hero Mamirima was also brought back to life by numerous birds touching his body with smouldering sticks. The torch ceremony seems to be women's powerful ritual answer to men's act of dramatizing descent from the ancestress by lying on and jumping down from the sacred board, which represents (the 
vagina of) the ancestress. Moreover, the female dignitaries represent watersnake (upako) women.

A final comment can be added. Naming the torch ceremony after a small bat may refer to the Tako ritual, which is dealt with next. Tako, however, is a larger variety of bat. A smaller kind of bat serves as a messenger for the bushwomen who replace the superwomen according to the myth associated with the bat ritual.

\section{The bat ritual}

As noted, the people who celebrate and attend Ema Kame are called tako we, or bat people. Another indication of the crucial importance of the bat ritual is Coenen's information (1963:37) that in the Sempan village of Omawka, in East Mimika, where Ema Kame is called Kiewa, the very start of Ema Kame is announced by men secretly cutting down a tree of the onati or enata variety. It is precisely this tree that is classified with, and is of one soul with (ipu enakoa), the tako bat (Indonesian: kalong) and the bat ritual. Not only is this tree placed on the platform where the bat ritual is performed, but splinters of its trunk are also distributed among all participants as a sort of pars pro toto at the very beginning of the Ema Kame rituals. This is said to promote fertility.

We owe a description of the first part of this ritual exclusively to Coenen. Zegwaard does not mention it, and I did not see or hear about it. It is called Meamo, which is the name for both the type of wood and the platform built from it. I quote Coenen (1963:45):

In Iweka-Temare (upper Kamora River, Central Mimika) it concerns - at least as far as I could trace it - the secret [kata] of two actors [the ènata wé] sitting on the platform opposite each other, feet touching, while two other actors perform the king parrot (mopoko) dance. Close to the actors are situated the following kinds of timber: otenaputajoro, an otepe [magical means] to catch pigs, poroto, to catch much fish, ewakoto, to catch ewako, a thorny fish. In front of them are two small trunks of the ènata tree [splinters of which were distributed at the beginning of the ritual]. The ènata wé and the mopoko wé are of one soul. In Mware there are bird of paradise (jawmako) actors instead of the king parrot ones. This ritual corresponds with the Emakasja of the Sempan villages and is still performed in most of the Mimika villages after the initiation ceremony of adolescents [the tawri or apron ceremony. Another name for this ènata ceremony is kiewa kasja. For a long time it was known as a not very significant initiation ceremony. In fact, it may be performed separately from Kiewa because this ritual is no longer carried out in its entirety. It functioned as the introduction to the real meamo ceremony, during which two actors, a man and a woman, performed the takò dance, the dance of the bats, hanging on a platform and acting out copulation. After this there was general promiscuity. This was concluded by formally pronouncing the prohibition of incest. A bat-actor was 
then sitting on the platform. People do not wish to perform this [coitus] ritual any longer, but it is still known.

During this Meamo ritual, men's noses are marked with a horizontal line of lime, a generally recognized sign meaning that a man wishes to have intercourse with a woman (Coenen 1963:70).

The king parrot and the bird of paradise are 'of one soul with' the forest of sago palms they feed on; therefore these two birds are associated with growth and fertility. It is not a coincidence that the initiation of boys and the initiation of adolescents take place on the top of a platform built of numerous containers of raw sago. The sago here clearly symbolizes growth and fertility. Coenen's remark that the Meamo ceremony is insignificant contradicts his own statement that it is still a standard part of the ceremonies initiating boys and adolescents, and may be due to the fact that Kiewa is not performed in its entirety. The abandonment of the bat ritual because of its elements of copulation and promiscuity seems more likely to be connected with the arrival of colonial rule and the Mission.

The rituals at the Meamo platform are clearly meant to promote growth, fertility, and reproduction of humans, animals and vegetation. Coenen does not describe the exact nature of the promiscuity. A boundless happy-go-lucky sexual orgy seems unlikely. My assumption is that it is a manifestation of lovers' (marakoma) relations. These are the informal counterparts of the formal exchange of sisters by males as the preferred type of marriage. Sister exchange often goes against individual preferences. (There may be a correspondence or similarity with the Asmat papish practice, a case of regulated ritual promiscuity in situations of crisis and danger.)

The announcement of the prohibition of incest with close, probably stipulated, kin is a perfect counterpart of the ritual show of eroticism and intercourse. Further, it is not a coincidence that, according to Coenen, after the acts of (presumably regulated) promiscuity and the announcement of a prohibition of incest, a kind of public confession of adultery and other trespasses takes place as a catharsis of human relations:

In Atuka the ritual is called Ireku nao, that is the name of the culture hero who is called Mirokotejao elsewhere. In Atuka confessions take place while people dance. Older men begin. Cases of theft of goods and of pounding sago in forbidden areas, which resulted in serious quarrels, are confessed. Confessions of indulging in sexual acts with marakoma are met with roars of laughter. The confessing offender takes care not to be in the vicinity of the offended party. Afterwards no problems with offended parties emerge. In Atuka people were very liberal in confessing. However, serious crimes such as adultery with married women, considered as theft, or black magic causing death, are not confessed. In Waonaripi people who confess sit on a ladder; this keeps a tighter rein on their sincerity [probably because 
sitting on a platform turns the confession into a more formal public act]. (Coenen 1963:101.)

One may conclude from this description that the promiscuity involves lovers rather than married women. Zegwaard alludes to public confessions under the heading of Iraku as part of his description of Ema Kame: 'The elders assemble all the people in the Keawa house. Everybody, while dancing and turning around, gets an opportunity to tell those present that he stole sago or fish or so-and-so [allusion to lovemaking; adultery]. There is much laughter.' (Zegwaard 1953-56, Kewa:9.)

The second part of the bat ritual follows after the display of fertility and eroticism. From the ridgepole a large number of bats, personified by male adolescents, are suspended, analogous to the way bats hang on trees upstream, very close together and in huge numbers. I read somewhere that young bats hang in huge clusters on particular branches, functioning as delivery rooms. The initiates imitate the screams of bats; there is a hell of a noise. The ceremony takes place late at night. Accompanied by their bride-receivers, the initiates climb the ladders to the ridgepole and hang on to it with hands and feet. The bat dignitary on top of the roof chants to them: 'What are you doing there? You are finishing up the fruit [an enumeration of kinds of fruit follows].' He hits the roof with a stick to chase the 'bats' away. They fall down and are intercepted by their bride-receivers, who take care that the initiates do not come to any harm. The initiates lie down on the floor. The play is repeated a number of times. Meanwhile, the singers and drummers recite a derisive song about bats with their lean and crooked behinds..$^{13}$ In everyday life, bats are a subject of mockery and jokes (Zegwaard 1953a:1-2), and this is true as well for the male adolescents who imitate bats in this ritual.

There are sometimes two dignitaries on the roof, one from the right and one from the left. At the end the initiates lie down on the floor, and talking and laughing are prohibited. The older men stay with them throughout the night. At dawn women, mothers and sisters line up in front of the house. Accompanied by the guild of singers and drummers, the right 'bats', followed by the left 'bats', leave the house in a procession. They are welcomed and embraced by their weeping, shouting, and highly emotional mothers and sisters. Beforehand the bride-receivers secretly remove the ladders and push them into the river, lest the women notice that the initiates have used ladders to climb up to the ridgepole. 
The glorious return of the initiates: the hornbill ceremony

The spectacular return of the initiates, appearing this time not as bats but as hornbills, requires a good deal of time-consuming preparation: elaborate hair care, decorating the body, building a footbridge, and collecting lots of food.

Close male relatives, but not affines, plait the hair of the initiates, since hair and hair care are a most private affair. In secluded locations, so as not to reveal the plaiting patterns before the 'show', strings of hair are tightly pulled and plaited in pathways on the head. Plaiting specialists are found and lavishly rewarded. The main pattern of the pathways is a left half and a right half, called tomoro, separated in the middle of the head by a central ridge, wayku (middle), another example of bipartition. After a couple of weeks or even months, the plaits are loosened and soaked in a red oily sap, wane, a fluid extracted from the $k u k u$ tree. This is believed to promote hair growth, an explicit symbol of fertility.

(In 1953 I attended a ceremony, called Imini, in Kaokonao demarcating the end of a mourning period, during which the plaited hair of twelve married women, carefully tended for months and kept hidden by a head shawl, was unveiled by removing the shawl. This imposing show of patterns of new plaited hair symbolized the renewal of life. Tradition has it that this ceremony was performed some time before celebrating Ema Kame. $)^{14}$

When the loosened hair has reached considerable length, tufts of hair are arranged in a sort of cock's comb on the top of the head. This offers a spectacular sight which makes the mothers cry. Some of them even say that they find it difficult to recognize their sons with such a display. Further, uu tawri, literally 'head fibres' of the sago palm, functioning as hair extensions, are attached to the plaits of hair. Many women also have tufts of hair shaped into a cock's comb. Some important female dignitaries have their hair extended like men do, while the hair of other women is cut by men around their heads. The men's custom of creating hair extensions in everyday life, as found in the Asmat territory, went out of use long before the 1950s.

A wide range of arm, leg and waist bands for the initiates and for participating men and women are plaited (by men and women). Various attributes for head and body decorations, such as plumes and feathers of birds of paradise and of king parrots, and the plaited young leaves of sago and coconut palms, tawri, are prepared. In Umar I was told that items of attire are secretly hidden in the house above the heads of the initiates at night, to be discovered as a surprise early the next morning.

Head ornaments made of wood or bark, in the form of stylized birds of 


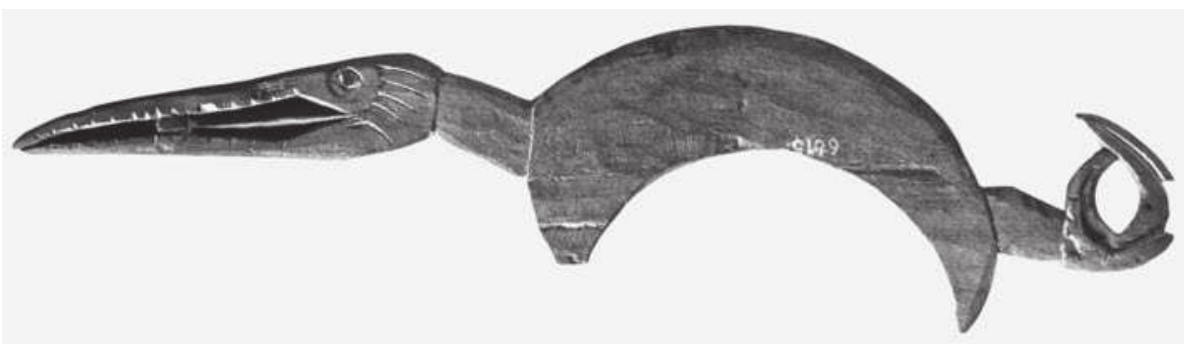

Head ornament representing hornbill, worn by initiates during final stage of Ema Kame, Mimika. Collected by Ch.L.J. van den Broek, before 1908. RMV: 3600-6615. See Kooijman 1984:33, Fig. 26; Smidt 2003:105, Fig. 63.

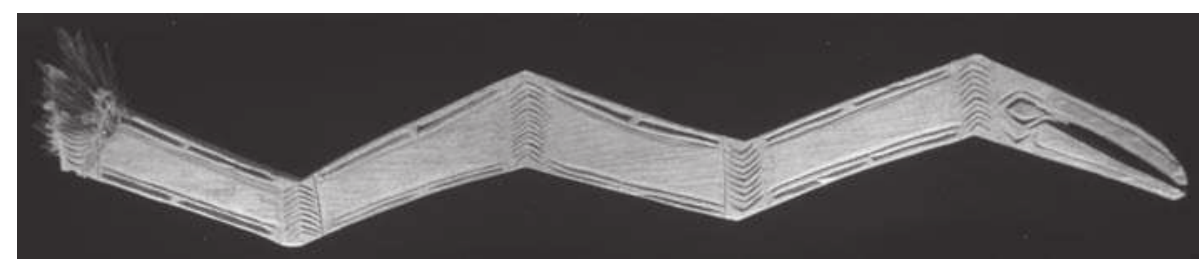

Head ornament representing highly stylized hornbill, worn by initiates during final stage of Kiawa (Ema Kame). From Cape Steenboom, mouth of Mukumuga River, collected by W. de Jong, 1903. RMV: 1416-32.

See Kooijman 1984:xv, 35, Fig. 31; Smidt 2003:68, Fig. 65.

paradise and king parrots and adapted to the form of the head, form the spectacular masterpiece of decoration. ${ }^{15}$ These are placed on and attached to the cock's comb of the initiates and of some participating women.

The highlight of the final ceremony is a procession in a right and a left line of the initiates, now called bird people (paturu we), each headed by a male hornbill dignitary, all fully dressed up and with the bird's head ornaments fastened to the cock's combs. The procession solemnly comes down from the house, along the footway decorated with young sago leaves. The bridereceivers and sisters of the initiates slowly pull the initiates down by means of strings attached to the wooden birds on their heads. The enthusiasm of fully dressed women, their bodies covered with white and red stripes, amounts to frenzy. Some women even roll on the ground. They beat the air shouting 
'Wayna waota, honour to our sons and young brothers!' The bride-receivers then take the initiates on their shoulders and turn round and round, dancing and singing. The ceremony ends with a dance around the dancing post, in which everybody, young and old, participates. Finally, the bodily attire, the bands, the tawri and the spectacular head ornaments are placed in trees around the creeks, so that the dead may share in the joy of the living.

In Potoway, in the far western part of Mimika, initiates carry carved mock shields while being attacked by women who hack and stab at the shields. This act probably refers to the Ema Kame myth about the monstrous monitor lizard or crocodile who swallowed the people and whose flesh, fat and bones were transformed into ethnic groups. However, this interpretation is an exception to the explicit universal rule throughout Mimika that the hornbill procession refers to the widely known myth of male adolescents who transform themselves into hornbills. The myth is as follows. A number of badly behaved boys play scandalous tricks on an elderly couple. The boys flee from the enraged couple by climbing a hollow tree, which the offended party proceeds to cut down. The tree carrying the offenders drifts downstream into the sea to the far western part of Mimika and beyond, off Mimika, into the underworld. There they meet up with a colony of women who make love with the now adult adolescents. The story ends with these adolescents shamefully transforming themselves into hornbills and departing from their desolate wives after enraging them by accidentally dropping coconuts. They do not heed the laments of their wives, who desperately try to stop the exodus. ${ }^{16}$ The ritual, a dramatized myth, clearly has erotic overtones and is overtly connected with the promiscuity of the Meamo ritual.

In an Asmat story, a hornbill carved by a male adolescent comes to life and then functions as a literal postillon d'amour by carrying the beloved woman on his wings to his master. ${ }^{17}$ Zegwaard, who collected this story, sees a connection between the regurgitating motions of the hornbill feeding its young and the movements of the man's penis in ejaculating semen. He also suggests a correspondence of the bird's spectacular beak chiselling its way into a tree with the human male chiselling and shaping the foetus with his penis and repeatedly feeding it with semen. The term maramo indeed has the meanings of hornbill's beak, chisel, and human chiseller. A male's contribution to the formation of a foetus in the female's womb compares with the hornbill beak's function: it chisels, shapes and feeds (Zegwaard 1995:317-8).

The hornbill ceremony marks the formal end of Ema Kame. At night the bride-receivers of the deceased proceed to collect the buried bones of the 
dead and the skulls stored in the houses (or buried) and throw these remains unceremoniously into and under the already wrecked Ema Kame house. The women, however, are under the impression that the remains are fully respected. They even provide the dead with food, which the men secretly consume. The house as well as the bones are left to decay, after two ceremonial staffs (pokay) covered with white feathers have been removed. In addition to pokay, these staffs are sometimes called ya mate, according to Coenen's informant in Kawkapu (1963:94). They are yet another representation of the ancestral mother and her husband. The feast is over and, after lavishly rewarding the dignitaries and the bride-receivers for their work, the hosts and guests return to their settlements downstream. It is ironical that, while the Ema Kame rituals clearly denote and connote life, the literal meaning of the name of the ceremonial house, which also denotes the ritual, derives from death: the bones that are left there to decay.

\section{Postlude}

The celebration of Ema Kame may be concluded with one or several plays (kamania or kakuru) that are mainly but not exclusively meant for entertainment. I will describe two of them. These may be combined with other ceremonies and rituals, or may be performed separately. The first play tests the dexterity and stamina of initiates; the second tests the dexterity and stamina of male adults and is another demonstration of gender antagonism.

The first one is called Ayu Kata or Opo Kata, 'upperworld secret'. I attended its separate celebration in Mioko, upper Kamora River, on 12 September 1952. Men of the right half and men of the left half make a ladder, one for each half. The left and the right rattan dignitaries together remove a strong rattan cane of about 25 metres in length from a tree in the forest and drag it to the village. A man of the right half climbs his ladder, placed against the local teacher's high breadfruit tree (usually a casuarina tree is selected). He wears an apron made of cassowary quills. Dancing and singing, he pushes the rattan over a branch high in the tree and then lowers the rattan so that it touches the ground. The right and the left sides of the rattan are then stretched, and fastened solidly to two constructions on the ground. The climber stays in the tree on a makeshift platform. The announcer of the play, who summoned men to fasten the rattan cane, lies down on the ground with a stern face, because the others do not really listen and seemingly have made a mess of the job. Then an old man, a rattan dignitary of the right half, is dressed up by his bride-receivers. Over his shirt he wears a white garment, and over this garment a blue coat with a stiff collar: he puts on all the clothes he has. He circles the tree and solemnly climbs the right ladder. One of his bride-receivers follows him, while trying to remove 
big red ants that have crept up and into the very layers of garments of the poor actor and are biting him, but the victim keeps his dignity. Male spectators roll on the ground in spasms of laughter (it is just one step from the sacred to the profane). Standing on the platform, he recites the names of varieties of fish that were taboo during Ema Kame, and warns people to resume eating these kinds of fish slowly and carefully, lest they fall ill. While reciting the names, he scratches his body vigorously and tries to remove the attacking ants, assisted by his bride-receivers. This elicits roars of laughter. Then male adolescents, initiates assisted by their bride-receivers, climb the right and the left ladders and descend along the rattan canes suspended on arms and legs, capering and shouting. Their bride-receivers watch them closely and even ascend the rattan in order to help the boys reach the ground safely. The play goes on for about an hour; a few of the initiates repeat the exercise. Meanwhile, the old man on the platform swings a lime-covered machete and threatens to cut the cane. By the end of the performance he descends in a dignified manner and touches the shoulders of his bride-taker assistants as a sign of appreciation for helping him reach the ground safely. The garments and the attire are removed in an equally dignified manner. Women watch the scene, keeping their distance. At night, while sitting round the fireplace in front of their houses, fathers and brothers of the initiates praise them for having reached maturity.

Impressed by this play, in 1954 I suggested inviting the Mioko people to give a performance in the administrative centre, Kaokonao, on the occasion of the Dutch Queen's anniversary. Initially the village elders turned down the request: 'It is not proper to mix your foreign celebrations with ours; we could fall ill and die.' But then the male adolescents insisted on displaying the agility they were proud of. The elders gave in. The play was performed, but only after the formal end of the Dutch celebrations. It went off well and was received with praise by hundreds of Kamoro spectators, although the Mioko elders were not quite comfortable with it (Pouwer 1955a:259-60). The upperworld secret play probably evokes the highly secret sun myth. The culture hero Murupiuta-onearth, who is the namesake of the sun hero in the upper world, visits the upper world. He makes the sun, hidden in a hut or factory, rotate around the earth to the benefit of mankind, and returns to earth by means of a long rattan cane. While making his way through the upper world from east to west, he lowers the cane at each village below. The villagers touch the cane, after which the culture hero lifts it and continues his journey. He finally descends in the settlement of Wakatimi, or Mimika proper, in Central Mimika. This village is the yao amako, the owner of the sun secret. ${ }^{18}$ The gesture of the dignitary of the play in touching the shoulders of his bride-receivers while descending the cane could 
well connote the villagers' touching of the mythical sun cane.

The second play, Tura Kata, the fire play, is not specifically related to Ema Kame and is performed everywhere in Mimika on a variety of occasions. It belongs to the category of $i m u$, a special form of akapa (laughing), a farce in which women playfully attack men as a part of joking relationships between the sexes and between bride-givers and bride-receivers (for more details, see Pouwer 1964). At dusk all the men, except the old ones, enter a space enclosed by a temporary fence of leaves and branches, which they are not supposed to leave during the play. Women encircle the fence laughing and shouting, while throwing smouldering pieces of wood or blazing palm leaves at the men. Sparks of fire rain down on the men, fended off by their bride-receivers who cannot, however, prevent their in-laws from being hit. The play goes on and on with violent ferocity, till a village elder orders the women to stop. The women enjoy themselves, since the men have to stay put lest they become a laughing stock.

It is interesting to note that in Potoway, close to the trade centre of Etna Bay, I was told that the fence was formerly shaped like a Chinese trading schooner, with an imitation mast in the centre and decorated all over with young palm leaves. The play was then called Tena $\mathrm{Ku}$, or Chinese canoe.

By the end of the play three male dignitaries take their positions in front, in the centre, and at the back of the imitation schooner (similar to the positions in the python ceremony and the Tama ritual). The dignitary in front, who relates as 'bottom' or 'root' to the other two as 'surface', as the owner-in-the-know to the secondary owners of the secret, summons the spirits of the massoi bark while clinging to the top of the mast. The medicinal bark is highly sought after by Chinese. The spirits of the bark, represented by dignitaries hidden in the woods, answer the call ' $u u u u^{\prime}$. The dignitary on the mast hits it with a piece of massoi bark. He has got the message: there is an abundance of bark. Collecting the bark of the massoi trees, growing upstream in or near the mountains, is a demanding job and moreover the tree is not easily found. The fire play in this form is a striking example of ritual innovation. Just like the climbing play, it shows that the boundary between social entertainment and ritual acts is indeed a thin one. ${ }^{19}$ 


\section{Chapter ili \\ The 'male' contribution to life Kaware ritual}

The Kaware ceremony belongs to the domain of men. It is considered to be the main social-ritual articulation of the difference between men and women. As such, it serves as a major symbol for male skills, such as the making of canoes, paddles and sago bowls, as well as for ritual and secret knowledge of all walks of life, embodied in dozens of otepe or kata, owned by men and inherited along patrilineal lines. Coenen (1963:22-65) lists sixty otepe covering all aspects of life. These include a plethora of ritual functions in Kamoro performances; they deal with the forces of nature and with a wide variety of diseases that are cured or caused by such forces. Men also dominate communication with the dead. Some cargo cults claiming the return of the dead and the emergence of paradise were initiated by men who had visited the underworld. In Kamoro representations, Kaware relates to Ema Kame as male to female, left to right, coast to inland, and east to west. This multiple dual division, however, is a cosmological one, which should not be confused with a historical-geographical point of view. The two configurations of rituals, like the majority of the ethnic groups, originated in the far eastern part of Mimika, spreading westward in a chain reaction of migrations. The Kaware ceremony is not known, though, among the ethnic groups of the Koperapoka region in the far eastern part of Mimika or in the Opa region in the far western part. The inland Sempanowe (Omawka, Inawka and Otakwa), close to the Asmat, do not celebrate it either. Therefore, it seems as though Kaware spread from east to west, with the large migrations coming up against resident communities that were not familiar with it.

\section{Kaware ritual and myth}

The Kaware ritual is associated with three different myths, each of them known in various versions, all of them situated in the far eastern part of Mimika. There is one feature common to Kamoro myths: their actors flee 
from the human world-in-between because of their own or their fellow men's wrongdoings. They cross the barrier between life and death and descend into the lower world, the paradisal abode of the dead who continue living in communities situated parallel to the communities of the living.

\section{Myth 1: Muanuru-from-above and Muanuru-from-below}

The first myth, well known throughout Mimika, deals with two namesakes, Muanuru-from-above and Muanuru-from-below, and is told in the Wania settlements of Central Mimika and along the Tipuka River. ${ }^{1}$ A strikingly similar Asmat version of this myth is deemed vital to Asmat culture, since it underpins the majority of Asmat institutions. The Asmat namesakes are called Ton-Yenip-from-above and Ton-Yenip-from-below. ${ }^{2}$

On their return from the sago swamps, parents order their unmarried son and daughter to stay behind, meanwhile relieving themselves [probably meaning that the parents had sexual intercourse]. Fooling his sister into believing that their parents had told them to have intercourse, the brother forces her to comply. As soon as the parents have returned, their daughter tells them what has happened. Ashamed, the son steals away and, via a partly submerged tree, descends into the lower world. Here he discovers a house, Kaware, and a beautiful garden with crops unknown on earth: coconut, papaya, white pumpkin (labu), breadfruit, sweet potatoes, taro, cucumbers, and so forth.

The son hears a man singing the (wrong) Kaware song in the house. However, a watersnake teaches the man the proper song, which the visitor overhears. As the Kaware man leaves the house, the son goes inside and, taking some mussels from a heap of mussels at the fireplace, eats one of the two bodies in each shell (this explains why, ever since that time, all mussels have been half empty). When the Kaware man returns, he notices the theft and discovers the thief, but says nothing. They turn out to be namesakes. After showing the visitor the house and the Kaware paraphernalia, the Kaware man lures him into the arms of the spirit poles placed in front of the house. The arms of the spirit poles then tighten up around the mussel thief. Now the Kaware man shoots small arrows, made from the ribs of sago leaves, into the visitor's body, starting with his toes and continuing up to his head. Just as he is about to aim at his head and eyes, the victim is rescued by his bridereceivers, who have followed him. The Kaware man is then decapitated. His victim is set free from the spirit poles, and returns to life and to earth. The paraphernalia of Kaware and the garden produce emerge. Muanuru-from-

1 For the text, see Offenberg and Pouwer 2002:108-12.

2 For the text, see Offenberg and Pouwer 2002:102-8. 
above passes on his knowledge and the Kaware ceremony is performed on earth for the first time.

\section{Myth 2: The culture hero Mamirima}

The second myth, about the well-known culture hero Mamirima (or Japako in western versions), is claimed by Tipuka in the Wania region, but it originated in the far eastern part of Mimika. ${ }^{3}$

Mamirima tricks his namesake (or, in other versions, his age mate) by having secret intercourse with his lover. The namesake, by way of revenge, goes off with the canoe of the trickster, who then has no choice but to return to the village hidden in the woman's canoe. Wrapped up in a mat, the man is swept overboard by sudden waves and drowns. His body is found by a flock of various birds on an island at the river mouth. Led by a sea eagle or a pelican, the birds peck at the vital parts of his body and touch these with smouldering sticks. This brings him back to life. After having intercourse with the birds' wives, the hero throws sand in the river, which causes the water to flow away and the river to dry up, so that he can get back to the mainland. There he builds a Kaware house, creates all the Kaware paraphernalia and, seemingly dead, lies near the spirit poles. Found by his parents and companions, he informs them about Kaware. However, the sounds of a drum that Mamirima made with the aid of a fish so much annoy a spirit that he kills Mamirima. His parents, in turn, kill the spirit and destroy the Kaware house. They throw their lances into the sand and return to the place where the house stood and then return home.

This story is also well known among the Asmat. ${ }^{4}$ Their hero, named Fumuripic, is a major Asmat culture hero. A 'modern' Asmat version even accounts for the Kamoro and the foreigners in Mimika, their power and commodities: wooden statues, drummed to life by Fumuripic, moved to Mimika - a clear Asmatization of a strikingly novel Asmat experience.

The two myths differ in that the first one explicitly accounts for Kaware's origin in the lower world, whereas the second does not include this event, and instead concentrates on the hero's resurrection by the birds.

\section{Myth 3: A widower and his daughters}

In the third myth, told to me in Umari (West Mimika), but also found in Tipuka and further to the east, a widower, Kinako or Nokoro, is being cheated by his two daughters, who keep the most delicious food, notably the sago

3 For the text, see Offenberg and Pouwer 2002:98-102.

4 For the text, see Offenberg and Pouwer 2002:93-8. 
grubs, for themselves, giving him only inferior food. Once he becomes aware of this, he sulkily and secretly builds an ironwood canoe with a sharp bow and stern. On the boards he carves motifs that have since then become common. He decorates the paddles, which he has also made of ironwood, and carves a spirit pole on the bow. After scolding his daughters for disgracing him, he takes off underwater - after all, ironwood is very heavy and sinks upturns trees and his daughters' house, follows crocodiles and big fish, and has remained in the lower world ever since. He leaves behind a sample of the canoe, the paddles, and a mamokoro mask he used while fishing. His daughters turn into trees. Ever since, whenever a tree suddenly falls down or is submerged, or whenever a fish jumps out of the water, it is said to be his doing. He is considered the 'father' of river-going canoes, of their carvings, and of paddles and drums. The mamokoro mask, also ascribed to him, is a special, more refined and elaborate spirit mask ( $m b i \mathrm{kao})$. It has a pointed chin.

These myths are re-enacted, although selectively, in the Kamoro Kaware ritual and in its Asmat counterpart.

\section{Male secrets versus female power}

In Kaware, secrets of myth and ritual receive more emphasis than in Ema Kame. This probably reflects the powerful social and economic position of women. In daily life men sometimes feel uneasy, laughed at, and threatened. Their refuge, Kaware, is therefore hedged with secretiveness. Kaware in this respect is not only a ritual affair, but also a male exercise in impressing women. Time and again the male participants attempt to awe the women. For their part the women play the game, at least pretending not to be in the know. Revealing Kaware secrets or being careless is considered a major offence. Around 1900, the Wania groups, assisted by the Koperapoka people and Atuka, waged a war against the Tipuka people, accusing them of carelessness in safeguarding Kaware secrets from the intrusive eyes and ears of female visitors from other settlements. Older women were slaughtered, and younger women and children taken captive. Tipuka, then a powerful community closely associated with Kaware, was decimated. There is reason to believe that sago resources, threatened by the numerous, powerful and boasting Tipuka, constituted an underlying cause for the attack. In the 1950s, Yaraya and Ipiri of West Mimika were reluctant to celebrate parts of the Kaware ceremony, because men in Kaokonao had been careless in relation to women in their use of masks. It seems significant that, according to my informants in the Wania region, Kaware was the first ritual to be discontinued after the Catholic Mission and the colonial government extended their stations in the 1920s, for fear of secrets being divulged. 


\section{Clearing the ground}

Kaware proper sometimes begins with a kamania - a play as distinct from a ritual - that alludes to the attendance of the dead at the Kaware celebration. At the beginning of the play that I witnessed in Yaraya in 1961, a number of men covered with lime emerge from a conical hut. Next, a man wearing armbands, strings around the legs, and a face mask made out of bark or coconut fibre appears and shows himself in and around the hut. The men flee hurriedly and fall down as if dead, some acting realistically with their tongues sticking out. When the masked man, denoting Aowameyao, said to be the dignitary (amako) of life and death, approaches them, their bodies writhe in rhythmic and disturbed movements, as if coming back to life. Aowameyao encircles them, feigning stabs at them with a spear, a gesture meant to impress the women and boys watching from a distance. Aowameyao's attribute is a bamboo horn (according to Asmat myth, blowing a horn breathes life into wooden statues).

The next scene is a regular part of Kaware. A casuarina tree (in coastal regions) or a breadfruit tree (in the inland) is cut down. Its branches are removed and its trunk is smoothed. The trunk is then transported to the location where the Kaware house will be erected. There the men belonging to the right and left halves of the celebrating groups, who are usually members of two or more settlements, approach the tree from opposite directions, dancing, drumming and singing. They line up along both sides of the tree and touch it rhythmically and repeatedly with their outstretched fingers. Informants explained that they are caressing the tree, which has been wounded by the men's actions. The meaning is not quite clear to me, but it is likely that the actors are apologizing to the tree and to nature for removing vegetation for the sake of building and celebrating Kaware. Trees are considered to have souls (ipu), just like animals and humans. Numerous kinds of trees are crucial to Kamoro cosmology and their system of classification.

Then V-shaped rakes are made and used to clear the ground where the Kaware house will be built. Called servants or slaves (manuku), these rakes are used at a later stage as supports for the roof structure. The tree and rake ritual is taboo for women and uninitiated adolescents.

\section{Erecting roof support poles}

Older men then measure the distance between the poles to be erected as main supports for the roof. They indicate the proper locations for the poles and plant sticks to mark the spots. The following day, two parties of 'right' and 'left' men depart for their own territories to cut down yatari trees to be used 
as poles. Uninitiated male adolescents accompany them as apprentices. The men tow the poles behind their canoes and return to the settlement at dusk. On their way back, women in the settlement are playfully (kamania) chased away by men wearing improvised, informal face masks. The trunks are left to dry near the Kaware location.

\section{Erecting the poles}

The next morning, women and children leave to collect pile-worms (koo). The men dig holes and erect the poles, as long as eight metres in height. The exact method of erecting the poles is shrouded in secrecy. When men explained the procedure to me and I tried to imitate it in a model, the informants pushed me to the ground and surrounded me, for fear of women watching and learning the secrets. To push up the pole they use a two-pronged wooden fork (yati) and a stabilizing stake fastened at the back with rattan. Once this job is finished, all the tools used are destroyed or hidden. There is considerable singing and drumming and much excitement. Uninitiated adolescents are invited to watch the scene, but looking into the hole after the poles have been erected is taboo for them. When the women return, they act out amazement, praise the men abundantly, and reward them with fried pile-worms.

Eight or more poles are planted in a single row, as I observed in Tipuka in 1952. There is a right and a left wing for the 'right' and the 'left' parties, and a central entrance. The broad front and the layout of the house resemble the Karapao house and differ from the Ema Kame ceremonial house.

\section{Enacting the death and resurrection of the mythical hero}

At dusk, the initiates, accompanied by their bride-receivers and other men, lie or sit down between the poles, pretending to be dead. They are told by the initiated that they will have to spend the night in this position. Food is offered by the women, but ignored. The men are naked, or nearly so. At last the older men extinguish the fires lit near the poles, and the food and water are removed. Pitying the initiates and the other men for their plight, mothers and other women go home, crying and lamenting.

Meanwhile, some older men furtively take smouldering sticks, food, water and tobacco to a secret spot behind the Kaware location, where material has been hidden to build a temporary hut. Now, to their utmost astonishment, the initiates, still believing they will have to spend a miserable night by the poles, are taken there and asked to assist the men in building the temporary hut. Having outwitted the women is reason to eat, drink and smoke. They are 
given food, water and tobacco and enjoy themselves while (or because) the women have been deceived. The fire dignitary (utemako) emerges from a hidden pit and has the fire transported from there to the hut. At dawn, the men complain loudly about the rain, the mosquitoes, and the cold. Stealthily, all of them, initiates and non-initiates, go into the river. Soaked through, they lie or sit down near the poles. The women wake up and approach them, wailing and weeping, still pitying them for their plight. Then, as if revived, the men move forward, making the noises and flapping gestures of birds. Pretending to be unable to walk, some of them stagger and fall down, first the men from the 'right', and then those from the 'left'. Other 'ailing' adolescents are carried on the shoulders of their bride-receivers. The excited women offer the men pile-worms and they light fires to warm the men's cold bodies. They put cigars into the men's mouths. Mothers embrace their sons. In the end everybody returns home. This serious play clearly acts out the death and resurrection of the mythical Kaware hero Mamirima.

In Tipuka, I was told that the initiates are confronted with a man wrapped up in a mat. Sticking out one of his arms, he grabs at the feet of the panicking adolescents: this is a reference to the mythical hero being thrown overboard by the waves. Coenen reports that the people of Inawka, belonging to the Sempanowe of the far eastern part of Mimika, who do not practise Kaware but are aware of the myth of the hero being revived by birds, enact the narrative as follows. Men disguised and adorned as various types of birds assemble, dance and sing around a (mock) corpse impersonating the hero called Fumarewa (compare Fumuripic of the Asmat). Squatting down, they pretend to defecate all over his body, whereupon the dead man is revived.

\section{The house-building ceremony}

Now follows a busy period. 'Right' and 'left' erect their parts of the house and the roof. The roof slopes down from the row of piles (menamo). The women collect atap for thatching the roof and perform the Ore/Atap ceremony song (see Ema Kame). 'Right' and 'left' each have their own entrances and exits (at the back). At the front is a porch. At the central entrance is a fireplace where the guild of drummers and singers, and older men, are seated. A bark floor is laid by bride-receivers of leading persons. Once the house is ready, 'right' and 'left', which relate as superior leaders (mapere) to followers (ipere), bang on the walls. Actors hide under leaves on the floor and at night they frighten the adolescents who are going to be initiated (this is similar to Ema Kame). 


\section{Making and erecting spirit poles}

Now it is time for the ritual cutting down of trees for mbitoro, or spirit poles. First, however, men make dozens of miniature spirit poles, on which they carve tree kangaroos, lizards, and other small animals. These are used to scare the women. While the women are busy preparing food, men burst in from the Kaware house, brandishing the imitation poles. The women flee and, as a practical joke, the men snatch the food, take it to the Kaware house, and eat it.

Once the trees for the real mbitoro have been cut, male adolescents are initiated into the secrets connected with it. One secret (out of many) is a rope used for dragging the trees to the riverside. Woodcarvers hew and chisel the statues of the dead that are to be honoured. The poles are erected with secret tools. The biggest and most important mbitoro is placed in the centre, and two others on the right and the left. Male adolescents revive the dead represented in the central mbitoro by touching the vital body parts with bunches of smouldering straw. This appears to be only effective, however, when older men touch the vital parts with a stick and order the dead to return to life. The mbitoro, lifted by many hands, moves slowly: it comes to life (for more details see Coenen 1963:67). Needless to say, this is another enactment of the myth. The mbitoro now erected connects the lower world with the upper world. Adolescents are forced to look into the hole where the mbitoro will be erected and are instructed about its deeper meaning. Smaller mbitoro, measuring some 1 to 2 metres in height, represent deceased persons of a lower status than those depicted in the larger ones. All the while, there is much drumming and singing, which refers to the Kaware myths.

From the top of the roof, near the central mbitoro, hang the images of two hunting dogs, made of wood or bark and facing each other. They have been attached there by one or two dog dignitaries. One dog represents the 'right' party, the other the 'left' one. Besides, 'right' and 'left' lances (apoko), which are used in pig hunting, stand piercing through the roof. These represent the hunting equipment of the honoured dead. Very secret bullroarers (payu or mirapoway), representing the voices of the dead, new wooden sago bowls, equipment for pounding sago, and paddles are also suspended from the roof.

When everything is ready, the women draw near, admire the mbitoro (from a distance), enter the house, and watch the dogs and the dog dignitaries hiding in the loft. They snatch the sago bowls and the pounding equipment. The men are praised. Everybody is excited and there is a large-scale exchange of food. The men and especially the woodcarvers are rewarded with fried sago grubs and other food, whereas the men offer the women pork. Young sago leaves (tawri) are fastened to shrubs and trees near fishing spots and sago grounds as a means of communicating with the living environment and with the dead. 


\section{The sago grub ritual}

In order to cultivate sago grubs, a number of sago palms are cut down by the 'right' and the 'left' groups and holes made in them. It takes two to four weeks for the grubs to mature. Then a number of older male dignitaries secretly go upstream to cut down a tree, similar to the tree used for making canoes, to commemorate the culture hero Nokoro (see third myth above). They split the tree lengthwise into two halves, leaving the ends attached to each other. Other men and not yet initiated adolescents are then called in. As part of their initiation, the adolescents are invited to split the ends. They do not succeed, however, until the older men have given them wedges to do the job: this is another secret. The boards (the two halves of the split log) are then taken to the Kaware house, to the accompaniment of drumming and singing. Women are carefully kept out of sight. Woodcarvers then carve the features of several animals onto one side of the boards, as if they were the sides of a canoe. Among the creatures carved on them are pythons, lizards, crabs, sago grubs, pile-worms, frogs, and various kinds of birds, as well as men.

Then a mat is fastened between the two boards. This object is called the nokoro kao, the outer cover of the hero Nokoro. It represents his canoe, but equally serves as a container for sago grubs. In Yaraya (West Mimika), I was told that after the making of the nokoro kao (or 'canoe container') Nokoro himself appeared at the border of the village. Wearing a play mask (not a mamokoro) and adorned with cassowary feathers, he scared women and children. In the Wania region, in East Mimika, where the greater part of my information about canoe containers was collected, this appearance of Nokoro was not mentioned.

Collecting the sago grubs begins with a mock fight in the settlement between 'right' and 'left' men, who carry kopa-kopa mats that are used as roofs for shelters near the sago grounds. Men fall to the ground as if dead. A 'right' woman hits a 'left' woman with a pointed stick (komane) used to remove sago grubs from the pith of the log. Then the men depart for the woods. Two 'right' and two 'left' men ceremonially mark the initial stage of collecting the grubs. Pile-worms and mussels are also collected. A number of older men secretly eat a meal of sago grubs. 'Right' and 'left' work separately. The next day, the men return to the settlement at dusk to watch two men dancing the Nokoro dance. This is a tense moment. The dancers, leaders of the guild of drummers and singers, toss their heads, which are adorned with bird of paradise plumes. Their bodies are covered with cassowary quills; they imitate the cassowary cry. The men from 'right' and 'left' line up on both sides of the canoe container and in front of the central entrance of the Kaware house. Lifting the canoe container, they move forwards and backwards at the entrance. While doing so, the dancers stand and dance at either end of the 
container. Then older men take a close look at the nokoro kao boards and at the bottom of the container. A man impersonating Nokoro stands in the centre of the canoe. The left half of his body has been painted white and the right half red. He also wears bird of paradise plumes, the outfit of the leaders of the drummers' guild. The uninitiated adolescents follow the example of the older men. 'Right' and 'left' men then throw large quantities of sago grubs into the canoe container. Finally, the dancing Nokoro man in the middle is surrounded on his left and on his right by large heaps of sago grubs. He then recites Nokoro's farewell speech, scolding his daughters and explaining his departure. This recitation is addressed to the women: 'Take good care of us, do not neglect us.' This speech is all the more appropriate since the men, after the Nokoro ritual, depart for the inland to cut timber for canoes; because of possible attacks by enemies, it is a risky trip that involves hard labour under unpleasant conditions. Sago grubs may also be thrown into the river as a sign to the women of Nokoro's arrival, and the grub faeces drifting in the river are an indication of his good appetite.

After Nokoro's speech, the canoe container is moved into the Kaware house and placed under the dogs and the lances. Two lance dignitaries mount the canoe container, seize the lances, and poke them, for a second time, through the roof. This marks the end of the ceremony. Huge quantities of sago grubs, pile-worms, mussels, and sago are then fried and baked. Again, there is a massive exchange of food. Hosts and guests from other settlements are treated to a copious meal in the living quarters; laughter and fun mark the occasion. The men dance while displaying bows, and the women respond by displaying mock arrows made of sago-leaf ribs.

\section{The festival of canoes}

The Kaware ritual now reaches its practical purpose: the making of canoes. To this end, two or more men wearing mamokoro masks walk and dance past the houses. Holding a long stick in their right hand they poke into each house. Women and children come out, touch the stick, and then follow the masked men, weeping and singing. They are taken to specific couples who 'adopt' them, giving them food and kopa-kopa roofing mats. In this way, they coerce the husband or some male relative of the receiving party to commit himself to leaving for the inland to cut down a tree, which is to be made into a canoe for the adopting party. He demonstrates his willingness to make a canoe for the persons specified by donning an armband plaited of white fibres. Women wallow in the mud out of sheer joy. A man may commit himself to making a canoe for his wife's parents, or for his older brother, his father, or his mother's brother. When the day of departure arrives, the masked men carry mats to the 
canoes for temporary huts, as a symbolic gesture and to emphasize that one has to keep one's promise.

Those who undertake making a canoe are assisted by their bride-receivers. Upon their return, the men ostentatiously deliver the dugout canoe at the riverside close to the receivers. The section deliberately left undug in the middle of the canoe has to be chopped out with an axe. The giver's bride-receivers (for instance the sister's husband) consider it a matter of honour to do this in the presence of the receivers and other people. Everybody takes a close look at the new canoes. The boards of the dugout have been adorned with traditional carved figures and decorated with young sago leaves; the outside has been dried and blackened by fires kindled with coconut husks. Needless to say, givers and workers are richly rewarded with food.

\section{The grand finale of Kaware}

People then prepare for the grand conclusion of the ceremony. The ceremonial announcer addresses the spirit poles: 'You leave for the mountains; take your dogs and lances along with you, and go hunt pigs and cassowaries. Leave us alone; we are heading for the beach.' Men hit the spirit poles with their paddles, collect the mats in which they have hidden their masks and other ceremonial gear, and leave for the beach and their 'right' and 'left' territories. The next day they return to the settlement, their canoes spread across the river in a wide arc. Their old and new paddles are adorned with white feathers. Dozens of men have donned their mbi kao masks and have attached fish to their fibre costume. These fairly simple masks are helmet-shaped (for an illustration see Smidt 2003:102, Photo 56). Crying and dancing women and children line up along the shore. They believe, or pretend to believe, that their dead children, siblings and parents have come back. Women remove the fish from the performers' clothing and fry them for the men. There is an abundant exchange of food. The sago grubs, shellfish, and other foodstuffs carried in mats by the women are snatched away and distributed by the men. When the performance comes to its end, the women go inside the Kaware house so that the masked men, with the help of older women privy to male secrets, have the opportunity to hide their gear in their homes. One man from the 'right' and one from the 'left' climb coconut trees and collect nuts, which inspires several others to do the same. The coconuts are distributed among the other men. This marks the end of a taboo: throughout the Kaware ritual, men are not allowed to eat garden produce originating from the Kaware house in the lower world. To perform and participate in the Kaware ritual implies an identification with the primeval act of founding the ritual, hence the taboo. The men secretly smuggle dry sago leaves out of emptied sago containers into the 


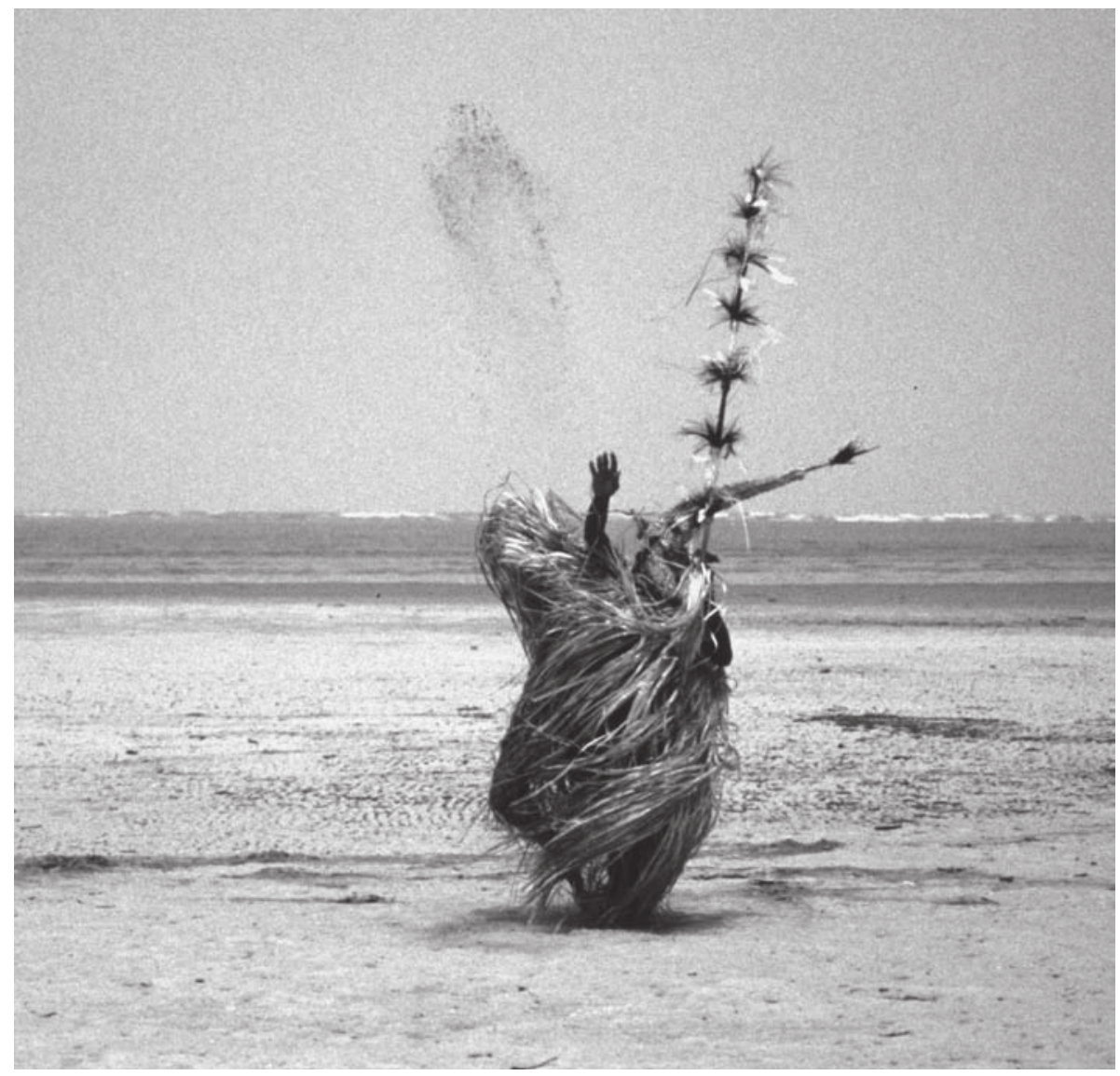

The dignitary Galus Mauria enacts the final stage of the Kaware ritual: while throwing lime-powder to mark the accasion he stabs an evil spirit with his ceremonial lance (apoko) in the sand of Paripia beach, West Mimika. From Pickell 2002: front cover. Photograph by Kal Muller.

Kaware house and set them alight. Making the frightened and crying women believe that the house is ablaze is just another example of male impression management. How convenient that water to extinguish the fire just happens to be at hand.

A glorious and spectacular canoe show marks the end of the ritual. 'Right' and 'left' women embark in the old canoes and wait for the men in creeks on the right and the left sides. Calling out 'row row', the men embark in the new, adorned canoes, white feathers decorating their paddles. Four canoes take the lead. The men in these canoes carry the 'right' and the 'left' lances taken earlier 
from the Kaware house by masked men from the 'right' and the 'left' groups. The official spokesman is in the centre. The women stay behind. The canoes advance to the beach over the full width of the river, in a formation like the arc of a rainbow. 'Right' and 'left' go ashore on their respective beaches. The lance dignitaries in their mamokoro mask outfits stab the lances into the sand. They enact the stabbing of the spirit who killed Mamirima. They then crush their lances and by so doing mark the end of Kaware. All the men return to the settlement. Masks and outfits are hidden in their houses. 



\section{Chapter iv \\ The initiation of male adolescents}

Among the Kamoro, little ceremonial attention is given to birth and marriage. Celebrating adolescence and adulthood, however, and parting from and commemorating the dead at various stages, are sharply marked, both socially and ritually. Boys reaching adolescence wear sago-leaf aprons (tawri) around their waists, and adolescent males have their nasal septum pierced when reaching adulthood. However, the arrival of the Catholic Mission and colonial rule in the 1920s led to a discontinuation of nose piercing. This was replaced by fitting tawri aprons, much to the disappointment of the older elite, but to the relief of quite a few young men. Evidently it led to some sort of ceremonial fusion or confusion of adolescence and adulthood. No doubt the nose-piercing ceremony was, and in its tawri guise still is, the ritual focal point arousing strong emotions among young and old, men and women. During my stay in Mimika in the mid-1950s, I witnessed or heard of at least ten Tawri Kame celebrations. During Tawri Kame festivities for adults in the district centre of Kaokonao, which I attended in 1954, I noticed that the chief of the village of Mimika proper propagated the idea that Uu Kame be celebrated upon reaching adulthood instead of Tawri Kame (henceforth also referred to as 'skirt-tying ceremony'). In the following, I concentrate on the nose-piercing ritual merged with the skirt-tying ceremony.

According to Zegwaard, the term karapao refers to the jointing beams and shoring wood set up to support the ridges of the roof. It is also used as the generic name for a ceremonial house, of a type similar to the Kaware house, used for celebrating adolescence and adulthood. In accordance with its specific functions, it is also referred to as tawri kame (literally 'apron house') or mirimu kame (literally 'nose house'). The former name refers to the aprons made of sago-leaf fibres tied round the waists of boys upon reaching adolescence, and the latter to piercing the nasal septum of adolescent males upon reaching adulthood. There is a third function, which may, however, be connected with a separate temporary construction, uu kame, the ceremonial centre for adult men whose nasal septum has been pierced and who are then subjected to various tests of manhood. Nose piercing as a ritual was in fact unique to the Kamoro. 


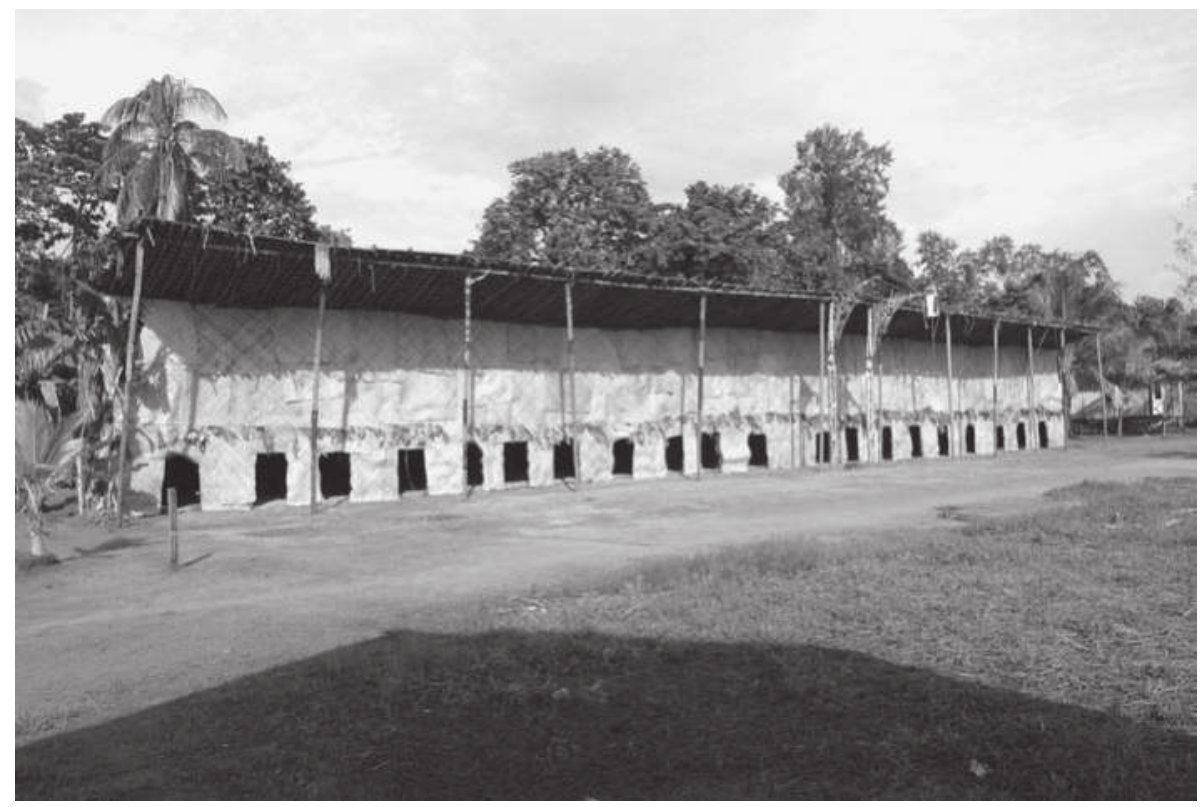

Karapao ceremonial house at Keawkwa, Mimika, June 2007. Each entrance corresponds to one or more initiates. Photograph by Kal Muller.

The Asmat practised it, but not as a public ceremony; it was done privately and during childhood.

The Kamoro themselves trace the nose-piercing ceremony back to the Utukae groups who then lived in the Koperapoka area to the east. While celebrating Mirimu Kame, these were attacked by the Naeweripi from the far eastern part of Mimika, who also practised nose piercing. The Utukae fled westwards. The groups living there borrowed or stole their nose-piercing tools and adopted the ceremony. Unlike Ema Kame and Kaware, the origin of the nose-piercing ritual is not ascribed to culture heroes, although it is associated with two mythical warlords, Aoweyao and Mbiminareyao, who led the attack on the Utukae. Their acts, their ultimate defeat, and the dispersal of the Utukae are narrated and sung about during Mirimu Kame.

Obviously, celebrating the nose-piercing ritual and the skirt-tying ceremony requires considerable preparation. Work, social obligations, prestige, play and ritual are intertwined. Work is motivated by this whole complex, and in this respect differs greatly from work in a modern, Western setting. In the following, a detailed account is therefore given of the ceremonies and the preparation for them.

The house in which the ceremony is performed has a wide front covered 


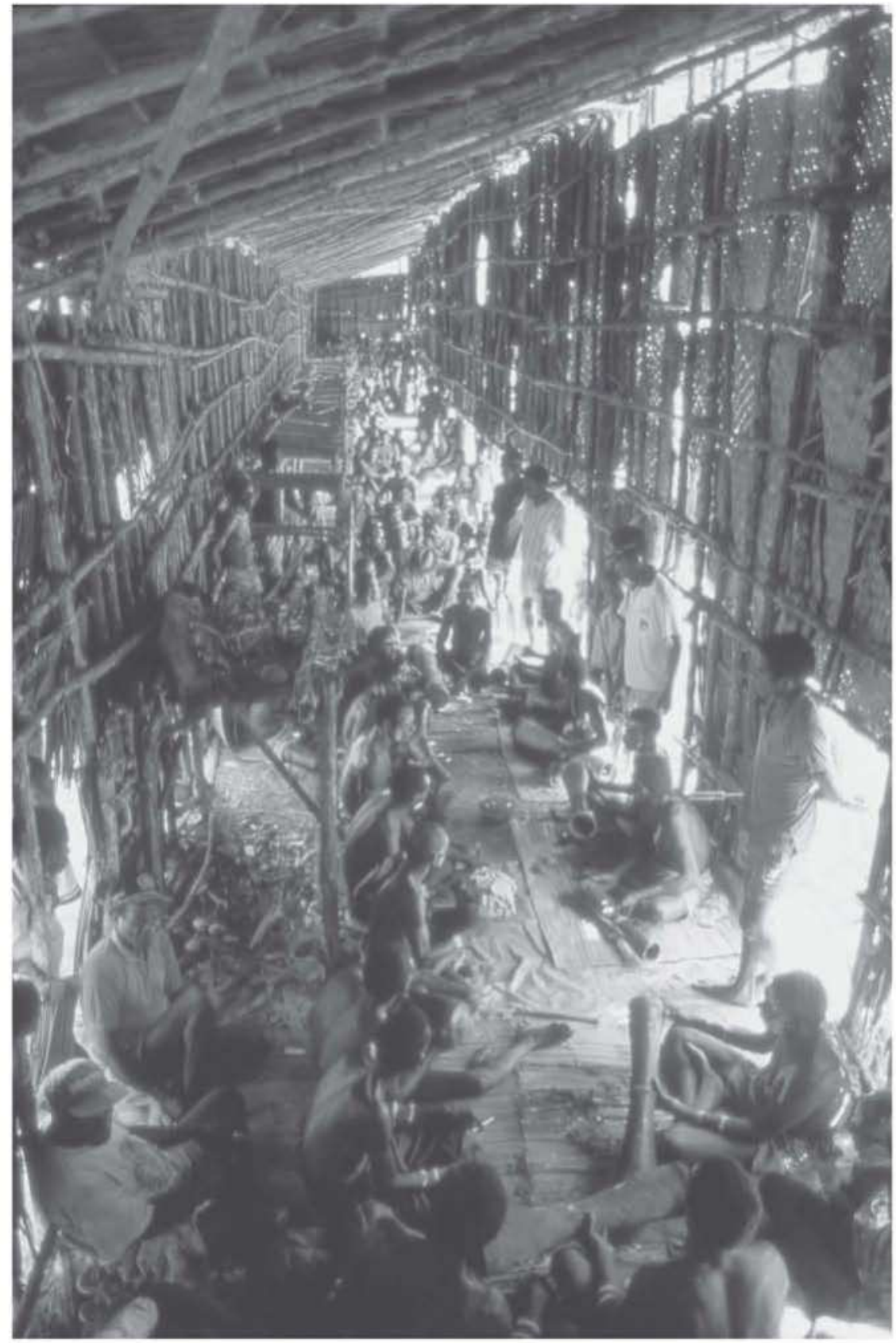

Exterior of Karapao ceremonial house during initiation, Timika Pantai, Mimika, 1997. From Pickell 2002:52. Photograph by Kal Muller. 


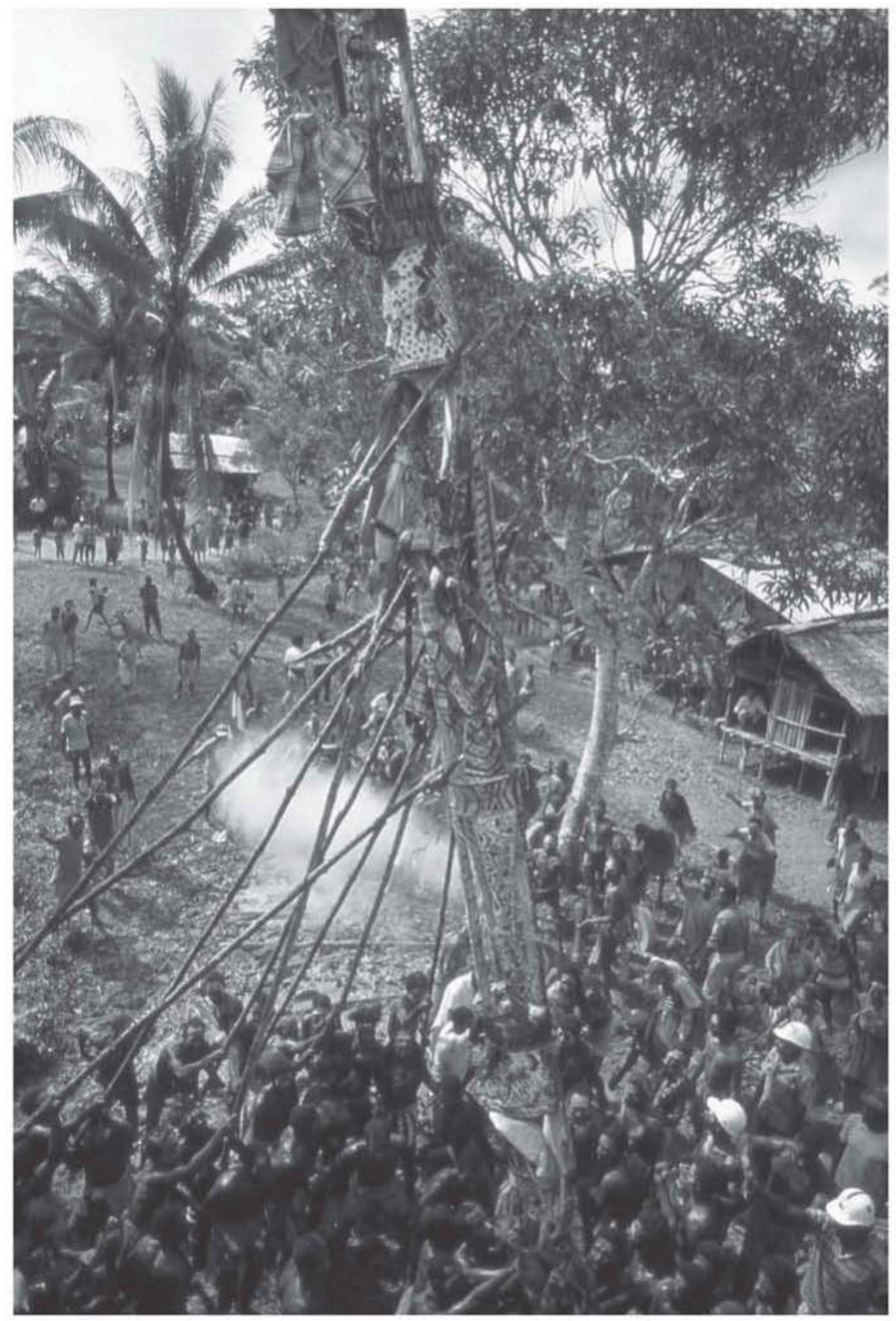

Raising the spirit pole; note the secret wooden forks. Hiripao, Mimika, 1997. From Pickell 2002:90. Photograph by Kal Muller. 
with mats, like the Kaware house. Its projecting roof is supported by eight or nine poles and slopes down at the back. It has four to eight openings, depending on the number of initiates. Each initiate has his own entrance. The house is some 17 metres wide, 6 metres high, and 5 metres deep. There is a porch (mbiti) between the front wall and the end of the overarching roof. This porch is protected from outside view by a row of mats hung parallel to the front wall behind it, and by sago leaves at the sides. The initiation takes place on this porch.

\section{Making and erecting spirit poles; collecting the food}

One of the first tasks is the making and erecting of one or more spirit poles, which represent fairly recently deceased community members of repute, male or female. (For details on the cutting down, transportation and erection of the spirit poles, see the description of Kaware in Chapter III.) The selection of persons to be honoured is a delicate matter, requiring much deliberation and display of power. The initiates attend all activities and are thus introduced to the various ritual roles (including their own) and the meanings of these. As usual, actors and dignitaries operate according to the division between 'right' and 'left', corresponding to 'root' (mapere) and 'surface' (ipere) knowledge, and to leader and follower. The dignitary entitled to cut down the tree - the actual work is, in fact, done by his sisters' husbands, his bride-receivers - delivers a speech boasting of his status and heroic deeds to impress the living and the dead. He then delivers the first blow with his axe, while calling out the name of his mother or ancestress. The hole into which the spirit pole will be inserted is covered with mats and lime: it is a sacred site. The spirits of the persons represented by the statue are believed to attend the ceremony from the underworld. Male adolescents carrying the spirit pole in a horizontal position, directed by an older dignitary, 'vitalize' the statue: it, or rather he/she, moves. It is asked whether an enemy is intending to attack the community during the celebration - in earlier times there was a real risk of this happening. The question is answered by the statue moving to indicate no. The living spirit pole is then carried around the settlement by the men. Women and children stay inside behind closed doors. The dead and the carvers are addressed and highly praised. Emotions run high; the statue is embraced and adolescents dance on it. After the spirit pole is erected, one or more dignitaries, followed and protected by their bride-receivers, climb the statue. They embrace the statue and set their teeth into the wood as a sign of admiration for the carvings. One of them, the imakatiri, calls out the names of groups living in the vicinity. He announces the celebration and invites them to attend. 


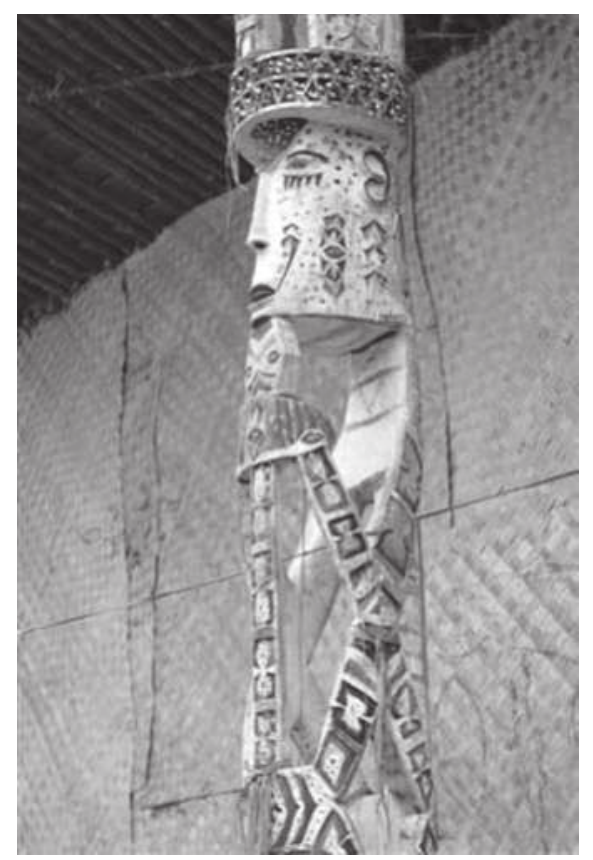

Upper part of the spirit pole in front of the Karapao ceremonial house at Hiripao, Central Mimika, February 2007. Photograph by Kal Muller.

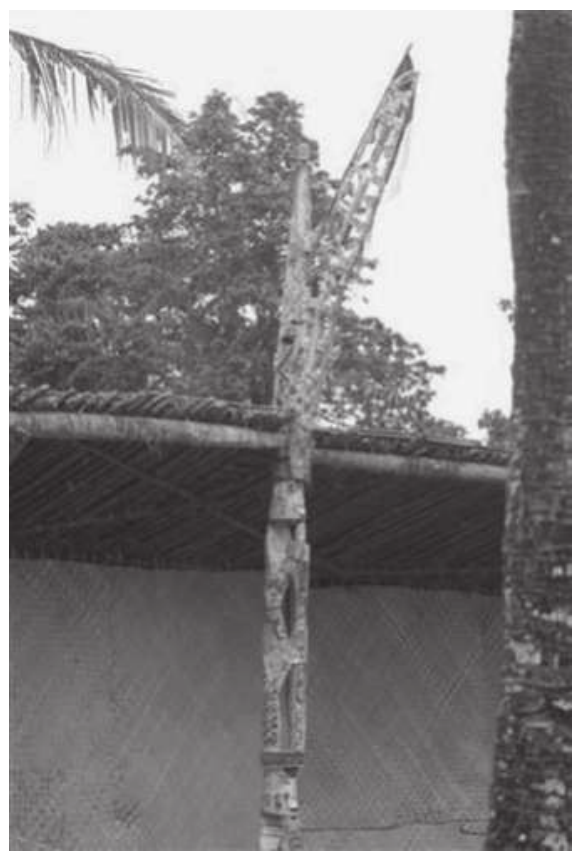

Upper part and 'wing' of spirit pole in front of the ceremonial house at Hiripao, Central Mimika, February 2007. Photograph by Kal Muller.

Meanwhile, the timber required for building the Karapao house is collected and prepared. The Tama song and the Ore song are performed by women and men respectively, the women delivering strips of pandanus bark for sewing the atap, while sago for roofing the house is the men's responsibility. There is also a mock war between the sexes. Assembling the wood and collecting large quantities of food are accompanied by ceremonies that are to ensure an optimal result. An abundance of food can be called for by acts and performances based on the major principle of cosmological classification, ipu enakoa (explained by Coenen 1963:43-8). All phenomena of nature, including humankind, are believed to be interconnected and to share one soul. This is why there are performances by specific dignitaries, and this is why particular plants, shrubs, leaves and trees, which are believed to be connected with sago, fish, pig, lizard, shellfish, and so on, are used or referred to in these performances and in other rituals. Both rituals (Tama Tao and Ore Tao) call for these items of food to present themselves in abundance. Therefore, the men and 
women manipulate the cosmological system by playing (almost literally) this interconnection to their advantage.

\section{Sago magic}

For collecting sago, magic is required. Magic is an empty term unless explained and specified, as I now proceed to do. Sago magic consists of three elements, the first being 'there is sago' (amaa poka). Before people leave for the sago grounds, two male sago dignitaries, who wield power over sago, ritually announce that 'we people, as we are used to do in this particular situation, are leaving for such-and-such sago areas where sago is abundant'. This is an official statement that implicitly serves as an exhortation to the sago spirits (amaa mbi). On the eve of departure for the sago areas, the leader of the sago people summons two female sago dignitaries, adorned with sago paraphernalia. All the men assemble, but all the women stay indoors. The leader of the sago people then summons the sun: 'Sun, shine upon the mature sago palms and fill them; let all areas be full of palms,' specifying the sago areas. Then the female sago spirits and the men go in a procession past the houses and boys shoot arrows made from ribs of sago leaves.

The second element of the magic is 'sago rattan' (amaa keme), involving three 'sago people' dressed up as three varieties of parrot often seen in sago areas. They perform dances near and on the rectangular collective sago container in front of the ceremonial house. Their leader announces that the birds and the sago palms of the area will grow and be abundant. Recall that birds and sago palms are viewed as having a soul (ipu) in common.

The third element is 'sago medicine' (amaa oto). Two or more fully dressedup sago dignitaries hide behind shrubs in the vicinity of the village. The initiates proceed to these shrubs, followed by older men singing and playing drums, remove the shrubs, and then confront the sago men. Then follows an act in which they uproot leaved twigs, which were 'planted' there for this purpose. The leaves, which are associated with sago and are 'of one soul' with it, are removed by the spectators and brought to the ceremonial house. This is done in two processions, a 'right' one and a 'left' one, both preceded by a man displaying a ceremonial staff (pokay). Two female sago dignitaries carrying a bag of sago on their backs join them. On the porch of the ceremonial house, the male sago dignitaries take a handful of sago from the bags and mix it secretly with the shredded leaves. Proclaiming that the bride-receivers have dutifully produced a large quantity of sago, they then throw it into a large rectangular container. All the men present follow their example. Mixing the sago with the leaves is believed to ensure that all cylindrical containers taken to the large rectangular box will be filled to the brim. 


\section{Pig ritual and hunt}

Although hazardous and unpredictable, hunting pigs is by far the most exciting part of all major ceremonies. It is therefore surrounded by taboos, such as abstaining from sexual intercourse and from the consumption of various kinds of fish, and it involves various hunting rituals aimed at attracting animals to the location of the bait (kawata). Pieces of adjacent sago palms are cut down and divided up for this purpose. In the four villages of Kaokonao (about 500 inhabitants) where I attended the skirt-tying ritual in 1954, ten wild pigs were killed. A number of working parties prepared the location of the bait and constructed a fence nearby in order to spear the animals at night while they were eating. The hunters were covered with lime and had their faces blackened in order not to be seen by the animals.

The preparatory hunting rituals include 'pig tails' (o mipi) and 'pig spirits' (o mbi). In the pig ritual, a number of pig dignitaries, 'pig people' (o we), paddle to an area to collect pig medicine (o oto). This consists of the leaves of a particular shrub, rattan, orchids and palms. When they return to the village they behave like victorious hunters, throwing lime as a token of their success. When the villagers question them about the success of the hunt, they respond positively. The women then line up in front of the Karapao house, their backs decorated with the leaves collected by the men, dancing and singing in a frenzy. A successful hunt is imitated and thus invoked. The leaves of the hunters and women evoke the image of pigtails: they are of one spirit.

In the pig ritual, the pig men assemble near the entrance of the ceremonial house around sunset (on the same day as the preparatory rituals), dressed up as pigs and wearing pig leaves. The leader of the sun dignitaries addresses the setting sun, a very emotional moment. He summons the sun, or rather 'he who sits on the sun', to be his witness in summoning the pigs: 'Pigs, do you hear me? Draw close from afar and come to our place [specifying the name].' Behaving like pigs and making pig sounds, the pig men stroll past the houses and hit the buildings with smouldering sticks. The leader carries a wooden image of a pig. When they have all returned to the ceremonial house, the leader of the sun people then names the location of the bait, and exclaims that 'the dogs will attack the pigs ferociously and the hunters will spear them'. Two images of a pig, cut from the spine of a palm leaf, are then placed in the ceremonial house, and prepared sago is offered to them.

According to information from Kaokonao, corroborated by Zegwaard and Coenen, pig women, dressed up with pig leaves, come crawling to the ceremonial house, begging for sago and firewood. They take this home, where they roast the sago and give it to the children, who, just as their mothers did, start crawling and behaving like pigs.

Informants also told me that the calls of various types of parrot and of the 


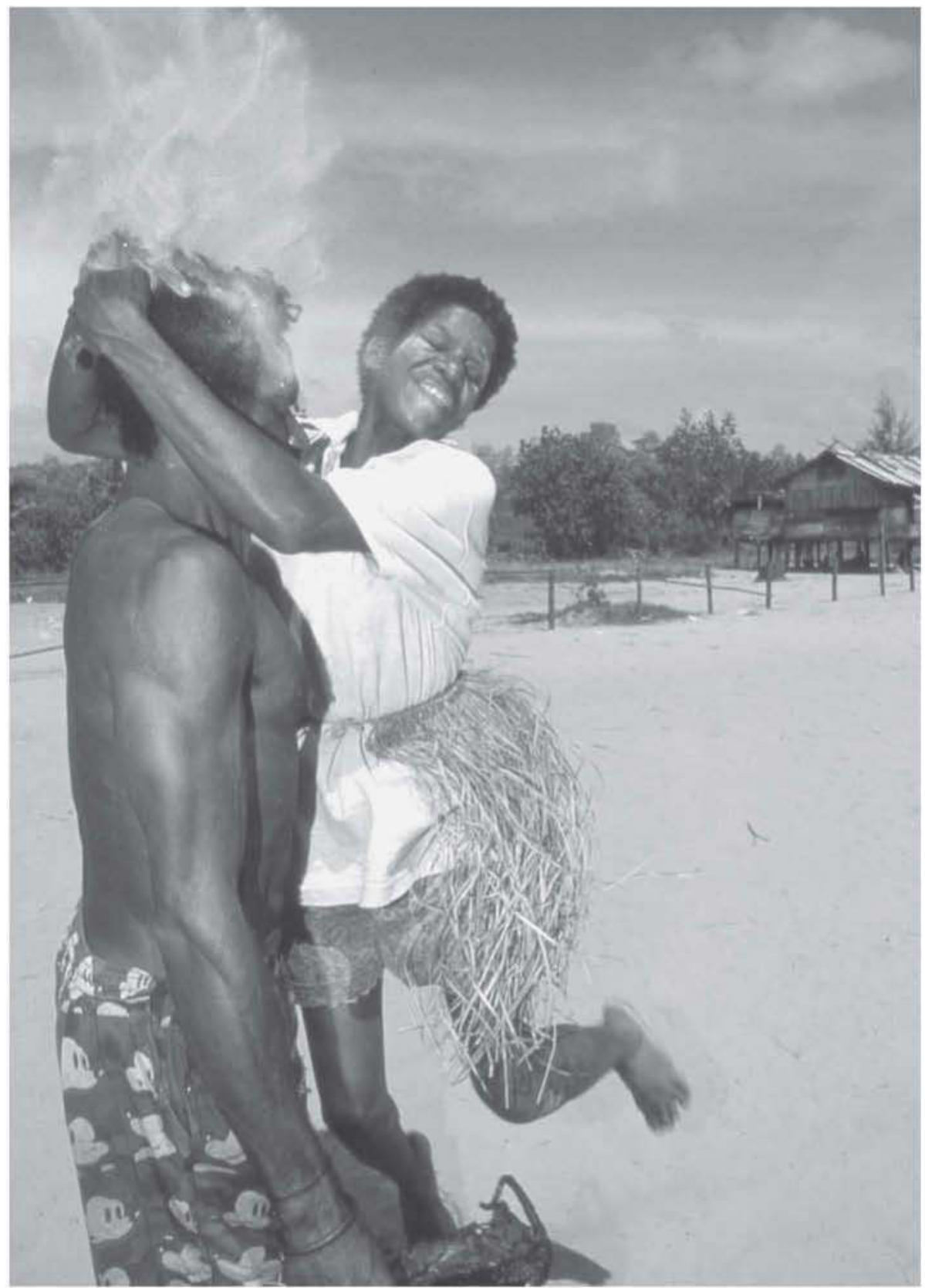

Embrace. Having speared a pig the night before on the occasion of Karapao, Petrus Taniyu was honoured as a hero by all the women. Timika Pantai, Mimika, 1997. From Pickell 2002:185. Photograph by Kal Muller. 
forest hen were imitated as a request not to alarm the pigs when the hunters approached. Zegwaard witnessed a ritual in Mioko (Kamora River) in which the arrival of pigs at the location of the bait was mimicked. Two rows of men lined up on the riverside and watched the 'pigs' coming from the bush and approaching the imaginary kawata. When the men 'speared' the 'pigs' with their spears, drumming rose to a crescendo. Then the 'pigs' fell down. The scene was repeated: this time the 'pigs' played dead. The pig leaves were then laid near the spirit pole at the entrance of the house as an invitation to human spirits to assist the living in killing many pigs. In the village of Yaraya, I was told that a gong, a precious object, was offered to the 'soul' of an ironwood tree, again associated with pigs and the power of pigs. The gong was removed if the hunt was successful.

About this time, the hunters waiting at night behind the temporary fence move cautiously, observing absolute silence. With a magical stick they entice pigs to the location of the bait and spear them. Early in the morning they light a fire and, using smoke signals, inform villagers of the presence of the pigs and their location. When the hunters arrive in the village with the game on their shoulders, the onlookers, especially the women, behave like frenzied lunatics. They praise the hunters liberally and embrace them. The more they praise them, the better the chance of receiving their share of the meat. Special pig men hang the butchered pigs from the walls inside the Karapao house. Secret rattles, operated by men in the Karapao house, add mystery to the excitement.

\section{Tree lizard ritual}

The tree lizard ritual aims at obtaining 'tree lizard medicine' (oko oto). To this end, two lizard dignitaries, one from the 'right' and one from the 'left', go out to collect a certain kind of leaves, leaving them attached to the twig. Back in the village, they rip the leaves from the twigs and store them in a mat. At dusk two rows of men, 'right' and 'left', stride through the village, accompanied by drumming. The two lizard dignitaries announce formally that there will be many lizards. All the men then scatter the shredded leaves on the ground, thus making a track that will assist the lizard hunters to locate the trees where the lizards (iguanas) can be found. The animals are caught alive, tied up, and taken to the village. Two of the lizards are ceremonially killed in the Karapao house, thus setting the stage for killing the others at home. 'Things have to be done in an orderly way,' as my informants in Kaokonao explained. Two lizards, one from the 'right' and one from the 'left', their skin stripped off in the middle, are displayed on a rack, together with a headdress for singers, two dancing skirts made of cassowary quills, a bundle of cassowary feathers to be 
used as leg decoration, and a zigzag-shaped wooden object for encouraging the sun to rise. This rack is placed in front of the central spirit pole. 'Right' and 'left' each have their own display rack. The articles displayed may vary, as I observed in three Kaokonao villages.

\section{Shellfish for the initiation ceremony}

Fish is another important item in the diet, as well as for gift giving on the occasion of an initiation ceremony. Special emphasis is laid on the preparation of a dish consisting of a special kind of mussel (onaki, also a generic name) and sago. The preparation of the dish is begun formally in the ceremonial house. Two onaki men (not women), from 'right' and 'left', beat two mussels against each other. The shellfish fall on a mat and are mixed with sago. The onaki men name the women involved in collecting the mussels. Only then will the women start working. They wrap the mixture in leaves, which they tie up into small parcels about 20 centimetres long - some of them wider or larger, for some special purpose - and then roast these. The mothers, sisters, and female cousins of each of the initiates prepare large quantities separately. The roasted parcels arouse vivid emotions, since they connote the mothers' and sisters' close ties with the initiates. The former once nursed the initiate, and now the nose-piercing ceremony (or its substitute) marks the coming of age, the parting from the family of procreation, and the expectation that the initiate will soon establish his own family. In the afternoon, each of the initiates will be standing on a mat in front of his parents' house, being dressed and made up by his close relatives. The boys will be wearing colourful new cloth as sashes worn across the chest, and a new loincloth, while red paint and white dots are applied to his body. The relatives also dress up.

All initiates will then, still in the afternoon, walk past the houses of the village, each followed by their mothers, sisters, fathers and other relatives and preceded by an older brother or a brother-in-law who carries a spear or a machete. The guild of singers and drummers also take part in this procession. They halt at the living quarters of the initiate's real or classificatory sisters, as well as at the homes of his mother's brothers. His mother or his sister will then take one or more mussel-and-sago parcels from a bag she is carrying and hand these to the initiate. He in turn presents these to his sister or the wife of his mother's brother, as a token of appreciation for the services of their husbands; this act is reciprocated by the initiate receiving young shoots of the sago palm in return. The roasted parcels are eaten immediately. This ceremony clearly marks all the persons involved individually: honour to whom honour is due. Thereupon the initiates and their retinue stride around the sago containers, the location of the initiation. They offer the larger roasted parcels to the two 
sago dignitaries, who are standing on the container. Their gift is reciprocated with a crockery plate. The real initiation will take place the next day.

\section{Sago supply for the initiation ceremony}

Compared to the elaborate social and ritual preparations described above, the initiation itself is a fairly straightforward affair. Even so, one major preparatory event that is given much emphasis deserves mentioning: the construction and filling of the two or more collective sago containers already briefly referred to. These are constructed on the porch of the Karapao house, preferably one for each initiate. The initiation will take place on top of these sturdy rectangular containers $(w u)$. The containers are constructed a few days before the initiation. The construction of the containers is initiated ceremonially by pushing two thick long rattan canes through the front wall of the Karapao house. The resulting scratching noise is supposed to frighten the women. The canes protrude slightly. They will be used at a later stage for lashing down the top cover of the container. Under the canes, sago branches are laid down and fastened with wooden pins. These form the bottom of the container, together with plaited strips of sago leaves, measuring some 50 by 125-150 centimetres. A latticework of sticks is erected around the bottom, which is covered with plaited strips of sago leaves. The height of the container depends on the amount of sago that the initiates' bride-receivers deliver. They are the ones who construct the containers. Then sago crumbs are thrown into the collective containers in the Amaa Oto or sago magic ritual. This ceremony formally launches the delivery of the cylindrical individual containers of sago that will be placed in the collective containers, a delivery that is to proceed rapidly. Each of these individual containers is marked by the giver and carried to the collective containers by the bride-receivers - not by the women, who usually carry them on their backs. There is a 'right' and a 'left' collective container, the distinction depending on the givers, not on the receivers, for instance the parents or brothers of the woman whose son or brother is going to be initiated.

While the individual containers are being delivered, the names of the givers are enumerated loudly by the guild of singers and drummers. Onlookers watch closely who is giving and how much, the prestige of both givers and receivers being at stake. Givers are praised; there is much commotion. When all the individual containers that had been stored at individual homes are piled up in the collective containers, or stacks, as I shall call them henceforth, they are covered with mats. The rattan canes in the front wall of the Karapao house are pulled out and used to lash the stack together firmly, thus creating platforms. The fence is removed to reveal the platforms so that they can be inspected and admired. A rattan construction depicting the bow of a canoe is 
attached to the front of the stacks, the sides of the platform being decorated with 'fingers' (maare, a generic term for protrusions) and with rattan models of birds' nests.

The stacks, the way of lashing them together, and their decoration with the bow of a canoe are reminiscent of the Asmat stacks of sago grubs.

\section{The sun dance}

The initiation is preceded by the sun dance (Yao Ndi), a night of dancing that starts around sunset and reaches its climax when the sun begins to rise. In the afternoon singers, drummers and dancers gather in the ceremonial house, where they dress up, paint their bodies, put plaited bands and belts (makara) round their arms, legs and chests and cassowary quills round their hips. A big fire is made in front of the house and the guild of drummers performs the sunset song, lowering the drums from time to time, in accordance with the movement of the sun. The 'left' leading singer or drummer answers the song of the 'right' one - one of multiple manifestations of reciprocity - in a compelling rhythm. While women and children watch eagerly, a leading dancer moves out in a staccato of mighty gestures and passes, as if in trance, aiming his bow and arrow in all directions. The others, all of them dancers specially trained for this particular occasion, follow one by one. Women sing, praise and dance. One dancer after the other jumps over the fire. The fathers precede their younger brothers, sons, and sisters' sons. The dancers face each other in two rows and dance, turning, raising and lowering their bodies. After the show the onlookers join them. This goes on and on.

At dawn, tension increases. The singers recite the names of settlements, beginning in the far eastern part of Mimika and proceeding to Kaokonao (where I witnessed the celebration), following and describing the course of the rising sun. The two leading drummer-singers answer each other, raising their drums to their faces. It is a magnificent show. No mistakes should be made, in order to avoid the risk that the sun will not rise. A sun dignitary shoots burning arrows in the direction of the rising sun to emphasize and encourage the sunrise. (In Kaokonao, at this very moment on 31 December 1954, the shooting was stopped by a priest who broke the arrows in order to prevent a presumed case of rain magic. It did rain most of the night, and the sun did not rise - the sunrise was invisible; according to my informants this was because of the priest's intervention.) The sun dance and ritual stop at about 7 a.m.; the exhausted participants then get some sleep.

In the morning a group of dancing women place sago balls on a mat in front of the ceremonial house, where the fence was partially removed the day before. One of them gives a bowl containing a small ball of sago and a pair of 
tongs to two male dignitaries. These (and not the women) roast the ball and then break the tongs, signifying that the pork should be taken from the walls, placed next to the sago balls, and distributed.

\section{The final ceremony: nose piercing}

For the final ceremony, the 'right' and 'left' initiates, fully dressed up, sit on their heels to the right and left of and facing the entrance. Each is accompanied by two of his bride-receivers squatting to his right and left. The two 'right' and 'left' ceremonial leaders of this ritual sit in the centre, the singers and drummers behind them. This is a solemn moment. Male and female relatives and others stand or sit at the back of the ceremonial house. Each of the two leaders recites an introductory song. The male and female relatives (not the affines) sing and weep. The two leaders touch the initiates' noses (a clear allusion to the nose-piercing ceremony that is yet to come) and weep loudly.

Then the drumming and singing stop. Parts of the right wall and of the left wall are successively removed. The right and left initiates pretend to flee through the opening, but are followed by a yelling, weeping and shouting crowd. The initiates are seized and taken to the stacks, carried on the shoulders of the bride-receivers. Each of the initiates mounts his own platform. Then the two bride-receivers remove the sashes across the initiate's chest, put the initiate down on the platform, hold his head between their knees, and pierce his nose septum in five stages, using sharp pins of palm wood (amupao) of everincreasing thickness and size. (According to a myth, the shavings of the pins, when cut, turn into clouds of stinging mosquitoes.) The bride-receivers call out the names of their mother or ancestress. The successive pins increase in length from about 25 centimetres to one or two metres. Their length depends on the number of bride-receivers, varying from five to ten, who clench the pin with both hands as a ceremonial obligation (as observed by Father Tillemans in the 1930s). The blood drips from the platform and is licked up by frenzied mothers. The bleeding is stopped by putting fresh sago leaves in the septum. Causing grief and pain to the victims, though unavoidable, is deplored by the bride-receivers, who as a rule are expected to handle their bride-givers with care. My key assistant told me that formerly, when nose piercing was still performed, the bride-receivers would surreptitiously rub the septum with lime beforehand, so that it would be thin on the day of piercing, in order to ease the pain. Moreover, before applying the pins they secretly pierced the septum with their sharp fingernails. During the operation there is loud weeping and crying. Mothers and others cling to the victims' feet and weep. When the piercing has been completed, the crying initiates are carried to their homes on the shoulders of the bride-receivers and nursed with compassion. After the nose- 
piercing (alternatively: skirt-tying) ceremony, the socially recognized new adults are to some extent entitled to have sexual intercourse, which enables them to learn the art of lovemaking.

Immediately after the ceremony, a mock fight begins, which may go on for hours. The women chase the men, in particular those who have performed the piercing, and hit them with smouldering sticks, lumps of mud, and so on. The men try to escape, and are not supposed to retaliate. An older man formally announces the end of this sometimes very aggressive mock fighting, and the sticks are thrown into a heap to signify the end. Two dignitaries ceremonially cut the rattan canes tied around the sago stacks. The givers of the individual cylindrical containers then carry the sago back to their homes and distribute it.

The alternative skirt-tying ceremony that I observed, in which long skirts made of young sago leaves are tied round the hips, is by and large similar to the nose-piercing ceremony. In former times, it is said that about one year passed between the initiation of boys and the initiation of adolescents. After the skirts are tied up, the bride-receivers cut off the edges. Then they knock two mussels over the head of the initiate; the fluid drips over his shoulders and body and is licked up by the bride-receivers. The cut-off sago shreds are set ablaze. The initiates extinguish the fire while jumping over it, assisted by their mothers. This is probably a cleansing ceremony (see next section).

The bride-receivers then line up to poke the initiates in the ribs quite forcefully. This calls for revenge by the relatives and sets the mock battle in motion.

It is obvious that sago and mussels and the combination of the two play a dominant role in the preparation and performance of initiation. However, this does not mean that there is a mechanical link between growth and fertility. When I asked a well-versed informant whether the initiates, while standing on the sago stack, acquire strength and growth from the sago, he smiled and denied it. As evidence for his opinion, he mentioned the well-known narrative of Aoweyao and Mbiminareyao, the strong giants and warlords who ousted the Utukae and by this act set the great western migration in motion. ${ }^{1}$ When these 'brothers' wanted to have their nose septum pierced, hardly anybody in the settlement was willing to assist them. So they pierced each other's noses or were assisted by their 'father' - a shameful act and very much against the rules - while standing on a mini-stack, since hardly any sago was delivered for the occasion. 'Yet,' my informant said, 'these two adolescents quickly grew into giants. So it was not the sago that did it. It is not the sago but the men who matter and are important.' This was a clever and thoughtful answer. It is not 
the sago or the mussels that matter - it is the classificatory system of relations between flora, fauna, objects, natural phenomena, and humans which does it, as used and manipulated by persons who are entitled to do so.

\section{The initiation of male adolescents into adulthood}

The Uu Kame (literally 'hair-extension house') ceremony is closely related to the Karapao rituals. It could even be considered as the final stage of Karapao. It is, however, discussed separately here, since it requires a house of its own. Zegwaard attended its celebration in Atuka, east of Kaokonao, in November 1951 (Zegwaard 1995:311-5). I saw it celebrated in Mimika proper, in one of the villages in the administrative centre of Kaokonao, on 5 May 1954. It is useful to compare the two descriptions, because they are similar in many respects and yet different. As mentioned earlier, the headman of Mimika would prefer this ceremony to replace the present skirt-tying ceremony, since the latter combines the celebration of adolescence and adulthood.

Formerly, Uu Kame was celebrated when the adolescents whose noses had been pierced had recovered from its ill effects. In the first stage the participants part from their childhood. In the second stage, their abilities and skills for adulthood are taught and tested. In the third stage they are provided with the insignia of adulthood: hair extension, anus shield, and penis cover.

A separate house, roughly similar to the longhouses beside a river in a sago area, is built and the initiates stay there for some time. In Atuka, the shed built for the occasion was two metres high at the front and closed off on three sides with sago leaves. In the front wall only a metre was left open in its upper part.

\section{The first stage: parting from childhood}

The participants are fed on the soft seeds of the pandanus palm, small mussels, and crabs, as if they are children. Their brothers-in-law feed them fish, first taking a bite themselves and then pushing the remainder into the mouths of the 'children'. Male relatives encourage them to go inside the hut, whereas female relatives dance outside. The 'children', painted with lime, ashes and ochre, are then exposed to thick smoke and heat rapidly building up from fires of easily combustible material over the full length of the back of the shed. Fathers and brothers join them, men standing shoulder to shoulder. The adolescents begin to sweat heavily. Their mothers and sisters outside come as near as possible and empty bamboo containers filled with water over the shoulders of their sons and brothers. This action is repeated many times. The brothers-in-law lick up the water running from the adolescents' shoulders. 
This exposure to smoke and water is meant to cleanse and purify the body and soul of evil 'smells'. It is practised both in Mimika and Asmat, for people exposed to the world of foreigners on board ships or while working as contract labourers in port towns. In this particular case there were twelve young men who had recently returned from doing contract labour in Sorong. The 'shower' ritual just described is meant to remove the ill effects of a specific period that has ended, namely boyhood and adolescence.

\section{The second stage: demonstrating skills}

There are several skills to be taught and demonstrated, including:

1. The use of bow and arrows. For this purpose, the guild of archers pushes a plank from an old canoe into the ground as a target. The oldest man then shoots the first arrow, followed by his 'brothers', his 'sisters' sons' and then his own 'sons'. The adolescents follow suit, aided by the experienced ones.

2. Spear throwing: this follows the same procedure as the shooting of the first arrow.

3. Asking for sago: the leader of the already initiated age mates beats a drum and forcefully asks his mother for sago while calling her names, both literally and figuratively. He adds: 'You with the red genitals.' The initiates follow suit. By doing so they show their superiority over the women: 'We are the boss at home' (or so it seems).

4. Fish spearing: the ceremonial 'fish man', the initiates, and their supervising brothers-in-law all board canoes and depart for the sea while throwing lime in the direction of the sea. En route the initiates follow the example of their supervisors by scooping up handfuls of fresh water from the river. At sea the brothers-in-law throw coconut shells into the water. These represent fish, which they spear. The adolescents follow suit, assisted by their supervisors.

\section{The third stage: providing the insignia of manhood}

This stage, it should be added, was not performed in my presence.

The adolescents are painted all over with lime, ochre and ashes. They are provided with decorative bands for their upper arms and calves, and with sashes across their chests. Thin strips of yellow fibres of sago leaf, plaited into cords 15-20 centimetres in length, are attached to their hair. These are draped over the back of the head and the neck. It is interesting to note that the Kamoro language has the same word for attaching hair extensions and for piercing the nasal septum: $u u$, which literally means 'to take care of the head'. Three kinds of ornaments may be inserted into the nasal septum: two pieces of a hornbill's 
beak held together and glued with string and resin, two equal segments of a sea shell, or two pig's tusks. Last but not least, the initiates are provided with an anus shield made of seashell, and a penis shell or a richly ornamented bamboo penis sheath. ${ }^{2}$

In the village of Mimika, I observed some additional demonstrations. Squatting adolescents are lined up in two rows, facing each other, and, while dancing, make gestures like scooping water from a creek until a kind of mud fish can be seen and grabbed, upon which they also make the grabbing movements. Catching this type of fish is exhausting and rates as an endurance test.

Another performance involves hopping around in circles in a squatting position on the floor while imitating the cry of a hornbill, signified in Kamoro narratives as a lovebird and associated with marriage and intercourse. The bride-receivers keep the initiates hopping and squatting by pushing them down repeatedly. This demonstration takes place in the shed or in a makeshift longhouse. The adolescents sweat all over their bodies. Women, mothers and sisters offer relief by showering them with water from bamboo tubes. Then, suddenly, two legs of a male person appear, piercing the roof and frightening both the initiates and the women.

In Kaokonao and in West Mimika an interesting variant of hair extension is practised. It was part of the ritual in the village of Mimika, where the cords fastened to the hair do not hang over the neck and shoulder, but are tied up instead, forming a sort of crown on the head. It is sometimes depicted in models of spirit poles made for tourists. There are even two or three variations on this type of hair extension. This could well be an interesting ceremonial innovation on the traditional type of hair extension, well known from the Asmat, but not practised in Mimika for at least seventy years.

2 For more details, illustrating possible meanings, see Kooijman 1984:133-45, and Zegwaard 1995:315-22. 


\section{Chapter v \\ Marking death}

\section{Critical illness, passing away and mourning}

Passing from life to death is by no means a private affair; it is in part a public happening. Two sharply differentiated categories of people are involved: (close) relatives on the one hand, and affines, especially bride-receivers, on the other. Relatives have ample opportunity to express their grief in the form of lamentation and mourning and are, indeed, expected to do so, in varying degrees of intensity depending on the degree of kinship. Bride-receivers, however, are not allowed to express their grief publicly and are even punished for doing so. Their duty is to take care of the deceased, assist the relatives, and relieve their suffering. They organize the funeral and participate in the ceremonies, for instance by performing masquerades. A third category is made up of friends of the deceased and distant relatives, whose position in the proceedings is a mixture of those of the first two categories.

The house of a person who is critically ill is crowded with relatives and affines. In Ipiri, where in 1954 I witnessed the death of a critically ill singer of repute, I saw that the head of the dying man was resting on the knees of his sister's husband (his exchange partner, the man with whom he exchanged sisters for marriage). The husbands of another sister and her daughter supported his right and left legs. His wife's son and his sister's daughter were seated close by, listening carefully to any sound he made. Late at night, his wife's acting mother (his mother's sister), attended to her 'son-in-law', lamenting: 'You recovered, and now you are ill again. You may have eaten forbidden fish. You were strong and travelled widely for the District Officer; you caught sharks and killed fat pigs. But you did not heed our advice to see the nurse at the hospital.'

The following day, when questioned by his relatives, he told them that his deceased bride-receivers were already on their way to take him inland to his deceased mother and relatives. A thunderclap had announced their departure. A dying person is thought to see his dead bride-receivers entering his house. His (dying) eyes stare at them, seeing nothing else. Then one of them stabs his heart, his inner body (ndata). His body bounces and death sets in. Ndata and 
soul (ipu) leave the corpse; only the outside 'shell' of the body (kao), compared by one of the informants to an empty cigarette tin, stays behind and withers.

When the relatives questioned him again, there was no answer: the patient was unconscious. More and more people came and gathered in front of the house. There was much wailing and loud talking. His wife just wept softly. At dusk, a massive wailing set in and went on for about two hours. In the late afternoon of the following day, when, as usual at this time of year, there was some soft thunder, the patient appeared to be dying. All the persons close to him started rubbing and pinching his body, moving his arms and legs up and down forcibly: the usual thing to do when someone loses consciousness. In this way people try to revive a person by enticing the soul to re-enter the body. But this time it was to no avail. Then a mighty wailing, mourning, and lamenting set in. The ever-growing crowd inside and outside the house swayed back and forth. People cried loudly (except the bride-receivers, who are strictly forbidden to do so). The lamentation went on for four hours. Calling out kinship terms, the people praised the strength of the deceased, his deeds and gifts. Afterwards, the wife of the man who had died left the house, brandishing a machete. Hitting trees, shrubs and the wooden frame of her house, she wallowed about in the mud, followed by close relatives. Returning to the dead man, she sat on his thighs, rubbed his body, and lay down on it over its full length. And so did the dead man's sister, his children, and his sister's children, irrespective of their age and gender. The wife's acting mother wept while touching the kneecaps, arms and heart of the deceased, saying: 'They moved, but they move no longer.' Living means moving and moving around.

At night, the guild of singers and drummers, fully dressed up, performed a strikingly beautiful, moving show in honour of the deceased, who was a distinguished member of the guild. They took care not to make any mistakes, lest the soul of the deceased should make them forget part of the texts. The performance lasted ten minutes. No wailing and lamenting was heard, though it was resumed afterwards and lasted all night.

In the case of protracted illness, which constitutes a heavy burden on those involved, people sometimes resort to a test. Its aim is to assess and speed up the dying process. At night an older man seated underneath the house or platform secretly pokes the patient in his back with an arrow. If the startled man asks to have a look under the house, this would be taken as evidence that he is not yet ready to die. If, on the other hand, the patient panics and staggers to the entrance with a distorted face and his eyes wide open with fear, this would be taken as evidence of the patient being in the transitional state of a mbi, a spirit. The patient then asks some older men seated near the entrance: 'Did you do this to me?', whereupon they would reply with spirit voices, distorted by leaves stuck in their mouths, 'Yes, we wanted to know whether you are willing to die.' They would then, however, also give their names, as evidence 
that they are not spirits. The patient, almost a spirit himself and cheated by others who are not, breaks down and dies. Detailed and reliable information from my informant's village established beyond doubt that this happened on a number of occasions in the 1940s.

\section{Disposal of the dead and bereavement}

In the case described above, the body of the dead man was taken outside and cleansed provisionally by his bride-receivers after the first two hours of wailing. 'Now his soul can travel to heaven in a clean state,' one of the spectators said. The body was brought back to the house, clad in trousers and shirt, the only ones he had, and covered with textiles. It rested in this state during the last period of mourning and lamenting described above. The next day, early in the morning, the last cleansing of the body was performed. Many women and men married to relatives of the deceased took part. Evidently, this was a social obligation: they jostled each other continually. Clad and covered, the corpse was returned to the house for a second time. The wailing stopped. A sister's son of the deceased officially marked the end of mourning by closing the eyelids of two participating distant relatives.

Next, some ten male bride-receivers prepared the coffin, roughly made out of an old canoe. When the body was laid in the coffin, only direct and close relatives, including the exchange partner, the deceased's wife's brother, cried and lamented. Then the coffin, accompanied by a procession of children from the village school, was carried to the cemetery. The village teacher performed Christian rites. Six men and nine women, married to relatives of the dead man, carried the coffin. The leader of the guild of singers, fully dressed up, was given a prominent place in the procession. The mourning stopped at the very beginning of the Christian rites, when the procession of pupils approached the house. The wife and children of the deceased, except for a married daughter, were conspicuously absent during the Christian service.

Shortly before the coffin was lowered into the grave, male bride-receivers of the deceased's married daughter and sister's daughter covered the hair of these two women with a cloth that was hanging down from their necks as a sign of mourning. Their hair was plaited. The cloths of these and of other female relatives of the deceased were removed much later during a special ceremony (Imini), which marked the end of mourning.

In the late afternoon there was an informal social gathering of men and distribution of some food, in order to relieve the sadness of the relatives of the deceased. However, his son, though present, did not mingle with the others, and kept silent.

In earlier, pre-Christian times the coffin of ordinary men or women was 


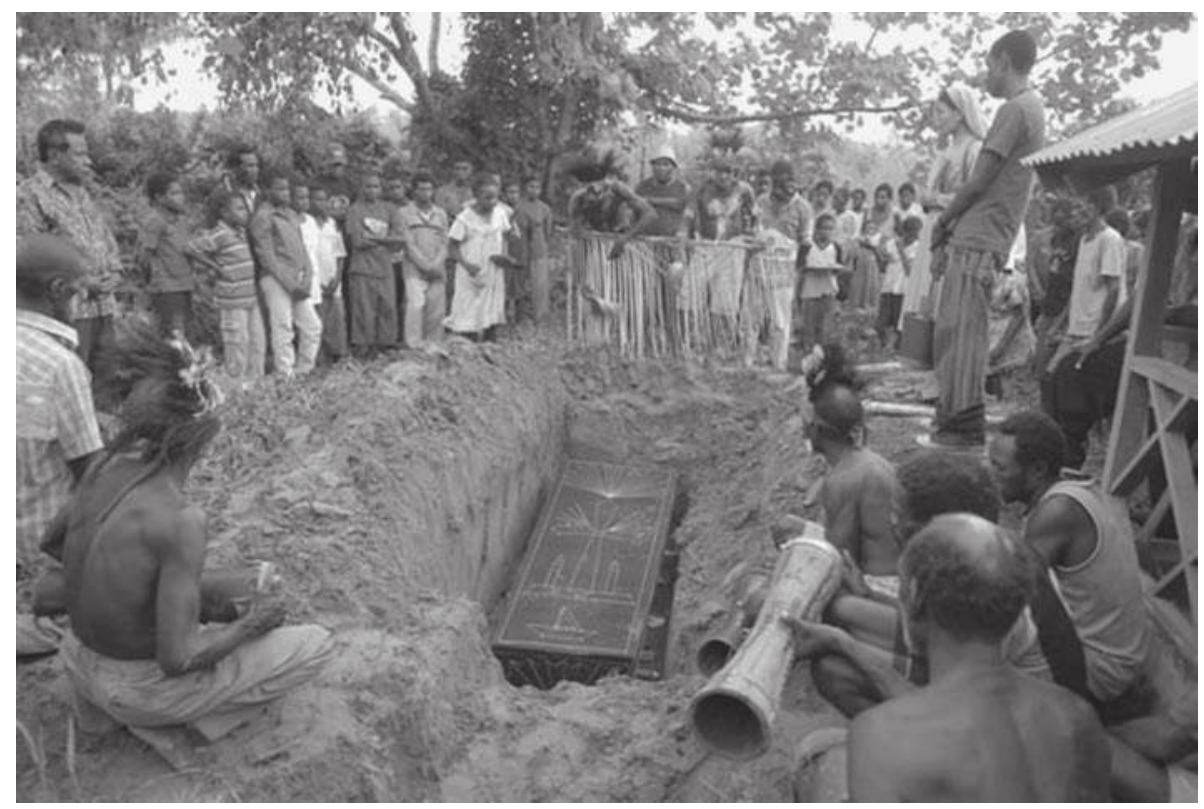

Funeral of Gabriel Yakopeyauta, at Kaokonao village, Mimika, on 2 November 2006.

The shredded palm leaves (tawri) attached to a stick in the background signify that he was a tawri dignitary. There are Christian symbols on the coffin. Photograph by Kal Muller.

placed on V-shaped trestles, or interred, whereas the corpse of an important and powerful man was exhibited on a platform. His canoe-like coffin was kept in balance by means of sticks. The remains of a child were simply put into a bag, which was then suspended in a tree in the woods.

The bottom of the coffin had openings for the fluids; the lid was decorated with carvings. Nearby a hole was dug. After the decomposition of the corpse, the bones were cleaned by the bride-receivers and returned to the coffin, which was then interred in the hole. A mat, carefully placed over the coffin, protected the coffin and the corpse (this is still practised). The trestles or the platform were situated near the settlement (as witnessed by the Wollaston Expedition in 1910-1913): the soul of the dead man stayed in the vicinity of the settlement and was occasionally induced to return to the grave. As long as the corpse in the coffin was not interred, the bride-receivers had to take turns keeping watch over the dead body, in spite of a repulsive stench that penetrated the settlement. The bride-receivers were warned to fulfil their unpleasant duty lest their wives be taken away from them. Keeping watch was meant not only to honour the dead, but also to dissuade the dead person's soul from visiting 
the village. Attitudes towards the dead are indeed ambivalent. Sometimes men from the settlement smeared their bodies with fluids and ground bones, secretly extracted from the remains of a powerful man or warlord. This happened in 1952 in Ipiri. It was believed this was a way to acquire power. An old man in another village told me that, before World War II, he extracted a maggot from the grave of a powerful man and placed it on his body near his heart. By biting his soul it entered his heart, causing an accelerated palpitation that warned him when enemies, including (pre-war) policemen, were approaching the village.

In 1951, a ceremony was performed in Yaraya, West Mimika, aimed at removing the soul of a recently deceased powerful man. His jealous soul, hovering about in the vicinity of the living, was considered frightening. The method of getting rid of him was similar to the way of speeding up the transition of a dying person to a spirit state, as described above. In the night after his interment, a dignitary in full 'battledress' approached his grave in a ritual dance (ndi). He pushed an arrow through the thin layer of sand covering the coffin until it touched the body. While doing this, he whistled and imitated a spirit, distorting his face and voice (his mouth was stuffed with leaves). In this way he enticed the dead man's soul to leave the grave through the hollow shaft of the arrow. The soul, accompanied by wandering spirit-mates, sat on the grave and then started to follow the man. Suddenly, turning around so that the dead man's spirit was in front of him, the dignitary stabbed it with a knife he had kept hidden under his feet, whereupon the startled spirit took to his heels. A similar ceremony was performed in Manoare, West Mimika, in 1953.

\section{Ceremony marking the end of mourning}

In keeping with common practice, the Mbi Warao ceremony, marking the end of mourning, is named after a dominant object that symbolizes the pertinent acts (a perfect museum display technique). It refers to the fibres of a particular tree that are used for plaiting an armband - compare 'nose-house', 'apron house', 'hair-extension house', and 'bones house'. I witnessed this ceremony in Ipiri in 1954. Three days after the singer's death, his son, having consulted his matrilineal grandmother, tied plaited armbands around the right wrists of a number of bride-receivers of his father's peraeko. The armbands are considered to be a token (kakari) of their social obligation to collect pile-worms to relieve the grief of the dead man's relatives. In this case, eleven men received such an armband. Assisted by some of their relatives and accompanied by some wives, who would also gather shellfish for their own purposes, they set out in the morning and returned in the afternoon. Portions of pile-worms, placed on a piece of bark and elegantly balanced on fingertips (not unlike 
the way a waiter carries a tray of drinks), were taken to the house of a crosscousin of the deceased who acted as his representative. The portions of pileworms were placed on a platform, next to sago pancakes prepared by relatives of the deceased. About thirteen male matrilateral or matrilineal relatives of the deceased, as well as the leader of the singers, then collected their share of pancakes and pile-worms. They consumed the snack at home, not while they were assembled together. The gift of pile-worms, just like a gift of sago grubs, has a high emotional value.

Five days after the funeral, the widow, her daughter, and her daughter's husband collected the fibres (beyao) of the aerial roots of a pandanus tree. The next day they made cords out of these fibres, at a hidden location outside the village. Assisted by a number of older women who were still familiar with the art of plaiting, the widow then prepared her mourning dress (unimi). This consists of:

1. A bark cloth suspended from the neck to below the buttocks (wata) and named similarly;

2. A jacket (papita), leaving the arms uncovered;

3 A hood (unumao) with flaps that make it impossible to look sideways and that keep out the wind (literally 'eyes-wind shelter');

4. Upper armbands (to ata); and

5. Decorative bands around the calf of the leg (ewa ta).

The preparation of the mourning dress took a fortnight and was done at the daughter's house. Then, surrounded by her helpers, who supported her as if she could not walk properly, the widow came outside. Not much public attention was given to this. The widow was required to behave modestly, and in the ensuing days she mostly stayed at home. Other female relatives wore only a bark-cloth wata. At the end of the mourning period, the bark cloth was removed by male bride-receivers without much ado. The widow's dress was worn much longer, until it fell off.

\section{Ritual cleansing and cancellation of food taboos}

This is an event I witnessed in Otakwa in East Mimika in 1952. A girl attending the village school, who had been taken to the hospital in Kaokonao, died in a canoe on her way back. Her parents and relatives were griefstricken. They ate hardly anything and completely abstained from eating bananas, because of the strong emotional feelings of having shared bananas previously with their daughter. In the afternoon, the guild of singers and drummers assembled and performed near the parents' house. The father then sat down 
on a piece of wood, part of an old canoe. His sister's and (adopted) daughter's husbands then cleansed the father of the mud that covered his body (as a sign of mourning). They simply threw a couple of buckets of water over his body and wiped it off. There was no drumming. Then the father sat down again on the piece of wood, silent, shy and resigned. His sister's husband, equally silent and without any expression on his face, offered the father a locally made cigar and put it into his mouth. Then the head of the father's village half produced new short pants and a shirt. One of the two bride-receivers turned each item of attire three times above and around his head, and together they assisted in putting the clothes onto the passive father. Some other men handed the father a fishing spear, a hunting spear, and a chisel, after first thrusting them into a piece of rotten wood. The father immediately followed their example. A dignitary performed the final ceremony. Holding the father's old clothing (a pair of shorts and a shirt) in his hand, he addressed the culture hero of the sun, taking him as his (divine) witness: 'He who sits in the sun: When his daughter was still alive, he wore this attire. Now he will wear it again.' He then passed the items of clothing three times over the father's head and returned them to him. Finally he took a partly peeled banana in his right hand and stated: 'His daughter ate bananas with him, now he will eat them again.' He invited the father to take a bite, and then did so himself. The mother joined him and also took a bite.

With this ritual, the parents returned to ordinary life and overcame the dangerous taboo situation (kaypiri) connected with their child's death. Similar ceremonies, although less explicit, were common elsewhere in Mimika.

\section{House of the corpse ceremony}

The Watani Kame ceremony marks the provisional end of the cycle of death rituals. The souls of individuals who have died recently leave the vicinity of the settlement and move inland, to the mountains, where they join their deceased relatives and affines and pass on to the state of unspecified spirits (mbi we). The relatives of the deceased also pay their debts to their bridereceivers, friends and dignitaries. A balance of reciprocity between persons and kin groups, which in fact is an ongoing process that is never completed, has then been temporarily achieved.

I witnessed Watani Kame in Ipiri, where I also attended the conclusion of the funeral proceedings described above. After some seventeen days had passed, due to work required by the District Officer and the Roman Catholic Mission, preparations were made to obtain the supply of fish needed for the ceremony. For three days, seven male fishing parties caught young sharks at sea and six mixed groups caught smaller fish in the tidal creeks. The fishing 
was thus a community affair, involving a total of 38 men and 16 women. Part of the catch was used for purposes other than Watani Kame. The catch of some close relatives, including that of the son of the dead man, was limited. This was attributed to a state of kaypiri, or danger and bad luck, due to close association with death.

On the fourth day, male adolescents supervised by the representative of the deceased man's taparu, erected the Watani house. It was about 6 metres long, and 1.25 metres high. It had no walls, merely a two-sided roof of mats. Young green strips of sago leaves served as 'walls' and decoration. The celebration was meant not only for the deceased, but also for another man who had died suddenly (after attending the rituals for the first dead man). He had lived in a neighbouring village. The deaths of three older women and a two-year-old child, all deemed less important than the deaths of the two men, were also commemorated. Other people had also died since the last Watani Kame, two to three years ago, but their relatives had not taken the initiative to remunerate the services of their bride-receivers.

At about 8 p.m., in spite of heavy rain, men from Ipiri and two adjacent villages assembled in the house. The singers offered a repertoire derived from Ema Kame (the song about killing the monster) as well as more informal songs. They also used the occasion to teach the songs to the young people. Meanwhile, frying pans were circulated, holding sago porridge supplied by relatives of the two dead men. There was a difference in quality: the best portions were given to those bride-receivers and friends whose assistance had been outstanding. The singers also recited the names of all the married women of Ipiri, according to the houses where they lived; though not present during the all-male sessions, these women were not forgotten.

Then the special Watani Kame song, the Mame Tao ('eyes song'), was started. To fully understand this, reference must be made to the pre-Christian treatment of the remains of the deceased. Prior to the preparations for Watani Kame, the bones of the deceased used to be dug up, obviously by the bridereceivers. In this particular case it would have been the (unpleasant) job of the daughter's husband and sister's daughter's husband. Their job was to clean the bones and skull. The skull was taken to the widow and the bones distributed among close relatives. The 'eyes song' explicitly enumerated the various parts of the body: 'The head is no more than a skull; the eyes are numb, they no longer move; the ears, the tongue, the heart, the lungs, the entrails, the elbows, the shoulder blades, the kneecaps, are dead, they move no more.' Each part of the body is remembered separately and repeatedly. Then the names of geographical sites and the places where pigs are caught were mentioned. The next song (Imini Tao) warned women in mourning attire not to eat oily fish, pile-worms, sago grubs, or other fatty creatures, lest their hair stop growing. Other Ema Kame songs refer to combs being made and to the final decay of 


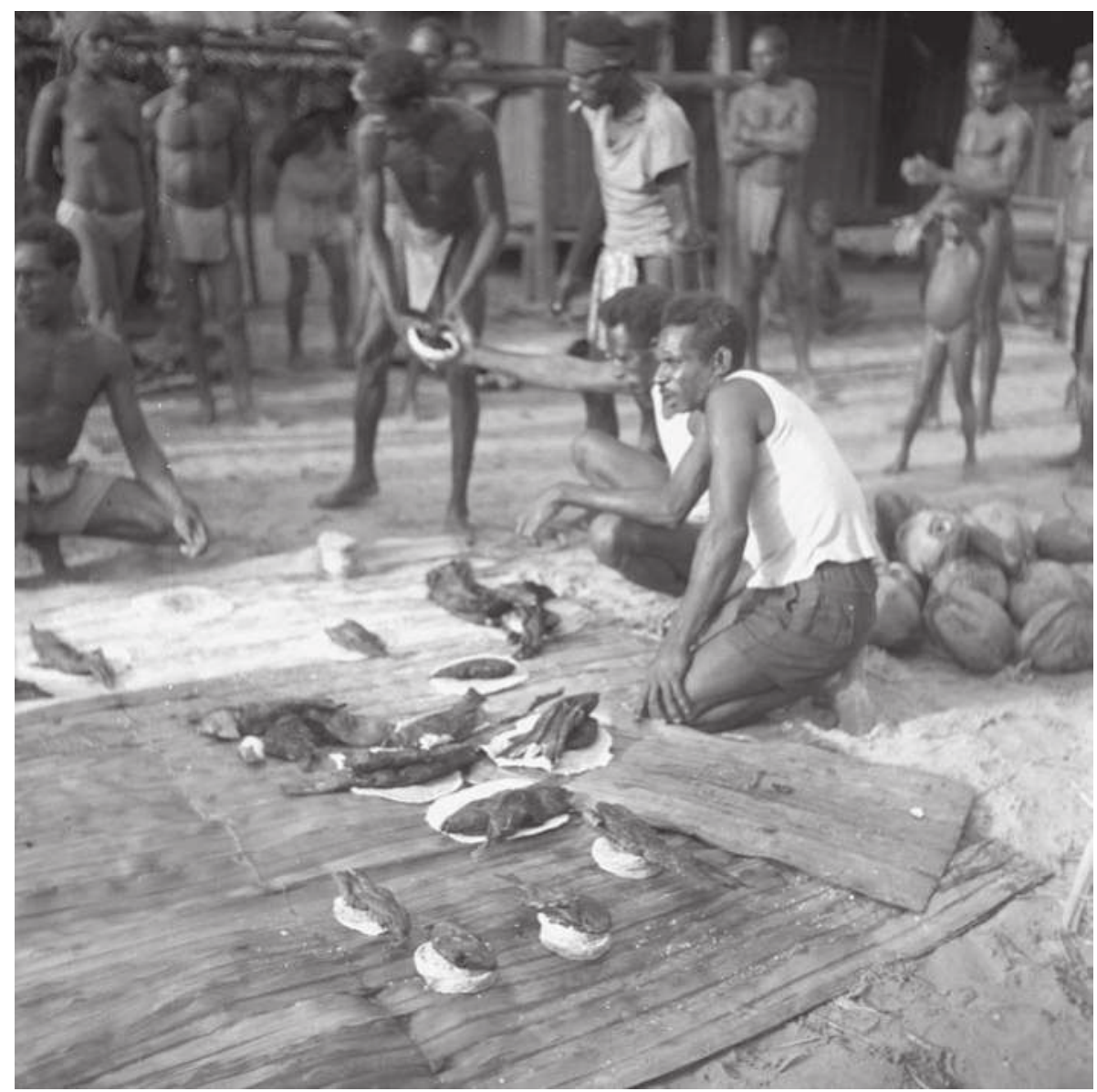

Vitalis, village head of Ipiri and relative of the deceased singer, in utter concentration while distributing roasted fish and sago pancakes to bride-taking affines of the deceased singer as remuneration for their services during Watani Kame. Ipiri, February 1954. RMV: NG-54-90. Photograph by Jan Pouwer.

the Ema Kame house and the bones deposited in it. So there is a clear connection between Watani Kame and Ema Kame.

Immediately after the performance, the young men who had erected the Watani Kame house took it down. On this very spot in the centre of the village, mats were laid out, separate ones for each person commemorated and for each village concerned. Next, about fifteen mainly matrilineal or matrilateral relatives of the man whose death I had witnessed brought roasted fish and sago pancakes. Their faces were numb, without any expression, as if it did not 
concern them: they acted as though they were ashamed (payti), a common attitude during public transactions of giving and taking in which one's prestige is at stake. The village head, the mother's mother's brother's son of the deceased acting as representative of the bereaved, assisted by his helpers, put the food on the mat. It was divided into portions of one pancake and one fish each. About 18 men and women, who were affines from the bride-taking category, and some friends, received the food, individually and with equally motionless faces. The distributor, in utmost concentration, saw to it that no one who had rendered services to the bereaved was overlooked. This was a serious affair, closely watched by critical observers. Not officially acknowledging services rendered would disturb relations between individuals. The distributor even drew on his private supply of fish at home to avoid discontent. The affines, who had helped the son of the deceased to prepare the food the previous night, privately received a double portion. The food received was consumed at the individual homes. There was no collective meal.

In pre-Christian times, immediately after the distribution of food, the skull was placed flat on the floor of the demolished Watani Kame house. It was suspended with rattan canes on a stick to keep it in the proper position, a point stressed by my informants. Then, one of the 'big men' of the settlement addressed the deceased as follows: 'You gave us much fish but now we have plenty. You were a man of courage, but so am I. We can look after ourselves, thank you. So please depart and leave us alone. The debts have been paid off.' Then one of the dead man's close affines, for instance his sister's husband who had dug up and cleaned the skull, started shooting arrows made of the ribs of sago leaves into the sockets of the skull: a graphic, visual acting out of the 'eyes song'. After this ceremony the skull was returned to the widow, who carried it with her in a bag or left it at home. After some time she hung the skull in a tree, where it was left to decay.

\section{Spirit platform ritual}

The Mbi Kawane ceremony is the middle stage in the rituals for parting from the deceased; it is performed for males and females of repute. Though celebrated in honour of specified named persons, the lapse of time since their death is, generally speaking, greater than in the case of the Watani Kame death ritual. There is no payment for the services rendered on this occasion. Only the persons who impersonate the dead in a masquerade (by wearing mamokoro or mbi kao, spirit masks) are remunerated. Needless to say, these are bride-receivers of the bereaved family. This more general ritual does not detract in the least from experiencing and expressing personal grief for the deaths of people not honoured in this way. 


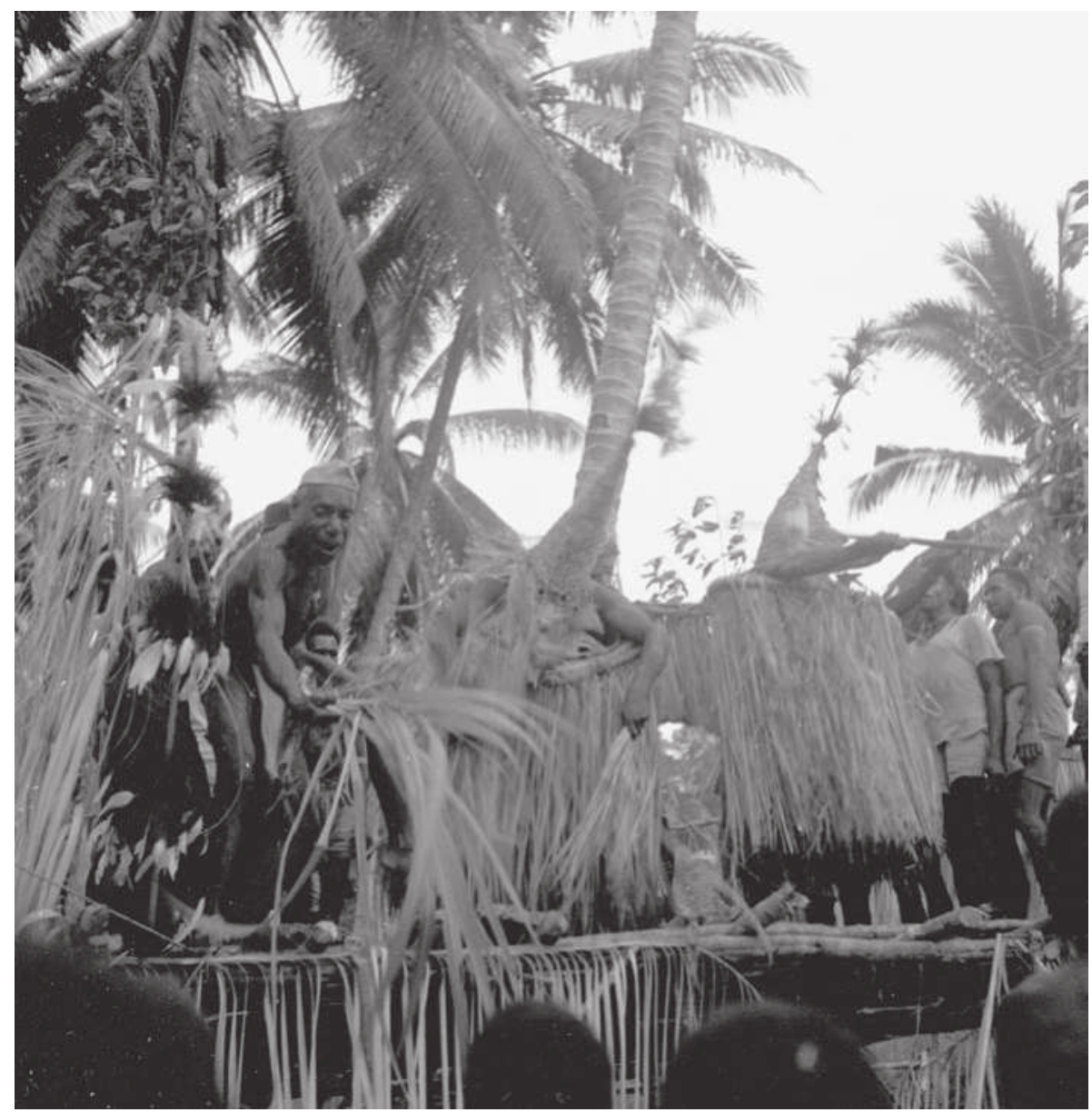

Spirit platform. One of the farewell rituals for the deceased in Mikiwia, Kaokonao village, Mimika, 1954. RMV: 10809-54-48. Photograph by Jan Pouwer.

I witnessed the simultaneous celebration of this ritual in the four villages of Kaokonao in 1954. The persons commemorated were selected from the dead of the two main villages, the other two villages serving as guests. The hosts and guests were considered to relate to each other as mapere to ipere, the former being superior to the latter. The persons selected were males, chosen for their personal qualities: a respected war leader, an outstanding singer, a gardener of repute who shared his produce with his fellow villagers, a very popular village chief, and a successful hunter. One of them had died in the 1940s, two died in 1953, and one some time later. In addition to their personal qualities, a 


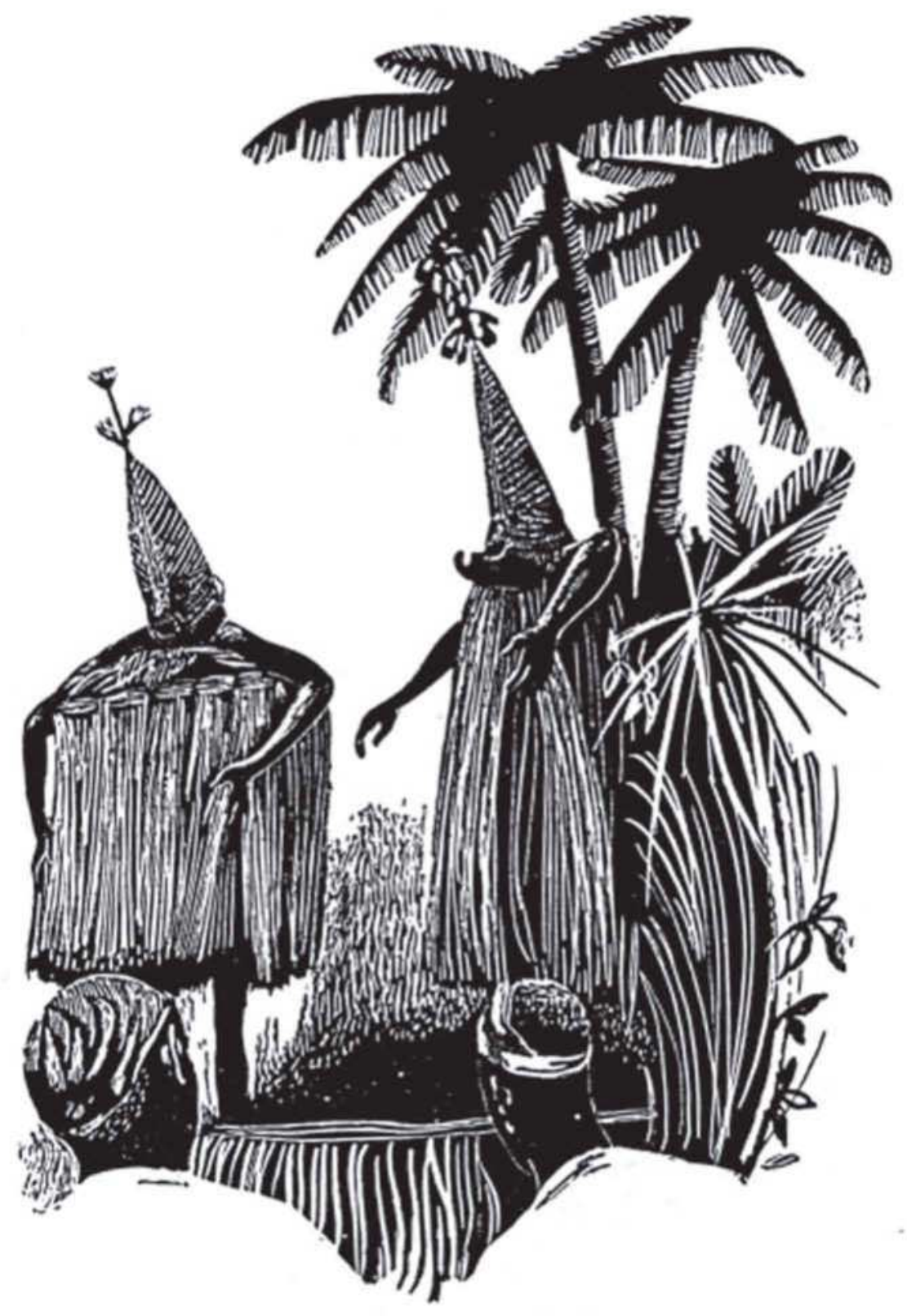

Figure 3. The spirit platform ritual. Farewell to the deceased, Mikewia, Kaokonao village, Mimika, 1954. Reproduction of a drawing by Henk Peeters, after a photograph by Jan Pouwer. From Pouwer 1956:375, reproduced in Pickell 2002:111. 
decisive factor was the relative size and power of their taparu descent groups. The last spirit platform ritual had been celebrated in 1941.

The two platforms were constructed by all the young men of the village, although according to the rules only bride-receivers such as sisters' and daughters' husbands of the deceased should do this. The platform looked like a wide diving board, its lower side reaching to the open ground facing the tidal forest. At the front of each platform and facing the village, two ceremonial poles (pokay), decorated with white feathers, were placed. They represented the two village halves. At the highest point of the platform, some decorative cloths, including a Dutch flag on a flagstaff, were placed. A hunting trophy, a bleached pig's skull, was also attached to a stick. Each platform was decorated with green fringes of sago leaves.

In the early afternoon, close female relatives (covered in mud as a sign of mourning; see danced on or near the platform, accompanied by the singers' guild. In the late afternoon, the first couple of masked spirit performers emerged from the tidal forest. They took the fringes of young leaves that entirely covered their bodies and tossed them into the air. They waved their arms and tottered like drunkards. The eye slits of their masks were so narrow that they could move around only with difficulty. They advanced in a cloud of powdered lime and were welcomed by the village chief, who reciprocated the lime-throwing. The names of Aoweyao and Mbiminareyao, the two culture heroes who caused the great migration from east to west, were shouted to scare the children. When the two spirit performers were about to climb the platform, the women previously dancing there moved back. They lamented and showed their affection for the deceased man being impersonated. When the spirit performers sat down on the platform, the men and women standing close to the platform grabbed the legs, thighs and feet of the performers and rubbed them. There was passionate weeping and wailing. Children clung to their masked fathers, really believing that they had returned from the dead. The spirit performers were handed attributes of their skills, such as spears, drums, and garden produce like sugar cane. They evoked the skills of the deceased by brandishing the tools given to them. The reply of the two male representatives of the two village halves was: 'Brother, you killed a large number of pigs, produced much sugar cane, bananas, fish, and so on. But listen, I know all the tricks myself. We have plenty of food.' In other words: you are not indispensable, move on. Again, an ambivalence towards the dead surfaced. The attributes were subsequently snatched back rather aggressively. Then the two masked performers retreated to the tidal forest, where younger actors took over. There were three or more performances. In the end, masked men showing strong emotions, who were the last set of masked performers, left the village at a trot. They were not driven out. At dawn they disappeared into the tidal forest, followed by a milling crowd. 


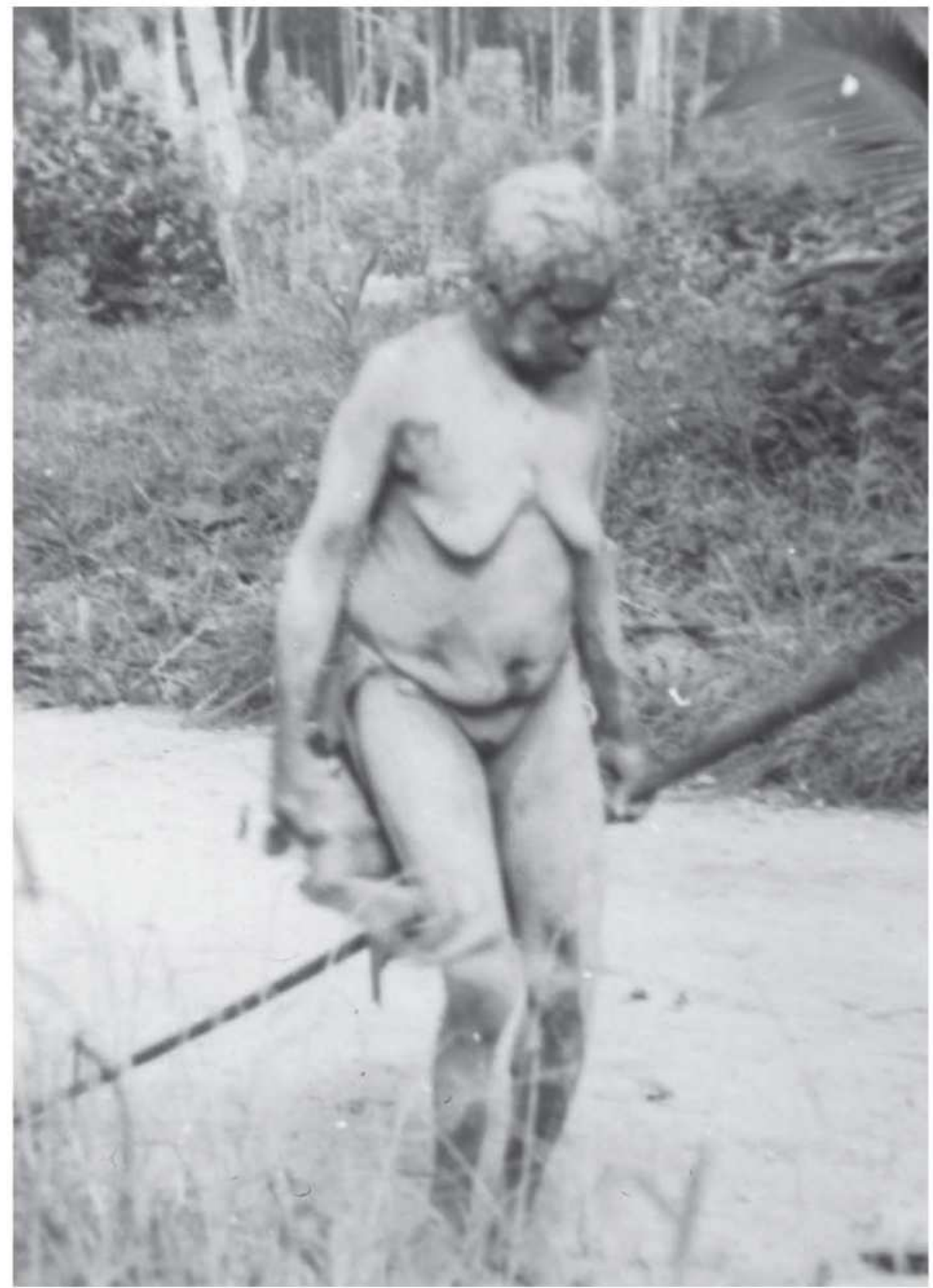

Mud-covered widow dancing in the vicinity of a spirit platform to commemorate the death of her husband, a successful pig hunter. She holds his lance as evidence. Mikiwia, Kaokonao village, 1954. RMV: NG-54-31. Photograph by Jan Pouwer. 
In the course of the evening the performers, all of them bride-receivers of the deceased, paid compensation money, a compassionate allowance for stirring up violent emotions of grief among the relatives of the dead being commemorated. They gave an axe, a shirt, a knife, a tin plate, a fishing spear, and so forth. They were rewarded for their services with large portions of prepared food. Even hours after the ceremony, women were still weeping, whether loudly or quietly, beside the blazing fires in front of their houses. Their wailing was also for dead relatives not officially being commemorated at that time. ${ }^{1}$

\section{Lifting the head-covering}

There is a special ceremony, Imini, to mark the end of the period of mourning. ${ }^{2}$ The cloths covering the heads of women as a sign of mourning are lifted, thereby also lifting the food taboos connected with mourning. I attended this ceremony in the Kaokonao villages in 1953. It was performed by bridereceivers, such as sisters' or daughters' husbands, while the women and men passed around a decorated pole to the accompaniment of the singers and drummers guild. The women's newly grown hair, plaited earlier in a variety of striking patterns, a source of pride and envy, symbolizes new life.

The plaiting had been done by male specialists who were paid for their services with food. The women ending mourning were warned by the singers to be slow and careful in resuming eating the forbidden foods (mostly oily and fatty ones, such as sago grubs), lest their hair stop growing.

The final stage of the cycle of death ceremonies is marked by throwing the bones of the deceased into the deserted Ema Kame ('house of bones'), as described in Chapter II. They are left there to decay. New life, so abundantly celebrated and promoted during Ema Kame rituals, takes over and continues.

1 For a more detailed description, see Pouwer 1956:373-86.

2 See also Chapter II under 'The glorious return of the initiates: the hornbill ceremony'. 


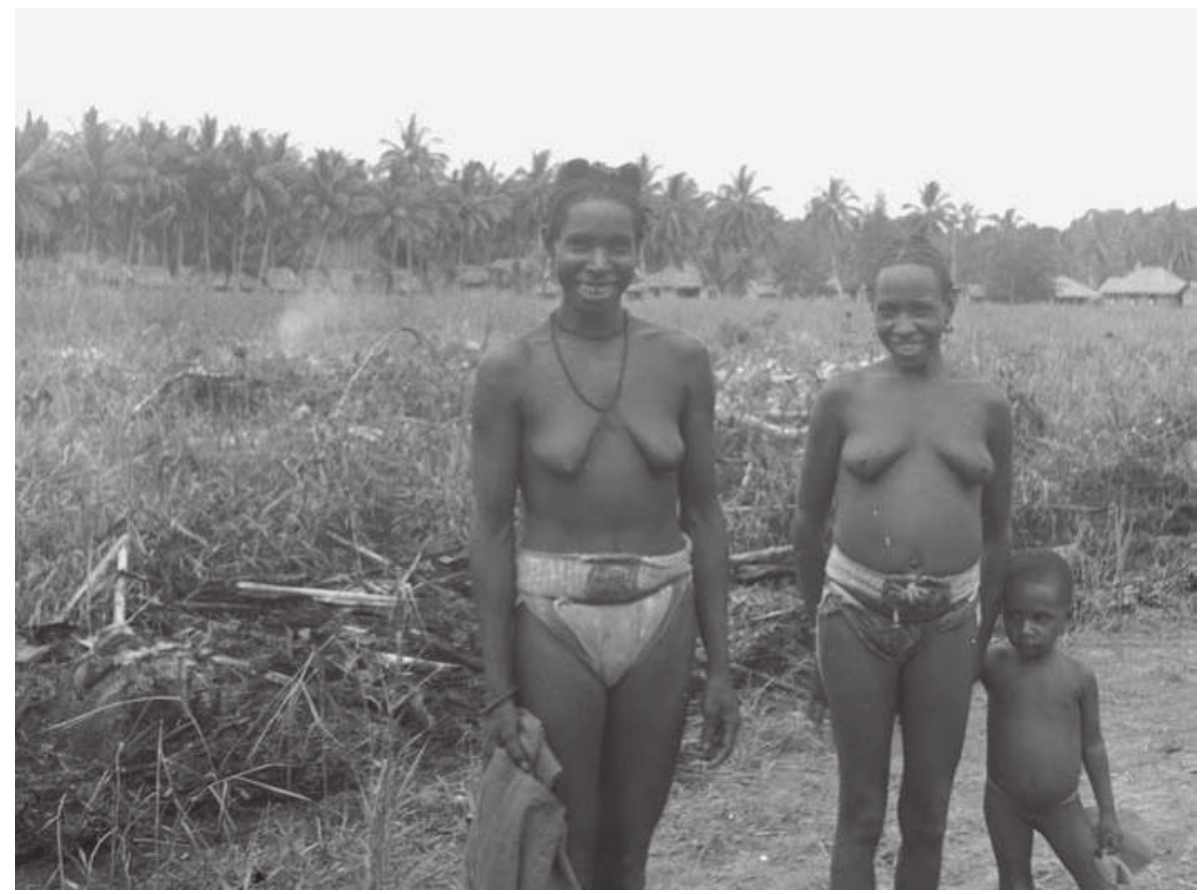

Two young women proudly showing their freshly grown and plaited hair after removal of covering cloths; this signifies the end of the mourning period for the death of a relative. Mikiwia, Kaokonao village, December 1953. RMV: NG-53-153. Photograph by Jan Pouwer. 


\section{PART TWO}

The Kamoro in relation to the Asmat 


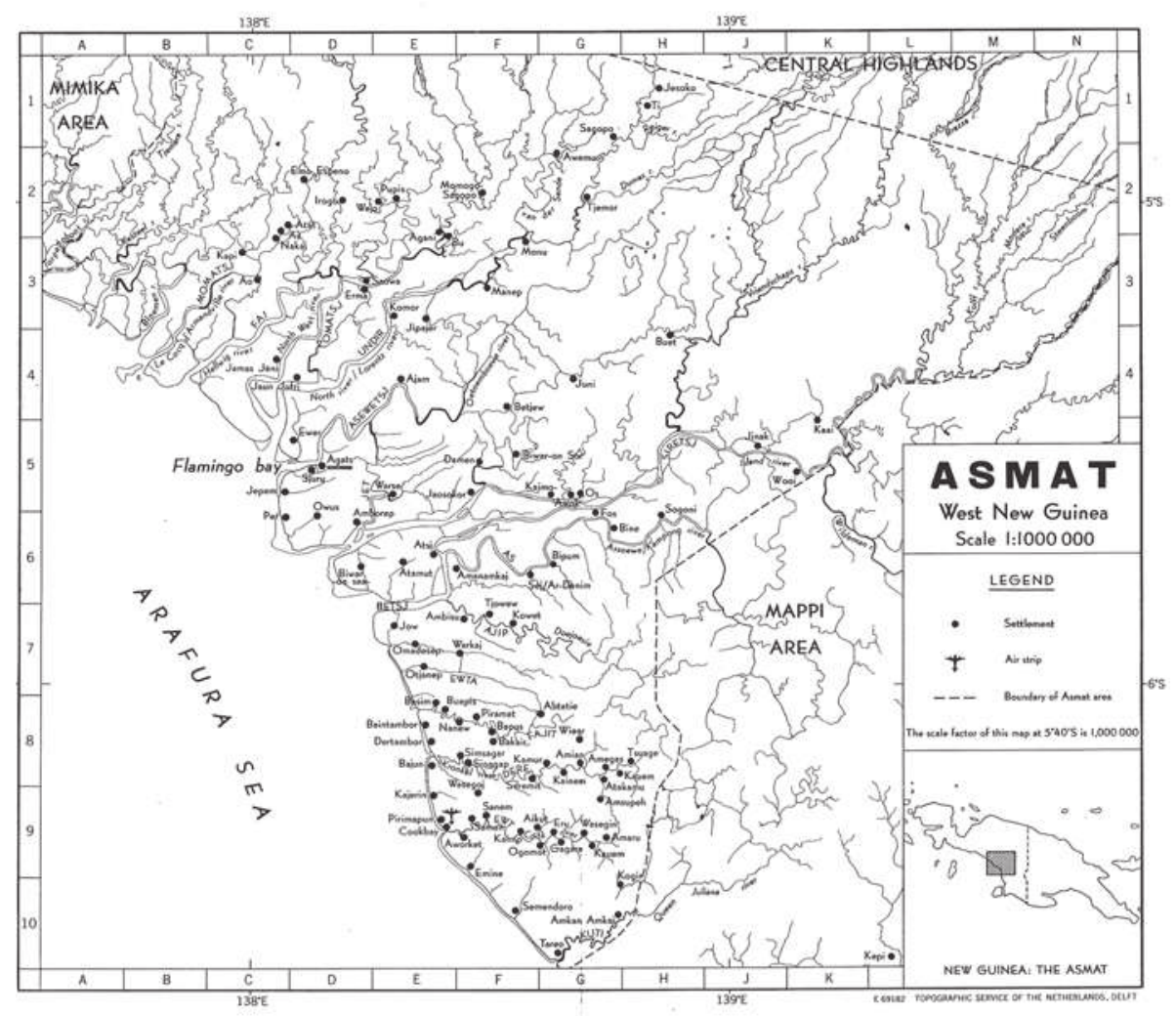

Map 3. Asmat in the 1960s. From Van der Schoot 1969: Appendix. 


\section{Chapter vi}

\section{The theory of comparison and the context of the rituals}

\section{The theory}

Observation entails comparing new information with information stored and systematized by the brain in a never-ending, always open-ended, dialectical process. Viewed in this way, 'raw data' and 'closure' are merely useful fictions. Most likely, the Kamoro information stored at present in my brain is not identical with information stored at the time of my observation in the 1950s and 1960s. The information has been extended since then, by new information (in particular from Zegwaard and Coenen) not readily available to me at the time, and also as a result of rethinking issues, theoretical concepts, methods and conclusions. No doubt there are incongruities and contradictions between the earlier and the later stores of information. Last but not least, the present book, as it now stands, could not have been written in the 1950s and 1960s.

These considerations call for a spelling out of the terms of cross-cultural analysis in use today. Any comparison is a construction or reconstruction, and any construction is meant to serve a particular purpose. So, what are my terms of comparison and what purpose do they serve? I tackle these issues by drawing on Knauft's comparison of South Coast New Guinea cultures, and on descriptions of these cultures by several other ethnographers in welldocumented, conventional monographs and accounts during a period of moderate colonization lasting till about the 1960s (Knauft 1993). Though the title of this chapter reflects current anthropological themes, and also since ethnography reflects the ethnographer's concern, ethnographic differences are not simply Western projections (Knauft 1993:10). One should not mistake the map for the territory. ${ }^{1}$ The territory of seven South Coast New Guinea culture areas, extending over some 2,500 kilometres, may justifiably be viewed as an ethnographic region, because the cultures share a number of salient features. 


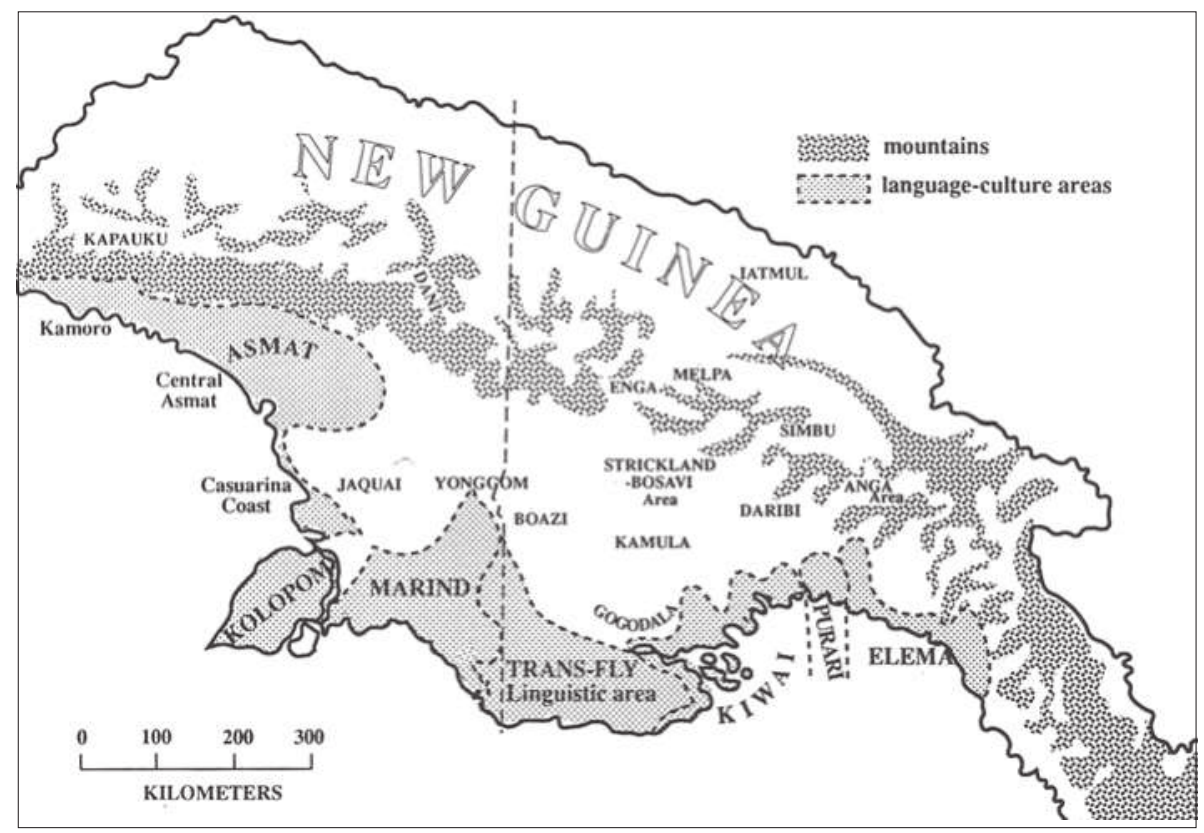

Map 4. Cultures (based on language used) on the south coast of New Guinea. From Knauft 1993:xiv.

These are summarized by Knauft (1993:37-41, 218-21) as follows. Additions, deletions, elucidations or cross-references that I make to quotations or texts referred to in Part Two or elsewhere in the book are placed between square brackets.

1. A variety of Papuan, non-Austronesian languages;

2. Abundance of wild [or semi-cultivated] sago stands, complemented by maritime or riverine resources [and supplemented in varying degrees by horticulture];

3. [Types of kinship and descent];

4. Potential [realized in varying degrees] for large-scale political affiliations or residential aggregates, despite a low population density;

5. Pervasiveness, in varying degrees, of multiple forms of dual organization and bipartition [including striking modalities of partition by gender];

6. Firm mythic-cosmological belief in the need for the regeneration of fertility;

7. A close articulation of these beliefs with:

a. commemoration of the dead; 
b. highly elaborate ritual enactment employing costumed or artistic embodiments [especially carvings] of mythical or ancestral beings [and recent dead];

c. elaborate heterosexual and sometimes homosexual fertility and rejuvenation rites;

d. warfare, particularly in the form of headhunting, to both reflect and augment the spiritual and social power of the local group.

Knauft notes that headhunting and ritual-ceremonial heterosexuality or homosexuality were absent among the Elema. Ritual-ceremonial homosexuality is absent among the Kamoro as well; the Kamoro ritual-ceremonial heterosexuality lacks the virulent intensity reported for the Asmat and the Marind. Unlike the Marind, Kiwai and Kolopom, the Kamoro and Asmat did not collect and apply male and female coital fluids. Admittedly, severing heads from bodies does occur in a well-known Kamoro myth of Kamora River groups, eliciting laughter among its listeners. An eloping couple chased by their relatives curse them to sink into the mud save for their heads, which are then severed by the elopers. They promptly feel regret and stick the heads back onto the torsos with resin. ${ }^{2}$ However, this narrative is a far cry from the elaborate ritual practice of headhunting, ascribed in a Kamoro myth exclusively to the Asmat. ${ }^{3}$ In various reliable reports about Kamoro pre-colonial warfare, there is no evidence whatsoever of headhunting or cannibalism (Pouwer 1953a:42-6; Harple 2000:105-7).

It seems that the features of Knauft's ethnographic region fade out towards its eastern and western borders. In East Elema, socio-political organization and patterns of social exchange approximate highland New Guinea ones; they were originally an inland population (Knauft 1993:204, 215). In West Kamoro, the mythical emergence of social groups as a result of dividing up a slain monster shows striking similarities to southeastern Bird's Head highland and lowland stories; only the manifestations of the monster differ (Pouwer 1999:480-8). Does this similarity point to age-old migrations, or to diffusion from west to east over hundreds of miles? The Kamoro narratives do mention pockets of small, scattered communities in West Mimika prior to the great migration from east to west. One wonders if the participants' explicit association of the myth of the slain monster with Ema Kame is not a historical afterthought. This could account for the remarkable absence of dramatization of this myth in Ema Kame rituals; the myth is, however, told in songs. Myths change more easily than rituals and ceremonial songs. 
Meanwhile, in spite of the similarities, the differences between the seven culture areas are so rich and of such a magnitude that Knauft is reluctant to force them into a comparative straitjacket by listing them. Doing so would also easily overlook the developmental configurations that are crucial for understanding intra- and cross-cultural divergence (Knauft 1993:209). But then, how are we to avoid academic, empiricist 'butterfly collecting'? Knauft attempts to overcome this Malinowskian dilemma by taking recourse to early Marxist concepts of social formation, social being, and social consciousness. He uses the term 'socio-cultural formation', which not only unites 'society' and 'culture' but, I would say, also 'process' and 'steady state'. 'Formation', as opposed to 'format', stresses ongoing activity. The Concise Oxford dictionary (2008) defines 'formation' as 'the action of forming or the process of being formed; a thing that has been formed; a structure or arrangement; a formal arrangement of aircraft in flight or troops'; indeed, a most fruitful collection of meanings. Further, to account for the process and dynamics of (socio-cultural) formation, Knauft re-casts the crucial Marxist concepts of 'social being' and 'social consciousness' into, respectively, the existential 'hard world' dimension and the symbolic dimension, or cultural impetus, of a social formation. ${ }^{4}$

Now, the strategic advantage of using this trio of concepts is that it enables us to grasp the reality of (social) formation as a truly dialectical process. As Knauft (1993:15) puts it, 'a core dialectic is constituted by the recursive qualitative impact that symbolic and existential dimensions of social action exert on each other over time. Along with internal cultural dynamics, this dialectic drives the endogenous development of socio-cultural formations.' On the other hand, 'the challenges, dissonances and refractoriness of culture's own existential manifestation provide tensions that drive development in the symbolic formation itself'. Knauft (1993:208) continues: 'Because the local interface between culture and practice [including history] is both recursive and generative, it produces remarkable differences among culture areas that nonetheless retain striking similarities.'

This reconceptualization of the Marxist trio produces in my view a relational dialectic, which rejects any final determination by either 'hard world' infrastructure or symbolic superstructure (see also Knauft 1993:14). As the neo-Marxist Althusser puts it, 'the last instance never comes'. What matters is neither 'matter', nor 'Geist', but the dialectical interface between the two in a given dynamic socio-cultural configuration. Put in a semiotic perspective, what matters is the events conceived as articulations, as relata, because the human (and animal) brain and the mind, having no immediate, direct access to reality, always articulate it. For instance, the hard-world phenomenon of 
sago stands in traditional South Coast New Guinea societies is articulated both as a physical-economic resource and as a physical-spiritual source of life; sago stands are not resources by themselves. Sago as articulated in this manner presents the people with both restraints and a boundless scope for signification, symbolization and creativity. A physical, social and spiritual articulation of sago in a modern, industrial society would be, and in fact is, radically different.

Knauft's neo-Marxist 'core dialectic' may in actual analysis be usefully combined with Lévi-Strauss's core notion of structure, more especially with structural history, a term he coined in 1960 in his inaugural address (LéviStrauss 1960, 1977:16). I cover ground similar to Knauft's and Lévi-Strauss's in my 'Structural history; A New Guinea case study', a semiological analysis of a Kamoro myth (Pouwer 1975:80-102). Structure in a Lévi-Straussian sense is a construct, an arrangement of complements rather than an empirical-statistical correlation of elements (Pouwer 1975:81). Hence it is accessible to reasoning, namely the logics of articulation, of signification by the mind, which has no direct access to reality: it is an analytical windfall that enables us to apply the logics of reasoning to the muddle of data and the flow of events. To Lévi-Strauss an arrangement is structured if it meets two conditions: 1 . it is regulated by internal cohesion; and 2 . this cohesion is not readily accessible to observation in an isolated system, but reveals itself in the study of transformations through which similar properties are recognized in apparently different systems (Lévi-Strauss 1977:18). These systems may be part of given configurations of a culture, such as the sub-systems of kinship and marriage, of politics, economy, ritual and myth. But they may also be part of a succession in time from one configuration to another. I define structural history as the study of the history of the succession of varying configurations in their dialectical interaction with the stream of events as articulated and signified. In terms of signification, the distinction between the order of events and the order of structure is merely an analytic one (Pouwer 1974:253, 1975:80-102). In other words, history 'happens' on the borderline between chance events and non-chance, non-contingent structure (Pouwer 1975:81).

It is on this borderline that Knauft's 'core dialectic' may be fruitfully situated. It has proven to be of great analytic value:

As cultural orientations were actualized in socio-material life, they were confronted with the often unintended existential effects of their own legacy. Repercussions of this nature were highly important in the development of each language-culture area. They are exemplified in the compromised fertility of the Marind; the relative defenselessness of the Trans-Fly people to ethnic encroachment; the relentless self-killing of the Asmat; the oscillating repulsion and spread of the Kiwai; the complete atomization of the Kolopom; the autonomous separation of Purari villages; and the great duration and economic scale of the Elema's hevehe. These 
outcomes reflect the recursive effects of divergent symbolic orientations as they became actualized in specific demographic, material, and biological conditions. (Knauft 1993:207.)

I would add that these conditions as articulated act upon the divergent symbolic orientations as articulated. From this development of each languageculture area to the succession of the next configuration in time is but one step. In this connection one is reminded of a profound remark by Durkheim, published in 1900: 'Structure itself occurs in the process of development. [...] It is ceaselessly forming and breaking down; it is life which has reached a certain degree of consolidation; and to distinguish it from the life whence it derives or from the life it determines amounts to dissociating inseparable things. ${ }^{5}$

Since Knauft deals only in passing with the Kamoro, which he saw as merely a small part of the Asmat language-culture area, ${ }^{6}$ I will attempt, in the following sections, to illustrate Knauft's dialectic by comparing the Kamoro with the Asmat socio-cultural formation. For the Asmat I rely mainly on Zegwaard's typed or cyclostyled reports and scattered notes, now available in the Zegwaard Archives of the Catholic Documentation Centre (KDC) at the University of Nijmegen. ${ }^{7}$ In addition, I refer to Knauft's observations in his main text and in an Appendix (1993:228-37), drawing on Zegwaard, Eyde, Schneebaum, Trenkenschuh and Sowada. I will proceed as follows: from a scrutiny, blow by blow, of the broad similarities, as listed above, will emerge a number of significant differences between Kamoro and Asmat. Can we account for them in a dialectical fashion?

\section{Languages}

The Kamoro language is spoken in a number of dialects, which cover the coastal and more inland areas from Etna Bay in the west to Koperapoka and the Mukumuga River in the east. The closely related Sempan language has speakers in the upper reaches of the rivers east of the Mukumuga. The neighbouring and little-known Nafuaripi presumably speak a Sempan dialect. They live upstream in a wide arc from Otakwa River to the upper reaches of

5 Durkheim 1953:190, as quoted in Lévi-Strauss 1977:17-8. Durkheim 1960 is an English translation of Durkheim 1900.

$6 \quad$ See Knauft 1993: Map 1, facing p. xii. See also mMap 3 and Map 4 in this volume.

7 Specific page-by-page acknowledgment of Zegwaard's information would be cumbersome and is not always possible for his scattered typed notes. Therefore, I refer simply to the Zegwaard Archives as 'KDC, File number'; the number as a rule refers to one item but may also include various items filed under one cover. 
the rivers around Flamingo Bay. The Asmat language area, beginning at the Momac (Le Cocq d'Armandville) River, includes a considerable number of dialects. They can be subdivided into a central coastal group of slightly differing dialects, with around it on the periphery upstream a number of dialects differing sharply from it, and the dialect of the Casuarinen Coast. ${ }^{8}$

The three languages are related yet different. They are classified as the Asmat Language Family, since speakers of the Asmat language dominate numerically: 40,000 to 60,000, compared to Kamoro's 15,000 and Sempan's 1,500, the Nafuaripi not included (Kamoro baseline study 1998:15). Despite considerable variation in dialects, there are no bars to comprehension within each language. The very differentiation into dialects and into three languages is evidence of longstanding migrations, and socio-political and cultural developments over hundreds of years.

\section{Sago stands, riverine, marine and horticultural resources}

The Kamoro, Sempan and Asmat share a vast, flat, marshy coastal plain and adjacent hinterland, densely covered with mangrove trees, tidal forests and rain forests, intersected by numerous rivers, creeks, and connecting shallow waterways. Yet there is significant ecological variation, which affects the size of the settlements. Since the central mountain range descends towards the coast in the far northwest and gradually recedes from the coast towards the southeast by several hundred kilometres, there is a difference in landscape and carrying capacity between the area west and the area east of Kaokonao (Central Mimika). In the former there is a clear, though continually shifting, borderline between a shallow sea and the land, marked by beaches and sand spits, enlivened by casuarina trees, and utilized for living and some horticulture. The rivers, creeks and connecting waterways west of Uta are fewer in number and shorter. Consequently, sago groves are not so abundant, there is more semi-cultivated sago (Amota pareta), and communications are more dependent on seagoing canoes originating from areas west of Etna Bay, which have almost supplanted the river-going canoes west of Kaokonao. In the east the shallow sea blends almost imperceptibly into the mudbanks and slush (rather than solid soil) of the coastal plain and into the aerial roots of the mangroves. An unusual extent of ocean incursion, as far inland as 125 kilometres at high tide, has created vast salty and brackish swamps. In these swamps extensive sago stands occur, at high tide extending to the middle and upper reaches of streams. Where the incursions of the tides cease, a different 


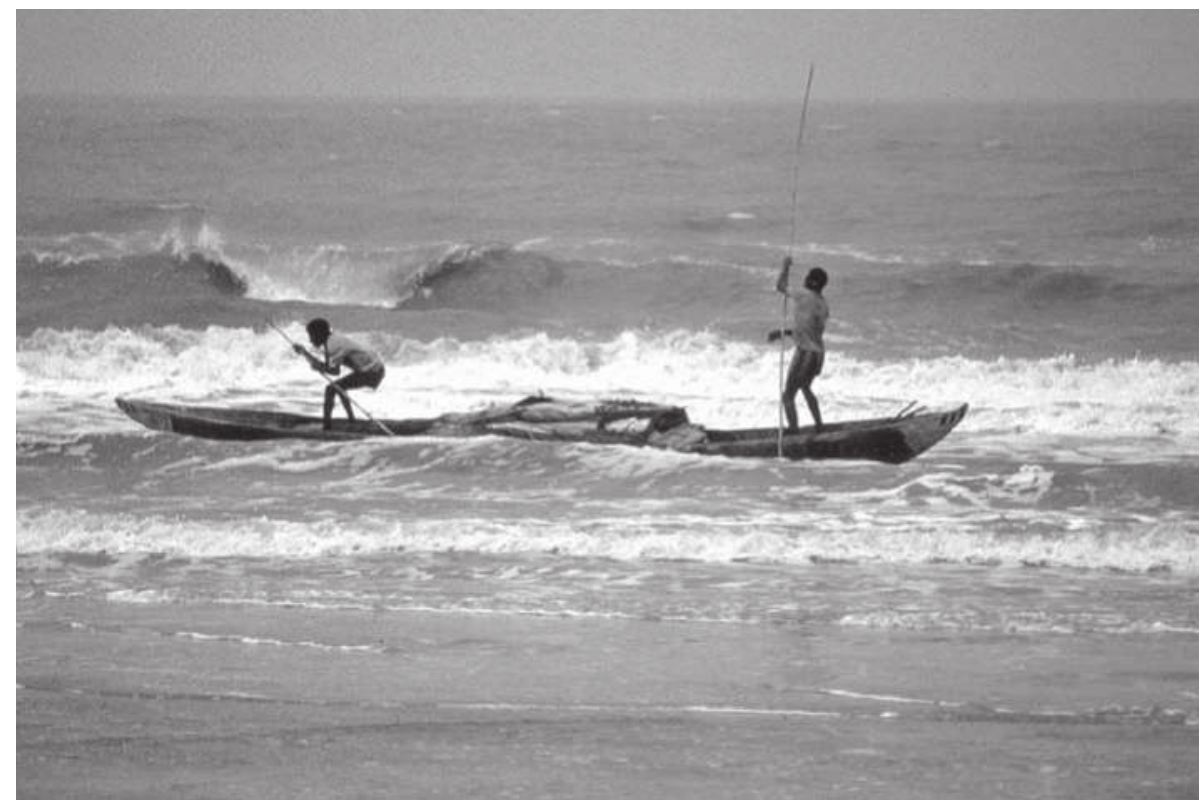

When the Arafura Sea is stormy, the only hope for a heavily loaded canoe is to pole it tediously along the boat channel inside the breakers near the shore. Near the portage to the Matoapoka River, Mimika, 1997. From Pickell 2002:164-5. Photograph by Kal Muller.

flora begins to dominate the riverbanks. Here there is an opportunity for gardening, especially on the upper reaches of the Wania and Mukumuga Rivers. This ecological situation is amenable to a higher carrying capacity. Whereas in West Mimika the size of settlements rarely exceeds 200 persons, in Central and East Mimika 200 or more is the rule rather than the exception. In coastal Central Asmat the upper limit is even 2,000. Inland settlements tend to be smaller (100 to 300 people) throughout the coastal plain. Another universal feature is a high degree of mobility, thanks to highly efficient dugout canoes well adapted to rivers, shallow creeks and waterways.

The ecological differentiation outlined above may be taken to constitute the existential dimension of the socio-cultural formations concerned. It is its dialectical interaction with the socio-symbolic dimension, as articulated, of the formations which determines their distinguishing features. 


\section{Types of kinship and descent}

Kinship and descent in Mimika and Asmat are roughly similar in that they combine a flexible, 'horizontal', strongly classificatory generation-type ('Hawaiian') of categorization of kin with a marked 'residential override', a term coined by Peter van Arsdale. ${ }^{9}$ Such a combination renders participants' thorough knowledge and recognition of actual and putative genealogical relationships, of descent lines and founding ancestors, superfluous and rather dysfunctional. Being a member of a domiciled core of kin is sufficient proof of being a relative. The paired terms of reference cemen/cen (Asmat) and kamare/wa (Kamoro), meaning penis/vagina and penis/anus respectively, are used, if need be, to designate the patrifiliation or matrifiliation of a particular person. A Kamoro man identifies his anus with his sister's vagina; he has two types of offspring: on the front side and on the back side, namely his own and his (classificatory) brothers' children versus his own and his (classificatory) sisters' children, his kamarima and his fatako. An Asmat man may even refer to his sisters' children by slapping his behind. ${ }^{10}$

Both the Kamoro and the Asmat strongly emphasize bonds between siblings as the core of kinship. The Kamoro refer to these in a generalized and metaphorical sense, irrespective of gender, by the term naoka-bikipa, literally 'younger/older brothers' (Pouwer 1955a:74). According to David Eyde the 'brothers', ofew, are the most important people for an adult Asmat male. This group includes not only younger and older (blood) brothers but also male parallel cousins and cross-cousins. It makes up the base of what Eyde has called a core conical kindred (Eyde 1967:210-303). These core kinsmen live next door to each other in a longhouse. In a metaphorical sense, ofew stands for kin in general.

The dualistic layout of Asmat and Kamoro local aggregates in a settlement, and the dual organization of performed ceremonies and rituals, enable persons of various kin and non-kin categories, including persons or groups originating from elsewhere, to assimilate easily without genealogical knowledge or connections.

Last but not least, the particular combination of generation-type kin classification, spatially expressed dualism, and residential override, allows for a flexible system of cumulative filiation or descent, attuned to locality of marriage, with some room for flexibility. There is a difference, though. The Kamoro and Sempan favour cumulative matrifiliation and matrilineal descent, the Asmat favour patrifiliation and patrilineal descent, corresponding to their

9 For details, see Pouwer 1955a:55-85; Van Arsdale 1975:12, mainly based on Eyde 1967:210303; Van Arsdale and Van Arsdale 1991:20. For the theory, see Pouwer 1966.

10 Zegwaard, personal communication, 1952. See also Pouwer 1955a:75. 
predilection for respectively matri-uxorilocal and patri-virilocal marriage. The Kamoro combine cumulative matrifiliation with 'horizontal', generational emphasis, by referring to male and female persons of ego's generation who have a mother's mother in common as 'my peraeko'. These peraeko often work together in sago production and fishing parties. Usually they live in the same settlement or the same part of a settlement. As a group and in a wider sense, they are referred to by the name of the focal grandmother. The group includes three generations and is exogamous. In the fourth descending generation the focal term of reference shifts to the name of another woman. ${ }^{11}$ The matrilineal peraeko of the Kamoro may be considered the counterpart of Asmat afayis cokom, literally 'grandfather one', those who have a father's father in common (Zegwaard and Boelaars 1955:286); this group is exogamous and patrilateral. The Kamoro and the Asmat share a low importance of lineal descent reckoning and an absence of named lineages exceeding three generations.

The reason for the (statistical) difference between matri-oriented Kamoro and patri-oriented Asmat could, and in my opinion should, be sought in a different style of political affiliation (see below). Adding to this difference is the fact that the Kamoro recognize and practise a clear distinction between superior bride-givers and inferior bride-receivers, combined with a preference for matrilocal marriage. In my description of Kamoro rituals, the special position of bride-receivers stands out. They are obliged to render a wide variety of services for their bride-givers, for which they are explicitly rewarded. Matriuxorilocal residence comes in very handy in such a situation. The special position of Asmat bride-receivers seems to be overruled by the strong and structurally fundamental emphasis on brothers. Though less conspicuous, among the Asmat the bride-receivers still occupy a rather special position. For instance, Asmat bride-receivers are required to assist in weaving masks for the benefit of their bride-givers. It is their duty to unveil a carved bow commissioned by their bride-givers to honour and avenge the death of a relative. Last but not least, bride-receivers are called upon to assist their bride-givers in acts of revenge during battles (Zegwaard 1959:1031).

\section{Residential aggregates and political affiliations}

Kamoro, Sempan and Asmat settlements consist of a varying number of localized descent groups in various combinations. ${ }^{12}$ The residential override of these aggregates is apparent from the literal meanings of their generic

11 For a striking persistence, compare Pouwer 1955a:76-80 and Harple 2000:234-6.

12 For more detailed descriptions, see Pouwer 1955a:85-107; Zegwaard and Boelaars 1955:24499, 1970:13-31; Van Arsdale 1975:10-2. 
names: taparu (Kamoro), yahe se (Sempan), yew se (Asmat). Taparu derives from tapare, meaning 'ground, territory'; 'taparu tapare enokoa' means 'taparu and tapare are one'. The linguistically closely related Sempan and Asmat terms literally mean 'longhouse mud'. 'Mud' refers to the mud-slab fireplace that prevents the fire from eating into the floor of the men's house. Each of the many doors in the longhouse corresponds to a fireplace (Zegwaard and Boelaars 1970:17). Yew se and yahe se stand for the men's longhouse, for the men's group, and by extension for the family dwellings around it and the associated kin group. The Kamoro have no separate men's longhouse, although there is some evidence for the pre-colonial existence of a special house (ate) for unmarried males (Van der Schoot 1969:36). In pre-colonial times they did have semi-permanent longhouses, situated upstream from the settlement and divided into (extended) family apartments, each with its own fireplace. In addition, there were and are temporary sites of simple, easily movable, matted family shelters near sago and fishing grounds.

Quite frequently, names of taparu are identical with or derive from the names of the territories they live on or once lived on; some of these names refer to features of the landscape. Other names refer to human beings, animals, birds, plants or natural phenomena featuring in narratives. These, however, are not considered ancestors, but may be associated with particular taparu or sets of taparu in terms of mythical power or ritual functions ascribed to members of the taparu. There is no evidence of totemism.

In a survey and a census including all Kamoro and Sempan settlements, I noted 160 taparu encompassing 8,500 people, which implies that the average size of a taparu is small (Pouwer 1955a:88). Although some names were identical or similar, a genealogical connection between two similarly named taparu was usually unknown or denied. Segmentation is conspicuously absent, in spite of frequent dispersion of persons and groups. Fragmentation is the rule. Residential override is so strong that interlocal genealogical ties easily lapse. One consequence of this is that, with the exception of cases of regular interlocal intermarriage, men or women originating from one village who settle in another village, for marriage or other reasons, may consider each other peraeko or close kin, irrespective of known or unknown genealogical or taparu connections, solely on the grounds that they have their settlement of origin in common. ${ }^{13}$

In keeping with the trend of increasing size of settlements going from northwest to southeast, the size of taparu east of Kaokonao and of the Sempan yahe se tends to be larger. Everywhere, taparu of limited size tend to be exogamous. They have a core of peraeko sets, which consider themselves closely related, 
even though genealogical interconnections are hardly known. In larger taparu, such as in the Wania region and in Sempan villages, the number of constituent peraeko sets is bigger and their genealogical relationships further removed. These units tend to be non-exogamous. Everywhere, marriage within the settlement, or within the river-bound association of settlements, is preferred.

The Asmat conforms with these trends in its own special way. A yew has at least 150 members, usually more (Zegwaard 1955:241). A men's house may be as long as 50 to 90 metres and may have ten or more doors and corresponding fireplaces, owned by 'brothers'. Their related families live around it in ten or more compartments of longhouses. Though the typical community includes several men's houses, each yew is a potential village (Eyde 1967:109). In a similar vein, some of my Kamoro informants in East Mimika labelled taparu as kampung (Indonesian: village). Van Amelsvoort (1964:39) reports that an Asmat man strongly identifies with his yew, but feels little loyalty to the community or village. Though less conspicuous, among the Asmat the bridereceivers still occupy a rather special position. A yew differs from a taparu in that it consists of named moieties, aypim (literally 'halves'). Each moiety has and builds its own half of the men's house and its adjoining row of (lower) family longhouses. One moiety relates to the other as the root of a sago palm to its shoots (Eyde 1967:98-100; Voorhoeve 1965:31). Their relative position is one of superior downstream to inferior upstream, even if the factual geographical position is the reverse of this because of fission of moieties or yew. Marriage is ideally aypim-exogamous and yew-endogamous. An actual analysis of Shuru by Zegwaard and Boelaars in 1953 (Zegwaard and Boelaars 1955, 1970) shows that more than half of the marriages are within the yew. Exchange of women may be and often is delayed in time and generation within a yew, but is usually not delayed outside a yew.

Coastal, downstream and midstream Asmat settlements, with 400 to 1,400 inhabitants, have three to five yew, whereas settlements situated further inland, often considerably smaller in size, have even more yew, sometimes up to fourteen (Van Amelsvoort 1964:39, 190-1). In West Mimika we also noticed that smaller settlements tend to have relatively more taparu. ${ }^{14}$ In my opinion the reason for this remarkable paradox is that smaller settlements and smaller yew/taparu go together with a larger dispersion of smaller wild sago stands and more numerous semi-cultivated sago groves. A larger concentration of largely wild sago stands favours larger settlements, and a smaller number but bigger size of yew/taparu. In a valuable comparative analysis of Kamoro and Asmat settlement patterns and demographic data based on missionaries' and government information and his own and my research, Eyde concludes 
that ' $[\mathrm{t}]$ he maximum stable units of Kawenak and Keenakap life [surroundings and western hinterland of Central Asmat Flamingo Bay, respectively] are twice as large as those of the Keenok [northwest inland Asmat], and twice as large as those of the Kamoro' (Eyde 1967:148). He continues:

It is everywhere [in Asmat] the case that the largest villages on a river are located in its middle course. The villages towards the coast are somewhat smaller; those inland are usually very much smaller. This middle zone represents, in general, the optimum balance between tidal swamp and fresh water swamp. It can, therefore, support a relatively larger population than areas downstream or upstream. (Eyde 1976:155.)

In my view this observation also applies to East Mimika and to Sempan.

This ecological interaction has important implications: the more manpower per yew and (association of) taparu, the stronger their political/military potential. Whether and to what extent and for what purpose this potential is realized is another matter.

It is in these areas where the rivers are wide and long that

competition for sago and fishing areas between unrelated groups residing up and downstream from one another has resulted in the development of a state of intensive warfare, which is not duplicated in the western Kamoro and Casuarine Coast, where the rivers are short and groups possess territories comprising both tidal swamp [fish] and fresh water swamp [sago]. Increased solidarity of males resulting from cooperation in intensive warfare has led to the development of men's houses or bachelors' houses [Yeenok]. [...] These are absent among the Kamoro and on the southern Casuarine Coast. (Eyde 1967:304.)

Wars were not absent in Mimika, but lacked the intensity and virulence of Asmat warfare. Unlike Asmat wars, Mimika wars were not a regular feature or obsession of daily life.

This takes us to the territorial and political affiliations between self-contained local aggregates. Although Kamoro taparu are not divided internally into moieties, they do tend to operate in dualistic, river-bound groups, which in my PhD thesis (1955a) I named 'tribes'. The taparu of an association used to live together in a semi-permanent settlement (later reconstituted and sometimes reshuffled in government-styled villages). Such a settlement is either divided into wards per taparu or into named parishes, each comprising a varying number of taparu. In the course of my fieldwork I counted 50 associations, each constituting a security circle. Three of them no longer exist; 21 consist of two taparu; the remainder are parishes, which, like the Asmat yew halves, relate as downstream to upstream. Some of these parishes are even subdivided into spatially marked sub-halves. These associations are usually not named. 
In their turn many adjacent settlements are federated in pairs. Some federations include more than two settlements. There are 15 paired settlements, and four associations that include more than two settlements. The latter, plus two paired ones, each have a name of their own. These six affiliations, with considerable numerical strength and guided by one or more powerful 'big men' (we ayku), pulled their weight in warfare. ${ }^{15}$

The Asmat federations are similar to the Kamoro ones, but there is a difference in scale due to the larger size of the components. A systematic survey of affiliated settlements is sadly lacking but some are at least known by name, such as - going from northwest to southeast - Emo-Espeno, Ac-Nakay, Yamas-Yeni, Yaun-Yufri, Saowa-Erma, Per-Owus, Aman-Namkai. Fortunately Zegwaard provides a unique, fairly detailed description of the oral history of affiliations of the Bismam group at Flamingo Bay, in particular those of Shuru, where he lived in $1953 .{ }^{16}$ For locations, see maps 2 and 3.

When the grandfathers of the present (in 1953) grandfathers were young, the inhabitants of the paired yew Ewer-Shuru lived downstream and the Uwus-Per upstream in one settlement on the upper reaches of the Bow River, above present-day Owus. The culture hero Beworipic and his wife Tewerawoc are said to have founded this settlement (Van Arsdale 1975). Headhunting and its associated ritual are ascribed to him and his brother Desopic. ${ }^{17}$ The Bayit, now forming a yew within Shuru, then lived elsewhere on the Bow River. At that time the paired settlements of the Yepem and Kaye yew were located respectively near and on the upper reaches of the Mani River (upstream of the present Per, Van Arsdale 1975). The Yepem now lived at the mouth of the Yomat; they had migrated there from the Citak region.

Then the upper Bow group began to split up. A man from Shuru killed a man from Amborep. This triggered a brawl about the dead body, a trophy for ritual headhunting festivities. The Owus snatched the body but the Shuru took it back. A Shuru man was wounded and, by way of retaliation, an Owus man was beaten up. The Owus then spread the rumour - a common political strategy - that this man had died. After a fight the frightened Shuru-Ewer took to their heels and fled to the mouth of the Bow River, later to the Ba River near Shuru's present location.

Owus realigned with the yew of Seper at about the present location of Owus, whereas Per moved to the upper Mani and associated with Kaye. Some time later, warfare broke out between the former allies: Owus-Seper against

15 For more detailed information about associations, see Pouwer 1955a:90-1. Lists, detailed by village, can be found in Appendix III, V and VI of Pouwer 1955a:282-7.

16 For additional information, see Zegwaard and Boelaars 1955:248-53; Zegwaard and Boelaars 1970:15-7; Van Arsdale 1975:56-60.

17 On the initiating myth and ritual, see Offenberg and Pouwer 2002:192-5. 
Per-Kaye. Kaye's warleader died, causing dissolution of Kaye and the mixing of its people with other Bismam settlements, particularly Shuru-Ewer. A present-day remainder of Kaye's influence in Shuru is the moiety of Bayen of the Shuru yew Awor (Van Arsdale 1975).

Then Ewer-Shuru split apart after a Shuru man raped an Ewer woman. In the ensuing retaliation by Ewer, the woman's father was wounded and died. Eco pok, signs of revenge, were erected. The two parties, anticipating killing and counter-killing, then agreed to pull out. They moved to their present locations. In 1904, when the ship 'Flamingo' sailed along the coast of Central Asmat, the Shuru stayed on their own at the present location of the Faramap River, whereas the Ewer lived at the mouth of the adjacent Ba River (Van Kessel 1962). Ewer associated with two other yew, which at a later stage dissolved and were incorporated into yet another yew, a new one (Van Arsdale 1975).

At the time of the Ewer-Shuru split, the settlement of Shuru consisted of the Ndendew yew (Nano yew in Zegwaard and Boelaars 1970:15) with its moieties Ndendew and Onom. In the course of time a number of fissions occurred, which I present in a diagram (Figure 4) for the sake of clarity: (a) a newly founded yew, Setmut, splitting up into Setmut-Ar; (b) Awor splitting up into Awor-Bayen; (b1) and (b2) temporary dual splits of Awor and Bayen respectively, which did not last; (c1) and (c2) temporary dual splits of first Onom and then Ndendew, which did not last either, for lack of numerical strength; then Ndendew and Onom reunited; (d) Ar splitting up into Ar-Baser; (e) Setmut splitting up into Setmut-Yismak. All these fissions resulted from conflicts of one kind or another.

So in 1953 the settlement of Shuru consisted of the mother yew Ndendew (-Onom) and five daughter yew deriving directly or indirectly from her. The moieties placed left in the compartments of the diagram give their name to the yew concerned. They relate to their partner moieties as downstream-superior to upstream-inferior. Ndendew-Onom and its Awor-Bayen branch (b) lived together downstream and related as superior to upstream Sotomot-Ar in their original settlement on the river.

Bayit-Wauco originated from the Momac River and joined Shuru after a number of moves. Along with a few people of the Awor moiety (Bayen), BayitWauco are the only ones not deriving from Ndendew.

We may conclude from the data that residential override and modalities of spatially expressed dual division - also operating clearly in ritual - dominate and permeate not only the social pattern but also the dynamics of the three societies concerned. Their constituents, kinship, (cumulative) filiation descent, if you like - genealogical knowledge and genealogical relations, and marriage patterns (though all of these are social phenomena and forces in their own right) are clearly conditioned by residential override and dual division. The latter provide an anchor for the instability brought about by endemic con- 

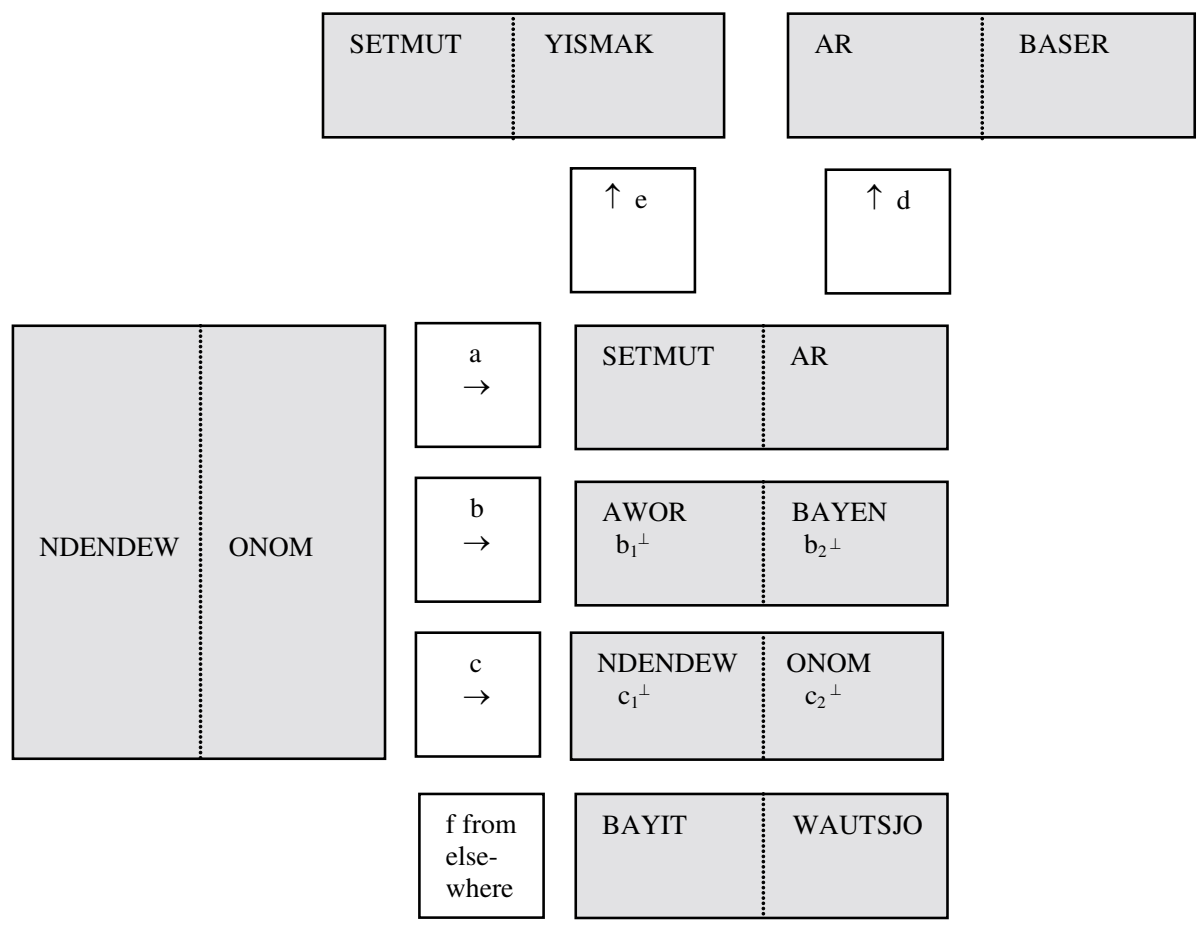

Map 4. Fission and fusion of yew in the Asmat settlement of Shuru

flicts, warfare, and subsequent shifts in domicile and affiliation.

The carrying capacity - an ecological interaction of individuals and communities with their physical environment as defined, articulated and signified in a dialectical process - tends to condition the differential manpower and associated political power of the communities, gradually gaining strength from northwest (Etna Bay) to southeast (Casuarinen Coast), particularly in the coastal and downstream regions.

However, these two types of conditioning, socio-political and existential, do not determine the total configuration of the socio-cultural formations concerned. First of all, each type of conditioning is in itself an open, never-ending dialectical process between people being conditioned and at the same time acting as conditioners through their articulating and signifying social practice. More especially, their symbolizing capacity, the complement and counterpart of carrying capacity, provides the social formation with its central impetus. It is this impetus which turns the (semi-)autonomous components of a social formation into a totality: it literally con-figurates them in a never-ending, 
never-closed, dialectical process. Its very 'totalizing' nature provides this central institution with multiple faces. Therefore, if it is observed that a particular social institution has multiple functions, this may indicate that the institution operates as what Marcel Mauss called a 'total social fact', taken here to mean a totalizer that functions as a cultural focus.

In modern Western societies the multiple faces and functions of the economy mark it as a totalizer. It seems to me that the Asmat social formation differs from the Kamoro one in that endemic political rivalry and warfare spearheaded by headhunting - act as a totalizing force. The evidence for my suggestion is provided by Zegwaard (1959). He concludes from his description of headhunting that it should be evaluated in the light of a complicated set of factors, which he spells out (Zegwaard 1959:1041). In other words, headhunting has many faces; these will be discussed in a separate section in Chapter XI. Cannibalism is merely a secondary part of this (Zegwaard 1959:1020). Meanwhile, it should be noted that the virulent, violent nature of rivalry and warfare and headhunting can easily turn this totalizer into its very opposite: a fragmentizer, even a self-killer. The dog bites her own tail in deadly dialectics. The Shuru case, and other Asmat ethnographic and historical evidence, supplies us with ample examples. Knauft concludes from a worldwide ethnographic tabulation that the Asmat killing rate is among the highest in the world (Knauft 1993:194). Numerous settlements have been wiped out or dispersed, or have seen their remnants absorbed into other communities. Zegwaard knows of 20 yew, or communities of yew, which have been wiped out or dispersed. The settlement of Kaimes, which had about 400 inhabitants at the time of the Military Exploration (1910-1913), no longer existed in the 1940s. Only 20 persons who trace their descent to it survive, having been assimilated by Ewer. From personal experience during his first stay in Shuru (1945-1947), Zegwaard reports 61 confirmed casualties, 56 of them having been eaten by Shuru's enemies: 16 men, 18 women, 22 children out of a total population of 675 . At that time Shuru was a favourite target because it had lost physical strength as a result of the Japanese killing of 21 married men and one bachelor. During his second stay, in 1953, Zegwaard had personal knowledge of 83 casualties in one year, due to headhunting between settlements in a 50-kilometre semi-circle around Flamingo Bay. He estimated that about 2 per cent of the population per year was killed by war and headhunting (Zegwaard 1977:22-5).

A striking example of the relation between differential carrying capacity on the one hand, and differential symbolizing capacity on the other, is provided by the difference (alongside the similarity) in impact of the consumption of sago shoots or sago hearts (known in Western countries as palmite or millionaire's cabbage), and of sago grubs. Throughout the region these forest products are highly valued as delicacies. Since they are an important source of protein, 
they add considerably to the carrying capacity of the physical environment. Sago grubs are even 'cultivated', by felling sago trees, cutting the trunk into chunks, and opening these up to the pith inside, in order to better enable the capricorn beetles to lay their eggs. Maturing takes four to six weeks.

There is more to these delicacies: they function throughout the region as a social good (biens sociaux). In the entire Kamoro-Asmat region a lover may express his - or more particularly her - feelings towards the object of affection by secretly offering a serving of fresh or fried sago grubs. Furthermore, almost any distribution of food during ceremonies and rituals, including the remuneration of services offered (especially the services of bride-receivers), involves giving or exchanging sago shoots and sago grubs. The Asmat, however, unlike the Kamoro and Sempan, tend towards a seemingly excessive consumption of the two. Zegwaard reports that hundreds of sago palms, presumably the more highly valued young ones, were felled in Shuru in 1953 for the acquisition of sago shoots and the cultivation of sago grubs, on the occasion of the ceremonial inauguration of a new men's house. At that time Shuru had about 650 inhabitants. ${ }^{18}$ Father Alphonse Sowada, attending a similar ceremony in Ac, with a population of over 1,300 in late 1969, counted somewhere between 700 and 900 sago shoots. ${ }^{19}$ In the course of another, related ceremony, Tow Mbu, a huge funnel-shaped tube about three metres long with a diameter of at least one metre at its top, is filled with hundreds of sago grubs. During the Kaware celebration of the Kamoro, both similar to and different from Tow Mbu, sago grubs also feature in a ceremony, but not in this way, nor in such huge quantities. In the 1950s Sempan villagers in East Mimika complained about Asmat invaders ruining their sago groves while searching for sago shoots. According to the oral history of the Bismam group of Asmat, and the Kamoro narrative of the great migration as discussed earlier, a scarcity of sago stands and famine are important reasons for temporary or permanent migrations, hostilities and wars. ${ }^{20}$ In the light of the excessive consumption of these social goods, one wonders whether this scarcity is due not only to poor quality sago (Van Arsdale 1975), but also to human causes, namely excessive felling and overexploitation for the sake of sago shoots and sago grubs.

Why this excessive Asmat consumption of social goods? The answer may be found in their connection with rivalry and warfare as a totalizer of the Asmat socio-cultural formation. In addition to having an emotional and social function, these delicacies also have a crucial symbolic meaning. Zegwaard describes the symbolic meaning for the Asmat - and probably also for the Kamoro - of sago grubs in particular, as spiritual power-food: it provides the 
many minor spirits (Asmat: nam yipi, Kamoro: ipu), located in particular in the joints which keep the body moving, with strength and vigour. Sago shoots and sago grubs are consumed in large quantities by Asmat prior to and after an attack. A related function of the sago grub for the Asmat is that its smell, together with the strong odour of a smoking stick rubbed with the fat of a cassowary, is believed to attract the souls (nam yipi) of the leaders of a hostile village. Their bodies will follow their souls, so that they will be an easy prey for the men with the 'smoking guns'. ${ }^{21}$

Every Asmat moiety and yew has a key figure. The extent of his influence is based, in addition to kinship, on his personality and his abilities (or lack thereof) as political spokesman, as primus inter pares. His political power and the protection he offers may affect the residential pattern in that followers, irrespective of kinship status, may wish to settle near him. Outstanding 'big men' (tesmaypic) almost literally embody the totalizing impetus of rivalry and warfare. The famous 'big man', warleader, and successful headhunter Warsekomen of Shuru, a key informant for Zegwaard in 1953 and still an important man in 1970 in spite of his age, is a prime example.22 His power was determined by the following factors: 1 . leadership of his yew Ar and the closely associated yew Setmot, which together constituted almost half (45\%) of Shuru's inhabitants; 2. his marriage to seven wives from other yew; 3 . his being a partner in a ritual wife swapping (papish, see Chapter XI) by six men; 4 . his relations with brothers and sisters and their offspring; 5 . his ties with relatives in four other settlements; 6. the shamanistic abilities (namer ow) of his wives (see below); 7. his abilities as an organizer and leader of ritual; 8 . his strong personality and intelligence; and 9. his thorough knowledge of narratives and history. All these factors enabled him to mobilize a maximum of material resources and manpower for warfare and headhunting. His many marriages gave him extra access to sago groves and fishing grounds. He acquired and boasted of a considerable number of captured heads in battles with various settlements.

Admittedly, Kamoro and Sempan also had their warleaders of repute. Like Asmat history, Kamoro and Sempan oral history after the great trek is marked by skirmishes and battles between settlements (or federations of settlements) and subsequent resettling. Yet there is a difference in frequency, scale, ferocity, and number of casualties. Most importantly, headhunting was not part of Kamoro and Sempan history. Similar to Asmat, Kamoro rivalries could also erupt within a settlement; likewise, casualties within a settlement were low and were preferably avoided. In Tipuka (Wania River, East Mimika) I recorded a vivid story, apparently also meant as entertainment, describing

21 See Zegwaard's 1988b comments on Schneebaum in Konrad, Konrad and Schneebaum 1981:109, 179; for more details, see description of Firao Wu and Tow Mbu ritual.

22 See a comment by Trenkenschuh in Zegwaard and Boelaars 1970:18. 


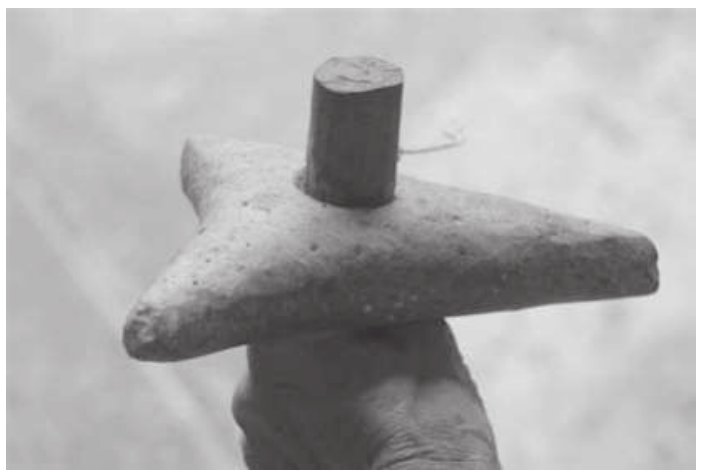

Star-shaped stone head of a club collected by Kal Muller in Ipiri, November 2006. Photograph by Kal Muller.

how an indecent love affair by a young couple, engaged in public bantering and mutual scratching, deteriorated into a full-scale, full-day brawl into which everybody was gradually drawn (Pouwer 1953a, Appendix XXV). The combatants were initially hitting out with any piece of wood at hand, but soon replaced these with professional clubs (mapipu) consisting of a shaft inserted into the round hole of a heavy, star-shaped stone. Everybody sustained cuts and bruises, though there were no casualties. Nobody could walk properly any more, but still the clubbing went on, even while sitting and lying down. Nevertheless, the story has it that at the end, the lover boy was carried around the settlement on the shoulders of the fighters, and the sticks and clubs were thrown onto a heap, signalling the end of the brawl. People of a nearby settlement treated the wounds with leaves and provided the exhausted combatants with pork and sago grubs.

The very same Tipuka, however, was attacked and decimated in a full-scale battle in about 1900, which is well remembered throughout Mimika. At that time, together with downstream Atuka, it was the most powerful community of the Wania region. Its people were at odds with its host neighbours on the Wania River and with nearby communities on the Koperapoka River east of them. Initially they had lived there - after migrating from an area east of the Mimika region - but they pulled out after they had killed a man of the Buka parish during a joint celebration of Kaware. They overpowered their host neighbours during numerous conflicts, involving among other things the exploitation of sago groves they were not entitled to. So there was plenty of willingness in surrounding communities, even communities on the Kamora River, to teach the Tipukans a lesson and break their power. When the Tipuka 


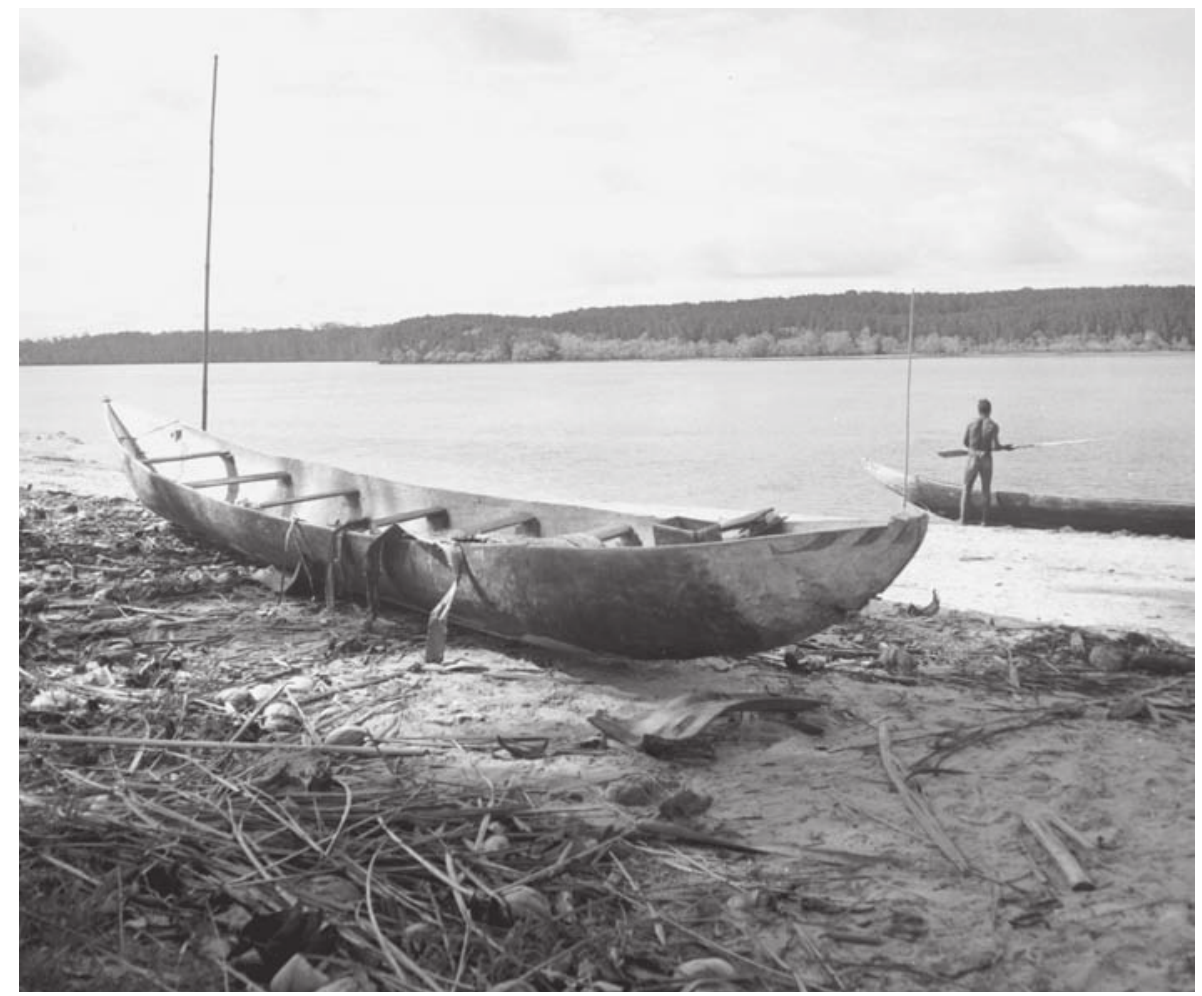

New seagoing canoe fabricated by Poraoko people (far western Mimika) in exchange for permission to gather sago. Ipiri sago groves, February 1954. RMV: NG-54-61. Photograph by Jan Pouwer.

men, in the final stages of their celebration of Kaware, left their settlement at the beach to go on a pig hunt, a war party of allied neighbours took this opportunity to attack the village. This war party killed the older women and imprisoned the younger ones and children. Tipuka men were also killed or caught; they fled in all directions. The aftermath of the battle saw Tipukans scatter throughout the area; many are known to have been traded as far as Arguni Bay west of Mimika. Descendants of the imprisoned men and women can still be found in the Koperapoka, Wania and Kamora settlements. In my 1952 census of Tipuka only 130 inhabitants were registered. ${ }^{23}$

Significantly, my informants throughout Mimika attributed the joint, massive action against Tipuka not to political threats or violations of claims to 
sago groves but to anger at Tipuka men for having been careless in keeping Kaware secrets hidden. Because of the men's carelessness, these secrets came to the attention of female guests attending the Kaware ceremony. Even if this argument was used merely as a pretext, it does point to the supreme value attached to safeguarding sacred ritual. It is firmly believed by men and women alike that violation of ritual taboos endangers the society (and the status of males). In my discussion of Ema Kame I mentioned that fears for people's health were expressed because of the inclusion of a ceremonial play in a programme celebrating the Queen's Anniversary. And when the wives of my houseboys accidentally noticed the pointed bottom of a used spirit pole stored behind my house in Kaokonao, before I dispatched it to the National Museum of Ethnology at Leiden, their husbands were terrified and concerned about their wives' health. A specialist ritually cleansed these women by means of a spell. Finally, my informants in Ipiri and Yaraya criticized the performers of the spirit platform ritual in Kaokonao in 1954 (see Chapter V), for not sufficiently safeguarding secrets from women's curiosity.

For me as an observer, the reason stated for the massive attack on Tipuka around 1900 and the fears described to me in 1954 are just a few of many indications of the viability of the ritual cycle's function as the focus and as a totalizer of Kamoro society and culture.

Returning now to the carrying capacity of the physical environment, this forms a condition for a given group's manpower and political power. Going from northwest to southeast, the groups gain in strength. Even so, precisely in the far western part of Mimika where, due to a receding hinterland, wild and semi-cultivated sago stands are scarce, a politically powerful federation of settlements operated under the collective name of Tarya We around 1900. It included the fairly small settlements of Poraoka, Kipia, Maparpe, Wumuka and also Umar and Ayndua. They operated together in acquiring access to the sago stands of settlements east of them, down to Ipiri and Yaraya, often in exchange for seagoing canoes and with a show of power. Their 'big man' and ruthless, legendary warleader, considered the terror of Mimika, was Naowa, well known and feared, from Etna Bay to as far as Central Mimika. This situation seems to contradict the correlation between abundance of sago stands and power. So where did Naowa's power come from?

The lack of natural resources and the scarcity of manpower were compensated for by the fact that the Tarya We occupied a key position in the Etna Bay area in the acquisition of Western commodities in high demand, such as iron tools, cloth, and body ornaments. Manpower was supplemented by firepower through the acquisition of guns. A beach near Yaraya, west of Kaokonao, was named Minaki Tiri ('gun beach', Pouwer 1955a:222) in commemoration of an attack by a war party of Noawa, which killed locals with shotguns. 
By 1800 there was an Islamizing trade-centred network linking the western part of Mimika with the Onin Peninsula on the southern side of the Bird's Head. There were even direct links between the West Mimika coast and the Moluccan islands, interpreted by narratives in a Kamoro-centric way. ${ }^{24}$ Naowa was appointed raja by the Islamic merchant-raja of Namatote, who had relations with Seramese traders and officials, and in his turn empowered his cronies at various settlements in West Mimika by granting them a plethora of Moluccan titles. Kipia became a central location for Kamoro's increasing appetite for ironware, tobacco and clothing. Tipuka, Atuka, and the Koperapoka settlements in the far eastern part of Mimika traded women and children as prisoners of war (manuku) to Naowa and to Etna Bay traders. Kaimana had a Kamoro colony in the 1950s, originating from Kamoro slaves imported there. Naowa and his allies attacked parties from Central and East Mimika, travelling to the far western part of Mimika to acquire Western commodities. He took quite a few Kamoro people captive, even stealing their captives and freshly acquired ironware. Communities between Uta and Kaokonao fled temporarily to the eastern Wania region, when Naowa treacherously attacked them after a ceremony of reconciliation (Pouwer 1955a:222-3). Islamic commercial expansion, via the emergent Tarya We's political affiliation, came to an end with the gradual establishment of colonial rule and the arrival of Chinese traders and the Roman Catholic Mission in its footsteps. Even so, in the 1950s I noticed some survivals of Moluccan-Islamic influence in West and Central Mimika. Village elders still claimed Moluccan titles such as raja, mayor and hakim. They had a predilection for wearing a topi by way of turban, and had at least the stated intention not to eat pork (Pouwer 1955a:255).

One may conclude from this comparative analysis of political affiliations that three cultural configurations - Central Asmat, Central and East Kamoro, and far-west Kamoro - have many traits in common, yet differ significantly in dominant orientation: they are similar yet different. It is obvious that natural resources and history (wars, migrations and trading) played their part in the emergence and differentiation of these orientations in a dialectics of the existential with the symbolic dimension of the social formation.

\section{Pervasiveness of dual organization}

Most of the multiple modalities of dual organization were discussed in the previous chapter. Bipartition also underlies the organization of Kamoro, Sempan and Asmat rituals, including the organization of the guild of drum- 
mers and singers. Rituals and drumming are used first in performances of the 'right' (Kamoro: mbaowooko) party or person, followed by performances of the counterpart (Kamoro: aopao), the 'left' (Kamoro: pakare) party. 'Right' usually relates to 'left' as root/bottom to branch/surface, on the analogy of a tree. 'Bottom' stands for origin or prior entitlement, 'surface' for derived or secondary entitlement. This also holds for Sempan and Asmat. The relationship between the two parties, though asymmetric and characterized by competition, is basically one of repetition and of complementarity. The Kamoro even conceive of the human body as a complementary duality; significantly, the right part is associated with the mother, the left part with the father.

Although the division by gender seems commonplace and universal, it must, just like sexuality, 'be analyzed as part of a whole, contextual, social tradition'. ${ }^{25}$ This is strikingly apparent from the Kamoro division of rituals into 'female' and 'male' ones, as discussed in Chapters II and III. Gender functions as a pervasive ritual totalizer. Among the Asmat such a division is not as explicit, but is nevertheless present. The location of all rituals, except Emak Cem, the counterpart of Kamoro 'female' Ema Kame, is the men's house. Emak Cem is the only ritual with a ceremonial house (cem) of its own. Its origin, as well as the origin of the wuramun or uramun, the spirit canoe, on top of which the Emak Cem initiation of male adolescents takes place, are attributed to the two crucial culture-hero brothers (or cousins) Kurap and Sarawap. They built the first-ever ceremonial house according to the instructions of their two mothers, who relate as sisters and are represented as snake women (ancestral mothers). In the upstream Kapi version these women even build the house themselves. Furthermore, two female dignitaries unveil the spirit canoe when the ritual is performed; they, not the men, also lift it up at the start of the initiation. ${ }^{26}$ Yet 'male' rituals dominate among the Asmat, whereas 'female' ones are preponderant among the Kamoro and Sempan. Asmat 'male' stands for virility, Kamoro 'female' for production, reproduction, and fertility.

Male and female status, though obviously a component of the broader socio-cultural division by gender, deserves a separate discussion. In this discussion I follow Knauft (1993:86-116), Herdt (1984:66), Feil (1987:170) and Sanday (1981), considering female status as reflected in: 1. women's sexual and marital choices; 2 . female acquisition of and control over culturally valued property; 3. female participation in public affairs and ritual celebrations; 4. incidence of female pollution and images of women; and 5. incidence of wifebeating and domestic violence.

Unmarried Kamoro women are very active in arranging secret meetings 
with men in the sago areas using verbal and body language, directly and often indirectly. To what extent these secret meetings lead to betrothal and marriage is, however, decided by the relatives of the romantic couple. The young man and young woman do have a say in the decision though. Nevertheless, since marriage is a social event requiring sister exchange, preferred as the ideally 'right' marriage to a 'left' marriage by brideprice, individual sexual or marital choice is overshadowed by considerations emanating from the relation between bride-giver and bride-taker. Romantic choice and marital choice may sometimes correspond, but often clash. There are three socially condoned traditional ways out. First, marriage by elopement; this is not common since, after the act, it requires a good deal of bargaining and personal strength. Second, conceding to an arranged marriage, but combining it with a marakoma relation; lovers' relations are very common and are often a public secret. Marriage by brideprice without sister exchange is a third option. Since access to commodities greatly improved, first by early trading in West Mimika and then by migrant labour, 'left' indirect exchange by brideprice (which allows for more individual choice) has gained in frequency, according to my census data. However, the superior position of the bride-giving party, irrespective of 'right' or 'left' marriage, implies that a married man, especially if young, is at a disadvantage vis-à-vis his bride-givers. This also reflects on his relationship with his wife, the more so since there is no end to a man's obligations to render labour, services and gifts to his bride-givers (though to some extent the bride-givers return the favours). If a married man performs well in fulfilling his obligations, the wife's relatives are reluctant to interfere in domestic arguments, violence, and wife-beating, which do occur. Fairly often, though, interference and beating are a matter of public theatrical performance, rather than reality. I have also observed that wives use the options of withholding their domestic and sexual services, extinguishing the domestic fireplace as a sign of protest, or taking refuge with relatives. Older women are often strong-willed and make a lot of fuss, causing roars of laughter.

Asmat attitudes towards marriage are roughly similar. Asmat women, however, are under the authority of their brothers; brothers are the most important people for any adult person (Eyde 1967:211-303). An unmarried woman could be beaten by her father or her brothers for promiscuity (Eyde 1967:22). The fairly high number of marriages by elopement (worowos) in Zegwaard's 1953 case study of Shuru - 48 out of 102 marriages (Zegwaard and Boelaars 1970:21) - can be interpreted as a way to escape from severe constraints. Marriage by elopement is surely not so common in Mimika, where a woman's choice carries more weight. It is interesting to note that one of the Asmat myths about the mbish, the spirit statues, ascribes its origin to a culture-hero-in-love who carves in wood his beloved wife in order to commemorate her during her absence 
or after her death. ${ }^{27}$ Women are drawn to aggressive men renowned for their fierceness and their success in headhunting. Although a man may marry without having successfully participated in a man-hunt, he may be scolded by his wife as a 'bit of meat' (nas minu), a man without spirit or courage, whenever she gets fed up with him (Zegwaard 1959:1040). It is small wonder then, that, given the preference for male aggression, wife-beating is quite common, without intervention of her brothers (Eyde 1967:192). Marriage by bride-stealing (okore, 'stealing') against her will is reported in Zegwaard's 1952 sample (8 out of 102 marriages, Zegwaard and Boelaars 1970:21). This results in a terrible fight between the two families. Abduction of wives without repayment is described as rampant (Sowada 1961:87). I suspect that bride-stealing was occasionally practised by the Kamoro, but evidence is meagre, and such practices rarely occur in narratives. Marrying women captured in warfare did occur.

An Asmat man is prone to extend his relational network by simultaneous polygyny. This gives him access to women's labour, and to their sago groves, for the benefit of the logistics of warfare and mass food distribution. In Zegwaard's Shuru case study, there were 17 polygynous marriages compared to 59 monogamous ones. The number of wives ranged from two to six. Zegwaard even knows of a 'big man' in Amborep who had 17 wives (Zegwaard and Boelaars 1970:18-9). Second wives 'may be little more than drudges' (Eyde 1967:194). They have no direct access to their husband and are controlled by his first and main wife. So there is some ironic dialectics in women being drawn to aggressive men and polygynous leaders. Polygyny in Mimika is far less frequent and usually restricted to two wives, since the Kamoro female workforce is not connected with endemic warfare and headhunting. On the other hand, at least in one universally known myth, dramatized in Ema Kame ritual, women act as warriors, though dressed up and armed as male combatants - an ambivalent reversal of roles. ${ }^{28}$ The superior 'women of the beginning' rebel against the men who enjoy themselves for ages in the ceremonial nosepiercing house, secretly keeping the delicious food, such as fruits and pieces of fatty meat, for themselves, fobbing the women off with inferior food and having them collect sago and shellfish in a dreary routine. The outraged women wage war, kill a lot of men, abandon them, and depart for the far western part of Mimika, passing over the foothills. They are said to be the ancestresses of white foreigners. The abandoned men initially have to make do with boys and shoots of bamboo impersonating wives, but are then united with anthropomorphic female animals of the forest, the ancestresses of the present race. The superior 'women of the beginning' are lost forever. 
One narrative (see Chapter I) is acted out in a ritual performed to ward off the dreaded danger of men being turned into women and burdened with the care of toddlers, as punishment for not properly looking after a wife who dies in labour. In this ritual, still practised in the 1950s after the death of a woman in labour, male actors, dressed up as the deceased mother and her female assistant, attack a man acting as the careless husband, and his companions..$^{29}$ These two narratives and associated rituals have not been reported for the Asmat. However, Asmat men do consider women who die in labour to be a real threat. Their spirits are known as dambir ow, with frightening looks, a sharp nose, sharp teeth, long nails, and eyes as red as their hair. They take revenge on men by carrying them to the underworld, where they torture them to death with thorns (Sowada 1995a:70).

Extension of Asmat men's relational network by means of papish, that is, establishing bonds between men by institutionalized wife swapping, is discussed in Chapter XI. It does not occur among the Kamoro.

As for acquisition of and control over valued property, Kamoro women clearly have a powerful position. Wild sago groves, in as far as they are collectively owned, belong to specified peraeko, represented in public affairs by an older brother and his real or putative younger brother. However, the female members of the group must be consulted and they have an important say in the exploitation of the groves and in allowing non-members access to these. At home the female head of the household controls the sago bag or sago container: her children must seek her permission and her husband must notify her when they wish to draw on the sago supply. Although a man officially owns the canoe, his wife controls its actual use. Men explain the woman's power over the canoe by pointing out that it is she who uses the canoe to transport the children and mats for roofing, sitting, and sleeping in the temporary huts near fishing and sago grounds. It is mainly a woman's job to pound sago, collect shellfish, and prepare food, but this applies equally to the Asmat. The gear for pounding sago, though partly made by men, is the property of women. Although men own axes and machetes, women have an important say in their use, for they collect and carry wood to burn in the fireplace. A man carrying wood on his back would make a fool of himself. Pandanus trees for matting and other uses are owned by women. They also have control of the many named tidal creeks (enata) fenced off by them, an important source of fish. ${ }^{30}$ Even exclusively male property, such as drums, cannot or at least should not be disposed of without consulting older females.

Information about Asmat female property rights is sketchy. Central Asmat

29 For details of the narrative and the ritual, see Offenberg and Pouwer 2002:148-50, and Pouwer 1987:36-8.

30 For detailed information about property, see Pouwer 1955a:146-51. 
call the husbands, not the wives, the owners (ar arat ow) of sago or fishing areas to which they have gained rights by marriage. Just as a sister is given to her husband, so are her sago paths and fishing areas. ${ }^{31}$ The ceremonial names given to women usually do not derive from their own, but from their husband's kin group. Women could, however, inherit rights to important song cycles. ${ }^{32}$

As for female participation in public affairs and ritual celebrations, Asmat women's part in rituals is not as complementary and integral as among the Kamoro. Among both Kamoro and Asmat, older women can sit in on male public discussions and raise objections.

As for the incidence of female pollution, both Kamoro and Asmat men steer free of menstruating women and women in childbirth, considering these to be women's secrets, ${ }^{33}$ but fear of pollution does not seem to be explicit. Asmat men attribute sorcery exclusively to women (Knauft 1993:101) and 'generally assume that women are hostile to them' (Eyde 1967:147). Kamoro men do not. In both societies, antagonism between the sexes is playfully but aggressively acted out in horseplay (Kamoro: akapa; Asmat: akap, 'laughing, joking'). However, one should distinguish between the horseplay and joking practised by bride-givers and bride-receivers on the one hand, and that between groups of males and females on the other. The latter is named imu by Kamoro as well as Asmat. Both kinds of joking, often going together, are part and parcel of rituals. ${ }^{34}$

\section{Cosmology}

The Kamoro and the Asmat share a dualistic representation of the universe that distinguishes between the complementary opposites of upper world and underworld (Asmat: safan). Its conceptualization is anthropomorphic though not anthropocentric. Humans share life with their natural environment in an intricate system of classifications, differentiated and united by the principle of ipu enakoa, as described by Coenen (1963:22-59, in particular pp. 32-3, 36-9, 43-8). This principle enables its believers to pull the strings of the universe, to manipulate the system of connections between phenomena to their own advantage. They do so in everyday life, for instance in their healing practices, but in particular by means of rituals, as described for the Kamoro in Part One. There is a difference, though, between Kamoro and Asmat: the Kamoro manipulate the system with special emphasis on livelihood, fertility and 
health, whereas the Asmat do so specifically for the sake of warfare and selfdefence. This difference corresponds with a difference in cultural orientation, as pointed out in this chapter.

Man-in-his-natural-environment is encircled and encapsulated by the complementary opposites of upper world and underworld. The landscape of the underworld is viewed as similar to the world where humans live, except that the underworld has paradisal abundance and marvellous beaches. The dead are in the underworld, in locations similar to settlements of living humans in the world-in-between. When humans die, their souls travel upstream, follow the foot of the mountains, and descend to the underworld along the pathway of the sun.

The upper world beyond the mountains and the clouds is primarily the seat of the aloof and respectable hero of the sun, Kumurupi (Kamoro) or Anemar Ipic (Zegwaard n.y.c, n.y.d), and addressed - at least by the Kamoro - by the kinship term noopa (grandfather), expressing both respect and familiarity. His bride-receivers, that is, his daughters' and sisters' husbands, the mythical sun people (yao we), live on the borders of the upper world in the far eastern and far western parts of Mimika, on the other side of a wide river and the sea, where the sun sets. The culture hero, carrying the sun as a torch, ascends to and descends from the firmament on the shoulders of his bridereceivers. These move the sun from east to west with ropes (rays), and assist the culture hero when he travels by canoe (or motor car, in a modern version) through the underworld from west to east in order to rise again in the morning. The hero of the sun takes pride of place in Kamoro and Asmat cosmology. In Mimika the sun dance and sun ritual at sunrise mark a sacred moment. The sun dignitary directs wild pigs to the bait. The fish dignitary invokes the sun, addressing him as The Old Man. The sago dignitary asks the sun to shine on sago palms in order to promote growth. In the 'banner' (or 'wing') of the Kamoro and Asmat spirit pole, a round, open hole represents the 'house of the father', the seat of the sun. The hero of the sun is invoked as a solemn witness when lifting food taboos. The sun is said to be the war leader, according to Coenen. After the taboo on drinking water is lifted, young initiates pour out water for the sun. Coenen rightly considers the hero of the sun to be a primus inter pares, rather than a supreme being or high god. A sun cult does not exist (Coenen 1963:83-4; Pouwer 2002:33-4). The hero of the moon, Paotaru (Kamoro) or Manma-tiw-nakap (literally 'the orphan boy', Asmat), also resides in the upper world.

In addition to these beneficial beings, there also live frightful characters in the upper world, such as the two initially terrestrial daughters of the culture hero of the sun, who suspected him of killing their mother and withheld food from him. Heavy wind, rain and thunder are ascribed to these women, as aopao for the exploits of their father (Kamoro version). In the song of the 
clouds (Onam So), performed shortly before Asmat men depart for an attack, a large number of deformed, malevolent and aggressive anthropomorphic or zoomorphic beings are enumerated. They embitter men's life (Zegwaard 1959:1034). Good and bad, like the upper world and the underworld, are complementary opposites. The abode of man-in-nature is an ambivalent betwixtand-between, a corridor, a passageway between the upper and lower worlds. Its heroes have a dual status with respect to the heroes of the universe. Witness the recurrent feature of mythical, terrestrially oriented culture heroes who, as namesakes of upperworld characters, provide the human world with the rotation of the sun and the moon, with rivers, sago, fire, hunting dogs, Western commodities, and iron tools, all associated with the sun and acquired, often by deceit or by accident, from an oblivious upper world or spirits associated with it. ${ }^{35}$ Witness also the tricky acquisition from the underworld of a ceremonial house, yew mopan (Asmat) or kaware (Kamoro), with its astonishing set of paraphernalia, adornments, and garden produce. ${ }^{36}$ In these respects, earthbound heroes and tricksters are clearly superior to their ignorant namesakes in both the upper and the lower worlds. The rotation of the sun is an invention of the terrestrial trickster, not of its upperworld owner. Likewise, the rotation of the moon is ascribed in Kamoro and Asmat versions of the moon myth to a terrestrial orphan boy who, neglected and distrusted by his relatives, discovers the moon in a basket while stealing food (Kamoro), or creates the moon himself (Asmat), and then takes it to the firmament. ${ }^{37}$ Another Kamoro version ascribes the discovery of the moon to illicit terrestrial behaviour of a sister's son towards his mother's brother (Offenberg and Pouwer 2002:78-80). The underworld proprietor of the ceremonial house and its attributes behaves in the Asmat version as a dummy; he rates as an inferior, unfinished male. The Asmat tend to ascribe the 'furnishing' of the human world to mere imitation of superior examples furnished by upperworld heroes. ${ }^{38}$ The in-between situation of the human abode in a spatial sense is graphically expressed by a striking metaphor which David Eyde came across by chance and communicated to the linguist Voorhoeve:

the territory they inhabit, the Asmat capinmi, is enclosed within, and lies at the bottom of, a gigantic coconut: their world is not convex but concave. The boundaries of their world correspond roughly to those of their language area: between the Casuarinen Coast and the Mimika Coast. And one can do the 'journey round the world' by setting out from the Casuarinen Coast, landing there, and then returning [overland] to the Casuarinen Coast. Through the middle of this world flows

See Chapter III, and see the narratives in Offenberg and Pouwer 2002:98-108.

Pouwer 2002:34-6; Offenberg and Pouwer 2002:76-8.

For an example, see Offenberg and Pouwer 2002:108-11. 
the great River Sirec, rising far away, somewhere at the top of the coconut, close to the holy entrance to the upper world. From this opening, in prehistoric times the heavenly beings descended to earth, in order to populate the world with their descendants. (Voorhoeve 1965:3.)

Such a 'heavenly being' is Baitshepsimit (literally the big Baitshep), an enormous androgynous pig, the size of a cow, reared by Manifuk, a supernatural being who lives in the upper world above the clouds on top of the mountains. There is a striking parallel with the primeval pig of the Yali people, a Dani exonym of their highland neighbours east of the Grand (Baliem) Valley. In versions of a central myth, specified rivers, sacred men's houses, and men themselves divided into clans, emerged from a partition of the huge pig at her own request by her son, or were shot by another male culture hero (Zöllner 1988:19, 173-4).

The central Asmat mythical pig has many children: Naneu and Kamkai born from the uterus, Kayir, Kaimes, Yepem, Owus, Sunu and Yaun born from her side or thigh; Ewer, her future son-in-law, is also born from her side or thigh. These are the founders of the yew of Island River and Flamingo Bay, named after them, the Bismam people. One day Ewer, the son-in-law, mistakes his father-in-law for a wild pig, shoots at him in vain, and runs him (or her) down, a capital though unwitting offence. Baitshep removes taro plants and liana and creeps into the hole beneath. He crashes down and down and arrives on the earth near the source of the Island River (Sirec). The noise of the 'earthquake' frightens a number of named, dismal, deformed, inferior men who thereafter stay behind in the upper world. [Compare this to the dismal daughters of the hero of the sun in the Kamoro version and the malevolent anti-human beings in the Asmat ritual song of the clouds.] Below, Baitshep meets Kaimes and Yepem, two of his sons. His other sons, in the upper world, follow his trail, remove the taro and liana put back by him, enter the hole, and are united with their father. Since the huge androgynous pig is far too heavy to climb back to the upper world, the party decide to move on downstream. They settle there. Baitshep teaches them how to attack their enemies, the people already living there: he bares his teeth and growls, and this has been imitated by his descendants during attacks ever since. He teaches his sons to beat the water with their paddles, creating big waves shaped like Baitshep's tusks so that the enemies' canoes will capsize. Baitshep ever since has accompanied them, hanging upside down from the stern of the canoe, his head and tusks facing forwards, thus adding to the size of the waves. ${ }^{39}$ The details of this story are characteristic of the aggressive, headhunting stance of the Asmat 
invaders, whose ancestors - in view of the pig parallel - seem to originate from the highlands.

The Sirec River connects the upper world with the sea. The sea is sometimes represented as a mere tributary of the Sirec, so that one can travel full circle through the human world, and return to its headwaters.

It seems significant that narratives about the origin of named ancestors of localized descent groups are lacking among the Kamoro. Their great trek from southwest to northeast, begun by the warlords and culture heroes Aoweyao and Mbiminareyao, was made by localized descent groups and descent groups not named after ancestors.

All Kamoro and Asmat narratives have one outstanding feature in common: the route of the human (or superhuman) creative beings to and from the upper world and underworld is not paved by good intentions but by anti-social behaviour, such as adultery, incest, theft, suspicion of murder, lack of respect, destruction or loss of property, excessive requests, or failing badly in reciprocity. It is this anti-social behaviour, committed either by them or by their fellow men, which drives them out and forces them to discover other spheres and cultural valuables crucial to human life. Again, in Asmat and Kamoro cosmology, good and evil are complementary. 


\section{Chapter viI \\ Ema Kame and Emak Cem}

\section{Ema Kame/Emak Cem and myth}

The Kamoro, the inland Nafuaripi (related to the Kamoro Sempanowe), and the inland Asmat all celebrate Ema Kame, called Emak Cem or Embakter (Yamas) by the Asmat and Imake by the Nafuaripi. From inland Northwest Asmat the ceremony spread to downstream settlements, but coastal settlements, such as Ewer, Shuru and Ayam, do not celebrate it. Nafuaripi information is almost lacking and Asmat information is sketchy. Yet documented similarities and differences are so explicit that it makes comparison with the Kamoro worthwhile. To what extent is Asmat Emak Cem just as much a 'female' contribution to life as Kamoro Ema Kame? What stands out about Kamoro Ema Kame is the promotion of fertility of man and his habitat (see Part One). Is this also the case with Asmat Emak Cem?

Fertility clearly has to do with reproduction and social reproduction. It is significant that Kamoro and Asmat narratives explicitly associated with Ema Kame/Emak Cem, whether in the text or by informants, irrespective of their diversity, have in common that they clearly address an almost universal logical paradox inherent to (social) reproduction, as succinctly formulated by Claude Lévi-Strauss (1968:217): how can one be born from two? In other words, how is it possible to bridge the gap between being born out of one yet born from two, which comes down to the gap between kinship and marriage? I have already discussed this paradox in a comparison of eastern Bird's Head narratives (Pouwer 1999:467-86). Here I tackle it again in the Kamoro-Asmat setting, by comparing summaries of relevant passages of Kamoro and Asmat myths, all but one of which are explicitly related to Ema Kame/Emak Cem. The stories are arranged from northeast to southwest (and back again), in accordance with the dominant direction of movements in Kamoro and Asmat narratives, in addition to the upstream/downstream movement.

M1 Ufiripic and his daughters. ${ }^{1}$ Informant Yufentias Biakai, museum cura- 
tor, from Yamas, post-1962. This version is the most elaborate of all versions documented by Zegwaard and Voorhoeve prior to 1963.

On the upper reaches of the Ayip River, in the far eastern part of Mimika, are two spirit women, who live in the aerial roots of a big waringin tree and can take on the form of a body whenever they choose. A human man, Ufiripic (king-parrot man), lives by himself in the same area. Going off one day to shoot birds, he discovers two red parakeets at the top of a sago palm. He wants their beautiful feathers, but does not know that the two birds are embodiments of the spirit women. He creeps up stealthily, but the parakeets hear him coming and fly away to the waringin tree. On passing this tree Ufiripic is attacked by the birds. They peck him on the right forearm [or on both arms, in another version]. The $\operatorname{arm}(\mathrm{s}) \operatorname{start}(\mathrm{s})$ to swell. In a dream the two spirit women then tell him that they have penetrated his $\operatorname{arm}(\mathrm{s})$; they tell him their names and instruct him to cut open his swollen $\operatorname{arm}(\mathrm{s})$. He does so the next morning with a mussel shell: Omarawoc and Dafarawoc are born. The girls grow up quickly, as culture heroes usually do, and turn into beautiful women. The father-parrot-man feels a growing desire inside his belly to have sex with them, but he realizes his daughters would not want it. So he resorts to a trick. Secretly he makes a bes, a shortcut by land connecting the upstream and downstream parts of the winding river. At the end of the shortcut he builds a house, near the junction of the Ayip and Bec Rivers (see Map 3). He returns to his daughters and then feigns illness and pretends to be dying. He instructs his tearful daughters to wrap his body in an old mat after his death (but not too tightly), to place it on a platform (but not too high), to remove everything from the house, and walk downstream along the river bank, where they will notice a house, said to be the dwelling of his younger brother who is his spitting image. So it happens. Meanwhile their father, after playing dead, rushes to the house via the shortcut and meets his daughters as their 'father's younger brother'. After lamenting and observing a period of mourning, the 'younger brother' tries to win the favour of his 'elder brother's daughters' by hunting pigs and by so doing to cajole them into marriage. He talks his 'brother's elder daughter' into hunting with him and then has sex with her. She persuades her younger sister to follow her example, but the latter, though seemingly giving in, remains suspicious. The sisters beget two boys, Kurap and Sarawap (ap is a diminutive). One day, when the father is looking after the babies while his wives are pounding sago in the forest, the younger sister, returning to replace the broken head of her sago pounder, overhears the father lulling her baby boy to sleep saying: 'I begat you, I took care of you, you are my son and grandson.' Now she knows the truth, tells her sister in anger, and has a row with her. The two are so ashamed that they decide to 
trick their father - as he tricked them - into a fishing basket, which he dives right into when bathing in the river. He manages to surface but to no avail: they refuse to rescue him. Before sinking back into the water and turning into a big $m b u$, or river turtle, he says to the women: 'Because you have done this to me, you must leave, go westwards tomorrow. You must row close to the coast and the river mouths. I will make you a canoe from the bark of a sago palm.' So it happens. The Asmat -o-we (people) have called him mbu cesar ever since, the sacred turtle, or cesar pok, the sacred animal resting on the bottom of the river, near the confluence of the Ayip and the Bec. Today Ufiripic is still the master and guardian of the spot. [Shuru has a similar guardian turtle.]

There is a partial similarity between - and an inversion of - this myth and the Kamoro narrative about the widower Nokoro and his two daughters (see Chapter III, myth 3) dramatized in Kaware. Nokoro is considered the 'father' of river-going canoes and of carvings. A model of his canoe is produced during the Kaware ritual, while a model of the two sisters' canoe takes pride of place in the Asmat Emak Cem ritual. Kurap and Sarawap and their mothers are generally acknowledged by the Asmat to be the founders and initiators of Emak Cem (see M7 below).

M2 Cic and the first woman. (This myth is not explicitly connected with Emak Cem, but there is an implicit link; see below.) Told to G. Zegwaard by the war leader Warsekomen in Shuru, Asmat, 23 September 1953. Shuru does not celebrate Emak Cem. ${ }^{2}$

Deep in the interior, deep in the forest, lives Tewerawoc [this name is identical to the name of the younger sister Dafarawoc in M1, in a different dialect]. She lives completely alone among the roots of a waringin tree. [This indicates she is a spirit woman.] She is pregnant, gives birth to a boy, and calls him Cic [rippling water, connoting the sea]. The baby grows fast and keeps on crawling indoors, downstream, upstream, and the other way round. One day when his mother goes to the forest to collect food, he repeats the crawling circle but then outside. Cic continues to grow rapidly [which marks him as a culture hero]. He keeps on asking: 'Is there only land? Is there no water, is there no river? Are there no people?' His alarmed mother flatly denies it: 'I am a tree-trunk woman, and you are a tree-trunk boy.' Next time when he is alone, he puts on all sorts of decorations, climbs the waringin tree to its top, and then discovers to his utmost astonishment, downstream behind the forest, a large expanse of water, a very wide river [the sea]. His mother 
hides her terror, but gives in: she digs a little channel and gives him a small canoe to play with. He performs magic on the tree so that it grows into the sky, enabling him to have a grand view, which confirms his discovery. Although his mother holds back, she can no longer resist him. She catches a python, chops off its head, and places it in the small channel, instructing the creature to turn the channel into a river. A heavy storm breaks out, the river is created, and the toy canoe becomes a real one. Not listening to his mother's grumblings, the boy names the river Ewec [compare the Asewec River of Shuru], puts on all his ornaments, and gets into the canoe with his mother. In utter joy he reaches the sea. He then keeps on killing one crocodile after the other [instead of the fish that his mother asks for]. His mother, realizing that her son has grown up but that there are no women to provide him with a wife, makes a big bag of pandanus root fibres [a typical female attribute, for carrying wood or a baby on her back], adds an apron and an oar to it, puts the bag in a rain mat, slides it under the floor mat, and orders the bag: 'You must become a human woman, put on the apron, and keep the oar within easy reach. For the time being you must hide yourself from Cic.' That night Cic goes off to catch perch and pike [instead of crocodiles] but does not have any luck. Turning his canoe to go home, he is startled, perceiving a beautiful woman coming his way. Cic asks: 'Are you a treespirit woman?' The reply of the bag-turned-woman is: 'No, I am a kawenak, a human woman.' Cic gets excited, proposes going home, but on the way home he can't wait any longer and tries to have sex with her. However, he does not manage to pierce her hymen. His penis hurts, swells and cracks, like the bark of pandanus roots. A puddle of water, semen and blood forms on the ground. Cic then orders the pandanus: 'Stand in the water with a cracked and lumpy bark as a permanent reminder of my failure.' His wise mother intervenes and tells him that the hymen has to be opened first. While mother and son are asleep, the woman pierces her hymen, creeps up and says: 'I am so cold. Now I am ready for you.' Cic tries again, but his penis has not yet recovered. The woman says: 'Let us wait until the wounds are healed.' And so it happens. [In the Kamoro myth about the rebelling superwomen, associated with Ema Kame, they provide a man with the red sap of a tree in order to have satisfactory intercourse.]

M3 Totepere. Recorded by G. Zegwaard and presented by him in summary form. The informant Mepe, of Koperapoka (in the far eastern part of Mimika), insists that this is the original and genuine Kiawa (Ema Kame) myth instead of the universally known Kamoro myth of Mirokoatayao (M4). ${ }^{3}$ 
Totepere, the wife of Naakawe, has an affair with her husband's younger brother. One of her children is a silent witness to this. When he and his brothers and sisters secretly eat up the tasty sago grubs his mother has ordered them to take to their father, the boy realizes that his secret will be found out. In order to avoid punishment, the young man tells his father about his mother's affair. His father orders him to keep silent. At night when the whole village is asleep, including his wife, he chops off her arms and legs [her name Totepere literally means shoulder stumps], carries her to a canoe previously made ready by him and provided with fire-making tools and sago, casts the canoe loose, and lets it drift downstream. When Totepere, pregnant by her lover, arrives downstream, on the other side of the world [underworld], she manages to give birth to a son and calls him Totepere-yao, 'son of Totepere'. He grows up rapidly, and in the sand he draws iron equipment, such as a machete, an axe, a fishing spear, a lance, a frying pan, a spoon, and a house with a zinc roof. He goes to sleep, and when he awakes the house and the equipment have emerged from the drawings. He goes further west, discovers a coconut palm [in the underworld], and climbs it. Its owner, an old man with a swollen belly, notices the stranger and also climbs the tree, but then upside down. His anus is blocked up. Totepereyao sees him coming, and pierces his anus. The fat man moans and groans and the contents of his intestines spray out. Grateful for this operation, he offers his benefactor one of his two wives. [In other versions, collected by Drabbe in Mapar, West Mimika, he is credited with the manufacture of iron tools and is apparently in possession of textile and metal ornaments. He and the young man are namesakes, like the culture heroes of the sun and the moon (Drabbe 1947-50:165-9). Totepereyao leaves with the newly acquired woman, but when out of sight he stabs her to death, chops off her arms and legs, wraps them in a mat, goes home, hides the mat, and feeds his mother [who can't feed herself]. At night he wakes her up and - surprise, surprise - attaches the new arms and legs to his mother's stumps. His mother is overjoyed, stirs up the fire, cooks sago, pulls her son towards her, and states solemnly (imakatiri): 'From now on I am no longer your mother but your wife.' Next, she gives him clear instructions on how to have sex with her. [Apparently he does not know.] She gives him tobacco [an erotic gift] and praises his penis [a common compliment].

[The young man in Drabbe's stories, who is said to have a mother without feet and anus, finds a red parrot in one of the boxes of the old blacksmith whose anus was pierced. He cuts the bird into pieces, which turn into a multitude of men. Compare Asmat Ufiripic, the king parrot of M1.]

In a strikingly similar Asmat version of this myth, recorded by Baudhuin in Ewer in 1996 (Baudhuin, Firkoman and Capu 1996:144-52), the son replaces the body parts of his maimed mother with those of a huge lizard [the monstrous monitor lizard of M4?]. However, the transformation from incest to 
marriage is lacking in this version, or possibly it was suppressed by the storyteller. Instead, in a typical Asmat vein, the son takes revenge by killing off the people of his father's village except for one woman, whom he marries.

\section{M4 Mirokoatayao and the crocodile (or monitor lizard). Recorded by Zegwaard} in 1950-1952, and by Pouwer in 1952-1954 in numerous local versions throughout West and Central Mimika (Pouwer 1954). The present elaborate, lyrical and consistent version was recorded by Zegwaard in Mikiwia, Central Mimika. ${ }^{4}$ The story is referred to in Chapter II. The name of the hero varies. Monitor lizards (yok) do occur in this area.

A crocodile born from an egg hatched by children in a settlement near the shore of Pura (west of Potoway, in the far western part of Mimika, close to Etna Bay, where the mountains descend into the sea) matures at an incredible rate. It gobbles up the children, the old, and the infirm, who had remained behind while the adults went upstream to pound sago. In an ambush it attacks the people when they return in their canoes. It swallows everybody except a pregnant woman, Mirokoata (miroko means python), who narrowly escapes. The crocodile is carried downstream and sleeps on Pura beach. His body is swollen from all the people he has eaten. He lets out a tremendous fart: $p u-p u$ (the sound of a ship's horn). At a good distance from the shore and the crocodile, the woman builds a birth hut and gives birth to a boy she calls Mirokoata-yao, 'son of Mirokoata'. The boy, a culture hero, grows up rapidly. He goes hunting for all sorts of birds and animals. His mother teaches him the names and what animals are good to eat or should not be eaten (such as the tree lizard, related to the crocodile, or monitor lizard). The son [like Cic in M2] yearns for the sea, in spite of his mother's warnings. He heads for the forbidden area and brings home fish, turtle eggs, and some sand and leaves. His mother, hearing the sound of the crocodile, is very angry with him but finally agrees to move to the shore. Terrified by the noise of the monster, she tells her son what happened. He is not alarmed and draws the outline of a house in the sand. A moment later the house is standing there, fully furnished. Without telling his mother, he thinks up a plan to kill the monster: he draws in the sand the outlines of an Ema Kame house, a pig house, a nose-piercing house, a Kaware house, an apron house, a semi-permanent house, and a temporary hut. He ends up with another Ema Kame building. The houses immediately materialize, in one row, in the order indicated and at right angles to the sea. A large quantity of iron tools and weapons hang from the ceilings, all positioned to fall and hit someone easily. Then he makes a big fire producing a lot of smoke, 
which penetrates the nostrils of the crocodile. Provoked by the smoke and the songs corresponding with the various types of ceremonial houses, the enraged crocodile enters one house after another. The weapons fall down and hit him. Exhausted, he enters the last house; this is the second Ema Kame house, which is extra strongly reinforced, with even heavier weapons. At the end of its tether, the crocodile is stabbed to death by the hero and his mother. Mirokoatayao starts to cut up the animal into pieces, sorting these by colour. The bones and skulls of the people swallowed are carefully removed and kept separate. It is a heavy job. The son therefore asks his mother for some tobacco, but, unfortunately, it has been eaten by the crocodile. The mother begins to flatter her son in an erotic way and invites him to have sex with her. The son says: 'We can't. You brought me into the world.' He scolds her: 'You with your red sex [vagina],' but finally he gives in with his face averted. Shortly after, the mother starts to bear successively: leaves to roll cigars in, strips of fibre used to bind the cigars, tobacco seeds, and finally tobacco leaves themselves. She makes three packages [apparently including one for her future husband]. The astonished son finally understands, approves of the tobacco, and rolls a cigar. Then the mother makes a solemn prediction (imakatiri): 'From now on, the sons and brothers will feed the children in the wombs of their mothers and sisters. That is, they will feed their semen into the womb before birth so that the foetus grows, just as the mother gives her baby the breast after birth. ${ }^{5}$

The pieces of meat turn into groups of people, the varieties of mankind, increasingly specified in subsequent versions of the narrative. The hero takes two beautiful women for himself and a perfect husband for his mother.

The story clearly denotes and connotes the transformation from kinship into sexual intercourse and marriage, and the part played by female and male partners in the conception of a child. Compare this with the incestuous intercourse of M3, which also includes the gift of tobacco.

M5 The python and Mirokoatayao. Recorded by Zegwaard, 1952. Informant Kapitan Tay, village chief of Keawkwa, Central Mimika, a noted and intelligent expert on traditions. ${ }^{6}$ According to the informant, this story comes from the ancestors of the Kamoro, who during the great trek moved from Minar in the Asmat region to Mimika. He considers this the eastern version of the Mirokoatayao story (M4). Keawkwa has close links with eastern Kamoro settlements.

5 See Zegwaard in Offenberg and Pouwer 2002:126, 186, note 22, although he switches from sons and brothers to husbands, without explaining himself.

$6 \quad$ For the full text, see Offenberg and Pouwer 2002:127-9. 
A group of sisters, the Muyaropo-ayti (sisters), living in the east, go to beat sago. They take the son of the eldest sister with them, a young lad called Muyaruru. After selecting, chopping down, and stripping a good sago palm, each sister is allocated a piece of the trunk in order of seniority, the eldest one getting the lowest and thickest part. While at work they hear a rustling sound like the sound of the wind, travelling eastwards, getting closer and closer. The eldest sister sends her son to see what is going on. He climbs a tree. From there he reports that a big python (miroko) is approaching through the air. He thinks to himself that the monster might eat up his mother (or mothers). But he is struck dumb and so his mother and her sisters are taken completely by surprise: the monster indeed swallows them (in order of seniority) and then goes to sleep. The lad ventures to climb down, and steps on the python, which addresses him by saying: 'Sit on my back.' At first the boy is frightened, but in the end he does what is asked. The python says: 'Show me the way to your home.' They arrive at the entrance of the settlement. The python solemnly states: 'Son, from now on I am your mother and your [new] name is Mirokoatayao. Now you must kill me, but stab me in the right side [the part of the human body ascribed to the mother]. When I am dead, you must cut my body into pieces from the right side and the left [father's] side, and lay the pieces from the right side and the left side in separate piles. Keep the stomach and the liver for yourself.' The young man kills the python with a lance and cuts it up, and places the pieces in as many piles as there are villages, eight in all, and in geographical sequence according to the position of the various villages [unfortunately the informant did not specify them]. He hangs up two fatty pieces of the stomach and the liver in the house. During the night the bones and meat come to life [as in M4]. New people are created: men, women, young men, boys, and girls. One of the pieces of fat becomes a white woman. Some of the bones become canoes: the long slender ones become river-going ones, the stumpy bones seagoing ones. The stomach and liver change into (Western) commodities.

The similarities with and differences from M4 are obvious. The python is evidently a transformation of the pregnant woman Mirokoata of M4, and the young lad a transformation of Mirokoata's son. The striking difference is that in M5 the pregnant woman and the monster of M4 are one character. The son kills his mother instead of having intercourse with her, an act that might be conceived as symbolic incest. From her body parts the various groups of humans emerge. There are five Kamoro groups, each group carrying the same name as its village, plus a group of white people, descendants of a white woman. In addition, the two different local types of canoes, as well as Western commodities, emerge from the python, features that are missing in M4. 
There is another parallel to an Asmat myth (i atakam, dealing with culture heroes as distinct from tarai atakam, stories about ancestors) from Yamas, an important Emak Cem site (Zegwaard 1953-56, Kewa:176-8), which may be summarized as follows. Yokor, a man from the upper Sirec River, is swallowed by a python (pit) travelling from the inland, who discovers him while his three wives, daughters, younger sister, and nieces are pounding sago. His head sticks out of the python's mouth. The terrified women enlist the support of the villagers, but Yokor in his curious position dismisses them, except his friend Yimin and his sister Kane. He orders the two to follow the python on his way, moving from tree to tree in the direction of the coast. Each time the python slides to another tree, Yokor's protruding head hits the next tree. [The story names and specifies these trees, which grow between the inland and the coast.] The trip goes on for many days. Every night Yokor instructs his friend and sister to erect a shelter for passing the night, while the python rests in a tree. Yokor admonishes his friend repeatedly not only to prepare a sago meal but also to have intercourse with his sister. On the ninth day the party come in sight of the sea. That night Yokor tells them to prepare a solid shelter, because there will be a downpour of rain. The heavy rain induces the python to slide down. Its head, and consequently also Yokor's head, is now above the shelter and within reach of the heavily armed Yimin. Secretly instructed by Yokor, the latter shoots an arrow into the tail of the python, who then falls down and is cautiously cut open by him. Yokor is removed from the python's body. After drying in the sun, Yokor explicitly insists on Yimin having intercourse with his sister. [Thus far, in spite of his request, this had not happened.] Yokor witnesses the intercourse. He then inspects and approves of the land. He builds a permanent house. Kane's son moves to another site and so do his sons and daughters, and so on. In this way Kane became the mother of all Asmat people.

Note the active role of the male founder Yokor, in line with the patri-oriented descent of the Asmat. Further, in spite of explicitly initiated and ordered intercourse, there is neither incest nor 'incestuous' killing in this myth. The descendants do not originate from an incestuous relationship. The passage from kinship to marriage is mediated by friendship.

M6 The journey of Ufiripic's daughters and sons to the far west. Final part of M1. Except in Yamas and a related settlement, where this journey is presented as a punishment of the two daughters for drowning their father, the narrative stands on its own elsewhere. ${ }^{7}$ 
As evening is falling there is a tremendous storm that lasts several hours with a heavy downpour, thunder and lightning. At daybreak the women find the canoe near the Ayip River as Ufiripic has promised, formed from the stump of a sago palm from which they have beaten the pith. [Compare this with the Kinako story at the end of M1.] They put their mats, nets, and digging sticks into the canoe, leaving nothing behind. They also take bamboo plants with them, put the boys Kurap and Sawarap in the canoe, and leave for the unknown far western part of Mimika, closely following the coast, passing one river mouth after another. At every spot where they take a break to spend the night or collect food, they make hollows for drinking water and plant bamboo cuttings.

At some point during the journey Omarawoc, the older sister, is enchanted and impregnated by a spirit who tells her to call her newborn son Seos. He [being a culture hero] develops very quickly and can already talk in the womb. Soon after birth he takes command: 'You must treat me as your oldest son.' He says to his cousins (half-brothers): 'You must all listen and take orders from me.' He stands in the middle of the canoe, which is the place of the oldest person who gives instructions. Whenever his mother and cousins want to go in a certain direction or wish to camp somewhere, he rejects the suggestion. Seos takes the decisions. Every time they camp, the boys practise Emak Cem songs, but Seos does not participate and stays in the canoe. A man in the forest called Yisbermerat hears the boys drumming and singing. He is a watersnake (yis) parakeet (bermer). In the early morning he goes to the coast and meets the two brothers: 'I know you are the sons of Ufiripic [who is an inland parakeet, whereas he is a seaside parakeet]. Your father and I are old friends; we are from the same place. Your songs are incomplete. I shall tell you the proper ones out of friendship for your father.' He teaches them the proper songs and, before returning to the forest, gives the boys a bag of secret magical objects to help them to learn and remember the songs.

After many days they reach the place Seos had wanted to bring them to. One side is called Upuye, and the other side (opposite the rivermouth) Esamu [Safan, or underworld]. The next day the two sisters immediately want to go fishing. They catch a whale (ndamim). Seos takes possession of the catch. He gets Kurap and Sawarap to skin it and cut the backbone out. He then starts his magic: the skin becomes the roof of the Emak Cem ceremonial house, the backbones the pillars. The two brothers collect the rest of the building material. They finish the construction of the ceremonial house. During the night one of them sings and drums, and the other blows on a bamboo horn, two blasts each time, a high and a low one. When they wake up, they discover to their surprise that the ceremonial house has collapsed. Seos recalls that in the night he saw a big monitor lizard swimming towards the house. They 
rebuild it, but it collapses again the next night. They rebuild it a second time. This time Seos stays on guard and kills the monster. Seos keeps on living in the house. He never needs to eat and drink. When he eventually dies, his bones remain in the ceremonial house and become pieces of iron. The two women and their children still live on Upuye, opposite Safan.

In the separate Kurap and Sawarap stories these heroes are associated with Ufiripic's older brother Bayndosopic, living in the far western part of Mimika. He and the two heroes are the lords of iron instead of their spirit cousin Seos. ${ }^{8}$ Compare this with the lords and manufacturers of iron tools in M3.

In a version of a narrative about the origin of Emak Cem (see M7) collected in Atat by Zegwaard (Zegwaard 1953-56, Kewa:77), Kurap and Sawarap and their mothers are said to travel from west to east, inland; the two sisters are watersnake (Asmat: yus, Kamoro: utako) women with a scaly skin. Their human or superhuman sons, noticing that there are no rivers, ask their mothers to make rivers. They make them from the mountains to the sea, from Ewerif to Bec (see Map 3).

Apparently there is some confusion between this story and the travel and exploits of the Kamoro sun hero (see Chapter VI under Cosmology).

A version of the same myth collected by Zegwaard (Zegwaard 1953-56, Kewa:79) has it that the two sisters travelling from inland to coast meet up with two women from the coast. The latter have real canoes, instead of the miniature ones the two sisters have, made from the stump of a sago palm. The sisters steal the real canoes after drugging the coastal women, and depart for the west. This theme recurs in a local West Mimika story: Two sisters cause a flood to punish their misbehaving offspring, and steal a canoe from two women coming from the east, loaded with Western commodities. They make for the far western part of Mimika, where they transform themselves into Jesus the son of Mary, and Wilhelmina, a former Dutch queen (Pouwer 1975).

It seems obvious that M6 is an Asmat interpretation of Kamoro M4, ascribing this narrative to their own culture heroes Kurap and Sawarap and their mothers. While the older sister is born by the intervention of a spirit woman from the upper world, she herself gives birth to a son, Seos, by the intervention of a spirit man from the underworld. The foreigners and their commodities originate from the underworld, located in the far western part of Mimika or near the Asmat Casuarinen Coast, southeast, called Safan according to both the Kamoro and the Asmat. The two ethnic groups missed out on the acquisition of (Western) wealth by mistakes, misbehaviour, and transgression of the rule of reciprocity. Compare this with the repeated request of the rotating hero of the sun to inhabitants of Central and West Mimika to chop his head off. 
Unfortunately they turned down the request, except for the people of Opa in the far west of Mimika (where the sun sets). These knocked his head off, and the head then turned into commodities, rifles, knives and tools. That is why the Kamoro missed out on wealth (Offenberg and Pouwer 2002:70-2).

Seos seems to me an ambivalent culture hero that embodies the foreigner. On the one hand he considers himself superior to the others, takes command, does not mix, does not participate in learning the Emak Cem songs, stays aloof and apart in the canoe, does not eat or share food. His bones turn into iron, which is reminiscent of Kamoro leaving the bones of their dead behind in the ceremonial house at the end of Ema Kame. On the other hand, he shows similarities to the Kamoro culture hero Mirokoatayao in killing the monitor lizard who destroys the ceremonial house. There is a striking difference, though: in the Asmat version the monster is not cut up into pieces that are transformed into the varieties of mankind. Instead, the bones of Seos turn into pieces of iron. Iron tools were fascinating to the Asmat when they first encountered foreigners. The Asmat version seems to confirm my views expressed earlier in this book, that the motif of a monster that transformed into varieties of mankind originates from an area in the far western part of Mimika, in spite of its explicitly recognized link with Ema Kame. The ritual seems to originate from the far eastern part of Mimika and inland (see M7). The myth of the monster, sung about but not acted out in Kamoro Ema Kame ritual, is absent in Asmat Emak Cem songs and ritual.

We are now in a position to address the universal contradiction or paradox of genesis: how can one be born from two - if born from Adam what about the origin of Eve, or vice versa - in a specific ethnographic-narrative context by means of conditional logic.

It is noteworthy that all the stories summarized above begin with one, though in different impersonations: a lone male hunter, a lone upperworld spirit-woman, a lone abandoned wife, lone survivors, namely a woman and a boy, of a disastrous monstrous attack, another abandoned wife (the co-wife, her younger sister, is of no further significance in the story).

The 'mechanism' of shifting from one to two is predominantly pregnancy and ensuing birth, though by different causes, and the symbolic emergence of a mother-son relationship (M4). The modes of pregnancy are: impregnation of a man by two upperworld spirit-women; pre-existing, unspecified pregnancy of an upperworld female; pre-existing pregnancy of a female by adultery; pre-existing pregnancy by intercourse with a husband killed in a disaster; female pregnancy by enchantment by a male underworld spirit. Note the contrast between a man impregnated by two upperworld women and a woman enchanted by an underworld male. The impregnation of a man is presumably in line with patri-oriented Asmat descent. The symbolic, explicitly stated 
mother-son relationship emerges from the replacement of killed real and classificatory mothers by their python-killer, who adopts their son. The killer in her turn is killed - at her command - by her adoptive son: a sort of self-willed, 'incestuous' matricide.

In all cases pregnancy or its symbolic counterpart results in the birth of culture heroes: a male in five cases, two females and their two sons in M1. These culture heroes are the ones who perform generative acts: the two mothers and their two sons are the initiators of the Asmat Emak Cem ritual (see M7). The culture hero of M2 is credited with the discovery of and the migration to the lowlands and the sea. The culture hero of M3 is credited with the discovery or manufacture of iron equipment, textiles, a house with a zinc roof, and the coconut palm. The culture hero of M4 generates humankind by dividing up a slain monster (compare this manifestation of la pensée sauvage with the generation of language and meaning by means of division into phonemes, words and sentences). The culture hero of M5 generates local ethnic groups, the ancestress of the white race, and the two varieties of local canoes, all by means of division. The aloof culture hero and foreigner of M6 magically generates a 'modern' emak cem (in the far western part of Mimika) from a whale whose bones turn into iron.

What about the function and meaning of having sex in its relation to the paradox of one yet two? It takes two to tango. Yet it does not seem accidental that the second party in the narratives is off-stage or not identified, or takes on a disguise. In M1 the second party is disguised as a pecking upperworld parakeet; in M2 the party is not identified; in M3 there is off-stage adultery; in M4 the second party is no longer there because of a disaster; in M6 the second party is a mysterious underworld enchanter. So the second party is blurred in various ways: one seemingly takes the stage.

In five out of six cases there is incest, or something like it: in M1 fatherdaughter incest takes on the disguise of pseudo-levirate, in which a dead man's brother marries his widow; in M2 there is a transformation from mother to wife by means of her manufacture of a women's bag: another disguise but then of mother-son incest; in M3 a deserted and maimed mother turns into the wife of her culture hero son on her initiative, after he has replaced the mother's maimed parts in the underworld; in M4 there is another plain case of motherson incest on the mother's initiative. In M5 there is 'incestuous' matricide on the mother's initiative, another disguise.

In all these cases the birth of culture heroes is not the result of unambiguous incest. The birth of the two culture heroes in M2 from 'real' incest of father with daughters is disguised as a birth from socially allowed pseudo-levirate marriage.

Why then the predominant connection of these stories with incest? What is its function and meaning? The initiating mothers implicitly or explicitly state 
it. In M2 the mother teaches her son, unsuccessful in initiating intercourse, that first of all the wife's hymen has to be penetrated; the performer of this penetration is not the husband but the wife herself. Only then is intercourse successful. In M3 the mother explicitly teaches her son how to have intercourse. She gives him tobacco, an erotic gift, and praises his penis, a common marital compliment. Note that no child is born from this incestuous union. In M4 a 'child' is born from incestuous intercourse, but not a human child; it is tobacco, the usual erotic gift. Also, the mother explicitly formulates the general rule that the semen produced in intercourse serves to feed the foetus (as the mother's milk feeds the baby after birth).

We may conclude that mythical incest serves to highlight the erotic and physiological functions of women as initiators of sexual intercourse and as producers of offspring. Women are the ones who usually take the initiative in lovemaking, especially in Mimika. The male role highlighted by these narratives is that they are the creators of the human race, cultural institutions, and artefacts, by means of division. It is men who have power over supernatural forces by means of magic and ritual. The narratives thus legitimate the functions and meanings of Kamoro conventional gender roles. It is obvious that gender overrides sex by far.

\section{Ema Kame/Emak Cem and ritual}

\section{M7 The narrative of the ritual}

M7 is a compilation of four versions of the narrative as told by three men from three inland settlements at the Momac River, Northwest Asmat, namely Ao, Kapi and Atat (Zegwaard 1953-56, Kewa:73-9). The stories are restricted to a description of the ritual, primarily ascribed to the two mythical sisters of M1, M2 and M6. Most likely this description also reflects the men's own memories of performances of the ritual they attended. Such performances ended in the 1950s, but parts of the ritual were resumed in the late 1970s and 1980s.

Two sisters Mberen and Mbuper and their sons Kur and Sawar live upstream on the Asewec River (in Central Asmat). The two sisters build an Emak Cem ceremonial house. [Its construction as briefly indicated by the stories is similar to Ema Kame.] The central beam (yeer), cut in the woods by their sons according to their mothers' instructions, is transported on their shoulders to the skeleton of the ceremonial house, not carried to the river and surrounded by canoes. The inland initiators of Emak Cem did not have the use of canoes. [Transport over the river is said to be a later development when the ritual spread downstream. This detail is meant to stress the inland origins of the ritual.] 
During the cutting and transportation of the central beam, two male dignitaries, Pipiripic and Mumuripic, originating not from the upper world but from the underworld, blow on bamboo horns while the two mothers sing ritual songs. The yeer, at one end of which the head of a crocodile is carved out, is pushed over the crossbeams - yeere denotes the cries of terror of the young initiates - which rest on a double row of poles (cuuk). Two parallel beams $(m b e)$ are placed likewise right and left of the central beam. The beams lean sharply towards the narrow end of the porch. The walls and roof are constructed. No opening or crack is left uncovered. Inside it is pitch dark. The two sons are locked up in the house.

The two mothers then cut a tow tree for making a spirit canoe. They shape it into what looks like a bottomless canoe. They carve a turtle $(\mathrm{mbu})$ in its centre, flanked by two evil sea monsters (okom); on the bow and the stern there are female spirits depicting white mole-like creatures of the tidal forest associated with death (ambirak); in the canoe are a number of frogs (eco) representing the dead; all the creatures are depicted with their heads down.

Now the real ceremony begins. The spirit canoe is placed halfway on a platform at the front entrance, from where steps connect the ceremonial house with the ground. The spirit canoe is supported on either side by a pole called a snake, amer. [These represent the two mothers, said to be scaly watersnakes who travelled from west to east in the Atat version.] An oval, fish-shaped wooden object called sawar [also the name of one of the two culture hero sons] hangs in the opening of the entrance. The two boys, Kurap and Sawar, scared by their mothers' performance, cry for them. Ordered to move from the interior of the ceremonial house to its entrance, they first touch the sawar with their heads, then the turtle with their feet. They step over the spirit canoe and finally lie down on their backs on the turtle, one after the other. There the mothers apply scarifications to their shoulders and thighs with shells. Finally the initiates jump down and stand to attention for a moment while their mothers yell.

The mothers then construct a platform between two sets of scaffolding at a short distance from the ceremonial house. They lie down between the scaffolds and cover themselves with leaves. By so doing they behave like spirits and scare the two initiates. [This is exactly what happened during the mud ceremony (Te Kata) I attended in inland villages along the Kamora River, Central Mimika, which is said sometimes to precede the Ema Kame ritual; see Chapter I.] The boys flee in terror. The two mothers then enter the ceremonial house, cover their bodies with lime and reddish clay, and hide under mats. When the boys enter the house, one of the women comes out. Again the initiates panic and run around in the ceremonial house until their mothers say: 'Don't be afraid. It's only us.'

The boys are then adorned with arm, calf, and ankle bands and hair exten- 
sions (yunum, Kamoro, uu, Asmat). The mothers dress up likewise. One of the mothers climbs the central beam, starts a ceremonial song, hoists one of the boys head-down to the central beam, tears atap from the roof, walks to the front end of the beam, and throws him out. The frightened boy screams, but his fall is intercepted by the second mother on the ground outside the house. She is beating a drum while the mother on the beam proudly keeps on singing a ceremonial song. The boy who stayed behind in the ceremonial house is then dragged to the entrance, where the mother on the ground applies additional scarifications, this time to his kneecap and breastbone. Afterwards he jumps to attention. The second boy is treated likewise. The following day the mothers hit their sons' buttocks with a banana stalk [in order to promote their growth; bananas are quick growers]. This ends the ceremony.

The version of this story, as told in Kapi, is clearly meant to provide the descendants of the two mothers with a model for the ceremonial house and its ritual: it highlights the significance of the original female culture heroes. However, it is remarkable that other versions present their sons Kur and Sawar as the initiators of Emak Cem, although they learn the art from their mothers. They (in their turn) lock up their sons and nephews. No fire is allowed inside. The initiates are instructed to behave like flying foxes (tar). Kur and Sawar scare and thrash them in the house with rattan canes and make them flee in all directions.

During a stay of a few days towards the end of March 1955 in the very settlements where these narratives were told, Zegwaard attended the first sequences of the ritual (Zegwaard n.y.d:34-40). Older men cut a fir-fir tree about three metres in height. They decorated it with lime, ochre, leaves and fruit of sago palms and then placed it near the settlement where the Emak Cem ceremonial house was being built. The men assembled in front of the men's house. While they were singing the Emak Cem songs, they were attacked and chased by women acting as a group and throwing smouldering sticks: the imu game (a term identical with the Kamoro term).

The next day the men assembled atap and chunks of young sago, and then used them to construct the roof and walls of the ceremonial house. Carvers from Atat, As and Nakay carved out a crocodile on the front end of the central beam. At dusk their bride-receivers took the young initiates to the ceremonial house. They imitated the movements and noise of flying foxes, while the men scared them by hitting the walls with fists and sticks. There was drumming and singing throughout the night.

The following day the women collected sago, which the men took in raw portions into the house [to be prepared and consumed secretly outside the house by the initiates at a later stage and without the women's knowledge]. 
At dusk the women in their turn hit the walls. [At this stage Zegwaard left the village.]

Zegwaard also gives the names of the male dignitaries of the various yew who were entitled to climb the central beam, like the mythical mothers did, in order to perform the songs and to throw an initiate out by his feet.

In June 1976, John Fleischhacker, OSC, the art collector Tobias Schneebaum, and Yufentias Biakai from Yamas, attached to the Asmat Museum for Culture and Progress in Agats, visited Biakai's village, downstream on the Pomac River southeast of Kapi and also an Emak Cem site of repute, to collect two spirit canoes that had been made for the museum. On this occasion the initiation of boys was reintroduced, and Amandos Amonus and Leo Bini gave the visitors a generalized description of the ritual (Fleischhacker and Schneebaum 1977:94-9). Amonus was the chief carver of one of the two spirit canoes, named after his deceased father. The second canoe was named after a deceased brother of the chief carver, Darius Faya. Each of the assistant carvers made his own carved human figure to commemorate a dead relative.

All the men of the village assist in cutting down an os eyok tree, which is put into the ground roots-up and decorated with the senap and other forest fruits in front of the site of the ceremonial house, facing the porch. They also cut down and assemble the material for the Emak Cem ceremonial house, which is built in one day. The central beam, carved at one end with the head of a crocodile (and at the other end with the long beak of a bird, Konrad, Konrad and Biakai 1987:483-509), is put into position. Beyond its nose hang decorations of sago leaves. At the narrow end of the house the wall is installed, giving onto a porch with the carved head of the crocodile positioned over it.

The boys, the initiates, live in the ceremonial house for a couple of months. On the morning after they enter the house, the men of the village cut holes in sago trees for sago grubs to grow. The boys go fishing, and go hunting pigs. The mothers and fathers bring them food. Boys who fall ill go to the men's house and the living quarters, preceded by men who twirl bullroarers (bian), so the women will run and hide. When the sago grubs mature (after four to six weeks), the carvers of the spirit canoe get to work in the secluded back part of the men's house, on the side away from the river. The carvers receive plenty of food from relatives of the dead represented in the spirit canoe. At night they cover the carvings with sago leaves.

When the spirit canoe is ready, painted and decorated with young sago leaves and cassowary feathers, it is covered with sago leaves tied up with rattan. All the doors and openings of the men's house are closed with atap. There is more collecting of sago and sago grubs, feasting and drumming. The food is distributed but the initiates, still locked up in the ceremonial house, are not allowed to share in it. After an official praising of the carvers, the men untie 


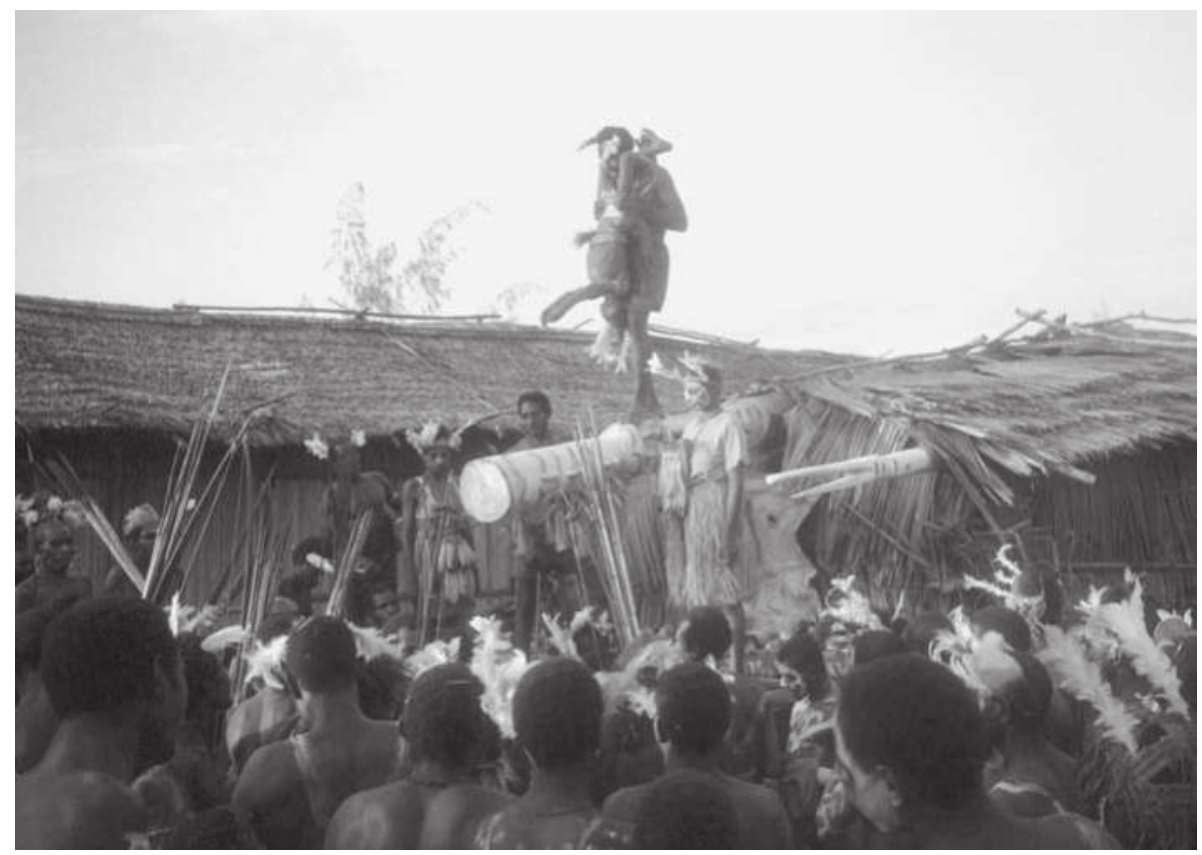

Polikarpus, a ritual dignitary, seizes a boy initiate by his feet and carries him headdown to the tip of the central beam of the Emak Cem ceremonial house. Yeni, Asmat, 1982. From Konrad, Konrad and Biakai 1995:254.

the rattan around the sago leaves that cover the spirit canoe. Two women [impersonating the two mythical mothers], with white cockatoo feathers in their hair, their faces red with red earth, wearing their bags with white feathers, remove the sago leaves from the spirit canoe. Two men [impersonating the two characters from the underworld] blow their horns, one after the other. The singers and drummers announce that they will carry the spirit canoe from the men's house to the ceremonial house. Women remove the atap from the doors and openings of the men's house. The men push the prow of the spirit canoe through the door opening, but pull it back quickly twice as a show-off [as is done with newly made mbish poles]. The spirit canoe faces downstream in order to show the dead in the spirit canoe the route to the underworld, the abode of the dead. The third time, it is carried down to the Emak Cem ceremonial house and put on the floor of the porch.

An old man climbs the central beam. He lifts up an initiate, officially denoted as batu pumter ('child who leaps down', Konrad, Konrad and Biakai 1995:255), by his ankles and moves to the front end of the beam. While being carried in this way, the boy opens up the roof by removing atap. He shouts: 'Come, my mother! Come, my father!' [Note that mother comes first.] Men 
outside the ceremonial house pretend to shoot him and jab at him with their bows, arrows and spears.

Then the chief drummer enters the porch, presses his right foot on the sea monster of the spirit canoe, and rubs it with his calf [and genitals]. Then he slides his other foot over it.

The two women [mythical mothers] on either side of the door lift the spirit canoe while a hissing sound is heard from the kasah, a snake spirit [Yisbermerat, the mythical teacher of the proper songs], impersonated by a man dressed up with a headband of cuscus and with many feathers and rattan bands. Two initiates draw near, holding on in terror to the bottom of the drum of the official drummer. Like the drummer, they slide over the sea monster of the canoe. They are then lifted up and placed flat on the floor of the porch [not on the spirit canoe in this version] with their heads towards the spirit canoe. They are decorated with white, red and black colours. The snake spirit quickly cuts an ofa, a wavy scarification, into the boys' shoulders, backs and buttocks, using a mussel shell. This happens so swiftly that the boys only learn of it later.

What happens to the 'roof crashing' boy lifted by his ankles is not told in the report. When all the boys but two have come out and received their scarifications, women enter the ceremonial house. They ask: 'Have all the boys come out?' and get hold of them for scarification. This signals the formal end of the ritual.

The next morning at dawn, men and women put their sleeping mats one after the other in a row in front of the Emak Cem ceremonial house. The initiates and their sisters lie down one beside the other - initiate, younger sister, initiate, younger sister - in a long row. A man comes along with a sharpened shell and cuts scars on the chests of the boys and the girls. One boy after another stands to attention and is then struck suddenly from behind with a banana stalk: twice on the upper part of his shoulders to make his body grow and twice on his buttocks to make his penis grow and twice on the back of his knees [to strengthen his walk, perhaps]. The younger sisters also receive these blows, in order to promote their fertility and an abundant production of mother's milk. This is the end of the initiation ceremony; the boys join their families at their fireplaces, eat and sleep.

In 1995 Gunter and Ursula Konrad and Yufentias Biakai published a revised and expanded version of an earlier paper (Konrad, Konrad and Biakai 1987) on Emak Cem myth and ritual after attending a celebration in the Yurat group of settlements of Northwest Asmat, including villages such as Kapi, Yamas and Shuru (Konrad, Konrad and Biakai 1995). The exact location of the celebration is not disclosed. From their detailed and valuable description the following information is culled, to which I add some comments. 
1. Biakai ventures the suggestion that the spirit canoe of the ritual represents the mythical bark canoe fashioned by Ufiripic; his father did not tell him (p. 231).

2. The majority of the initiates are six to eight years old (p. 232).

3. The term fir-fir denoting the tree erected at the site of the ceremonial house has a number of further meanings: the ancestors, the dead during the period of celebration, reverent term of address for the dead (p. 232).

4. The names of the recent dead are mournfully enumerated while lime powder is flung at the tree before felling it. This also happens when felling the tree for the central beam (pp. 232, 234).

5. The beam is identified with the deceased after whom it is named. This is the reason why the tree is handled with care, must be carried on the shoulders of men and not flung into the river (p. 234).

6. The drum-shaped frontmost end of the central beam, called wucai, adjoining the jaw of the crocodile, represents the top of a sago tree and might be a symbol of fertility (p. 234).

7. In view of the central significance of the Northwest Asmat spirit canoe we may now understand why the narrator of the Totepere myth (M3), a member of the Koperapoka people of the far eastern part of Mimika, maintained that this is the true myth of origin of Ema Kame. The canoe of this story is also associated with the dead and also travels to the underworld in the far western part of Mimika. This story seems to fit in with Asmat Emak Cem and in this respect constitutes a transition to Ema Kame as celebrated by the Kamoro, in a ritual in which the spirit canoe does not occur.

8. The ceremonial house seen and photographed by the Konrads (p. 234) is apparently only a model. It measures four by four metres, whereas the real thing in Mimika, according to Wollaston's (1912) observations, is much bigger (see Chapter II). The Asmat example was erected in a few hours. Presumably this was due to the Indonesian government's prohibition of Asmat ceremonies for several years and their tacit reintroduction in a quite different situation. The actual ceremonies that the Konrads and Biakai attended lasted only four days.

9. It is fascinating to learn from their report that about a metre above the fireplace of the model ceremonial house a board is attached between two posts, representing a yirai fish (p. 235). This board, together with the oval fish-shaped object hanging at the entrance and representing the sawar fish after which it is named (p. 239), apparently corresponds with the two puru mane boards of the Kamoro Ema Kame ceremonial house, centrepieces of their ritual. Their position in the house is exactly the same. Unfortunately, the precise symbolic meaning of the two Asmat fish is not given. However, it is said that touching the yirai fish board infuses 
initiates with a sense of responsibility for and identification with the community (p. 239), while touching the sawar board is said to transmit to the initiates its spiritual abilities. Kamoro initiates similarly identify with the sacred boards by touching them. These boards represent their communal ancestors. Opposite the Asmat yirai fish board in the centre and attached to the wall posts, one finds a large statue (tem as) made of rattan, representing a spirit who guards the interior of the Emak Cem ceremonial house and bestows masculinity on the initiates (pp. 235, 239; photo p. 236). So a link between the Asmat boards and the ancestors seems plausible.

10. The official entrance to the house is closed off with a pandanus mat, and stays so until the initiation begins (p. 235). It is named after a deceased person (p. 253). Meanwhile, a small unofficial opening at the rear gives access to the house.

11. In the afternoon of the first day the initiates are taken into the ceremonial house through the back entrance. An official narrator of myths (atakam ipic) solemnly asks if all boys to be initiated are present. The assembled men loudly confirm that 'the children inside are our children' (p. 235). This is apparently a ritual statement of fact - similar to what the Kamoro do - meant in this particular case to inform the spirits that the initiates belong to the in-group.

12. At dusk the women hit the walls with their stone axes, producing a rattling noise meant, in my opinion, to frighten the initiates rather than to chase away evil spirits (p. 235). The initiates then imitate with vibrating voices the sound of flying foxes (p. 235), as the Kamoro initiates do also. The men, by way of ritual confirmation, respond by asserting again to the attending spirits that the initiates are their children.

13. The women then go home, while the men sing, drum and dance throughout the night. The initiates are instructed to be absolutely quiet, even when they are suddenly confronted inside by a hidden masked figure covered with mats (p. 236); compare this with the two hidden masked mythical mothers founding the Asmat/Kamoro ritual, who scared the boys with their sudden appearance.

14. The next day the men assemble in front of the men's house at dusk. An old man standing at the entrance to the ceremonial house solemnly inquires about the presence and the name of a particular initiate [who is presumably informed beforehand]. Then he asks whether the mother of that boy is at hand, and she confirms this: 'Yes, I am here, but please don't take the liver and heart out of my son's body.' Two men then enter the house, snatch the boy by his shoulders and legs, and put him on the yirai fish board. They pull and push his body forwards and backwards over the board. The boy cries: 'They are tearing the heart and liver out 


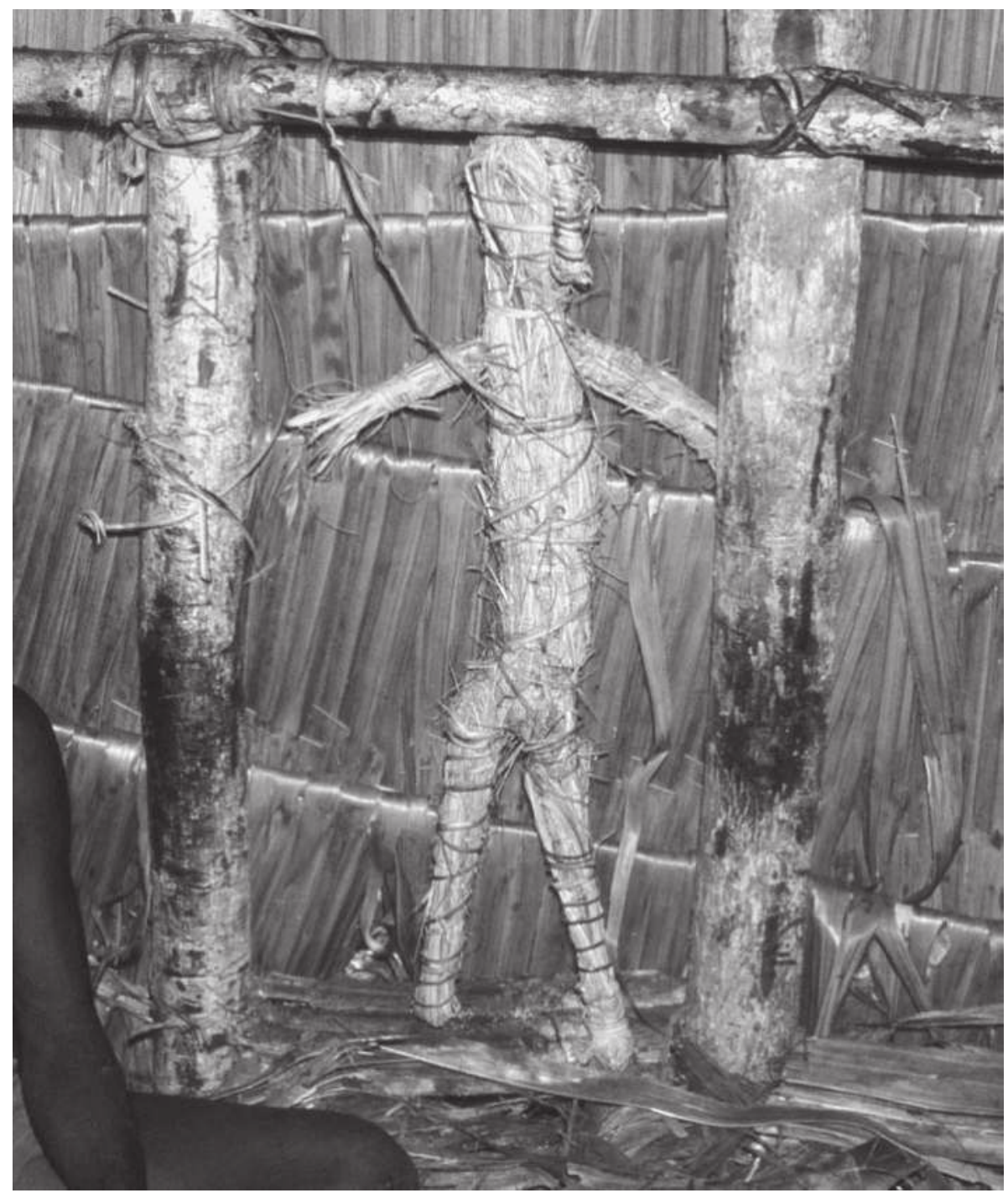

A male figure representing a spirit guardian oversees the Emak Cem initiates. Yeni, Asmat, 1982. From Konrad, Konrad and Biakai 1995:236.

of my body.' The attending initiates are instructed to likewise cry and shout at full strength. These actions are repeated for every initiate ( $p$. 236). [Apparently this is meant to scare the mothers outside.] The comparable Kamoro actions on the central board suspended in the middle of 
the ceremonial house have a different meaning: these simulate birth from the ancestral mother. However, in spite of these differences in meaning, ancestral life force is believed to be transmitted from the central board to both the Kamoro and Asmat initiates by being suspended on it. Note the Asmat aggressive frightening demeanour, which is lacking in the Kamoro actions.

15. Later that same night, the men see to it that the women and children are shut up in their houses. Then, accompanied by the completely blackened initiates, they roam around going from house to house, while the initiates make a deafening noise by blowing on bamboo flutes. This is to scare women and children into believing that the spirits have arrived to cut the heart and liver out of the boys' bodies. The next day the women avenge themselves by waging a mock war [imu] against the men (p. 236). This reciprocal expression of gender antagonism, not noted as such by the authors, is in line with Kamoro behaviour at Ema Kame, though this happens at a different stage (see Chapter II).

16. After secluding the initiates, the men leave the settlement to build a large wooden fish weir (cir) near the river at some distance from the village (see photograph, p. 237). Both Asmat and Kamoro normally use such a construction to fence off a tidal creek for fishing. In this ceremonial context, however, it represents for the initiates the way Ufiripic was caught and drowned by his daughters. The fence is decorated with fot manamok, literally 'eyes of butterflies', that is, the eyes of the spirits, represented by squares of plaited rattan on poles (p. 237).

17. For the cultivation of sago grubs, the various families fell sago trees, then cut and mark square holes in them, so that the grubs will grow and multiply. As many as 1,200 trees may be felled for this purpose.

18. Then the spirit canoe, wuramun or uramun, is made and carved. Wur is said to mean thunder, amon or amun 'to call' (p. 238). Thunder is indeed interpreted by the Kamoro as a call for the 'soul' to leave the body (see Chapter V). The corresponding Kamoro term puru mane, denoting, however, not the spirit canoe but the two sacred boards representing the ancestors, literally means 'sacred two'. The spirit canoe in this particular case has a length of 8 to 10 metres. In one way or another, it depicts 22 recent dead (p. 263). Recognized carvers do most of the carving. However, individual male relatives are obliged to carve out the last details. They do so a few hours before the ceremony begins (pp. 239-40). Only then do the carvings come to life, that is, the spirits of the dead draw near. The attitude of the living towards the dead is ambivalent. They honour yet fear them. So the spirits should not be present too early and should leave in time. That at least is my interpretation of the reason for waiting until the last minute to finish the carvings. 


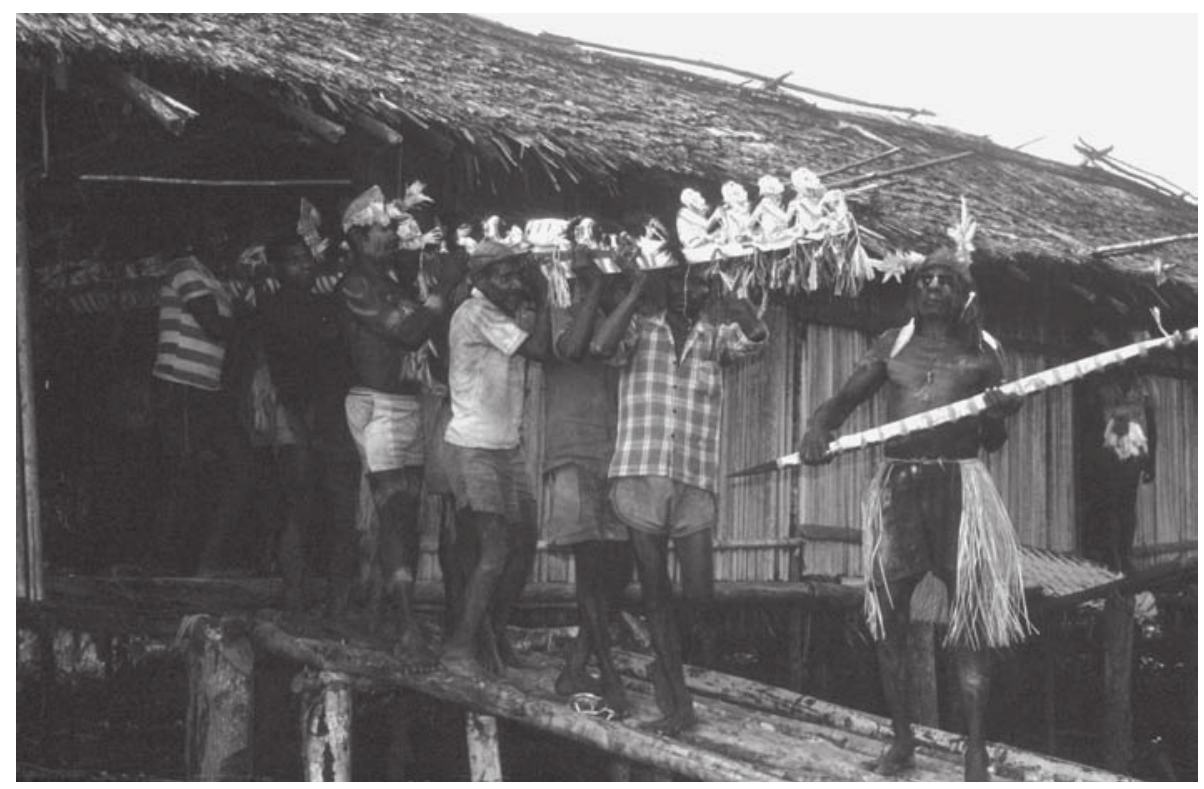

The spirit canoe is carried from the men's house to the Emak Cem ceremonial house. Yeni, Asmat, 1982. From Konrad, Konrad and Biakai 1995:244.

19. In the late afternoon the master of ceremonies leads two women fully dressed up and adorned, representing the two mythical sisters, to the spirit canoe in the men's house. They take up positions one at the front and one at the back of the canoe, while the master of ceremonies exclaims in excitement: 'We wonder if the two of you recognize the children' (that is, the dead persons being commemorated). The two women, assisted by men, cover the carvings of the spirits with sago leaves. The men then take the spirit canoe on their shoulders and stride carefully to the entrance. The procession is preceded by an older man who holds in his hands a wooden staff, painted black, red and white, about 1.20 metres in length, representing the primeval snake (amer nak, 'black snake, the true one') who gave birth to the first human being and took him from the upper Sirec River to the present downstream location (p. 243). The bow of the spirit canoe is dragged repeatedly outside and inside the entrance, amid clouds of lime powder, bows and arrows, shouting and drumming. A young man, representing the initiates inside the Emak Cem ceremonial house, dances on the central beam above the porch.

20. The procession then moves slowly to the riverside, while the spirit canoe seemingly looks around. It is thrust three times towards the opposite side 


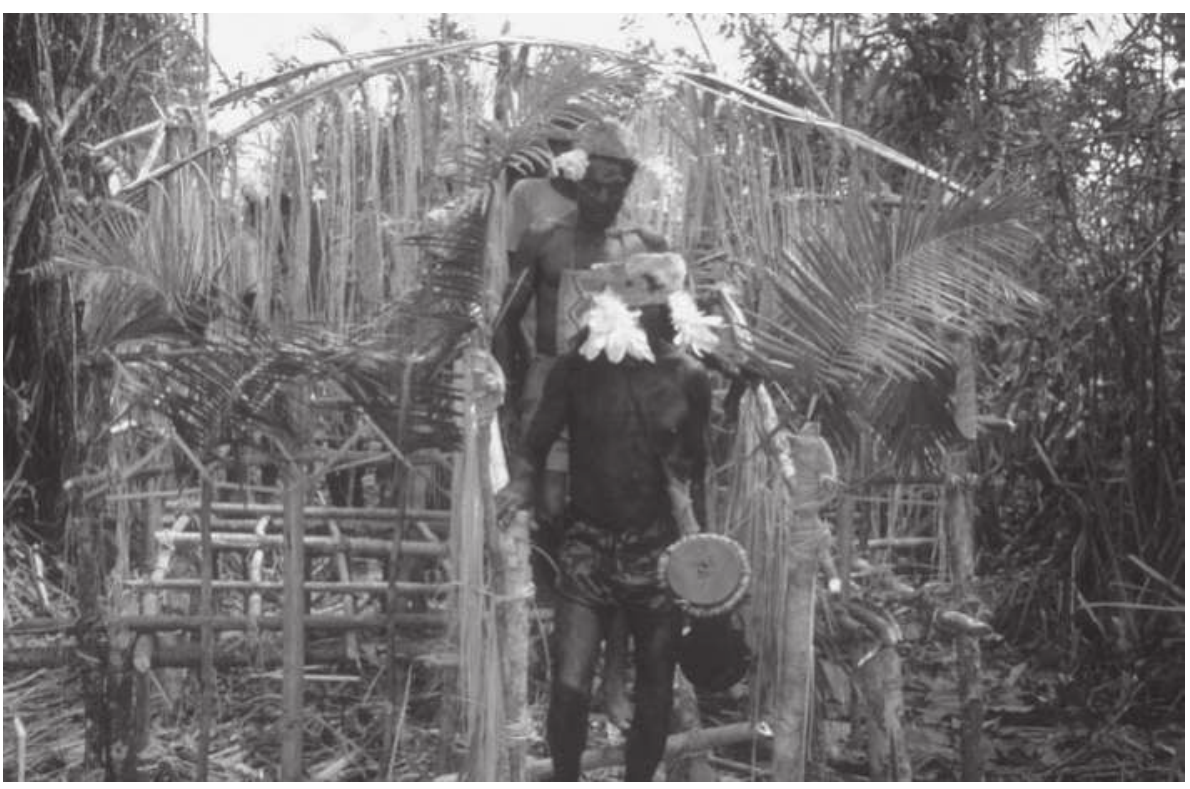

Drummers silently cross the ritual secret house accommodating the spirits of the dead attending the Emak Cem ritual. Yeni, Asmat, 1982. From Konrad, Konrad and Biakai 1995:249.

of the river downstream, in the direction of safan, the abode of the dead in the underworld. All of a sudden the hectic noise of voices, drums, bamboo flutes, and bullroarers stops. A long line of men on the riverside leaning against the walls of the men's house then start to weep passionately, their heads buried in their arms: after the joy of reunion follows the sadness of separation, the farewell to the beloved dead who are returning to the underworld (p. 244).

21. The procession then continues to the entrance of the Emak Cem ceremonial house, where the spirit canoe is placed on the porch. Singing and exaltation reach a crescendo. Axes, spears, paddles, and digging sticks are tucked in among the figures in the spirit canoe.

22. Early in the morning of the second day, the men and the totally blackened initiates board the canoes and paddle in a showy semicircle to a location on the shore some kilometres upstream on the village side. The men go ashore, remove the vegetation at some distance from the shore, and build a leafy temporary hut on poles with an open roof (p. 248), while the initiates paddle across the river in a sprint race, remove the black paint from their bodies, and collect edibles in the forest by way of testing their abilities. The temporary hut is called kasha cem (Kamoro: kata kame), liter- 


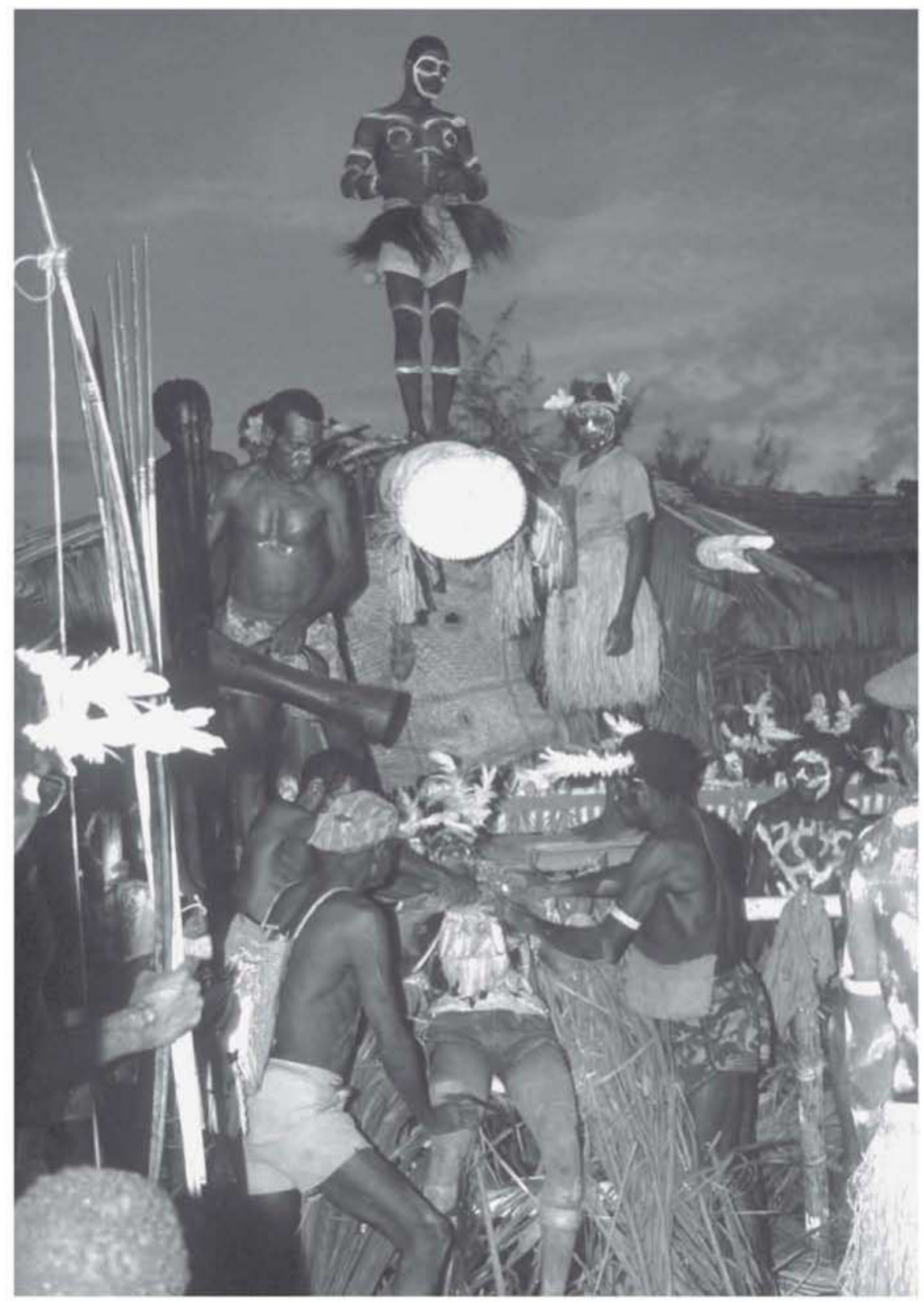

Hidden under the entrance stairs of the Emak Cem ceremonial house, a dignitary makes small incisions in the back of the knee. Yeni, Asmat. 1982. From Konrad, Konrad and Biakai 1995:259. 
ally 'ritual secret house', not 'house of spirits' as the Konrads and Biakai suggest. The house accommodates the spirits of the dead, called up by chanting men. To them are offered the edibles from the forest collected by the initiates - and tobacco in case no edibles were found - after the men have told the initiates to return. Accompanied by the men, the initiates ascend the steps of the temporary hut on one side, quickly cross the room without anyone looking sideways, without anyone drumming, in absolute silence, descend the steps on the other side, directly board the canoes, and return to the village. Two small, stripped trunks covered with leaves are stealthily taken aboard to be hidden under the Emak Cem ceremonial house (pp. 248-9).

23. The next day the initiates are fully dressed up and adorned by their mothers' brothers and other relatives in the men's house, and their bodies are covered with red paint. Outside, the two trunks are processed for the secret fashioning of a ladder connecting the porch of the Emak Cem ceremonial house with the ground. The ladder is covered with leaves and made invisible.

24. In the early afternoon the initiates enter the ceremonial house through the back entrance. The two women representing the mythical sisters, their faces painted red and a ceremonial headhunting net draped around their breasts (it was mythical ancestresses who initiated headhunting and then handed it over to men, a mythical inversion) unwrap the carvings of the spirit canoe and take up their positions, one on each side of the mat that closes off the entrance.

25. The young man who represents the initiates and who is called cuuk, a name identical with the name of the piles supporting the central beam, again dances on the front part of the central beam. Some men remove the atap adjacent to the central beam. A dignitary, an older man, climbs it from the inside. The cuuk comes down and hands the first initiate, known as batu pumter, through the opened roof over to the man on the central beam. As described earlier, the initiate, head down, is flung outside the ceremonial house, where assembled men threaten him with spears, bows and arrows. The batu pumter is the first initiate to receive scarifications [not mentioned in the earlier version]. Furthermore, contrary to earlier versions he is not placed on the spirit canoe but on the ladder covered with leaves, face down. While men hold him tight, the dignitary, said to represent a spirit [the mythical Yisbermeyat?] hidden beneath the ladder and the leaves, carves a gash in the back of the initiate's knees. Sago flour is applied to his forehead. From now on, he belongs to the adult men and may dance with them (p. 256).

26. The two mythical sisters are then summoned by men to lift the mat closing off the entrance. They pretend to be surprised to see inside so many 


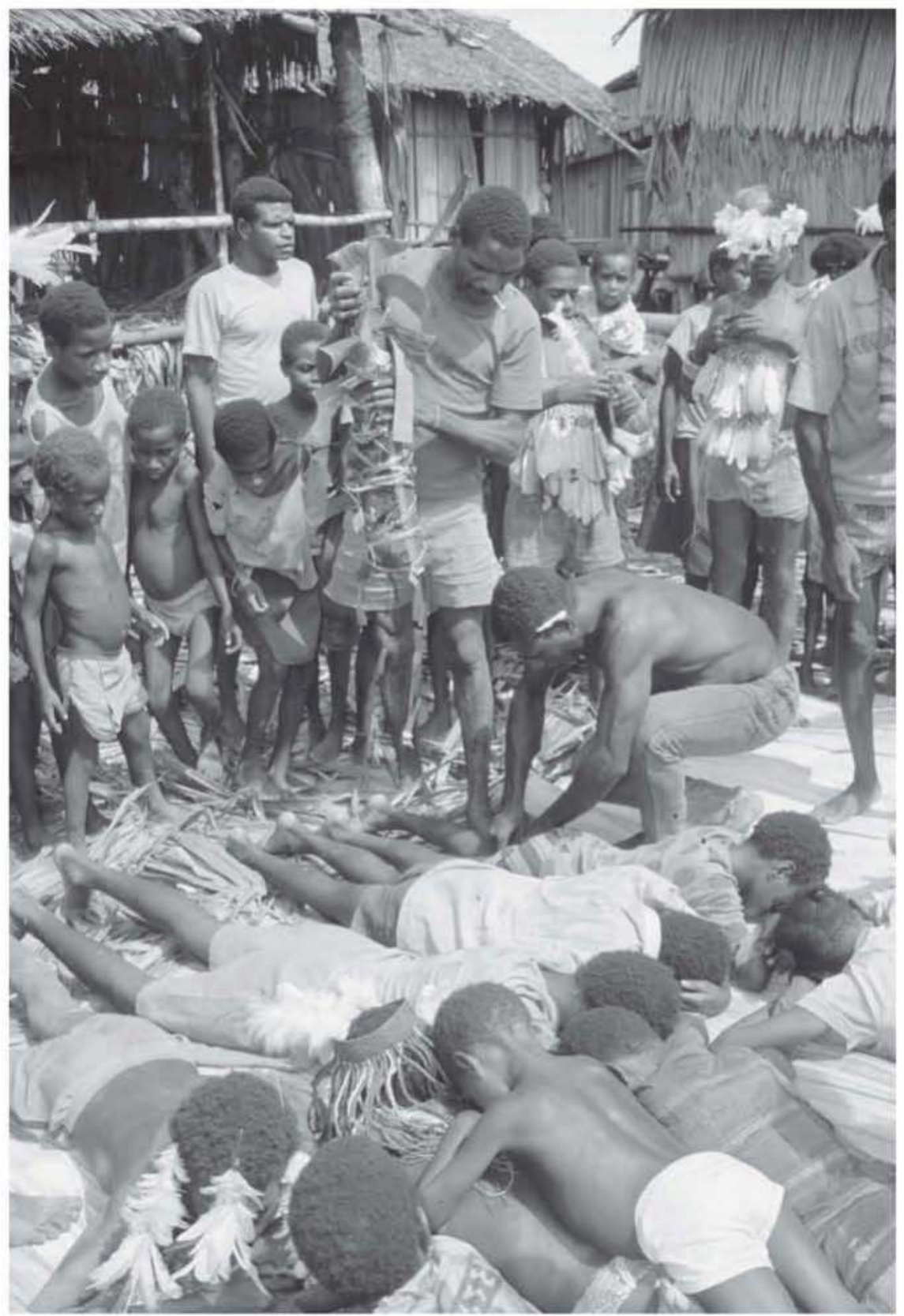

Male initiates and their real or classificatory sisters lying on top of each other in front of the Emak Cem ceremonial house are hit with a banana stalk, to promote their growth. Yeni, Asmat, 1982. From: Konrad, Konrad and Biakai 1995:261. 
children who have arrived from the world of the souls and spirits, and invite them to draw near. A hesitant and frightened initiate comes along, touches the sawar board at the entrance with his forehead, and tries to set his teeth into a dangling lump of sago containing fried sago grubs, crosses the spirit canoe while touching the okom carving, symbol of masculinity and strength, with his genitals, and is then scarified on the ladder as described. All other initiates follow suit, including the last one, who is seemingly 'discovered' by men checking whether 'all our children' have come forward (p. 260).

27. On the last day, a long row of mats is laid out in front of the ceremonial house. Pairs of 'brothers' and 'sisters' and also previously selected future spouses, all of them of marriageable age, are placed on top of each other, girls on top of the backs of the boys [in earlier descriptions side by side]. I presume this symbolizes both brother-sister exchange and marriage itself. Then scarification of all of them in the back of the knee is performed, and they are hit with a banana stalk, as described earlier. The ceremony ends by applying sago flour to the forehead and chest (pp. 260-1).

\section{Comparison}

A comparison of the striking similarities and differences between the ceremonies of Ema Kame (Kamoro) and Emak Cem (Asmat) as described above may shed more light on the variegated history of the ethnic groups and on their different cultural orientations. To begin with, one may wonder why the Northwest Asmat Emak Cem tradition, apparently focused on the spirit canoe, the wuramun, has an explicitly stated mythical origin, whereas the far more elaborate Kamoro Ema Kame tradition, focused on the two sacred boards, the puru mane, places no emphasis on a mythical origin. The mythical origin is taken for granted, in contrast to an explicitly stated mythological origin of its structural counterpart, the Kaware ceremony. In the Kamoro central myth M4, explicitly associated with Ema Kame, the origin of the ceremony is not accounted for. Instead, the narrative emphasizes the function of the Ema Kame ceremonial house, as part of a row of ceremonial houses erected in order to kill the monster: it is erected twice. The monster receives the final blow in the second house from the end of the row. The Asmat whalebone ceremonial house (M7) seems to be a secondary 'modern' interpretation of this.

One also wonders why the use of a similar name for the two material foci goes along with an apparent difference in kind and meaning, the more so since the two ceremonial boards corresponding to Kamoro puru mane are present in similar positions in the Asmat ceremonial house, but named and signified differently. 
The Asmat and the Kamoro admittedly concur in their narrative location of Ema Kame/Emak Cem's origin: the hinterland, characterized by the initial absence of canoes (M1, M2, M6). The canoe and its conditioning waterways are believed to have been introduced subsequently by creative acts or by theft (Asmat M2, inland Kamoro M5, and Asmat M6). The discovery of the sea and the coast rates both among the Kamoro and the Asmat as an exploit of the initially inland-based culture heroes of the ritual, travelling to the coast.

It seems likely that the powerful Asmat, whose ancestors in long-ago history originate from a more easterly situated inland area and who migrated to the coast, adopted the ritual from the pre-existent Nafuaripi residing inland, midstream. A brief police report (Algemene Politie 1961) provides some details about an Imake ceremonial house. The protruding front part of the central beam was said to depict the open beak of a fish [crocodile?]. Underneath was a spirit canoe and in its vicinity a firi-firi, a small spirit pole. The central beam, also called imake, represented specific dead persons. Subsequently, in more recent history, the invaders attacked and hunted them, like the Koperapoka Kamoro did. The devastated Nafuaripi retreated further inland to the upper reaches of the rivers in the hinterland of the far eastern part of Mimika and of Northwest and Central Asmat. Inland Northwest Asmat possibly modified the Emak Cem ceremony, as compared with its presumed predecessors; it then apparently spread in more recent times to several coastal Asmat settlements, though not to all of them. This is a process which was still going on during Zegwaard's stay in the 1950s.

What is the relation of the Kamoro and the Sempan (adjoining the Asmat) to the Nafuaripi? The Nafuaripi and Sempan languages have been shown to be closely related, if not identical. It is quite likely that culturally they are at least similar. I would even venture to suggest that not only the early, inlandoriented ancestors of the Sempan but also the ancestors of the Kamoro merged with or might even initially have been part of the Nafuaripi in long-ago history. Therefore, to their presumably not so numerous descendants, their inland location and the Ema Kame ceremony might have been self-evident.

Then the participants in more recent waves of migrations of powerful, more numerous coastal and Kaware-oriented Kamoro communities from far eastern to Central and West Mimika, set in motion by attacks and migrations of peoples bordering on or living in the present Asmat territory, might in their turn have adopted the Ema Kame ceremony from the pre-existing, smaller Kamoro-Nafuaripi, inland-oriented communities with whom they merged. The narratives of their migrations do include encounters with persons and small communities who already lived there, mainly upstream (Pouwer 1953b). To these presumably dominant coastal immigrants of relatively recent history, the inland origin of the Ema Kame ceremony was not self-evident. This might explain the ideologically inland orientation of Ema 
Kame in Mimika, in spite of its universal occurrence. For the midstream and downstream-oriented Asmat, however, who did not merge, the ceremony is both factually and ideologically inland, although more recently it also spread to coastal communities.

It is all the more striking, then, that right across the intricate vagaries of history and migrations, across differences in cultural focus, across the narrative and ritual variants, all of the myths of Ema Kame and Emak Cem address the paradox of the genesis of humans: born out of one, yet born from two. One aspect they have in common, though in different ways, is that the role of the second party is either not identified or is disguised. Also, although in the majority of cases incest does play a part in the transition from kinship (mother-son, father-daughter) to marriage (husband-wife), incest among the Kamoro highlights the procreative erotic and physiologically nurturing functions of women in copulation and in the process of conception. Men had to learn the art of lovemaking from women. It is telling, though, that in the narratives no human child is born directly and unambiguously from these incestuous unions. The female contribution to society, both for the Kamoro and the Asmat, is that women, not men, are the procreators of human life. Note that Kamoro myths proclaim in name (M4) or in fact (M5) the land snake, the python, as the mother of mankind. The two primeval mothers of the Asmat culture heroes Kur and Sawar are also depicted as anthropomorphic snakes. In the Kamoro Ema Kame ceremony it is a female dignitary impersonating a watersnake who brings the effigy of the ancestral mother to life with a burning torch. In the Asmat Emak Cem ceremony its centrepiece, the spirit canoe, is preceded by the male carrier of a wooden staff, which represents the black snake said to be the primeval mother of mankind. The Kamoro, in their matrioriented setting, even ascribe the origin of lovemaking to women. An incestuous union of mother and son produces tobacco as a gift that initiates betrothal and marriage. In Kamoro daily life it is mainly women who take the initiative in courting. Moreover, the mythical incestuous union explicitly produces the ingredients for the growth of the foetus.

Whereas in narratives women are credited with the physical genesis and multiplication of humans, their social genesis is ascribed mainly to men. It is male Kamoro culture heroes who, by cutting up a monster, achieve the social articulation of the Kamoro, and of other Papuan and foreign categories of the human race. This concept of the cutting up of a monster as an articulating symbol probably derives from the far western part of Mimika. In a similar yet different vein, it is the Asmat male culture hero Fumuripic, the initiator of the Asmat counterpart of the Kamoro Kaware ceremony, who articulates non-Asmat categories of the human race, including groups of foreigners, by 
carving statues and bringing them to life by drumming. ${ }^{9}$

It is also the role of males, highlighted in numerous Kamoro and Asmat narratives, to create cultural institutions. It is true, though, that in an important version of the Asmat myth it is two mothers who initiate the Emak Cem house, the spirit canoe, and the ceremony, but, as the other versions make clear, they mainly serve as teachers of the males (as the Kamoro mother does with respect to lovemaking and copulation). It is their sons who, as culture heroes, then take the stage and perform the ceremony, either by imitation or on their own initiative. Males are also considered the main instigators of various other Asmat institutions. It is telling for their patri-oriented tradition that an Asmat male culture hero cum ancestor produces culture hero sons from his arms; however, note that these sons are generated by spirit women. The matri-oriented Kamoro oral tradition knows only of ancestresses producing culture hero offspring.

It is important to note that the external, differentiating foreign historical impetus still depends for its signification on a common internal motivation. It is telling that the final sequences of both the Ema Kame and Emak Cem myths, each in their own way, concur in attributing the creation of Western commodities, wealth and tools to the geographical-mythical, far western part of Mimika, the underworld.

The ceremony, both Kamoro and Asmat, clearly has its mythical roots in the female physiological genesis of man, versus his male social genesis. Ema Kame/Emak Cem signals the transition from childhood to adolescence. It is a rite of passage. In accordance with the myths, the ceremony is classified as 'female', not only by the Kamoro, but also by the Asmat. ${ }^{10}$ It is also telling that the Emak Cem ceremonial house and the location of the events of the ceremony, like its Kamoro counterpart, stand apart, whereas all the other Asmat rituals dealing with social genesis are directed from and performed in the men's house.

The Emak Cem centrepiece, the spirit canoe, both as object and as ritual, constitutes a perfect socio-cultural symbol of the life cycle: the honoured dead depicted in the canoe are invited to depart for their abode in the underworld, while the 'new arrivals', the newly born, the young males, are literally marked as their successors, stretched out on or in the vicinity of the spirit canoe. The marking takes place on the turtle, that is, the mythical lord of the land, the land of 'our children'. ${ }^{11}$ The marriageable boys are marked again, but then

$9 \quad$ See Zegwaard in Offenberg and Pouwer 2002:96.

10 Gerard Zegwaard, personal communication, 5-6-1996.

11 For an example of the turtle as lord of the land, see Zegwaard in Offenberg and Pouwer 2002:213. 
together with younger sisters outside the ceremonial house: the basic pair for social exchange between groups by means of marriage. So, filiation, descent and marriage, the basic mechanisms of social continuity, the business of males, are carved out in both a literal and a figurative sense during a 'female' ritual.

There is a striking functional similarity between the Asmat ritual centrepiece, uramun or wuramun, the spirit canoe, and its Kamoro counterpart puru mane, the two sacred boards. How do the two relate? Let us take the puru mane as the starting point for our comparison. As described in Chapter II, the board placed in the centre represents the putative matrilineal or matri-oriented ancestress of a neighbourhood, whereas the other board, serving as a threshold for the initiated who go over it and the uninitiated who go underneath it, represents the husband of the ancestress. The ritual simulates the birth from the ancestress. The sacred boards are part of an elaborate matricentric fertility complex displayed in the Ema Kame ceremony. It includes the famous statues of pregnant females, representing the ancestresses standing in front of the ceremonial house, examples of which were seen and collected as early as 1913 among the Sempan living inland on the Otakwa River. The location of these statues is by no means accidental: it points to the Nafuaripi/Sempan origin of the Kiawa and Ema Kame ceremonies. Also part of the complex are three sacred ceremonial shields varying in size, which depict the ancestress, her husband, and the peraeko subdivisions of a taparu kin group, together with their voices, the sacred rattles. A further part of the matricentric fertility complex is the Meamo platform, with its manifold vegetative paraphernalia promoting growth and fertility, and its staged bat dance of sexual intercourse. Add to this the female dignitary who brings the effigy of the ancestress to life with a torch. Last but not least, there is the dramatization of the mythical uprising of the amoko kaoka, the superwomen who wage war with men, and the glorious return of the initiates, who act out the narrative of the young men who deserted their wives by turning into hornbills. It is true that there may not be a myth which specifically accounts for Ema Kame, but this does not detract from the fact that the ritual is replete with denotations and connotations of central Kamoro myths and sacred songs. They include the (imported?) narrative and song of the monster from whose body mankind was socially articulated. The monster (and its explicit connection with the underworld cum world of the foreigners and their wealth) had such an appeal all over Mimika that it rates as the quintessential Ema Kame myth. Ema Kame is mythologically associated with the coast of Mimika's far western part immediately adjoining the hinterland, in spite of its real, historical inland provenance in the far eastern part of Mimika.

This elaborate complex emphasizing the female and matri-oriented orientation of Kamoro society and culture is simply missing from (or at least unreported for) the Asmat Emak Cem ceremony. The very elaborateness of the 
Kamoro ceremony, contrasting with the far simpler Emak Cem ceremony of the Asmat, points in my view to Ema Kame as an age-old institution capturing the main orientation of former Nafuaripi-Kamoro, originally an inlandoriented culture and society, which was subsequently 'flooded' by migrations of much more numerous coastal communities for whom the 'male' Kaware ceremony was a major ceremony shared with the coastal Asmat.

Admittedly, a major element of the Kamoro complex, even the sacred centrepiece of Ema Kame, the set of puru mane, is present in the two Emak Cem boards (they are even positioned similarly), but it is not the element itself which matters; it is the relation of the element to the other elements of the complex, in other words it is the element as complement, as relatum, that counts. The Asmat boards, named after certain kinds of fish, the meaning of which is unfortunately unknown to me, are not likely to represent an Asmat ancestress and her husband. The Kamoro rite of acting out a matrilineal or matricentric emanation from the vagina of the ancestress carved out in the central board is absent in the Asmat ritual. On the relevant Asmat board the mopere, a pervasive motif in Kamoro carvings, does not occur. The special and sacred ceremonial shields, representing the ancestress, her husband, and her matrilineal offspring, are likewise absent in the Asmat ceremonial house. Instead, the two Asmat boards, apart from their general, non-specific identification with the spirits of the group, are used to scare the initiates and their mothers. The link of the initiates with specified dead persons of their yew is expressed and acted out in the spirit canoe. So there is a substantial shift in central signification from Kamoro puru mane to Asmat wuramun, in spite of some similarity in name. The spirit canoe belongs to the Asmat male-centred complex of warfare, to which also belong the multiple military and ritual war shields. The latter are part of eco pok, that is, the act of revenge and the multiple objects named after the persons killed in battle which constantly and compellingly remind the living in everyday life to take revenge. These objects include canoes and parts of canoes, houses and their components, spears, paddles, bags, dogs' teeth used for decoration, even dogs themselves and pigs. A bundle of firewood may be called after a person killed and then presented to people with the intention to urge them to take revenge. ${ }^{12}$ The objects offer a vivid illustration of Shakespeare's 'The very dogs bark at me'. The elaborate complex of traits of warfare clearly demonstrates the main orientation or focus of Asmat culture. It is this central orientation which has reinterpreted the elements and complements of the Ema Kame ceremony borrowed from the inland Nafuaripi. It is paradoxical that the Asmat shields, which are so explicitly present in their society and culture, have nevertheless not been converted 
into ceremonial shields (yamate) in Emak Cem, in contrast to the Kamoro Ema Kame in which ceremonial shields signifying the dead are a paramount feature. The Asmat war shields, including ceremonial ones, are evidently too much part and parcel of a different culture complex. Their manufacture is even the subject of a separate ceremony. ${ }^{13}$

Another example of a similarity in name which disguises a substantial difference in meaning and function is the use, by the Sempan and their Asmat neighbours, of a similar name, namely Kiewa kasha (ritual secret) and kasha cem (ritual secret house), for two quite different secret and sacred rituals, each deemed of major importance by its participants: the Kamoro Meamo ritual, staging fertility and sexual intercourse followed by regulated promiscuity, and the Asmat offering of gifts to and identifying with the spirits. ${ }^{14}$

One even wonders whether the ultimate Asmat ascription of Emak Cem to the myth of Ufiripic, who tried to convert his daughters into wives (M1), partially enacted in Emak Cem but absent in Ema Kame, is not in fact the result of an Asmat afterthought. A pre-existing theme, namely the paradoxical relationship of kinship to marriage, common to a number of Kamoro and Asmat narratives, may have been resorted to, irrespective of their specific ascription of Emak Cem to the mythical sisters and their sons (M7).

In spite of the differences arising from a dialectical interaction of Ema Kame and Emak Cem components with differing cultural orientations, the rituals do agree in the sense that both are a rite of passage from childhood to adolescence. As is usual with such rites of passage, the initiates are secluded and taught adult male secrets; they are confronted with spirits, laughed at, intimidated and frightened. In both rituals they are addressed as and ordered to behave like flying foxes (Kamoro: tako, Asmat: tar). In Kamoro daily life, flying foxes are a laughing stock. ${ }^{15}$

These creatures are associated with women. A small type of bat functions as a messenger in the central Kamoro narrative about the rebellion and trek of superwomen alluded to in the mock war of women with men in the course of the Ema Kame ceremony. In an Asmat narrative told in Ewer (Flamingo Bay), a set of aprons left behind in a bag suspended from the central pole of the men's house by the mythical woman Tewerawoc and her equally well-known husband Biwirpic, appears to have been transformed into women when the husband returns to pick up the bag. He pities their fate in being left behind,

13 Yokapem, cited in Konrad, Konrad and Schneebaum 1981:44.

14 See Coenen 1963:70. See also the discussion of the bat ritual in Chapter II of the present book, and Konrad, Konrad and Biakai 1995:248-9.

15 Sowada 1980a; Zegwaard n.y.b; see also Zegwaard's comment on an Asmat myth collected and published by Sowada 1979, in Zegwaard n.y.a. 
whereupon the women turn into flying foxes. ${ }^{16}$ One wonders whether there is a remote link between this Asmat story accounting for the female origin of flying foxes and the fact that in the Kamoro ritual the initiates behave like flying foxes when suspended from the central beam of the ceremonial house. The wings of flying foxes when hanging on the branches of a tree apparently evoke a comparison with women's aprons.

So, for men, initiates are a laughing stock associated with women, women who nursed them and from whom they will be separated when reaching adulthood. The Asmat scene of the roof-crashing boy symbolically shot at by men signifies the end of seclusion, but evidently also functions to frighten women.

Another common feature is that both the Ema Kame and Emak Cem ceremonies are explicitly meant to promote fertility. At the conclusion of the Emak Cem ceremony both the male initiates and their sisters receive blows to promote their growth and fertility. However, the Ema Kame ceremony is far more explicit and elaborate. The association of Ema Kame with female sex, gender, fertility and reproduction is far more explicit, variegated and sophisticated than its Asmat counterpart. This and other Mimika rituals excel in mimicry, theatrical effect, and sophistication. The explicit Kamoro Ema Kame association of female-male complementary opposition with central narratives and myths is striking. Ema Kame also includes vividly portrayed scenes and ceremonies, which are absent in Asmat Emak Cem: the rattan ceremony, the Tama ritual of women's secrets, the elaborate display of magnificently carved yamate, and last but not least, the glorious return of the initiates adorned with spectacular head ornaments of stylized hornbills. Finally, the Kamoro carvings decorating the beams are much more elaborate.

Admittedly, the spectacular carvings of the spirit canoe offer a magnificent display of craftsmanship, but on the whole the Asmat ceremony is far less sophisticated and elaborate than the Kamoro one. Also, there is a ceremonial inauguration of freshly made and magnificently carved war and ceremonial shields (yamesh), named after and representing selected males who have recently died. The mainly abstract carving pattern is clearly anthropomorphic. These shields are displayed in the men's house, not in the emak cem, and this ceremony belongs to the male sphere. For more details see Yokapem (1981) and Zegwaard (n.y.g.).

A third common feature, which physically marks the transition to maturity, is constituted by scarifications. Coenen noticed in the 1960s a scarification on the left buttocks of Kamoro men and women above the age of 45, a sign of their having fully participated in the last complete Kiawa/Ema Kame rituals 
35 years earlier, celebrated in the 1920s or 1930s. There were not many such persons left. The scars were oval-shaped, resembling a mopere, a navel with a cross inside (Coenen 1963:70). It is likely that these were applied outside the ceremonial house, as during Emak Cem. Wollaston, when he observed a ceremony around the sacred board in the centre of the house, would no doubt have noticed scarification if it had been performed at that time, but he makes no mention of it. Scarifications did exist at that time (1910). Wollaston's team member Cecil Rawlings reports that all men in the settlements of Wakatimi and Parimau, downstream and upstream the Mimika River respectively, had a 'tribal mark' on their buttocks in the shape of a diamond with three lines radiating from the corners (Rawlings 1913:60). He noticed the same 'tribal mark' in the settlement of Ibo, upstream on the Kamora River. Women did not have such marks (Rawlings 1913:145).

One may visualize the historically mediated relationship between Ema Kame and Emak Cem rites of passage by means of a triangle. The top corner represents a 'female' matri-oriented elaborate fertility complex. The left corner of the base stands for an extension to an articulation of mankind and of wealth, conditioned by an interaction between the western coastal part of Mimika as the main locus of historical commercial intrusion by various categories of foreigners and their wealth on one hand, and on the other the participants' association of the western coast with the underworld. The right corner of the base represents a meeting, merging, reinterpretation, and even partial replacement of the complex in confrontation with another society, namely the intruding Northwest Asmat, conditioned by a male and patri-oriented cultural orientation of warfare and headhunting. 



\section{Chapter ViII \\ Honouring the dead Asmat display and performance}

\section{The myth}

The Kamoro display of ceremonial shields, meant to recall (literally as well as figuratively) and honour the dead during Ema Kame, has its spectacular Asmat counterpart in the separate coastal Yipae ritual, called Nat Pokmbu inland. Its grandeur and socializing effect probably match Ema Kame. There is a difference, though. Yipae's centrepiece is not a show of ceremonial shields but of masked performers, who likewise represent the dead, more particularly selected deceased persons of repute. Yet there is a similarity as well: the Asmat masquerade has much in common with Kamoro Mbi Kawane, the spirit platform ritual (Chapter V).

Zegwaard (n.y.g), commenting on a report by Yokapem of Ac about a shield ceremony in his village in 1978 (Konrad, Konrad and Schneebaum 1981:44), writes that Yipae together with Mbish and Emak Cem constitutes the 'female' component of Asmat society, as opposed to the 'male' component consisting of Yew Mbu, the ritual construction of a new men's house, Ci Mbu, the making of canoes and spears, and Yimis Pokmbu, the making of ritual and war shields. The 'female' component, he points out, articulates the position and functions of women and their part in bearing children, especially male children. I would say that it articulates social reproduction, as it does among the Kamoro. Therefore, it seems to me no coincidence that the mythical origin of the Yipae mask, the spirit's costume, and the masquerade is ascribed to an orphan boy who was denied the care he was entitled to. He invented a masquerade in order to redress the balance. It was his ruse which induced men to introduce the secret Yipae ritual. This ritual sees to it that never again will an orphan be neglected: every orphan (whether male or female) is provided with new parents and relatives.

A compilation of the narrative as written down by Zegwaard in various versions, in Kapi (inland) and Shuru (coast) in 1954, and a brief version by 
Frank Trenkenschuh in Ac (inland) in 1969, follows. ${ }^{1}$

Ayirat, an orphan boy whose parents were killed in a headhunting raid [Shuru version], lived in a settlement upstream on the Yic River [Bloemen River, Northwest Asmat, Kapi version]. He was very skinny. Nobody in the village would give him any food. Nobody felt responsible for him. He lived on stolen food and on sago chewed and spat out, collected underneath houses. When he tried to catch small fish or to collect shellfish while sitting in a canoe, people pelted him with lumps of clay, fruit, and sharp wood splinters from one side of the river. When he fled to the other side he was attacked from there. He was treated like a dog. Desperate, he sought the support of his very old grandfather, the only relative he had left, who, however, no longer had the means to help him out. He then thought up a trick and enlisted the secret cooperation and advice of his grandfather. Ayirat collected a lot of bark fibres (fum), dried these, then wove cords from them, made himself a rattan belt and attached, while plaiting the cords, a sort of cloak to it; he also plaited a hood. [The story gives full technical details of how these items were made.] He used these to completely cover his body. Then, hiding himself along a path - or river - which women used on their way back from gathering sago, he jumped into their midst. The terrified women, thinking they were being attacked by a spirit, dropped their bags, tools, and sago shoots. The boy made off with the loot. In a similar way he collected firewood and fish, and repeated the trick on the following days. The women, at their wit's end, enlisted the support of equally terrified men. A number of men laid an ambush and captured the spirit. Ripping off the cloak they found the boy, who began to cry, and then explained why he had frightened and chased the women as a nat imu or yipae (mock spirit). The men took pity on the boy and admitted that they were wrong. They talked the matter over and agreed among themselves to keep the spirit business a sacred secret. They decreed that upon the death of anyone in their village, some other villager who could afford it would put on the cloak and the mask and pretend to be the spirit of the dead person. Any orphan, any person left by himself, would then call the performer his father (or his brother) and the performer would adopt him as his son (or brother). Never again would there be an abandoned orphan.

It is interesting and meaningful that this myth accounts for the origin of the sacred mask representing the dead, and not for the (profane) mask of the orphan boy himself, merely meant to frighten the spectators. The two masks relate as older to younger brother and as sacred to profane (Zegwaard 1991). 
The sacred mask is carefully stored away and hidden after use, while the fun mask is jettisoned or left for children to play with until it falls to pieces. The complete costumes including the masks are known under different names, depending on the regions in which they are made, ranging from Flamingo Bay to coastal and inland, north and northwest Asmat areas. The sacred mask is called spirit (bi yumbo, dat yumo, dato, det or doru); the profane mask is called bunmar or manimar (orphan). In Pupis on the Wasar River, north of Erma-Saowa, where they call the Yipae ritual Yiti (yi or ye, 'spirit'; $t i$, 'child'), there is an additional costume, called yi wawoka (female spirit), representing a mythological old woman. The Safan group of the Casuarinen Coast calls the two types of spirit costumes dato and biu. ${ }^{2}$

\section{The ritual}

\section{Introduction, preparation}

The description of the ritual below is based on field observations by Zegwaard in Kapi (inland) in 1952 and Shuru (coast) in August/December 1954; by Eyde in Ac (coast) on 29 August 1961 and thereafter; and by Sowada in Erma/Sona (inland) on 10 April 1962 and thereafter. ${ }^{3}$

The Indonesian authorities prohibited Asmat ceremonies in the 1960s and destroyed men's houses, on the erroneous assumption that these ceremonies promoted headhunting and cannibalism. With the advent of tourism, the authorities adopted a more relaxed attitude. The Asmat took advantage of this and, in spite of a lingering prohibition by local authorities and belittling comments about it being evil, stupid and backward, they resumed celebrating Yipae in the early 1980s. Celebration of Yipae was resumed, according to Sowada (n.y.), after almost twenty years, in 1981 (Erma/Sona) and 1982 (Shuru/Ewer).

Preparations for the ceremony involve the sensitive question of which persons' deaths will be commemorated and, even more sensitive, who will be invited to represent the dead in the masquerade, which in its turn implies the question of who will weave the masks (Zegwaard n.y.e:44-7, 1991). Informal,

2 For this information about costumes and for magnificent photographs, see Konrad, Sowada and Konrad 2002:326-39.

3 For the texts, see Zegwaard 1953-56 (Kewa 83-6), n.y.e:44-7 and 1991; Eyde 1967:338-44; Sowada n.y. and 1995a:215-25. The latter is a German translation of his original, mimeographed report in the English language, undated but written in or after 1983 and available in the Zegwaard Archives. It describes the celebration of the inland version of Yipae, called Pokmbu or Pokomban. I used the English text. 
complicated talks require many weeks. They take into account the strength of the various yew and the competition between them. Discussions involve personal prestige, conflicts and brawls, and aim at participation by all groups.

On this occasion the outcome of the informal talks was confirmed in a formal meeting (ashu mapom cemes). Four dead men were selected, three of them members of or related to a particular yew, though not necessarily residents. The son of the fourth man, from a different and leading yew (Ar, see Figure 4), took the initiative. Being a soldier in the Papuan army, he felt called upon to commemorate his father, the victim of a headhunting party. However, he did not enlist the support of his own yew: because of considerations of prestige, neither the older men nor his age-mates were willing to accept his guidance. With some difficulty he succeeded in gaining support from the Mbait yew of the other three dead men. His position was presumably a marginal one, since he had migrated from elsewhere (see Figure 4). A leading man from this yew wished to commemorate his only child, who had died young, and his halfbrother's son, who had fallen ill shortly after marriage. The reason for selecting the third man is not clear.

In Erma/Sona seven deceased men from past years out of Erma's eleven yew were selected: four from the main host, the Apen yew, and one each from four other yew, which I presume belong to the opposite moiety. Apen's longhouse was to be the main avenue for the ritual. Sowada (n.y.) does not mention the reasons for selection.

As to the important question of who was to represent the dead by wearing the mask and the spirit costume, Zegwaard notes that the oldest man at the official meeting offered an arrow (as a token of agreement) to each of the assembled men. Initially nobody accepted the arrow, explaining that they had no stone axes or any other valuables. After that, however, the principal leader named the persons who were still willing to meet the challenge: they accepted the arrows in silence on a tacit understanding reached beforehand. The reasons for acceptance were not quite clear to Zegwaard. A man who accepted an arrow wore the mask representing the deceased, and even replaced the dead man by adopting his name. By so doing, he was adopted as a relative by the family of the deceased.

Affines of the relatives were excluded from representing the dead because of the difference in status between affines and relatives. The only (but fairly common) exception to this rule is the exchange partner, that is, the real or classificatory brother of the wife of the deceased, involved in the brother-sister/ sister-brother, direct or delayed exchange of women between moieties for the purpose of marriage. The relationship between exchange partners is a very close one among the Asmat, as it is among the Kamoro. They look after each other's children in any case.

There is hardly any information about the selection of the man who is to 
wear the orphan's costume, except about the selection in Erma/Sona, recorded by Sowada, of a middle-aged man. He had no wife and children and very few people he could depend upon. A man from his yew adopted him, gave him sago and an axe and the name of a deceased son. The adoptee was thereby admitted to the circle of relatives of the name-giver.

Sowada is the only one who provides details about the weavers of the individual masks representing the seven dead. The relatives directly or indirectly involved in fashioning the mask (from the point of view of the person responsible for paying the mask weaver) were: mother's brother $(3 \mathrm{x})$, wife's brother $(1 x)$, sister's husband (1x), younger classificatory brother from a different yew (1x) and classificatory father from a different yew (1x). So maternal, affinal or classificatory kin were mobilized for recruiting the services of weaving specialists.

With regard to the wearing of masks, there is a marked difference between the Asmat and the Kamoro. The Kamoro wearers for the spirit platform ritual are selected from among the bride-receivers of the deceased; these persons represent the dead but do not replace them, nor are they adopted. They fulfil social obligations as bride-receivers and even have to pay compensation money for their performance, to make up for the grief inflicted on the relatives of the dead (who later reciprocate by giving counter-gifts).

In the Shuru case there was also foreign influence, as perceived by the participants. Two out of four of the mask-wearers were outsiders originating from elsewhere; these two men secretly cherished the hope that in the end they would be rewarded for their services by being allowed to exchange their stone axes for steel ones, available in Shuru but not in their own settlement. Younger men working for foreigners in Shuru or elsewhere were favourite candidates. Quite a few older men in Shuru who did not have this access to commodities or were short of traditional valuables, flatly refused to wear the masks. They feared being unable to meet the cost of the offerings they were supposed to make as a reward for being adopted by the family of the dead. The reward is expected to exceed the counter-gifts offered to them.

Those who are going to wear the spirit costumes are called yunum eperak (people to whom strings of sago leaves are attached, to cover their bodies). It is a pseudonym for the real name, fum, that is, the bark cord of which the mask is fashioned. This name is taboo (karo or puri). The named wearer of the masks and his helpers (ofew, 'brothers') who agreed to assist him were immediately showered with gifts of food, to be reciprocated by return gifts throughout the ceremony.

The ceremony opened with massive wailing by the women as an expression of sorrow for spirits of the deceased who were not present to celebrate (Sowada n.y.). The men engaged themselves with collecting and drying the 
fum bark and plaiting cords from its fibres for specialists to use in making the masks. Weaving the masks and preparing the costumes take several weeks or even months. During this period the cord plaiters and in particular the weavers were treated to plenty of food in the men's house of the main host, by relatives of the deceased men being honoured. An abundant variety of food was essential, because mask-weaving 'drained' energy and required replenishment; it was important to ensure that no weaver would become ill and fail in the monumental task (Sowada n.y.). All the members of the weavers' families shared the food. The weavers did not work industriously but in a relaxed way, and they took time to enjoy the exquisite food given them.

Women and children were not allowed in or near the men's house where the weavers were at work. Seeing the taboo masks, the names of which are equally taboo, could cause sickness (Sowada n.y.).

Almost every night women, especially the younger ones, indulged in mock attacks, hitting out at men. This is called faimuc, the literal meaning of which is 'peace' (Zegwaard 1991). Men started the game by challenging the women, calling them names, such as 'you with your tiny turtle head, flat fishy nose, red eyes, baggy chin, fat belly', and so on. Sexual allusions were not allowed (Zegwaard 1991). The women playing at being angry rushed out of their houses and chased the men. In Erma/Sona the headmen and adult males from all yew paddled canoes slowly along the village shore, shouting and hitting the sides of the dugouts. As they passed by each section of the village, women, decorated as warriors, shot blunted arrows or arrow tips wrapped with burning grass at the men. While handing chunks of sago to the men, they simultaneously burned them with firebrands (Sowada n.y.). This shows a marked similarity with Kamoro women waging war as part of the Ema Kame ceremony (see the Tama ritual, Chapter II). In Shuru the men apparently imitated an upright stance in a canoe by carrying a thin trunk on their shoulders in a row; they walked up and down the festive grounds. The women attacked them with arrows, spears and daggers, though with no intention to inflict serious wounds. Yet men often did get wounded, presumably by accident. In Erma/ Sona the men compared the scars they had received from the firebrands and burning arrow tips and bragged about them. A man who got an exceptionally large burn on his back took immense pride in it, for it illustrated a woman's special sentiment for him (Sowada n.y.). Male participants in wife-swapping were favourite targets. In Erna-Sona Sowada witnessed the performance of three older men and a woman as jesters. The men waged mock fights among themselves and sometimes attacked the woman with feigned thrusts of their daggers, whereupon the woman fell on her back, kicked her legs rapidly, and squealed. At other times the men boarded a dugout, and paddled in opposite directions from each other until the canoe overturned. They playfully attempted to drown each other. They also made bawdy remarks directed to 
those about to marry.

The purpose of these faimuc, which are also called akapes (compare with Kamoro akapa), is to create a pleasant, relaxed, friendly, festive mood, which enables both female and male participants to ventilate aggression and affection without really endangering social relations, hence the equation of faimuc with peace. Hidden or explicit grievances about not living up to the requirements of affinal exchanges were publicly expressed in a relaxed atmosphere, and new marriage deals proposed or made. Yipae, like the Ema Kame/Emak Cem ceremony, contributes significantly to social harmony.

According to Zegwaard (n.y.e:44-7), akapes stands for the scarification of women and adolescent girls by their husbands or brothers, performed intermittently during the mock attacks in coastal Shuru. Apparently scarification, at least in this context, functions as a form of retribution by men for the scars they have received from women. Its designation as akapes seems to imply that this scarification of women by males is conceived as a playful act.

Scarification is not reported for Erma/Sona and Kapi, which could point to its inland origins as part of the Emak Cem ceremony. Sometimes these scarifications depict snakes, frogs, discs associated with headhunting, or shells used as nose ornaments.

Another link with the Emak Cem ceremony is the songs relating the exploits of the culture heroes Kurap/Sarawap and Fumiripic, especially their adventures in the far western part of Mimika, the underworld. To these culture heroes, in a 'modern' extension of the story, is ascribed the creation of Kamoro and foreigners. The song about Kurap was repeated a thousand times. In Shuru, the Fumiri so (song) performance in the open air took a full night. This song is sacred and retells the myth associated with Tow Mbu and Yew Mbu, the paired ceremonies for the inauguration of a new men's house, the counterpart of the Kamoro Kaware ceremony. Women and children were not allowed to attend (Zegwaard n.y.e:44-7).

By day the details of an orally expressed cognitive map of the territory claimed by the settlement were recounted in song by reciting the names of significant varieties of trees, birds, animals and fish, moving from upstream to downstream. This was a way of informing the spirits and their mates, represented by the masks, that the ritual was soon to begin. The spirits were supposed to come from the upper world to the seaside-underworld. Represented as toothless, they are said to hide themselves in the aerial roots of trees near the festive centre.

The anthropologist Eyde, especially interested in socio-political organization within an ecological context, gives a vivid and detailed description of gift transactions during the afternoon preceding the appearance of the masked impersonators of the spirits in Ac on 29 August 1961 as soon as the masks (yinic) were completed: 
Two masks of the dead were moved to positions in the men's house in front of the fireplaces of the men they represented. There was one jinic mask on each side of the men's house. There, they were tied upright with strings of rattan from the rafters. The members of the men's house group then began to bring large lumps of sago into the men's house. The first sago was brought in by a woman who was the daughter of one of the men represented by a jinic mask. She put her sago down by that mask and then left the men's house. In the other half of the men's house the first sago was laid down by [...] a younger brother of the man represented by the jinic mask.

Once these representatives of the two groups, which 'owned' the jinic masks, had laid down their sago, the group-wide donation of sago began. Both men and women of all the conical kindreds [bilateral kin-groups] within the men's house group brought in lumps of sago. On one side the sago was laid down in two piles, one towards the centre of the men's house, the other towards the end. One of these piles was formed around the jinic mask; the other was not piled around anything. In the other half of the men's house three piles were made, one around the other jinic mask.. [...] The piles laid down did not correspond to [single] doorway sections of the men's house, but rather to pairs, except in the case of the third pile on one side, which did not correspond to a single doorway section. The two sponsors of the feast, who were important men in the conical kindred that owned the masks, also made two smaller piles of sago on either side of the central fireplace, wojir. A small pile of sago was laid by one man around the clown mask, manimar, which was set in front of, and to the one side of, the central fireplace. As each man brought in his contribution of sago there was a roll on the drums, and the chanters and drummers shouted, 'Waah!' A really impressive amount of sago was collected. Almost the entire floor of the men's house was finally covered. Some people, who lacked enough sago, contributed coconuts and bananas to the piles.

When the donation of food was completed, the men of each moiety picked up all the food on their side and carried it piece by piece to the other side, where it was laid down once again. After the food had thus been exchanged between moieties, it was then distributed among the visiting guests from other men's house groups. The older men on both sides oversaw this distribution, making sure that no guest of importance could feel slighted.

The sago laid at the sides of the central fireplace and around the clown mask was taken by the men who made and decorated the masks and by the men who danced in them. There was no kinship relation here. This was payment to an expert [the mask weaver] for a service. This sago was not moved in the exchange of sago between the halves of the men's house group. (Eyde 1967:339-41.)

Eyde then gives the details of another pile of sago, opposite the pile around the clown mask. This sago was given in return for the gift of a pig, which had nothing to do with the ritual. However, as Eyde points out, this pile made the layout on the floor of the men's house approximately symmetrical.

This fine description by Eyde of his on-the-spot observations highlights the crucial importance of the distribution of food by gift giving and giving in return, of the spatial and relational precision, and the impressive quantities. 
The distribution of food is a most serious affair, affecting the prestige of both givers and receivers. In addition, it highlights dualistic organization and spatially expressed symmetry. It also demonstrates the dominant role of sago in the 'female' Yipae ritual, as opposed to the major significance of sago grubs in 'male' rituals, discussed below. Sago is associated with women, sago grubs with men, and both are associated with growth, fertility and vigour.

\section{The masquerade}

Late one afternoon, the whirring sounds of bullroarers were heard from the woods behind the village, an indication that the manimar, impersonating the orphan boy, would soon arrive (Sowada n.y.). By daybreak he appeared on the opposite bank of the river, performing a lumbering dance in his elongated, inverted basket mask to which sago fronds were attached as a skirt:

He was helped into a dugout and stood in it swaying from side to side. [...] As the dugout came closer to the village the shouts of the people increased in volume. [...] Once helped to the shore, the people shouted in unison three times and then became silent. Manimar stood solemnly facing the people, swaying from side to side. Suddenly he began to dance disjointedly, occasionally making abrupt advances towards the people. They backed away with shouts of surprise. He hopped about more rapidly, and finally charged at the row of people. He chased individuals, especially children. They pelted him with seed pods, shouting that he leave the village for he was an intruder. They screamed that he had no right to enter the village for he had no father, mother, brothers or sisters in it. Therefore he had no right to ask for food. Manimar continued his awkward dance down the village pathway. The children pelted him continuously. He reached the house of Juak [the man who adopted him, as described]. Juak welcomed him and gave him sago to eat. [...] He reappeared throughout the day to chase the children, who loved it. Late in the afternoon, he disappeared. (Sowada n.y.:9-10.)

It is obvious that the manimar myth is enacted selectively, mainly as a source of derisive fun.

The following day, in the late afternoon, the masked spirits appeared from the woods in an open area slightly behind the village. Older men and women, relatives of the deceased, went to meet them. The leader of the ceremony told them that the spirits, having come from the far west (the underworld), were very tired and were asking for food. Tomorrow they would leave. He told their names (Zegwaard n.y.e:44-7). The women wept and touched the masked figures. The men hung parcels of sago grubs (Zegwaard n.y.e:44-7) and decorated bags (Sowada n.y.:10) on them. They were welcomed with a cloud of lime powder. They were asked whether all was well with them, to which the spirits only nodded their heads, since spirits cannot talk. They were then led 
to the village, sometimes to their former houses, and given sago. At dusk they were taken to the festive platform in front of the men's house, and suddenly treated to a mock attack (Zegwaard n.y.e:44-7). They returned to the woods, to come back later and mingle freely with the dancers on the festive platform in front of the men's house (Sowada n.y.:10). They often climbed into the men's house to have other men, their 'brothers', secretly put on the masks, as these are heavy. There are many parallels with the Kamoro spirit platform ritual, except for the free mingling of men and women.

The (Asmat) spirits would pull on the budding breasts of little girls and the penises of little boys in order to further their growth (compare this to Emak Cem). Arrows may be attached to a mask as a sign that the persons represented were killed in battle.

Dancing and singing continued until sunrise. The masks were then donned again by the principal men entitled to wear them, for instance by an older brother of the deceased. Standing straddle-legged, these men were then presented with big quantities of sago gifts (Zegwaard n.y.e:44-7, compare this with Eyde's observations). They were then taken to the end of the village, bade farewell, and told to return to the spirit world. As with the Kamoro, the Asmat attitude towards the dead is an ambivalent one - of fear, respect and superiority. In Kapi (Zegwaard 1991) and in Ac (Eyde) the mask spirits were 'killed' by hitting them gently with a wooden board. Seeing to it that the women did not attend, the men sent them home and informed them afterwards about the killing (Zegwaard n.y.e:44-7). In reality the masks were secretly stored and hidden. Presumably the women, especially the older ones, were in the know, but they played the game throughout the ritual.

\section{Donning the armbands}

After the exchange of food marking the end of the masquerade, the weavers set themselves to fashioning kon armbands, using the split rattan that had been prepared for fashioning the masks and secretly stored in mats. They wound fibre from the inner bark of the paper mulberry tree around the rattan and attached a plume of cassowary feathers to it. Each armband was given the name of an honoured dead person. Compare this with a ceremony - performed as part of the Ema Kame rattan ritual - in Umar and Potoway (in the far western part of Mimika). Similar armbands (koni), each representing a particular deceased person, are cast around a stick while the name of the dead person is solemnly pronounced (see Chapter II). Before they are used, the armbands in Asmat are as sacred and taboo as the masks. They are never offered in ordinary, non-ceremonial exchange. In Erma-Sona 57 arm- 
bands were made. ${ }^{4}$ The armbands were meant primarily for the men who impersonated the dead in the masquerade, and for their relatives (Zegwaard 1953-56, Kewa 83-6; n.y.e:44-7) but, presumably by extension, were also given to persons similar to the deceased in terms of body shape, facial features, mannerisms, or abilities (Sowada n.y.). Some close relatives of the deceased took the impersonators of their dead to the latter's home, where all his relatives had assembled. There each individual relative selected an impersonator and one of his relatives, matching their sex and age, took them to their homes, and dressed them up with hair extensions, armbands and calf bands made of sago fibres and sago leaves (Zegwaard 1953-56, Kewa 83-6; n.y.e:44-7). Men in the men's house shouted to hurry up. The decorated persons were then taken to the festival ground in front of the host's men's house and placed in parallel lines facing each other, according to the deceased individual who was being honoured (Zegwaard 1953-56, Kewa 83-6; n.y.e:44-7 and Sowada n.y.). In Shuru six to seven persons per deceased were selected. Only adult men, women, and male adolescents about sixteen years of age were chosen. In the men's house red paint was applied to their faces and, in some cases, on the torso. Black, white or red dots or line designs were applied to their faces. Circles or squares were painted on the shoulder blades and around the breasts and navels, using white or black or both (Zegwaard 1953-56, Kewa 83-6; n.y.e:44-7 and Sowada n.y.). They were given decorated spears connected to each other. They held them in their hands, parallel to the ground.

Then the ceremony, during which the decorated persons were adopted by the relatives of the deceased, began:

Senior men [taking the kon armbands from a spear to which they were attached, Zegwaard n.y.e:44-7] slid the kon over the right hand of each individual so that it hung on the wrist. This was a signal to the drummers to beat the drums rapidly. At the closing crescendo of beats, the adoptees raised the spears to chest level, yelling 'whuuh' along with the rest of the people. The crescendo was repeated twice more; each time arms were elevated higher so that the kon slid down to the upper arm, where it is properly worn. (Sowada n.y.:12.)

The relatives of the deceased then offered stone axes, spears and arrows in their homes to the adoptees, and these were reciprocated with similar gifts and food in the adoptees' homes, but considerably more than the adoptees had received. The adopted relatives initially went out of their way to care for their newly acquired relatives. They were also frequently addressed by the newly adopted name of the deceased (Zegwaard n.y.e:44-7, 1991). Gradually their former, proper names were used again, but whenever the adopting relatives at some stage wanted to make an appeal to them, they could do so 
simply by addressing them by the name of the deceased.

The impersonation of the dead in the masquerade and the ensuing adoption of the impersonators and their relatives in the kon ceremony have a strong socializing and revitalizing impact. The deceased are replaced and the numerous persons involved are bonded together. This aspect of honouring and replacing the dead is missing in Mimika, where perennial headhunting and its serious negative demographic effects were absent. However, there is a comparable ceremonial 'adoption' as part of the Kaware ritual. Two or more masked men, accompanied by women and children who catch hold of a stick dragged by the dignitaries, formally designate selected men to fashion new canoes for their wives' parents, older brothers, fathers, mother's brothers, and so on, by having them don an armband of white fibres. The designated men are said to be 'adopted' by the women holding the stick. The latter give them food and roofing mats, to be reciprocated by fashioning and giving canoes. The ceremony is meant to put some pressure on men to fulfil their social obligations. The conspicuous role of women, 'adopting' men, including bride-receivers, is a good example of the difference between the Kamoro configuration and the Asmat (see Chapter III). 


\section{Chapter ix \\ Male to female Social opposition versus communal solidarity}

\section{The myths}

This chapter takes us to the 'male' socio-ritual sphere. Two out of the three Kaware myths (M1, M2) summarized in Chapter III are strikingly similar to, yet different from, their Asmat counterparts. ${ }^{1}$ In Kamoro $\mathrm{Ml}$ and its Asmat counterpart the two heroes of each set, though named differently - Kamoro Muanuru and Asmat Yenip - are also namesakes, one from the world-inbetween of humans, the other from the underworld. In this respect they are similar to the Kamoro heroes of the sun and the moon related to the upper world. Likewise, antisocial behaviour, namely brother-sister incest on the initiative of the brother (unlike Ema Kame) in the case of the Kaware and Yew Mbu myths, adultery with an older brother's wife (Kamoro sun myth), and theft by a neglected orphan (Kamoro moon myth), drives the hero out of his world and into the world beyond. In Kamoro M2 and its Asmat counterpart the terrestrial hero, Kamirima and Fumuripic respectively (similar names, different language), arrives at the underworld after drowning in a dubious accident after having intercourse with his mate's mistress.

Also in line with the upperworld narratives, the earthly hero of M1 and his Asmat counterpart get the better of their underworld namesake. The plot is identical. They use a trick to pilfer their namesakes' 'fried' mussels or sago grubs (Asmat). In addition, the Asmat earthly hero appears to be superior to his namesake in being physically complete. The underworld hero's eye sockets and anus are stuffed. His earthly namesake opens them up with a bamboo knife. In spite of this benevolent service, the Asmat hero from below, like his Kamoro counterpart, punishes the earthly visitor for stealing his sago grubs (or mussels) by tricking him into the arms of a human mbish in the central pillar or - as in Mimika - a separate spirit pole. The victim gets stuck and is in the process of being tortured to death when his earthly relatives and affines arrive 
just in time to chop off the head of the underworld malefactor. The earthlings get off with the booty. There is a difference, though. The Asmat loot includes almost every item of material culture: the blueprint of the men's house and other ceremonial houses, war shields, eating bowls, various kinds of bags, a variety of tools, drums, and all kinds of ceremonial outfits and carvings. With canoes brimming to capacity, the men return to the village in triumph: 'That is why we now have men's houses, why we wage war and hold festivals. Thanks to Yenip, life has become worthwhile. [...] Some people learned to drum and sing; others learned to work wood. Each family was assigned a task. ${ }^{\prime 2}$ Before the exploits of Yenip, 'when people had not been living in this country for long, there were no yeu [yew]. [...] Each family lived and took care of itself. Their lives consisted of nothing but collecting food, eating and sleeping. There was no entertainment (Offenberg and Pouwer 2002:102).' In short, the Asmat ascribe their cultural heritage to the exploits of Yenip. This also includes the prescribed way in which the body of a victim of headhunting is dealt with. Yenip's sister cuts off the head of his underworld namesake after he has been killed. The rest of the body is butchered and cut up as they used to do with pigs of the forest. So Yenip-from-below rates as the first victim of headhunting. ${ }^{3}$ This 'total' ascription of society and culture to the exploits of Yenip seems to reflect and validate the central position of the yew and the men's house in Asmat society and culture. The Kamoro, however, restrict their narrative ascription of cultural items to the blueprint and paraphernalia of the Kaware house and ritual, but do include all the sacred songs of all their rituals, taught to them by a noma watersnake in the vicinity of the ceremonial house. This specific Kamoro addition seems to highlight the dominant position of males in oral communication with the sacred (puri) world of the dead and the spirits. In the Asmat story the watersnake teaches Ton Yenip the proper yew songs; he was singing the wrong ones. The Kamoro also owe to the culture hero Muanuru all foreign garden produce, such as coconuts, white pumpkin, papaya, breadfruit, taro and sweet potatoes; these are not mentioned in the Asmat version. This may equally reflect the important though not exclusive say of males in the ownership of garden produce, especially of the arboreal kind (Pouwer 1955a:151-6).

Kamoro M2 and its corresponding Asmat narrative initially revolve around the theme of life and death. An anthropomorphic sea eagle resurrects the dead body of the culture hero, washed up on an island, by spreading medicine on its vital parts with a smouldering stick (Asmat). In the Kamoro version the body is revived by a variety of scratching birds and stinging ants and wasps. 
This reflects what happens when, for instance, a woman in labour faints: the ipu (Kamoro), the spiritual life force that is supposed to have briefly left the body, is recalled by means of applying a smouldering stick to vital body parts. When the Asmat hero is brought back to life, he says that he did not even know he had been dead (Offenberg and Pouwer 2002:95).

After this common start, the Asmat and Kamoro versions, both widely known throughout the area, diverge. The Asmat hero, returning to the mainland and feeling lonely, builds himself a yew house and carves out men and women on small poles, and they come to life through his drumming and singing (Offenberg and Pouwer 2002:96). I presume that these 'small poles' are believed to constitute the foundation piles of the first men's house from which humans originate (Eyde 1967:335). Eyde makes the important observation that

[e]laborately carved poles resembling foundation pilings [though bigger] are carved during the spirit mask ceremonial cycle [Yipae] among the Keenok [inland Northwest Asmat], but not, to my knowledge, among the Kawenak [lowland Central Asmat around Flamingo Bay]. Even among the Kawenak, however, the pilings of men's houses which perform the Jipaj ceremonial cycle are crudely carved into human form. (Eyde 1967:335.)

While travelling west immediately after his creative act, Fumuripic repeats the exercise, thus bringing to life the people of other Asmat yew, of the neighbouring Kamoro settlements, and of other Papuan locations as far as Kaimana in the far western part of Mimika. He also creates the Surabaya people (white men), and arranges for the present location of Kaokonao, where he builds a big men's house and supplies the local people with iron axes. He then returns to Asmat, to the Fai River, where two of his sons supplied with guns were already living (probably a reflection of a police station in this area). He leaves for Kaokonao a second time, calls in there for a big feast, but then discovers that the people have stolen his axes. He shoots them all, but for one man and one woman from each river (who then multiplied). He then proclaims himself to be the District Officer, and arranges for his children to join him: they become the Chinese traders (who had a store in Kaokonao) and look after his supplies.

So the Asmat story accounts for their neighbours and for the foreigner, his wealth and power. By far the greater part of the myth deals with foreigners. The section on the District Officer was added by men from Ewer who happened to attend the telling of the story by men from Shuru (Offenberg and Pouwer 2002:97). This second part of the Fumuripic narrative, rather than being on a par with the second part of the Kamoro Mamirima story, resembles the Mirokoatayao story of Ema Kame. The two heroes have in common that they carve out the social groups of their kin, though in different ways: one 
from the flesh of the monitor lizard, the other from piles of the men's house. In this way the previously unknown is appropriated, 'kamoroized' and 'asmatized' respectively. The killing of the monstrous monitor lizard in the ceremonial houses constructed by the Kamoro hero is located on a beach on the far western border of the Kamoro area. The site of the men's house built by the Asmat hero is also located far to the west: on the shore of the mainland opposite the island where he was brought back to life. This site is said to be near the mouth of the Owap River on the far western border of the Asmat area. He himself originates from the Sirec River to the east in Central Asmat. (The site is not too far removed from the Kamoro island of Puriri in Pisang Bay, where Fumuripic's Kamoro namesake Mamirima is said to have been revived.) The Fumuripic narrative, like the Mirokoatayao narrative, is sung but not acted out during the Yew Mbu and Ema Kame rituals. This is another parallel, which might have a bearing on the 'foreign' subject matter.

The second part of the Kamoro Mamirima myth, instead of dealing with the articulation of social groups, foreign commodities and power, exemplifies Kaware ritual. Mamirima not only constructs its ceremonial house on the model seen in the underworld - like Fumuripic who builds the first men's house, the ritual centre of most Asmat ceremonies - but also initiates the ritual of male adolescents, who lie down at the central supports of the house as if dead, without a fire or loincloth, entirely naked, and with drawn faces like the dead. Evidently this is an enactment of the hero's death, followed by an enactment of his subsequent return to life (see Chapter III). The story also tells of his invention of the drum, in which he is assisted by a fish, which hollows out a block of wood. The drum serves to accompany the sacred songs acquired in M1. The story continues with the hero carving out a mbitoro and making the nokoro kao boards for the symbolic canoe of the culture hero Nokoro, two crucial Kaware ritual attributes. A malevolent earth spirit is annoyed by the drum, tramples it to pieces and kills the hero, who is hidden in the drum. His parents, meanwhile, arrive on the scene, mourn their son, and avenge his death by beating the evil spirit to death. They then thrust their lances into the sand of the shore: they wage a battle against the evil comrades of the killed spirit. This battle is acted out on the beach as a spectacular show: it marks the ritual end of the Kaware ceremony. Finally, in the story as well as in the ritual, Kaware is concluded by a social ceremony: a massive distribution of pile-worms and mussels among the guests 'from the east and the west', as the story has it (Offenberg and Pouwer 2002:102). All these enactments (except the distribution of food) are absent in the Asmat ritual.

So, the Kamoro differ from the Asmat in that there is a close correspondence between the myth and the ritual. In Tipuka, which rates as the Kamoro main centre of Kaware, the initiates are even confronted with the hero's dead body, while the Sempanoweof Inawka, who do not celebrate Kaware, never- 
theless re-enact his resurrection by birds (Chapter III).

The virtual absence of correspondence between the Asmat Fumuripic myth and the ritual of Yew Mbu/Tow Mbu on the one hand, and on the other hand the similarities to myths accounting for the genesis of ethnic groups, including the ethnic groups of foreigners and their wealth, give credence to Eyde's (1967:335) suggestion that Fumuripic's creation of humans from foundation piles of the original men's house is associated with Yipae, rather than with Yew Mbu and Tow Mbu. In addition, foundation piles of men's houses, where their occupants perform the Yipae ceremonial cycle or the related Firao Wu cycle, are carved into a human form, whereas piles of houses, where the men perform different cycles, are not (Eyde 1967:96). The sacred songs about Fumuripic (see Chapter VI) are performed together with songs of the Yipae heroes Kurap and Sarawap in the course of the Yipae ritual. Since Yipae originates from inland Northwest Asmat and this region is adjacent to inland Nafuaripi to whom the Sempanowe are related, the very fact that the Sempanowe of Inawka (who do not practise Kaware, yet re-enact the resurrection of the hero) seems to point to an original connection between Fumuripic and Yipae. Yipae relates to the Mbish ritual and to Emak Cem as the 'female' component of social reproduction of Asmat society. Its 'male' counterpart, Yew Mbu, is associated with political power and communication with the underworld and the upper world.

The Kamoro Kaware myth M3, which has no Asmat mythical parallel (although it does have a ritual one, as we shall see), is partially a 'male' inversion of the 'female' Asmat Emak Cem myth of Ufiripic and his daughters (Chapter VII, Ml). In Kamoro M3, the widower, Kinako or Nokoro, is cheated by his daughters. He deserts them by leaving for the underworld in a short and heavy ironwood canoe of his own making. He leaves behind a longer model of it for them. This is the mythical predecessor of the traditional river-going dugout canoe. In the course of the story the daughters turn into tidal trees subject to submersion, ever since then tormented and shaken by their father as a punishment for shaming him. In the Ufiripic story it is the other way round: the father cheats his daughters into marrying him. When they find out and drown him, he turns into a turtle, ever since then considered to be the sacred local lord of the land. Not he but his daughters leave for the underworld with a prototype of a canoe of their father's making, his invention left for them. He orders them to go west. In line with the 'female' Ema Kame/Emak Cem orientation, these women are instrumental in the making and acquisition of earlier Western wealth by their male companion on the far western border of Mimika. It is interesting to note that Nokoro, as well as being acted out in the 'male' Kaware ritual, also turns up as a Kaware counterpart of 'female' Ema Kame by the acquisition of contemporary Western wealth in East Mimika. This has materialized since the arrival in the 1960s and 1970s of the huge Freeport Indonesia mining enterprise, which 
excavates copper and gold and attracts Kamoro labourers from west to east. It so happens that Freeport's Portsite complex, including a facility for drying copper concentrate and for loading it onto ships, situated at the mouth of the Tipuka River, is adjacent to an island called Nao Nokoro by the Tipukans, or Karaka (lobster) island by outsiders. This island is part of the territory of Tipuka, the main location of Kaware celebrations. Its name means 'Nokoro in the shadow (or invisible)' (Drabbe 1937:86). At high tide it is submerged, and therefore invisible. Hence the belief that Nokoro has resided beneath the island ever since he left his daughters. ${ }^{4}$ An Atuka group of men moved to this island in the early 1970s to work for Freeport at the Portsite Amamapere. They did not compensate Tipuka for the use of their island, for ' $[t]$ hey [the Tipukans] never come out here to challenge us because they are afraid of a giant whale that according to their stories lives just on the other side of this island' (Harple 2000:201). It seems likely that this whale impersonates Nokoro, who rocks his daughters, alias the tidal trees, with huge waves. Tidal waves are indeed heavy in this area, due to the shallow sea. It is also interesting, as Harple rightly notes, that the Tipuka mythical fear of Nokoro is resorted to by the Atuka mining personnel to justify their occupation of the island without compensation. There may be even more to it. Harple refers to a solemn prediction (imakatiri) in which an elderly man, Natalis Nokoryao, from his hospital bed in 1960, 'claimed that he had prepared roads for cars at Timika [the inland main site of Freeport] in order to receive goods that would arrive on large boats. He went on to say that the goods and the boats were already present, but not always visible' (Harple 2000:184). He 'held that at some point the goods would become visible and very quickly be spread throughout Mimika'. ${ }^{5}$ Numerous Kamoro came to his bedside (Harple 2000:185). His cargo-cult-like prediction was made in an atmosphere of high expectations raised by the activities of the Dutch colonial government and initial explorations by a Dutch company, a predecessor of Freeport. The prediction came true. That same year a company expedition reached the Ertsberg, thus confirming Nokoryao's prediction, although political circumstances delayed its actual realization (Harple 2000:196). Unfortunately, we do not know whether the name Nokoryao, meaning son of Nokoro, is merely coincidental, or whether it was given or claimed on purpose as a reminder of the culture hero. 


\section{The rituals}

Eyde (1967:334-5) notes that there is a tendency for Asmat ceremonial cycles to be arranged in pairs: another manifestation of dual organization. The inauguration of a men's house and the sago grub ritual is such a pair. Although the cultivation and consumption of sago grubs are part of almost every Asmat ceremonial, the connection between the inauguration of a men's house and the sago grub ritual is intrinsic and strong (Zegwaard 1953b). The sago grub ritual is also part and parcel of Kamoro Kaware, but is explicitly associated with Nokoro (see Chapter III). This is not so among the Asmat, at least not explicitly. Zegwaard's report is based on observations by David Yakafa, a Sempan assistant teacher from Otakwa, who attended the ceremonies in Kapi, Northwest Asmat, celebrated from 7 January to 29 March 1953. His findings tally by and large with Zegwaard's own experience observing these ceremonies in Shuru, in December 1954.

The Kapi recently lived together with the Ao-Marpac, but a war in the region and brawls with Ao-Marpac occasioned a retreat. Its 300-350 inhabitants were organized in two sets of paired yew mopan, hence two times two, Amnes-Taray and Kapono-Kapi. The four men's houses or quarters were situated in that order on one side of the river, from upstream to downstream. Amnes was the host of the ceremony, assisted by Taray; Kamtar, a fairly young man from Amnes, was the leader. On 7 January all the men of the village went to a particular site in order to inspect the number and quality of mature sago trees to be selected for the cultivation of a large number of grubs, a sort of stocktaking by the feast givers meant to show their generosity to the guests, namely the two other yew. At night there was yi muc singing in the village: songs (muc) about yi, the sacred 'in the beginning', by professional singers and drummers. The next day temporary shelters were made on the site. Kamtar invited volunteers for felling the first sago trees. After some [merely theatrical?] hesitation, a man of the host yew volunteered, assisted by two others. He was presented with an axe by Kamtar; its acceptance commited him and his helpers to providing the singers with plenty of food during the ceremony. Four men representing the other yew also offered their services. The seven volunteers selected four adjacent mature sago trees, one for each yew. While felling these, they saw to it that the trees crashed down simultaneously with one impressive thud. These acts were accompanied by songs sung by the official singers about cutting the tail (epe) of a tree kangaroo and the juicy top (wu, 'palmite, millionaire's cabbage') of the sago tree. The two extremities (epe) apparently have their vital energy in common [compare this with Kamoro ipu enakoa]. Also, four axils of palm leaves were cut for making four bowls, one for each yew. Finally, four cylindrical blocks of about 80 by 35 centimetres were cut out of four trees [or one tree, according to informants from elsewhere]. 
These, representing the four yew, would serve as ceremonial containers for the heap of sago grubs at the ceremony.

These acts ceremonially announced the start of massive felling of trees, in which many personally owned square holes were made, serving as cultivation beds for the sago grubs, which take about eight weeks to mature. During this period the sacred songs about Ton Yenip and Aman Yenip of M1 were performed at night and repeated many times by professional singers. The singing rose to a climax at sunrise, and, similar to its Kamoro counterpart, was attended by every adult and young man.

New canoes were made in this period. However, hewing canoes is not restricted to one ceremony but also occurs during rituals such as Emak Cem and Yipae. Songs in honour of deceased persons carved out in a sitting position at the bow of the canoe are also performed repeatedly.

If the bark of the blocks of wood is so dry that it makes a ' $\mathrm{krr}^{\prime}$ noise when it is scratched, the sago grubs have matured. On 2 March the grubs were ready for consumption. The next day men left for the woods to collect materials for building a new men's house. The bachelors in particular were assiduous. Women and children were not allowed on the premises. After three days of keen work, the materials were ready. The construction of a men's house is described in detail by Eyde (1967:90-7). Here I merely note some distinguishing features. The men of Kapi cleared the vegetation from a rectangle of about 54 metres on each side. Around this clearing, piles stripped of bark, 5 to 6 feet long, cut with points at one end, notched on the other end, and spaced about a metre apart, were pushed into the ground by groups of men. They climbed on them or embraced them, giving a loud 'vuh' with each heave that forced the pile into the ground. Zegwaard notes that heaped trunks reinforce the muddy ground of the rectangular clearing. The construction has to be solid to accommodate hundreds of people, including many guests, and must stand up to massive dancing and stamping. On this foundation a floor of rounded hard outer layers of sago trunks, face upwards, is laid on and tied to underlying joists with the piles as their support. The piles are lashed together with poles running the length of the house. Two horizontal lines of poles join long vertical wall-poles over the full length of the house. Walls are braced with split ribs of sago fronds. A line of very long posts (yipic oc), extending 5 to 6 feet above the walls down the length of the centre of the house, supports the roofbeam. These alternate with shorter posts (mis os), each with an arm sticking out and upwards (an aerial root stood on its head) that support in their crooks the poles on which the rafters rest; the rafters in turn support a thatched roof. Provisions are also made for a covered porch at the front of the house.

In Kapi the shorter posts were not carved. Usually crude carvings represent deceased relatives of a household, the members of which sit and lie underneath and between these posts around their fireplace. A square about 3 by 3 
feet formed by four poles surround the fireplace; a rack above the fireplace serves to store firewood, fish, meat, weapons and other personal possessions. In the new men's house in Kapu there were seventeen fireplaces, each corresponding to a door opening: eight upstream, eight downstream for each moiety of the Amnes [or for each yew of the pair; the description is not quite clear on this point], and a common fireplace in the middle. The space at the rear running the length of the house near the central beam was reserved for living quarters. Its width of about two metres was considerably less than the adjacent open space on the front of about three metres over the full length of the house for public use, walking, dancing, sitting and lying. This division was reflected in the roof: its rear side was shorter and steeper than its front side (Zegwaard n.y.e:3). The front wall or parts of it are often left uncovered as a reminder of unavenged relatives (Zegwaard n.y.e:3).

The construction of the men's house was completed in one day. The neighbouring villages of Kapi, Yeni and Atat were then invited to attend the inauguration of the house.

This began with a festive testing of its strength. Men and boys trampled the floor over its full length while beating shields with daggers. Bachelors' houses upstream the Utumbuwe and Sirec Rivers are inaugurated by women dancing in it for a full night and morning (Zegwaard n.y.e:3). Sometimes men of other yew, with the approval of the builders, playfully attempt to ruin the new house by forceful dancing and stomping.

On 8 March men and women left together for the sago grub sites to collect the grubs and in particular to fill the four ceremonial bowls made earlier. These bowls are named after living or deceased of the four yew, particularly murdered male or female members. Their bride-receivers are the stewards of these bowls and it is their duty to fill them; for instance, one bowl, named after a living man called Kakay, was administered and filled by his daughter's husband. Meanwhile, a number of men in the village prepared a long cylindrical tube about 3 metres long, made of pandanus leaves with the sides of the leaves sewn together. It is called samu mini, meaning spirit of a decapitated member of one's own yew. It was placed in the centre of the new house. The tube was named after the host's main wife, who was deceased. A special platform was built above it. The trays stuffed with grubs were provisionally stored in the vacated men's house and decorated with paint, feathers, and young sago fronds. Large quantities of grubs were stored in family houses. At night the trays and the four cylindrical blocks were taken to the new house. The blocks were placed in a square around the bottom of the tube, thus constituting a container sharing its name with the tube. The women danced wildly, and the drumming was highly excited. The grubs were placed carefully into the tube by women [and men?], who emptied and refilled the trays. The quantity of grubs was so huge that a surplus was deposited on the platform. A Taray dig- 
nitary, a young man, was the master of ceremonies. He inherited the function from his father, a renowned storyteller. He sang: 'We, as numerous as parrots, will eat today the sago grubs of ...', and then enumerated three sites. The people distinguished between grubs consumed during the drumming sessions and grubs consumed in honour of the new men's house. Bride-receivers of the host slowly unbound the upper sides of the tube, seeing to it that no grubs came out until the moment the lower sides were opened up. Then the grubs tumbled out in large quantities and spilled over the enclosure. The adolescents fled in all directions. The grubs were then distributed, first to the men of Yeni and Atat, then to the men of Kapom and Kapi, and finally to the men of the hosting yew of Amnes and Taray. The massive consumption and distribution of sago grubs, promoting a sense of community, probably has connotations of fertility. Sowada insists that it was at this time that new papish partners were selected and that communal wife-swapping was celebrated. At the conclusion of this phase in Ac there was mass wife-swapping (Trenkenschuh 1970c:37).

On 10 March the guests returned home and the people of the village went fishing. On 11 March some men worked on their new canoes, while others took it easy. On 12 March festivities resumed. Now it was women's day, their turn to celebrate. Fully dressed up, they danced on the premises of the men's house. Kamtar's bride-receivers made a new tube, with a different name (acir), made of different material: sheaths of the sago palm decorated with big leaves of a passion flower which are used in mock battles; hence the name nao (killing) in a headhunting party. The tube was named after a festive leader's young daughter who had died when the ceremonies began. The same young man acted as ceremonial leader. The tube was opened in three stages by bride-receivers, during which there were three bouts of ceremonial praising of headhunting achievements in three locations. Again the young men fled when the sago grubs tumbled down. A number of older men took this opportunity to collect and hide a good number of grubs for their own secret consumption. By so doing they acted out what the culture hero Yenip-from-above did when he deceived Yenip-from-below. Zegwaard notes that during the ceremony in Ayam older men even made a double bottom in the tube to secure their secret share of the catch. It is this observation of the Asmat ceremony which makes intelligible a similar act by Kamoro older men during the Kaware ritual: secret consumption of grubs (see Chapter III). Women have priority in the distribution of sago grubs. There was drumming, singing and dancing until dawn. In Amborep (November 1952) and Shuru (December 1954) women danced in the men's house.

After a fortnight's rest there was a spirits' (nat) play by women on 25 March. The men left the village in their canoes in a semicircular war formation. The young men went fishing while the older men stayed in temporary huts. In the 
village a number of older women, impersonating spirits wearing mock battledress made of big leaves as mentioned earlier, chased the younger ones with fronds of sago leaves; this mock battle went on for hours. At dusk all the men returned, blowing on bamboo horns as if returning from a headhunting party. The young men meanwhile shared their catch of fish with the older ones. As soon as the women heard the horns, they stopped the game. A communal fish meal concluded the day.

After a few days of collecting sago, the festivities continued at dawn on 27 March, by acting out how Yenip-from-above evaded his namesake while pilfering his sago grubs by moving round the row of burning firewood over the full length of the men's house, in a direction opposite to the direction his namesake was moving in. A row of burning firewood was placed over the full length of the men's house. Young men from upstream Amnes and Taray lined up on the upstream side of the men's house, and young men from downstream Kapom and Kapi lined up downstream. While singers performed 'in the beginning' songs, the two parties shifted their position: from upstream to downstream and the other way round. This game of running youngsters was repeated many times, for about two hours. Then people were free to take a nap, but everybody was on deck again for the final sunrise singing and dancing (as in Mimika).

The ceremony ended with another massive exchange of sago grubs. On 28 March everyone except the singers and drummers collected large quantities of sago grubs at the cultivation sites. At dawn part of the harvest was tacked on sticks and taken to the men's house. First of all, the singers received their share from everybody. Then a ceremonial exchange was performed between the paired upstream yew on one hand and the paired downstream yew on the other. The upstream ones took their grubs to the centre of the house and offered these to the downstream yew, then the latter moved to the centre and reciprocated. The grubs were consumed at the individual fireplaces. Singing and dancing continued till sunrise. After this collective exchange there was also an individual exchange. All social and individual relations were expressed and confirmed by these exchanges. On later occasions these exchanges were sometimes recalled as ibu ipic: 'the man (ipic) with whom I exchanged'. On the same night four large parcels of about $125 \times 15$ centimetres stuffed with large quantities of grubs were made, roasted and stored in racks. The next day these parcels were exchanged among the four yew and ceremonially carried to the canoes. They were taken to the temporary shelters for consumption. Men of note and the singers stayed there and enjoyed eating the grubs, while the others went fishing. After some days of rest or working on canoes, the last of the grubs were eaten. It was now time to move seawards and enjoy fishing. 


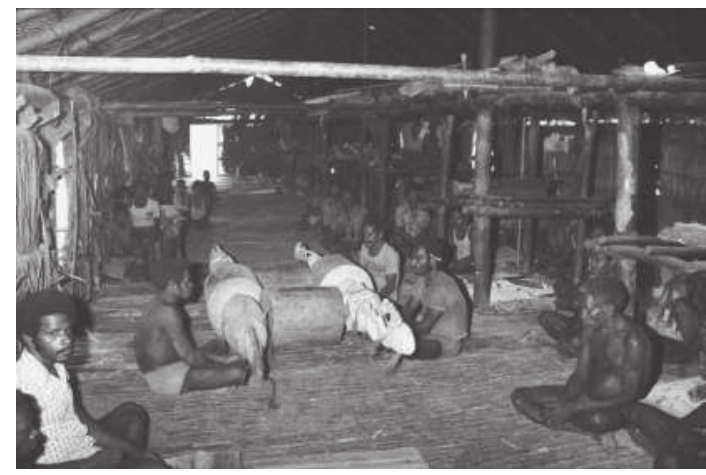

The container for sago grubs in the ceremonial house of Kaimo village being prepared for the basu suangkus ritual. Kaimo, Asmat, 1982. From: Konrad, Konrad and Sowada 2002:153.

In a comment on an illustration of a container for sago grubs used at the initiation of a new men's house in YaoSokor, in 1978, after 20 years of prohibition, Schneebaum (1985:105) opines that this container, known as basu suangkus, is unique for some Keenakap-speaking villages of upstream Sirec River and surroundings. Zegwaard (1988b) disagrees; according to him the basu suangkus is merely a local variant of the samu mini container as described above. It differs only in that the Yao-Sokor four cylindrical pieces, cut out of one trunk, are interconnected by a mat serving as a bottom of the container. The two horizontal sections also have carved human figures at each end. This container constitutes to my mind the fascinating 'missing link' with the Kamoro Kaware container for sago grubs, also provided with a mat serving as a bottom. This container represents nokoro kao, the outer form or cover shell ( $\mathrm{kao}$ ) of the short sinkable (ironwood) canoe of the culture hero Nokoro, by means of which he travels underwater to the underworld (see Chapter III). The tube is missing in the Kamoro ritual, but 'right' and 'left' men do throw large quantities of sago grubs into the canoe container; the dancing Nokoro impersonator standing in his canoe container is surrounded on his left and right by large heaps of sago grubs that are then distributed, as in the Asmat case. It seems likely that the Asmat containers are also at least reminiscent of canoes. Hence the human figures representing deceased persons of note, carved on the imaginary bows of the Yao-Sokor container. These persons are explicitly sung about in the ritual song Ci Bi So, literally the (canoe's) bow song, performed during the period of maturation of sago grubs and on the day the tube is opened for women, a tube that explicitly connotes war and headhunting parties. Although, at least as far as we know, Nokoro is missing in the Asmat myth and men's house ritual, the ceremonies and massive ceremonial distribution of sago grubs of Kamoro and Asmat are similar in their evocation of threat and war by men in canoes. There is a difference, though. In the Kamoro case Nokoro standing in his canoe exhorts the women to take good care of 'us men'. His call is yet another demonstration of gender opposition. The men board canoes for a 
risky and demanding trip inland to cut timber for new canoes; they run the risk of falling victim to an attack. The Asmat case evokes its very counterpart: not the victims but the initiators of an attack, men boarding canoes for a war party. The emphasis is on gender solidarity in the face of war. Both men and women act out a mock war, each in their own way. Kamoro and Asmat final ceremonies have in common a massive distribution of the powerful delicacy of mussels or sago grubs.

\section{Conclusions}

The intricate web of connections between myths, rites and social reality, and a comparison of the Asmat and Kamoro rituals, may be summarized as follows.

Both the Asmat and the Kamoro associate two myths, respectively about Yenip (Asmat) or Muanuru (Kamoro), and Fumuripic (Asmat) or Kamirima (Kamoro), with the ritual concerned, though in varying narrative versions. The Kamoro myth about Nokoro is, as far as is known, not shared by the Asmat. However, the Asmat and Kamoro do have the subject matter of this myth, namely the sago grub ceremony, in common in the rituals under discussion.

Nevertheless, there are marked differences in orientation and focus between Kamoro Kaware on the one hand and Asmat Yew Mbu and Tow Mbu on the other.

The main concern of the Asmat ritual initiation of a new men's house, the sago grub ritual, is the celebration and promotion of communal strength and solidarity, explicitly including relations between men and women. Its principal culture hero is Yenip-from-above, Ton Yenip. He is credited with the transformation of society from small, dispersed, rather isolated, self-sufficient bands that scarcely made a living, into a large, powerful community enjoying access to abundant natural resources, and the pleasures of a rich social and cultural life, including warfare and headhunting as highlights. In short, Ton Yenip rates as the primeval founder of Asmat society and culture. His exploits playing tricks on his namesake-from-below are re-enacted in the ritual. The massive ritual collection and distribution of sago grubs expressing and promoting cross-gender social strength, solidarity and exchange, is accompanied by a mock enactment of warfare by males and females separately. In the course of the ritual, females praise and encourage males in their martial exploits, which are proudly spelled out by the war leaders. In the past, the ritual was either preceded or followed by a headhunting party.

The exploits of Fumuripic, the culture hero of resurrection and of the creation and demarcation of neighbouring and foreign social groups and 
their wealth, are not enacted in the ritual but are sung about. His exploits are associated with the more inland-oriented Yipae. It is reported, though, that the choreography of dances performed while reciting the Fumuripic myth on the occasion of consecrating a new men's house in settlements at the Sirec River mimics limbs that come to life and slowly begin to move to the rhythm of drumming. ${ }^{6}$

For the Kamoro, on the other hand, the Kaware ritual marks not the solidarity but rather the opposition between males and females. Kaware is primarily a male affair. It is men's prerogative to communicate with the dead. The transition from death to life is a male secret. Not the myth of Muanuru, but the myth of Kamirima's resurrection is acted out. The male initiates play dead and stagger back to life. Kamirima himself is regarded as Kaware's initiator. The effigies in the mbitoro spirit poles, representing recent dead, are also ritually brought back to life by men. Nokoro of the underworld is impersonated as well. He acts as the males' representative in demanding and receiving large quantities of sago grubs and he exhorts the women to take good care of the men. Last but not least, it is the men who act out the revenge of Mamirima's violent death by waging war and thrusting their lances into the sand: they are crushing the evil spirits who killed the hero and who threaten human life. Kaware also offers a proud demonstration of male skills: men construct canoes, sago bowls, sago pounders, paddles, masks and spirit poles in the course of the ceremonies and they are ceremonially rewarded for their services by women. In sum, in terms of gender relations, Kaware is a demonstration of male impression management, male secrets, and male skills and tricks, such as snatching prepared food from the women.

The myth of Muanuru only shows up in the Kaware ritual in the prohibition on consuming garden products that originated from the ceremonial house in the underworld.

Admittedly, Kaware also resembles the Asmat Yew Mbu and Tow Mbu rituals in its massive exchange and distribution of pile-worms and sago grubs, but its emphasis is on highlighting the contribution of males to life, in contrast to the Asmat demonstration and promotion of a sense of community among both men and women. For the Kamoro there is no 'women's day'. Kaware is a male stronghold. 


\section{Chapter $x$}

\section{Initiating young males and commemorating the dead On nose piercing and spirit poles}

One may initially doubt the connection between the Kamoro ritual marking of male adolescents' maturity by nose piercing and the Asmat commemoration of the dead marked by erecting a spirit pole. One difference is that Asmat nose piercing of boys and girls is not celebrated but is an informal private act performed during childhood; another is that the various descriptions of Asmat spirit-pole myths and rites do not include the initiation of males. Yet since the Mbish rituals are considered the 'male' counterpart of 'female' Emak Cem, one might assume the initiation of male adolescents into maturity to be part and parcel of boys' Mbish rites. Some observers even consider the mbish pole the 'vertical' coastal version of the 'horizontal' inland spirit canoe, on and around which male adolescents are initiated. This interpretation finds support in the fact that the bottom portion of a mbish pole often depicts a miniature canoe (for an illustration see Konrad, Konrad and Sowada 2002:155). In line with this, this portion is called canoe (ci) (Kuruwaip 1974:20). Further, the mbish pole is strikingly similar to (yet different from) the Kamoro mbitoro, which is explicitly associated with the initiation of males.

A commonly held Asmat view ascribes the mbish spirit pole to the Bismam group, literally 'the makers/carvers of the mbish'. This group includes the coastally oriented settlements of Central Asmat between the Unir River north of Flamingo Bay and the Ewta River of Ocenep, on the border with Casuarinen Coast settlements. The spirit-pole ritual has spread from there to settlements of the upper Sirec River like Yao-Sokor and Fos, and to the Casuarinen Coast. ${ }^{1}$

The riddle of the seeming absence of a connection between the Mbish ritual and the initiation of male adolescents into maturity is solved when one learns that initiation, together with the Mbish ritual proper, was part of the head- 
hunting rites and practices which were discontinued in the 1960s. Since then, the Mbish ritual has lived on in its own right up to the present day. It is still strongly reminiscent of war and of headhunting. The first of the two myths specifically associated with Mbish also has affinities with one of the founding myths of headhunting. The initiation component of the Mbish ritual is no longer celebrated. It differs from the initiation of male adolescents connected with the spirit canoe. It is briefly discussed by Zegwaard, but under a different heading, Nao Pokmbu (Zegwaard n.y.e:25). The severed head of a man killed during a headhunting party is ceremonially offered by the killer to his adolescent real or classificatory younger brother or son. By this act the latter is proclaimed an adult. He assumes the name of the dead man, and henceforth his relatives will address him by this name and even treat him as if he were the actual person. Since headhunting has been discontinued, it follows that this type of initiation no longer exists.

The myths: a summary

\section{The story of Seitakap}

This narrative was told to Abraham Kuruwaip, curator of the Asmat Museum of Culture and Progress in Agats, by a man called Bai of Ac, and confirmed by four narrators of Amanamkai and Omanesep, three settlements on or near the Bec River (Kuruwaip 1974:12-4).

Inland, on a site of paradisal abundance at the confluence of the Sirec and Sitan or Brazza Rivers [Kuruwaip mistakenly speaks of a place called Sitan] live Beworpic [pic, 'man'] and his wife Tewerawoc [woc, 'woman'; these two names occur regularly in Asmat narratives] and their two children. Far away downstream at the mouth of the Sirec River live the older and younger brother Tewer and Seitakap at a site where there is hunger, sickness and war. ${ }^{2}$ Seitakap is an outgoing and cheerful person. His older brother admonishes him to keep quiet because of the imminent danger of attack. Beworpic furtively approaches the two brothers, throws his spear and kills Seitakap, then cuts off his head and slices up his body. He returns home. His wife notices him approaching the settlement and throws lime, out of joy and excitement. From all corners of the village people rush to the scene and accompany Seitakap's head to the men's house. His flesh is distributed carefully and the bones are thrown into

2 I wonder if the opposition between an inland of abundance versus coastal misery may be ascribed to Kuruwaip's Christian interpretation of the upper world as heaven and the underworld as an evil place; he derives the name of the Sirec River from Surku, which is presumably a corruption of Indonesian surga, 'heaven'. 
the fire. There is drumming and dancing. Suddenly, a strange voice is heard coming from the fire. It is Seitakap's voice, explaining that he is not really dead, but has already travelled to the underworld, by way of the Ayiw River, which connects the present world with the abode of the ancestors. The ancestors have instructed him to return to the living and teach them a new custom that will keep them in touch with their ancestors and bring them happiness. He teaches them a new sacred song, which is to be used only by male adults and always with great reverence: 'Seitakap, Seitakap, you have been lost; you went by way of the Ayiw River and you have returned, for me you have returned.' He tells them that the ancestors have promised to protect the living as long as the living make carvings to commemorate the dead and name them after the deceased. A dead man's deceased wife and children must be commemorated in the same way. After having sung the Daiso song celebrating the successful manhunt that took place before he heard the voice from the fire, Beworpic replies that he is ready to learn the new song. He immediately cuts down a nutmeg tree (tow) and follows the carving instructions given by the 'returned' victim Seitakap. The story then relates how to proceed. All the men are instructed to sing another new song before beginning to carve the mbish: 'Mbish! Dance and hide with a peaceful heart. Mbish! You have preceded me [us] and are now hidden. You dance the dance that comes from your heart. The hair on your head moves and there is a union between seen and unseen.' They first carve Beworpic's deceased father. Seitakap then orders the men to sanctify the carving with blood drawn from the victim's [Seitakap's] head and body that they have eaten. Seitakap tells them that it is blood that makes the mbish powerful.

\section{The story of Mbish, the ideal wife}

This attractive lively narrative, replete with colourful details, was recorded in the vernacular by Zegwaard in the 1950s, presumably in Shuru; the narrator is unknown. ${ }^{3}$ Kuruwaip recorded a shortened, less accurate, and less detailed version told by Ewerpic and Sakarpic of Ewer, confirmed by various carvers of Shuru (Kuruwaip 1974:14-7).

A long time ago a very beautiful girl, called Mbish, lived in Kaymo, midstream on the Sirec River. Her beauty aroused the emotions of Dariw, the headman of one of the men's houses, so much so that he neglected his responsibilities as leader and even blocked the central hearth at a ceremonial distribution of sago grubs to celebrate the completion of a new men's house: he demanded Mbish as his wife. However, after marrying her he became so jealous and suspicious that he did not allow her to leave the house, and even forced her 
to sleep in a sack he made out of two sleeping mats. She was given food and drink and was allowed to defecate through one and the same opening in the sack. It was not long before she grew dirty, began to smell, felt miserable, and lost her appetite. Her husband decided to organize a headhunting feast. At that feast he would take her out of the sack and do her the great honour of letting her become a naowam woman, a woman who severs the head of the victim while beautifully decked out and wearing a naowam, a frond made from pieces of bamboo: the queen of the headhunting feast. While Dariw set out to realize his plan, Mbish's older sister Waise took the opportunity to liberate Mbish and wash her in the river. She then lit a big fire to get rid of her awful smell by means of perspiration. Mbish's relatives gave her a new apron and a good meal. They put sago and fishing gear into a big bag and took her in a canoe to the junction of the Sirec River with the Sitan or Brazza River. She was then left on the shore, and had to make her own way to the land of the ancestors at the source of the Sirec/Sitam, inhabited by people living high in the trees. Meanwhile her husband returned with a slain enemy, but hearing that his wife had run away he cancelled the ceremony. Searching in vain and abandoned by his followers, he died of sheer misery. [Father Baudhuin ${ }^{4}$ recorded the text of a song called pis [mbish] purmbut recited in Ewer during a recent Mbish ceremony, which vividly describes Dariw's attempt to make a canoe in order to follow Mbish, 'like a wriggling snake follows its prey'. However, nobody gave him a hand. While he was cutting down a tree single-handedly to make a canoe, a splinter pierced his body and killed him.]

Mbish had begun her long walk to the headwaters of the river, setting up camp every evening. Trees and animals, well disposed to her, assisted her in crossing rivers and land. A high palm tree lifted her over the forest. A cassowary adopted her and showed her the way. After three days and three nights they reached the sacred Ayiw River, which connects the earth with the world of the ancestors in the mountains. From afar they heard a faint sound that turned out to be the sound of Pupuripic, literally 'hornblower', the son of [yet another] Beworpic and Tewerawoc. For years the hornblower had been trying to enchant his beloved Mbish with the sound of his magic triton shell, the name of which is taboo and hidden beneath its pseudo-identification as a bamboo horn. His parents met with Mbish after his father tried in vain to kill the cassowary with his spear. They were then told that the cassowary was her stepmother. It also appeared that Mbish's earthly mother and Pupuripic's upperworld mother were namesakes [compare Kamoro namesakes in myths]. The hornblower slid from his tall tree and discovered the beautiful Mbish hidden in a mat by his parents [a perfect contrast with her earthly sack of mats]. The couple had a wonderful hunting and sago-beating honeymoon. Now and 
then Mbish went off with other women. At such times he missed her badly. One day he hit upon an idea. He felled a nutmeg tree, divided the trunk into three sections, and carved a female figure in the middle section, birds and other animals in the upper part (in fact the root), and a canoe/bowl for food in the lower section: the first-ever mbish. Whenever a beloved one is absent, you can still have a wooden image of him or her.

Meanwhile a coastal, earthly grandson and namesake of Beworpic in the upper world had heard the magic shell. He had gone into the interior to meet his namesake-grandfather. He asked for the magic shell. It was refused. But then Pupuripic made a formal statement: 'From now on, son [Beworpic junior], you will take over my place and my name. I will move to the coast and settle with Mbish in Sarew. From now on my name will be Fumiripic, the Hornblower.' And so it happened.

\section{Comments}

The first story is evidently a spin-off of the myth institutionalizing headhunting. ${ }^{5}$ Its plot and construction are strikingly similar. The main characters of the headhunting myth are Desoipic (man with wound) and his younger brother Biwir-ipic or Bewor-ipic (coloured-parrot man, compare Emak Cem Ufiripic, 'king-parrot man'). They live by themselves, probably inland; there are no other humans. Because of his physical condition the older brother has to stay indoors and the younger has to go out to support him. No longer content with his younger brother bringing him merely the head of a hunted pig and pinning it to the floor in front of him, the older brother suggests that he replace it with a human head, his own head. The younger brother protests vehemently, but finally gives in. He severs his older brother's head. The detached head of the self-professed victim then begins to speak and to give instructions to Beworpic, his younger brother and killer, on how to proceed with the (his) head and the body. The ensuing ritual is then spelled out. In a similar fashion, but then in a peopled world, the severed head of coastal Seitakap tells the inland killer Beworpic how to proceed with the ritual. The similarities between the two institutionalizing stories are too striking to be merely coincidental. The severed head plays a dominant part in the initiation of a son or a younger brother of the headhunter. The initiate takes the place and name of the victim. One gets the definite impression that the first Mbish narrative was modelled on the basic headhunting narrative after the cessation of the practice of headhunting, as a way to legitimate the retained Mbish ritual. 


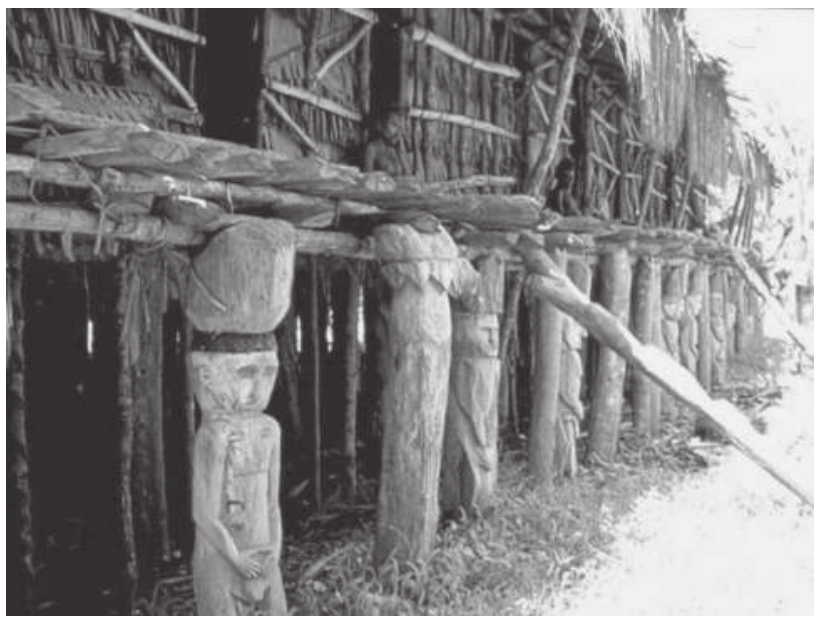

House posts. Ewer, Asmat, 1993. Photograph by Ursula Konrad.

As for the relation of the first to the second Mbish story, it is noteworthy that they share two main characters, the inland Beworpic and his wife Tewerowoc, and the upstream site at the Sitam River, the gateway to the upper world. They also share the distinction between inland and coast. The configurations of the narratives differ. The narrative of Mbish, the ideal wife, accounts in a widely recognized and far more romantic manner for the carving of a beloved wife. However, it also expands the reasons for carving, namely to commemorate any beloved absent woman or man. Physical absence and separation probably also connote death. After all, the beloved Mbish did cross the boundary between the living and the dead (the ancestors). Zegwaard also mentions a version from Ao told to Fleischhacker and Schneebaum, according to which Mbish dances with the other women on the evening of her marriage and dies the following night. Her mourning husband ties her body in a corner of the yew, and it is then transformed into a wooden statue (Offenberg and Pouwer 2002:117). Note that alongside the romantic aspect of the story there is the realistic picture of an aggressive war leader who is despised and in the end abandoned by his followers. Such leaders do occur and are dreaded. Sometimes they are dismissed.

The Mbish narrative ends with a surprising transformation. The carver Pupuripic yields his place and name to his 'son', that is, the grandson and namesake of his father Beworpic. This grandson left the coast to meet his inland grandfather. In his turn Pupurupic and his beloved Mbish move from the inland to the coast, where he takes his 'son's' place and adopts the name 
Fumiripic, the hornblower. So he is, or is at least equated with, the Asmat culture hero who carves out male and female human figures in the foundation piles of the yew and drums them to life while travelling west to the Kamoro, as far as Kaokonao and even Kaimana. There is also a fascinating Kamoro connection with the Mbish story. Although Mamirima, the Kamoro counterpart of Asmat Fumiripic, is not credited with the creation of male and female ancestors, but with the founding of Kaware, a well-known Kamoro Ema Kame myth does have affinities with Fumiripic's creative act, at least as far as the origin of female ancestors is concerned. ${ }^{6}$ In this story the original female ancestors of the Kamoro, the kaoka oko, literally 'genuine women', living in a coastally oriented settlement, abandon their husbands because they were cheated by them. Their place is taken by the wamoko kaoka, literally 'upstream women from the inland forest', depicted as varieties of forest animals but equally and fully human. The latter are considered to be the female ancestors of the present Kamoro. According to Zegwaard and later Coenen, they are also called amoko kaoka, 'culture hero women', but I wonder whether Zegwaard perhaps confused amoko with wamoko. In my opinion they are not superhuman but in fact inferior to kaoka oko, the original, genuine women. In the myth wamoko rate as second-class women and are sometimes disparagingly referred to as quadrupeds. Male adolescents from Kaokonao, who had many contacts with foreigners, even called them cheats and shit women (Offenberg and Pouwer 2002:183). After abandoning their husbands, these 'genuine women' travelled from the eastern part of Mimika to Etna Bay in the far western part of Mimika. They are seen as the ancestors of white foreigners (Offenberg and Pouwer 2002:138). They left for the West after constructing a steamer by drawing one in the sand. Other descendants of these women are said to live along the upper course of a river at Etna Bay (Offenberg and Pouwer 2002:148). A wellinformed storyteller, familiar with East Mimika, told Zegwaard in Keawkwa that these 'genuine women' originated from man-size mbitoro made by men who provided them with attractive ideal physical features. The statues came to life in the course of the night (Zegwaard 1952:31). So here is the link with Mbish, the ideal Asmat woman, and her lover-carver Pupuripic, transformed into Fumiripic. The Keawkwa informant did not refer to Mamirima. This link puts the individual Asmat 'romance' in a wider social and even cross-cultural perspective of the life cycle. The individual inland Asmat maker of commemorative statues of beloved ones and endeared dead is transformed into the coastal creator of male and female statues coming to life as human beings. For the patri-centred Asmat, these constitute the ancestors of the neighbouring Kamoro and of foreigners. For the matri-centred Kamoro, the coastal 'genuine 
women' (also manufactured by males) are, by default, equally the ancestresses of foreigners, superior to their own ancestresses. A difference in lineal orientation shows up in an enchanting cross-cultural pas de deux, a mixture of unity in diversity.

\section{The rituals}

Kuruwaip is the first observer to give a lengthy account of the Mbish ritual (Kuruwaip 1974:20-4). His description may be summarized as follows: the ceremony can be divided into six stages, in accordance with the stages in carving the mbish. The feast takes six or seven months. After an agreement has been reached as to which persons will be commemorated by the carvings and the obligations for the living relatives and affines, the war leader blows his bamboo horn for a meeting of all males. The men are told to decorate their bodies and paint (or repaint) their canoes. They depart from the village in search of a proper tree, amid shouting and excitement as if they are going into battle. The women remain in the village and, by way of exception, enter the men's house to drum, dance and sing. The men divide into three groups: one gathers bunches of young sago leaves, the second clears the undergrowth around the selected tree, and the third remains in the canoes as guards. The sago leaves are tied to the selected trunk as a decoration. The men then return to the village. A few days later they depart again to cut and prepare sago trees for growing sago grubs. The second phase sets in some thirty to forty days later when the grubs have been harvested. Amid the din preceding a battle and with full body decorations, the men leave for the selected tree, while the women again enter the men's house for drumming and dancing. Some men gather more sago leaves, others go fishing, while yet others hunt for baka peor, a type of yellow finch. The men divide into two groups corresponding to the two sections of the men's house. One group goes ashore for cutting the $\log$, and the other remains in the canoes and prepares for a mock battle with those who will load the log. The latter approach the tree as if attacking an enemy (hence the decoration of the trunk). The war leader, carried on the shoulders of his relatives, calls out the names of six enemies he has killed. He makes a few chops at the tree. He is then replaced by another war leader, and so on, till the tree finally tumbles down. The mock battle ensues and continues until the fishermen, the hunters, and the collectors of leaves return to the site. The log is decorated anew with fresh leaves, fish and birds. The main war leader measures the log for the mbish carving. Another war leader begins hewing at the designated spot, then stops to enumerate several more enemies he has slain. Another leader takes over in a similar vein and finishes the cut. [Compare this with the three Kamoro dignitaries crouching near the 
tree they are entitled to cut for the python ceremony, and with the reddish track giving the impression of a serpent who attacked and swallowed people; see Chapter II.] Finally, the bottom portion of the tree is marked for carving a small canoe and a sago dish. (A buttress root is saved for the 'wing' portion of the pole, the cemen, a general term for any protrusion.) Stage three involves dragging the logs - a small one inside a canoe, a big one tied to a canoe - to the village site, approaching the village quietly and slowly; women are strictly banned. Stage four concerns the arrival of the mbish in the village. When the women, drumming and dancing in the yew, hear the men coming, some of them hide along the riverbank, acting as spies. They return to the yew and report. All the women reach for weapons (spears, knives, sticks, and so on) and initially pretend not to be aware of the men's arrival, but finally begin to throw ashes and lime into the air. The women refuse to answer the repeated question of the shouting war leader: 'Who is in our place?' A leading woman makes her appearance from the yew and asks: 'Who are you? This is the place of our ancestors.' On hearing this reply the men begin to beat the sides of their canoes with their paddles to frighten the women. Withdrawing a bit to allow the women to leave the men's house, they come ashore; the women rush to attack them fiercely. Some men receive serious wounds (and are proud of it). At the end of the mock attack the men drag the pole into the yew and place it on the bark of a tree. The fifth and sixth stages concern the carvers' completion of the three sections of the mbish. The main war leader begins to chip at the pole to make a rough outline of the human figure, while again enumerating slain enemies. Expert carvers take over and complete the outline. The pole is then carried to the ecawor, and part of the yew is partitioned off for more detailed carving in relative privacy. The first section of the mbish to be finished is the mbish cemen, the protrusion or wing. At this point the men gather to name the mbish after the main victim of a battle or after a naturally deceased person of repute. His or her relatives offer food to the carvers and their assistants. They finish the cemen section. Meanwhile the relatives of the honoured person go hunting for a pig and take the meat into the yew. The women are invited to share the meat, but presumably do so outside the men's house, and this is the occasion of another mock battle with the men that lasts well into the night. The cemen phase is terminated by distributing fish, sago and sago grubs throughout the village. Then the middle section of the carving, the mbish anakat, representing a number of male (top) and female (bottom) figures, is completed. The war leader summons the men for a headhunting party, while the carvers proceed to complete the lower section: a small ci and a bino (sago bowl). When the warriors return, they rub the entire carving with the victims' blood. Special attention is given to the vital organs of the carved figures, such as eyes, mouth and sexual organs. More sago trees are cut down and prepared for growing sago grubs. At the clos- 
ing phase of the ceremony there is massive collection of sago, fish and sago grubs by men and women in the woods. The men take these food items to the men's house in huge quantities. The women wrap the sago grubs in leaves in their individual homes and then take them to the yew. On this day the men finish the mbish by painting it red, white and black. Towards the evening of that day everyone gathers in front of the yew. There is a massive distribution of food, which is taken back to the individual homes. All then return to the men's house to witness how the mbish, newly completed and brilliant in fresh colours, is carried from the ecawor to the main entrance of the yew and placed on the floor. Several men rip off a section of the roofing and partially elevate the pole for display. There is intense general mourning of the commemorated dead. When the crying has stopped, the men return home to get their drums. Dancing, singing and feasting go on until daylight. There may be some licensed sexual intercourse, although Zegwaard's informants deny this. After daybreak the mbish is transported to a predetermined site in the sago grove and erected. The hand of the statue is broken off to prevent the spirits of the mbish from obstructing anyone passing by. Attitudes towards the dead are quite ambivalent: a mixture of respect, reverence and fear.

\section{Comments}

Since the Mbish ritual - at least as it is described here - hinges on the spirit pole, my comparison with Kamoro Mirimu Kame, including its pendant Oo Kame, and Kaware, as far as the erection of a spirit pole is concerned, will concentrate on this issue. In both cases, the name for the spirit pole has an identical meaning. It has a common function, namely the commemoration of recent male and female adult and juvenile dead. It also shares a tripartition, namely a protrusion or 'wing', an upper and lower section depicting a man and a woman respectively, and a bottom section including a pointed end. Juvenile dead are often represented by carved heads at the bottom of the wing. There are some Asmat mbish with a representation of a woman on top. The main figure in the mbitoro of Kamoro Oo Kame is the honoured woman who took charge of the slaughtered pig (Lagerberg 1956:8). The term 'phallic wing', sometimes used by students of Asmat art, is misleading. The Asmat term cemen stands for protrusion in general, including bodily protrusions such as the penis. In many mbish the wing protrudes precisely above or beneath an explicitly carved penis, or even above the carving of a woman in the top middle section. Quite often the Asmat top section includes a representation of the upper part of a man's body together with the wing (penis) protruding from his belly or his legs. The Kamoro top section of the mbitoro does not depict a human figure and consists exclusively of the wing (pinamo, 
'buttress root'). Both the Asmat and the Kamoro have spirit poles varying in size, in keeping with the relative importance of the honoured persons. The biggest one is placed in the middle of the Asmat men's house or the front wall of separate ceremonial Asmat and Kamoro houses. Middle-sized ones function as supports for family fireplaces in the Asmat men's house. In Kamoro Kaware similar ones are placed left and right of the central pole in front of the house and sometimes also against side walls inside. Small imitation statues are used by Kamoro to frighten women and to pilfer prepared food, as mentioned earlier. As well as winged statues, both the Kamoro and the Asmat have wingless, freestanding ones, such as the famous statues of ancestresses in front of eastern Kamoro Sempan Kiawa or Ema Kame houses. ${ }^{7}$

Along with similarities, there are also striking differences. The Kamoro mbitoro not only commemorates the dead but is also a major marker of cosmology. It connects the upper world with the lower world via the world-inbetween of humans. The wing represents the upper world. Its central feature represents the remote supreme being of the sun, not by an anthropomorphic carving but by an oval or round openwork one, may kame, depicting his abode (kame), sometimes surrounded by representations of clouds (tami). Next to it are representations of various animals and objects, which are presumably the otepe or kata of groups or persons that are 'of one soul' with the phenomena depicted (Coenen 1963:67-9). The pointed bottom section is strictly taboo for non-initiated males and for women. Underneath it are the assembled spirits of the dead, especially of the honoured ones. These and similar cosmological connotations of the spirit pole are apparently absent, or at least not reported, among the Asmat. The Asmat wing does not depict the seat of the sun; its varieties of carved spirals denoting the tail of a tree kangaroo, or the spirals of a nose ornament, are said to connote the nameless ancestors of the organizing yew. The pointed poles are as a rule not inserted in the ground but placed on platforms in a vertical or sloping position. Carvings in the bottom portion of the coastal Asmat and Casuarinen Coast spirit pole sometimes denote other ancestors in an openwork Kamoro-like fashion. However, often a small canoe and a sago bowl are depicted. These are absent in Kamoro spirit poles. The canoe seems reminiscent of the Asmat inland spirit canoe (wuramun). It is the canoe rather than the pointed bottom which for the Asmat connotes the underworld: the spirit canoe takes the dead to their abode. So, going from coastal and inland Asmat to the Kamoro, one moves from the presence to the absence of the underworld canoe in representations of the dead. On the other

7 For a good, more detailed comparative description of Asmat and Kamoro statues from the point of view of comparative art in its context, see Pauline van der Zee's PhD thesis; Van der Zee 2005:418-66. 
hand, moving in the opposite direction, one proceeds from Nokoro's canoecum-grub-container in the Kaware ritual, via a grub container in the shape of the bow of a canoe of Asmat Keenakap-speaking villages of the upper Sirec River, to the simple grub container (samu mini) of the coastal Asmat Yew Mbu/ Tow Mbu counterpart of Kamoro Kaware. A Boasian, empirically detailed cross-cultural comparison of similarities and differences is required to reveal the fascinating meanderings of unwitting intercultural borrowing.

The body of the Kamoro carved human figures is hollow. This is explained or at least rationalized by participants in this way: the 'real, inner body' (ndata) of a person is no longer there after passing away or, rather, after passing on to the underworld through the upper world. Only the shell $(\mathrm{kao})$ is left. The Asmat, though presumably having similar notions, do not express it this way; their carved bodies are not hollow. A paramount feature of all Kamoro anthropomorphic carvings, including objects other than statues such as the handles of drums, is the mopere, the symbol of life and of movement. It also connotes ancestresses and is therefore a central feature of the two sacred boards of Ema Kame. It is found on all joints in anthropomorphic carvings: to live is to move. This motif and its meaning are shared by the Asmat oval or round bianam (eye socket), though it is not so predominant. In Asmat carvings scarifications on the limbs are prevalent. These may denote muscles, yuerfepin, apparently symbols of power, which seem to reflect the Asmat cultural orientation of physical/ political strength and warfare. ${ }^{8}$

The Kamoro mbitoro ritual presents a clear dramatization of the resurrection of the Kaware culture hero Muanuru, the counterpart of the Asmat culture hero Yenip. Its spirits are also consulted in an act of divination. These two features are absent, or at least unreported, in Asmat ritual. The Asmat Mbish ritual is clearly inspired by war, revenge, and headhunting. When cutting the tree for the mbish, the trunk is even attacked as if it were an enemy. There is a mock war between the men of the moieties; the women repeatedly wage a mock war against the men. The war between the sexes is just as much a salient feature of all Kamoro rituals. The two societies concur in frequently expressing antagonism towards the opposite sex by means of mock attacks (Kamoro akapa, Asmat akapes, both denoting joking and laughter). Akapa, a mock fight between 'right' and 'left' men, occurs during Kaware to mark the start of collecting sago grubs. When attacked, men fall to the ground as if dead, which might connote war and not just a local brawl. A 'right' woman simultaneously hits a 'left' woman with a stick used for removing sago grubs. This might reflect fights over sago grub sites, also reported for the Asmat.

8 For a clear and convincing case, see oral information supplied by Piet van Mensvoort MSC, quoted by Van der Zee 2005:447. 
Acting out interlocal war, however, does not seem to be a significant feature of Kamoro ritual.

The Asmat spirits of the dead honoured by the mbish and the spirit canoe are invited in the end to return to the underworld by going downstream. The Kamoro, on the contrary, exhort the spirits of the mbitoro to leave the settlement by going upstream. The spirits are even equipped with a dog and a lance for hunting inland. The male participants of Kaware then move in the opposite direction and go downstream. However, the final destination of the Asmat and Kamoro spirits of the dead is identical: the underworld. The Kamoro men who move downstream at the end of Kaware return to the settlement in the masked disguise of the recent dead, who temporarily return from the underworld in order to visit their surviving relatives. 



\section{Chapter XI}

\section{Asmat headhunting and the initiation of male adolescents}

\section{The myths}

We owe a description of headhunting and its complement of male initiation first and foremost to Zegwaard's (1959:1020-41) classic paper in the American Anthropologist. The paper is based on a narrative type of information provided by his main informant, the war leader Warsekomen of Shuru, himself an expert in headhunting. In addition, a slightly varying but most interesting story was told to Bishop Sowada by Pirimbu (65) of Biwar in 1979 (Sowada 1980b). In the 1950s Pirimbu, a violent and hot-headed war leader, had been the terror of the region. He accidentally killed his wife an hour before Zegwaard's arrival on one of his tours. He was both feared and praised in the village. ${ }^{1}$ Another narrative he told Sowada about Cowoc-Biwar, the primeval mother of Biwar, puts the male practice of headhunting in a female-oriented cosmological setting. ${ }^{2}$

In Chapter X, I summarized the mythical introduction of headhunting by the younger brother Beworpic's severing of his brother Desoipic's head at the latter's own request. The talking head of the victim [an archaic precursor of the modern TV 'talking head'] spells out how to handle the victim's body and how to celebrate the initiation of young males. The story has it that Desoipic was disappointed about being offered merely a pig's head, pinned to the floor by the point of a dagger thrust into the pig's throat. He demanded a human head for consumption, and since there were no heads of other people around, it would have to be his own head. Pirimbu's story offers an interesting alternative to Desoipic's dog-bites-its-own-tail request: On the upper reaches of the Sirec, near another river specified as the Brazza, and downstream of the Sirec [note the dualistic set-up] lived two couples. These couples initiated the domestication of wild boars. Their offspring, the wild pigs, increased so much in number

1 Offenberg and Pouwer 2002:252, note 1.

2 Sowada 1980c; for an earlier account, unclear on some points, see Offenberg and Pouwer 2002:197-201. 
that they began to attack people and to make their lives miserable by causing many wounds. So the men began to wage a war on the pigs. However, the battle was so uneven that the people became dispirited. Fortunately, one day a man called Beworpic - the younger brother in Warsekomen's story - managed to kill a huge wild boar. He cut off its head. The people, in a vengeful mood, tore the boar's body to pieces, cooked the pieces, and feasted on the animal's flesh. Beworpic and his men launched other expeditions and killed many pigs. [The story implies that humans then succeeded in getting the upper hand.] On one occasion Beworpic killed yet another boar, severed its head, and stuck his cassowary dagger through its neck until the point of the dagger protruded from the boar's snout. He then called his wife Tewerowoc [here she is again] into the ceremonial house and placed her on a mat in front of the central fireplace. Spreading her legs, he placed the boar's head between them. Tewerowoc was elated at being honoured in this lofty manner. The next day she was dressed up and decorated by her husband with soft sago fronds in her hair, woven bands on her arms, and a finely woven belt around her waist. He also tied a cuscus fur crown on her forehead and inserted a bone through the septum of her nose. He gave her a fine carrying bag in which he put the boar's skull. She proudly carried the bag wherever she went. However, she complained that the teeth and tusks of the skull cut sharply into her back while she was gathering food, harvesting sago, or fishing. She suggested to her husband that a human skull [without jaws] would be more convenient. She addressed her husband and the people: 'You and I hear a man shouting at the headwaters. His name is Siwet. Go and kill him.' [Knowing the victim's name is imperative in headhunting.] Beworpic and his men took her advice, located Siwet, and killed him. Beworpic's first act was to sever Siwet's head. He then shared the flesh with the other men [as he had shared the flesh of the boar; note the parallel]. This head turned into a 'talking head', who gave instructions about the proceedings of the feast and ritual, the decorations, and so on. 'When you make a mbish pole, carve my features exactly. Call me Siwet or Mbish.' [Compare this with the female Mbish of the story in Chapter IX.] Beworpic placed Siwet's head between his wife's legs, but the talking head exclaimed: 'You have placed me incorrectly. Turn my head around so that it faces Tewerowoc, with the dagger protruding from my mouth.'

This story not only circumvents the 'incestuous' fratricide of Warsekomen's version, but also introduces the (male-derived) honour bestowed on the killer's wife, which is part of the ritual. Further, it allows for a female initiative in the introduction of hunting human heads, by reason of the pig's skull hurting the wife's back - an amusing afterthought. Waging war on people is modelled after hunting pigs. The head is a trophy and the protruding dagger a clear symbol of male prestige.

Pirimbu's story proceeds from the animal to the human sphere: Beworpic 
decorated his wife as he had done for the boar's head ceremony. He added momentum to it by painting her with white lime enlivened with red ochre. The people drummed and danced through the night. On the third day of feasting, Beworpic and his people took Tewerowoc and placed her in the central section of his canoe [note the male-centric wording]. She stood sullenly while the men rowed downstream. At the ceremonial house Beworpic presented her with a new carrying bag containing Siwet's skull. She decorated the skull with cassowary feathers and with grey and red seeds. [Note the progression and the amplification in the ritual, moving towards the final episode, which consists of the initiation of a male adolescent. In the ritual it is the male adolescent who stands sullenly in the central section of the canoe, and it is to him that a decorated skull is presented.]

The story continues as follows. When some time had passed, Beworpic gave the command to haul the canoes onto the riverbank in order to dry and seal them. They then went downstream on the Sirec and discovered some people hunting for food. Beworpic captured one man and stabbed him with his cassowary dagger. The man shouted: 'Why kill me?!' Beworpic answered: 'It is necessary for us to make war.' He proceeded to stab the man through his shoulders. He placed the body in an upright position in his dugout and decorated him with white lime. When he arrived at the village he beheaded the dead man and placed the head in front of the fireplace. The people celebrated with drumming and singing. During the evening Beworpic sat his son Ariwetekap on a mat in front of the fireplace and placed the head between his legs. He repeated the ceremony he had performed for Tewerowoc. [The story gives all the details again.]

I have rendered the narrative almost verbatim in order to bring out its fourlayered composition, which legitimates the social institution and convention of waging interhuman and intergroup warfare on the model of humans waging war with pigs. The first episode of the story establishes the war between humans and pigs, concluding with the triumphant beheading of a boar. The second episode connects this war and its pig's head trophy with the paying of tribute to the killer's wife (and her kinfolk). In the third episode a human head replaces the pig's head, which adds to the wife's male-derived honour and convenience. The fourth episode connects both headhunting and the honouring of wife and mother with the initiation of adolescent sons and their classificatory equivalents. War/headhunting, male prestige, revenge, reverence for wife and mother, and male adolescent initiation aimed at replacing the dead (see below) thus became normative and related features of Asmat society. Zegwaard (1959:1020) rightly stresses the point that cannibalism is not the objective of headhunting but only a subsidiary part of it. For the participants, the consumption of human flesh is analogous to vengefully eating 
the flesh of the boar, the killing and decapitation of which served as a model for human headhunting.

As to revenge, the story ends with Tewerowoc being abducted by the victim Siwet. Siwet runs away with Tewerowoc, explaining: 'Why did you ask your husband to kill me? Now I wish to marry you.' By doing so Siwet initiated the chain of revenge, including the capturing of women.

The third narrative, about Cowoc-Biwar, the female founder of Biwar (cowoc means woman), also told by Pirimbu, provides headhunting with maternally inherited vigour. It relates headhunting to the occupation of territory and to the dispersion of people, and to localized cosmological power. Cowoc-Biwar is represented as an imposing woman, the leader of her group. She was peculiar in that she, throughout her life, never had sexual relations with her husband Baiku (1979 version), yet, and equally peculiarly, produced offspring. She was a man-woman, yipic-cowoc (1954 version). Initially she lived with her people on the upper reaches of the Sirec River, indicated as its tail (epmak) and at present known as the Brazza River. One day she decided to find a new place of residence. With her older and younger brothers, her husband, and a good number of others, she travelled downstream and settled on the Sor River, near present-day Biwar-on-land (Indonesian: darat). From there she and her people explored the Powec, Asewec, Undir, Pomac and Fai Rivers and, via the coast, also the Yec, Binar and Oap Rivers. So she is presented as opening up the entire Asmat region north and northwest of the Sirec River, where she placed various individual 'brothers' on various specified rivers. She herself returned to the Sor River. After giving orders that the canoes be dried out and sealed, she departed for the downstream areas south of the Sirec: the Bayir gully connecting the Sirec and the Bec and the Bec and Ac Rivers. Specified areas were claimed by specified individual younger brothers. She then settled in the vicinity of present-day Biwar-on-sea, near the Omosmos River. So the story considers Biwar the centre of the entire Asmat world north of the Casuarinen coast.

On the sands of the seashore of Biwar-on-sea, Cowoc-Biwar planted various jungle fruits and roots and two coconut palms. She hung her carrying bag on her spear, which grew into a huge ironwood tree (it fell down, but a new one emerged and is still there; the area near this tree is sacred). She continued her journey by travelling to a river near Ac. There, without having sexual intercourse, she gave birth to a rattan liana (Zegwaard version), an amber snake, a flying fox, and a yuwur tree for making canoes. She cut up the snake and divided it among the people she had settled on the various rivers, together with spears, bows and arrows. Specified brothers, among them Acakap (at Ac), received head, tail and gall respectively. Their descendants will therefore be yokmen, courageous and destructive like the teeth of the amber snake. Headmen of five specified settlements refused to take a portion 
of the snake. Hence their offspring lacked fighting spirit and were therefore doomed to die off or be forced to join other villages (1979 version). According to the 1954 version, she also gave birth to a sawfish (ar) in the Ac area. Hence the ferocity of the Ac fighters, matching the destructiveness of sawfish teeth. One day Acakap discovered people downstream harvesting nipah nuts. He quietly came up to them and killed a specified man, belonging to the Sogoni people (at present living upstream on the Bec River). The phrasing signifies headhunting. The next day the Sogoni people killed Acakap. They cut off his hands and raised them on a spear across the river of Acakap's people. When Cowoc-Biwar recognized the hands, she shouted to the Sogoni people that they were free to consume the flesh and have a feast, on the condition that Acakap's genitals (usually not eaten) be placed on the tip of an arrow on the riverbank. She put the genitals in her carrying bag, which is still in the care of specified descendants of Ac (Offenberg and Pouwer 2002:253), as an heirloom (eram ese), a centre of sacred power. After establishing other villages, such as Ayam, she settled with her husband near present-day Biwar-on-sea. There she built her own hut and a bachelors' house. According to the 1954 version, she did not wear the usual apron of sago-leaf fibre (awer), but wore a starshaped disc (mbiwamun) with an opening in the middle through which she urinated. With this disc and the corresponding shaft (nao onak, 'killing stick') she terrified her enemies, said to be the bird people who lived in hollow trees upstream on the Omosmos River. She was merciless and aggressive and so are her descendants: they are proud of their nickname 'the snakes'. However, she and her people soon travelled further south. Killing people of specified settlements along the way, she headed towards Safan, the underworld beyond the Casuarinen coast. There she settled for good. [The narrative mentions names of villages which remind me of the Wildeman River (Watiwamen) and Kepi (Kopa), the administrative centre of the Mappi district. From there, colonial officials and missionaries made exploratory trips into the Asmat region.]

The 1954 version presents a different, viri-centric interpretation of the end. After returning from the coastal settlement to her residence upstream on the Sor River, Cowoc-Biwar noticed that her brothers had meanwhile turned into autonomous leaders. They were no longer prepared to accept her authority. A quarrel broke out; the brothers joined forces and killed her, her husband and her father.

It is evident from the two versions of the narrative that Cowoc-Biwar was not only an imposing woman; she was also an extraordinary person, both a man and a woman. The 1954 version gives some fascinating details that confirm her double gender. Children of the woman's brothers, who are her classificatory children, came across suckers of the liana to which she gave birth. Since these suckers blocked the Bayir gully, her 'children' had to cut them away. However, they only cut the right-hand side of the suckers and left 
the left-hand side untouched, because they were born out of Cowoc-Biwar. Some un $p a$, sturdy roots of a mangrove tree, also blocked the gully. This time the left-hand side was cut away and the right-hand side left untouched. The Kamoro consider the superior right half of the human body to belong to the mother, and the inferior left half to the father. Theirs is a matri-oriented system of descent. Apparently the Asmat have similar beliefs, but then reversed, in keeping with their patri-oriented system of descent. I take it that the left part of Cowoc-Biwar, corresponding with the soft liana suckers, is ascribed to her mother and to the female side. The right part of her body, however, corresponding to the sturdy roots of the mangrove, is ascribed to her father and to the male side. Her double nature is repeated in her offspring, hence the saving of the left-hand (mother's/female) side of the liana and the right-hand (father's/male) side of the mangrove roots. The male aspect of her personality is evident from the star-shaped disc cover for her genitals. The disc, placed on a shaft, was used by her and by men as a club in brawls and wars. The Kamoro also had similar clubs. ${ }^{3}$ Her disc is said to be still there, as an heirloom in the care of Biwar-on-sea. Surprisingly, people asked Sowada if he would like to see it. Pirimbu showed it to him in 1979, on condition that he would not insist on purchasing it.

The narrator, Pirimbu, solemnly placed an aged carrying bag, closed at the top with a bone pin, on a mat in the centre of the [bachelors'] house. He proceeded to open the bag slowly, and cautiously removed the object inside, which was attached to a cord. To my surprise it was a deep black star axe, with a hole in its centre. As he placed the axe gently on the mat, I admired it, explaining that I had never seen an axe so beautiful. I made a motion to pick it up, but a hand stopped me. An elder explained that the object could not be turned about or turned over indiscriminately, since it was sacred. They went on to explain that Tjawotsj-Biwar wore the axe beneath the genitals. One of its prongs stuck out, making her appear like a man to other people. The area of the axe's hole was liberally covered with waseh, the red paint made from burnt mud. There were mud spots on one of its prongs and I asked their significance. The people explained that whenever anyone dies, as had happened the previous day, mud is placed on the axe. Then, as we were discussing the axe, one of the elders got up, pointed to the hole in the axe, and excitedly explained that the opening represented the opening from which pigs, crocodiles, other animals, and men, too, were born. [Compare with the 1954 version, which has it that the woman urinated through the opening in the disc.] [...] I asked whether, at one time, they had used the axe in warfare or for opening the skulls of enemies in order to extract the brains [Sowada apparently mistakes the club's disc for an axe.] Surprised at the question, they stressed that its use in such a manner was forbidden. When I asked how the axe was obtained from TjawotsjBiwar and handed down through the generations, they said that this was the axe 
that Tjawotsj-Biwar had hung in a carrying bag on a spear on the Omosmos River. Later, the woman Darkau, while fishing on the Omosmos, had discovered the spear and the carrying bag in the jungle. It had been there for a long time, as the bag had deteriorated considerably and one of the axe prongs stuck out through the bottom. As Darkau did not know what the object was, she ran off to call her husband, Yuwus. She brought her husband to the spot. Yuwus, too, was puzzled. He carefully lifted the bag by the strap with a piece of wood. They took it into their hut. Yuwus, afraid of the object inside, attempted to remove it with wooden fire tongs, without success. Finally, Darkau pulled the axe out with her hand. At that moment they realized that the axe had belonged to Tjawotsj-Biwar, and that it was necessary and good for them to have it. To the people of Biwar Laut [Indonesian for 'sea'], the axe is proof of Tjawotsj-Biwar's existence and of her being the origin of the people. To this day, the axe is handed down through her relatives. (Sowada 1980b:68-9.)

This extraordinary field report by Sowada provides us with clear evidence that Cowoc-Biwar is considered the primeval Mother of the Human World, man himself included, at least as far as Biwar is concerned. She is the sacred 'lord of the land', she opened it up, furnished and allocated it. Her sacred heirloom-disc symbolizes fertility and virility, female and male genders. The disc in combination with the shaft is a powerful weapon that represents dominant male power. However, the constituents of the disc, namely the prongs and the hole, represent male gender and virility and female fertility, respectively. It may be concluded that the person and the emblem connote the ambivalence of gender and of male/female power. Compare this with Baicep, the huge anthropomorphic male/female sacred pig of the mountains, whose children are the male ancestors of the Bismam people, who are likewise dispersed (see Chapter VI). Note that their territory overlaps the territory claimed by the Biwar people, so that there are competing claims. The aggressive features of Baicep were also passed on to his/her descendants. He is believed to still protect and encourage his offspring by accompanying them wherever they go. With their paddles they create semicircular waves that are shaped like Baicep's tusks. Baicep will then make the waves bigger, so that enemy canoes have difficulties and capsize (Offenberg and Pouwer 2002:215). Naneu, his eldest son, afraid of being outstripped by his younger brother Ewer, shot a female being in the crown of a tree belonging to the bird people, a being said to be not human but crazy and dangerous for humans. Ever since, Naneu's male descendants are equally reckless when attacking an enemy (Offenberg and Pouwer 2002:213). Ewer earlier killed a turtle that turned out to be a local female guardian, called Buciawuc. She exclaimed: 'Who are you? Why do those people from above come here to bother people from below? Because you have shot me, you may not stay here, but must settle on the coast.' The people cut her up, consumed her flesh, singed her hair and rubbed it over their head and shoulders [thereby identifying with the 
victim, as in headhunting rituals]. Her emptied head was put in a bag as a sacred heirloom (Offenberg and Pouwer 2002:213).

Baicep and Cowoc-Biwar can be said to relate as male/female to female/male, and so do their competing descendants, the Bismam and Biwar peoples. The double and ambivalent gender is reflected in the ambilineal Asmat practice of appropriation of land, in the ideas and practices of war and headhunting, and in the ambilineal practice of descent, although patrilineal descent tends to predominate.

How do the Kamoro traditionally conceive of the Asmat? They used to call them we manawe, that is, people who are eaten by people, not people who eat people (mana means food/eating), ${ }^{4}$ yet they were feared for just this. The neighbouring Sempan were constantly on their guard. When somebody shouted 'We manawe', people took to their heels; the term connoted terror. ${ }^{5}$ The denotation of cannibals is reflected in a narrative related to Zegwaard by Epepea of Iwaka (Kamora River, Central Mimika) and in an abbreviated version of it related to me by Tay, a well-known leader and storyteller of Keawkwa, Central Mimika (Zegwaard 1952:51-3; Offenberg and Pouwer 2002:195-7). The story deals with Manawe, said to live in an area east of the Sempan and west of the Asmat. Upstream is the Akimuka catchment area where the Nafuaripi live; downstream are the Miwar estuaries, situated west of the Sirec River near the border of the Asmat region. It is this area from which the great trek to the Mimika region is said to originate. The names of the terrifying culture heroes and giants Aoweyao and Mbiminareyao who set the trek in motion are associated with this area. The main theme of the narrative is a rebellion by children against their parents, with the former being punished by the latter.

Epepea's version of the story is as follows. The men and women of a Manawe settlement in the far east leave the village in order to catch fish and collect pile-worms in the downstream mangrove forest. They are unwilling to take their children with them, so they leave them behind in the care of a few elderly people. One of the boys, Minare [name derived from the Minar estuaries], is furious. He initiates a rebellion of all the boys and girls of the village. They board canoes and go upstream. An old mother's brother of Minare sympathizes with him and joins the party. En route the children grow up fast, as is usual for culture heroes. They build a longhouse. The mature, strong men divide the women of equally magnificent build among themselves. Some couples live upstream, some midstream, and some downstream in the longhouse; in short, it is a full-grown village.

Minare, having grown into a real giant, has his apartment at the end of the village on the riverside (as is appropriate for the leader of a settlement). 
When their parents return from fishing in the evening and call out for their children to receive their portion of pile-worms, there is no answer. Informed by the elderly people that the children have rebelled against them and gone upstream, the parents cry. Minare's parents prepare a bundle of fish and pile-worms to placate their son. They leave the village the following day to look for him. When they arrive at the longhouse in the early morning, the mother approaches his apartment cautiously. She whispers her son's name, but he shouts with a gruff voice: 'Who is there?' His frightened mother takes to the canoe. Minare's mother's 'brother' interferes. The parents are invited to the scene by Minare's [brand-new] bride-givers and then surrounded by the rebels, who threaten them with their lances. The parents ask their son for forgiveness. They are 'paid' for being frightened with a copious meal of wild game. The parents return to the village carrying a yardstick given to them, which indicates the height of their son and his age-mates and is meant as a challenge: 'We are grown up and married'. The people of the village respond to the challenge by preparing for war (wiko). When they approach the longhouse, they mistake the mother's brother of ordinary height for his sister's son Minare. They feel cheated, and launch an attack. Minare's mother's brother answers the challenge by shooting quite a few men. A canoe capsizes. Then Minare, thus far concealed behind the longhouse, comes into the open; people panic. He boards his canoe, advances towards them and, standing at the bow, shoots and kills all the men on his left-hand side, but saves the lives of the men on his right-hand side [Kamoro: mother's side, Asmat: father's side].

The losers, after a period of mourning, plan a counter-attack. A scabby old woman, the wife of one of them, attracted by the saga of the giant warlord, runs away and joins him by means of a ruse: she attracts him by imitating the call of a crown pigeon. Sitting in his canoe she offers him food, which he accepts grudgingly because he has noticed red entrails hanging from her vulva. However, after taking a shower she is reborn as a magnificent lady. He finds her under a mat. They embrace and she becomes his [second?] wife. The men of the village, further infuriated by the elopement, wage another war against Minare. After some heavy fighting, while moving to the bow, Minare does not notice a hole in the canoe. He falls through and gets stuck. His enemies take this opportunity to kill him. [An adversary of Aoweyao and Mbiminareyao meets his death in a similar way.] Accompanied by his weeping lover, they take his body to the village as a trophy and drop it on mats in front of his parents' hut. Then the bride-receivers, acting in reverse to the normal practice of caring for an affine, slice the body into pieces, which are then divided according to the rules of distributing flesh among relatives and affines. Even his father and mother receive their normal share. At night a boy asks his mother for water because the meat was very fatty. She goes outside to help herself to water. Meanwhile a female spirit (mbi kapere) takes her place 
and offers water to the thirsty boy. When the real mother re-enters, she and her son realize what has happened. The female spirit, accompanied by another one, has bewitched the meat by blowing over it: 'This is our punishment, for you have killed Minare.' They bewitch the houses as well: these topple and sink into the earth.

Tay's shortened version offers a different interpretation: The parents and their rebellious children are not Manawe but Kamoro culture hero-ancestors (amoko we). They are not cannibals. Cannibalism arises from the bad conduct [Tay's personal comment] of Minare rebelling against his parents, a capital sin. Punishing him is correct in principle. When the children defeat the parents, the latter enlist the support of the Manawe (Asmat), the Naowapinera people originating from the parents' area later at Koperapoka basin, and the Tarya We of West Mimika. The giant Minare and his age-mates are then defeated. He is killed by a Manawe. It is the Manawe who chop Minare into three portions: they lop off his head and divide his body lengthwise into two. They give the left part of the torso to the people from below (that is, from the west), the Kamoro. They say: 'Eat it, it is nice and fat.' But the Kamoro say: 'No, that is not proper, not right.' They use the bones, sharpen them, and make spears from them. The Manawe eat all the meat, including the head. They take the women with them, as is usual after a headhunting raid.

So the two versions agree in that the leader of the revolt against the parents is killed and his body cut up. Note that the Kamoro term wiko, denoting the attack, refers to a brawl within the group or the federation. In this context killing, and even more so headhunting, is in principal prohibited. If killing does occur, indemnification is called for. Wiko, internal brawl, is opposed to mokare, war with people outside one's own group or federation. The corresponding Asmat distinction is between owen on one hand and ndao mber on the other. The latter term means headhunting, and can also mean a person whose head has been taken. ${ }^{6}$ In the first version the parents-in-a widersense are punished for their 'incestuous' cannibalism by female spirits. In the second version the enlightened, sophisticated village chief Tay ascribes cannibalism to the Asmat, not to the parents' group. The Kamoro merely prefer the bones to the flesh, an inversion of a Dutch saying, because human bones lend themselves better for daggers than cassowary bones. Tay's message is: We are civilized people, the Asmat are not. The two versions correspond in negating the conspicuous role of the severed head in Asmat myth, ritual and social life. In a comment on the Iwaka narrative, Zegwaard notes that, when the Asmat of Yoni were told the end of the Iwaka story, they were surprised to learn that the Kamoro are familiar with a story which they had assumed 
was known only to them. My guess is that, assuming that an Asmat version of the Iwaka story really exists - Zegwaard gives no evidence - it might serve to legitimize the Asmat norm not to raid nor to take heads of people or groups considered closely related or allied. However, political intrigues often circumvent the norms. ${ }^{7}$

\section{The ritual}

In this section I have rearranged the data provided by Zegwaard in his 1959 article in the American Anthropologist and in earlier typed drafts under a number of headings, so as to offer more systematic intelligibility: prelude, the raid, initiation. We concentrate on the ritual aspects. Zegwaard had ample opportunity to study headhunting practices on hundreds of occasions, since he was the first white man to take up residence at a time when Dutch colonial rule was not yet established there (Zegwaard 1959:1020). Raids, however, were relatively rare, as these require a good deal of ritual preparation and the well-planned organization of assistance by alliances. People preferred to avail themselves of opportunities that came to hand, which did not require preparation, such as treacherously killing guests or people who ventured too far from home. It often happened that visitors were cordially welcomed, even given presents, but later killed, preferably in their sleep. The protecting family acting as host was overruled by the majority of the settlement and humiliated. After one such occasion in Shuru, a hosting warlord and his group broke away and built a new bachelors' house at another spot.

\section{Prelude}

There are a variety of methods of ritual preparation. The very variety points to both the importance attached to a raid and the risks of waging it.

1. Simulation. It is believed that simulation of a raid ensures its success. A major type of simulation is the Firao $\mathrm{Wu}$ ceremony that opens the celebration of constructing a new men's house. Among the many sago palms - sometimes hundreds of them - cut down for the maturation of sago beetle grubs, there is an outstanding one impersonating an enemy. The 'enemy' is 'killed' by pig hunters - the strongest men - and hit with spears and daggers when 'he' falls down. While the lower part of the palm is sliced and provided with openings for the beetles to deposit their eggs, 
the upper part is opened carefully so that the body of young palm pith ending in a thick knob, kus (head), can be removed in its entirety. This is decorated with rattan and various types of leaves, and then carried in procession to the canoe on the shoulders of a number of enthusiastic men, to the accompaniment of a singing and dancing audience. The 'pith man' is placed in a vertical slumped position in the canoe on a number of crosspieces (similar to handling the body of a slain man). On their way to the village the men sing the cloud song (see below) and the paddle song, as is usual when returning from a headhunting raid. There is bamboo-horn blowing and a loud reception in the village, where the oldest man asks: 'What have you brought?' And the reply of a senior man in the canoe is: 'We have killed a big man, he is lying in the canoe.' There is much yelling and throwing of lime. At dusk the 'pith man' is taken to the men's house and surrounded with chunks of sweet sago pith. His head is severed and his body cut up into chunks that are hurled in the direction of the senior men and consumed by them. At midnight the 'head' is consumed in secrecy by some of them (compare this with the secret consumption of sago grubs by senior men during Kamoro Kaware). A 'pith man' may also represent a deceased relative instead of an enemy. Father van Kessel reports from Basim that the 'head' of two 'pith men', named after the dead parents of the feast-giver, was fried and consumed by his bride-receivers (Van Kessel 1962:2). Evidently one does not eat one's 'own' head. According to Zegwaard's typed field notes on Firao Wu, this ceremony is also enacted as a preliminary to large fishing or pig-hunting parties. There is a clear analogy between the three Kamoro modes of simulating a successful pig hunt as described in Chapter IV on the one hand, and Asmat simulation of a man-hunt (or fishing and pig hunting, for that matter) on the other, but an equation of the Kamoro pig hunt with the Kamoro man-hunt, as suggested by Zegwaard (1959:1030), is not warranted by ethnographic evidence.

Simulation may also be performed by means of a graphical pantomime. A Shuru warlord imitated a woman preparing to pound sago and her male companion looking for his paddle, bow and arrows. He then enacted their departure for the sago woods. His men picked up the hint and laid an ambush near the Seper River. Shortly two men from Amberep arrived and were killed. Their wives, who had followed at some distance, managed to escape. Had the warlord only foreseen this arrival, or had his pantomime induced them to come along? The Shuru people are inclined to believe the latter (Zegwaard 1959:1035).

2. Evocation of or identification with the founding ancestor. In Shuru a pig hunt was organized on the eve of a headhunting raid. The pig was butch- 
ered in an open space between the war canoes, lined up in two rows. The pig's head was offered to the leader of the raid. This evoked the presence and support of the mythical founder Baicep, an androgynous pig believed to join the raid and to cause a curved swelling of the water corresponding with his curved tusks; this turbulence of the water gets the enemy into trouble.

In Amberep one of the women dancing on the eve of a raid tied the head of a pig to her buttocks. The older men were supposed to comment that it would be better to have a dance with human heads, a clear allusion to the myth accounting for headhunting (Zegwaard 1959:1035). In Biwar the men sat around the sacred disc of their founding female ancestor. By moving their bellies in the direction of the disc while sighing, they evoked emulation of the courage of the ancestress, and of the ferocity of her serpent and sawfish offspring (Zegwaard 1959:1033). Were they emulating their birth?

Each founding ancestor left to his/her descendants sacred objects, kept in a bag, eram ese: tusks of a wild boar, a string of dog's teeth, the gall of some serpent, and so on. These objects or 'things to frighten with' (omer pok) are manipulated to scare the enemy and make him an easy prey (Zegwaard 1959:1033).

3. Enticing the enemy. On the occasion of the inauguration of a new men's house, the lower part of a thin 'magical' trunk (eram asa) is smeared with a particular mixture. Its ingredients and the kind of tree are known only to the performer. One of the ingredients seems to be cassowary fat. At night fires are solemnly built in the new fireplaces. One of the leaders holds the trunk in the fire. Its smoke has a penetrating smell. The wandering souls (nam yipi) of much feared enemies are conjured and invited to consume the smell. If such a soul, when roaming around while its owner is asleep, 'eats' the smell of the trunk, or the smell of roasted pig or some other food, this person is likely to be killed a few days later by the inhabitants of the 'hosting' village. This person's friends may be able to avert the disaster if they notice the wandering soul (Zegwaard 1959:1030). Similarly, a ball of sago and some sago grubs may be placed on a small platform in a river bend near an enemy's settlement. By uttering a spell while lifting the food in the enemy's direction and throwing some sago grubs in the river that drift towards the village, the souls of the enemy are enticed (by the smell of the food offered) to draw near. The bodies will follow shortly and can then be killed. This kind of enticing is called fo fum, meaning 'carried by the wind' (fum). The ceremony is performed by young males united in a joking relationship (as akap; compare Kamoro akapa) on the occasion of an imu (Kamoro: imu) play involving joking and jostling. This play confirms 
the spiritual ties between boys and girls who have their spiritual name in common, given to them by a (usually female) medium (namer ow) shortly after they were born. This generates life-long ties of friendship between age-mates. On this occasion the age-mates offer sago grubs to their bridereceivers, but only after they have offered fum food to the enemy's souls (Zegwaard 1988a). In my view this ceremony commits young males to participate in warfare if need be. A similar ceremony is performed on the occasion of unveiling the carved memorial prow of a canoe named after someone who has been killed. The brothers-in-law of the deceased are then the performers. The platform is erected in the vicinity of the spot where their affine died. The food is offered to the spirit of the deceased, and is not meant for the enemy. It is even taken back, roasted and eaten by the brothers-in-law themselves. The carving is then revealed by removing the mat that covered it. By this token the brothers-in-law commit themselves to take revenge. The ceremony is considered a threat (Zegwaard 1959:1031).

The odour of the massive quantity of sago grubs thrown into the tube fashioned for the sago grub ritual on the occasion of the inauguration of a men's house (see Chapter IX) is also believed to attract the roaming souls of enemies (Zegwaard 1988a).

Finally, enemies are lured into an ambush with the collarbone of a turtle or with a forked bough, while the war leader beckons: 'Come this way.' In an opposite movement, sorcerers approach the village to be attacked on the eve of the raid and throw water in the directon of the enemy or blow water through a loophole (Zegwaard 1959:1034).

4. Augury. A dignitary smears his right hand with lime powder mixed with pulverized leaves; he rubs the hand faster and faster, so vigorously that blood trickles down: there is going to be bloodshed. The raid will be successful. In a shamanistic trance he takes his right hand in the left one and swings both hands through the air while moving up and down the men's house. Suddenly he runs at a man and makes a movement as if severing his head and slicing his body. He regains his senses by holding his hand in a fire (Zegwaard 1959:1035).

5. Psychological warfare. Implements of war such as arrows are placed in conspicuous places to intimidate the enemy. A favourite trick is spreading lies (nao piri), which is intended to confuse enemies and make them nervous. A go-between man is selected, for instance because his decapitation name originally belonged to someone in the enemy's village, or his mother originates from there, or because he is being given in ransom by the village concerned. All the men present rub his body with chewed sago; sometimes the sago is mixed with his blood. The man then departs for the 
enemy's village to spread concocted rumours. For instance he makes them believe that his fellow men have left for a fishing party; this gives the prospective victims an opportunity to slyly gather sago on the territory of the people thought to be absent for fishing. These villagers are then attacked (Zegwaard 1959:1032).

All sorts of body ornaments such as red ochre, white chalk, black ash, bones and feathers, nose shells and other symbols of strength and courage, are meant for display as well as to frighten the enemy. These body decorations are armaments as much as ornaments. Consequently, they are banned when on friendly visits, as they invite trouble (Zegwaard 1959:1033).

Last but not least, there is the custom of bragging and boasting (dewen atakam) about the number of men or women a person has killed; he enumerates their names and the exact locations of killing. This is performed on various occasions, such as at the first stroke of the axe when carving an ancestor pole - Kamoro men then call out their mother's or grandmother's name - or when a sago-grub tube is opened, or when new warriors are inaugurated. Boasting is meant to impress and frighten visitors. Interestingly, bragging also occurs in awkward situations, when the braggers are not self-confident and do not feel at ease. While travelling on unknown rivers, for instance, at every tributary and also at whirlpools, which are thought to be entries to the underworld, men boast about their exploits. Even after death, the deceased is believed to tell hair-raising stories about his achievements in an attempt to frighten the dangerous spirits and to overcome his own fear. The potential danger of new situations, awkward experiences or encounters (such as meeting foreigners) is thought to be neutralized by boasting. The Kamoro speak of kaypiri, a new and potentially harmful situation (Zegwaard 1959:1031). When travelling by canoe to the far western part of Mimika, I noticed that my rowers, unfamiliar with the area, moved their paddles backwards, making the water splash: 'Kaypiri', they exclaimed. They tried to counteract the potential danger by behaving themselves contrary to ordinary behaviour - an analogy of abnormalities! Most interestingly, Kamoro kaypiri is the linguistic equivalent of Asmat papish, the ceremonial, strictly regulated swapping of wives for one night by papish friends, briefly referred to earlier (Offenberg and Pouwer 2002:237-41). The Asmat myth accounting for this institution deals explicitly with an unusual situation encountered on a fishing trip ${ }^{8}$ by Biwiripic [again] and his wife Kankani - a name connoting something unusual, strange, the realm of spirits - of Basim. They 
chase a fish with harpoons but in vain: the fish turns out to be a spirit. The spirit in the guise of a fish takes them to the underworld, where they are hosted by their deceased relatives. The different atmosphere, however, turns the female visitor into a seemingly dead one, and the male visitor seems to be close to death too. The woman is then revived by shaking her body. The relatives in the underworld attempt to restore her good health by administering succulent food. Alas, the food turns into shit, worms, and seawater. The sago flour rubbed on her forehead becomes as hard as clay. Under these circumstances, the couple have no choice but to return to earth, loaded with presents from their dead relatives. On their arrival back home, Biwiripic orders the villagers to make big fires with the explicit purpose of producing a lot of smoke. The couple arrive in a cloud of ashes and stand in the smoke, perspiring heavily. In this way the bad odours of the dead are purged, so as to prevent illness. The woman Kankani also initiates wife-swapping. Consequently, Biwiripic and the headman Fayit exchange wives, as a way of counteracting danger. Ever since, wife-swapping has been practised by Asmat in unusual, potentially dangerous situations, such as severe floods, thunderstorms, and encountering unfamiliar objects, such as gramophones and radios, as well as unfamiliar persons such as missionaries. This may very well be the first example worldwide of a case where the coming of missionaries led to wife-swapping.

The Asmat, as well as the Kamoro, 'steam' or 'smoke' people and their commodities when they return from a stay in foreign locations, as is the case when contract workers come home, or when a person returns from visiting a foreign ship. The Kamoro do not practise wife-swapping. There are indications that wife-swapping was imported via the Casuarinen coast from southern coastal Papua. ${ }^{9}$ Given the Asmat cultural focus on war and headhunting, it is understandable that wife-swapping bonds are mobilized to ward off danger particularly in interlocal political alliances made for the sake of warfare. ${ }^{10}$

6. Mobilizing commemoration and revenge. Shakespeare's 'The very dogs bark at me' is echoed in Asmat a thousand times by all sorts of objects named after the dead. In the event of killings, these objects, called eco pok, 'things that make great', connote revenge. The very walls, posts, roof beams, new canoes, houses, spears, shields, paddles, bags, strings of dog's teeth, even domestic dogs and pigs or a bundle of firewood cry for com-

9 Compare with Marind Anim otiv-bombari, regulated heterosexual promiscuity in similar situations of danger; see Knauft 1993:163-7, based on Van Baal 1966.

10 For an example I refer to the grounds for the political power of the warlord of Shuru Warsekomen, discussed in Offenberg and Pouwer 2002:236-41. 
memoration and revenge (Zegwaard 1959:1029). Private and public property barks at you. These powerful reminders of revenge surround their addressees night and day. There is a parallel with the Kamoro naming of walls, posts, and shields as a commemoration of the dead (see Chapter II, Ema Kame), but the Asmat take it much further and explicitly use it as a means to mobilize revenge. Anything may serve this purpose. Van Kessel notes that in Basim the brother of a victim deposited a sago ball in the men's house: anyone eating from it would thereby commit himself to take revenge or punish a theft, as the case may be. Once an old woman took a bag of parched fruit, no longer fit for consumption, to a man. After enquiry, it turned out that she had filled the bag recently with fresh fruit as a reminder of the fact that men of Ocanep had murdered her child. The fruit was meant to stay there until her child's death was avenged. The man to whom she gave the bag managed to change her mind. She then left the bag with him to prevent the men of Basim from getting 'hot', that is, enraged (Van Kessel 1962:5).

\section{The raid}

A raid is normally launched shortly before daybreak. The party consists of three groups, namely the leaders, the seniors of the family; the archers, strong middle-aged men who have distinguished themselves on former occasions and who open the attack from a distance; and the spearmen, mainly young men who are being given the chance to prove themselves and gain renown. They form a semicircle at the back of the village and attack the frightened women and children who have fled to the woods. Men may put up a fight, but sometimes feign flight. The invaders therefore have every reason to strike quickly, for the fortunes of war can easily turn. After having taken their positions, one of the attackers makes a noise. From the houses some man will call: 'Who is that?' and the reply might for instance be: 'Your husband, Shuru.' Panic breaks out. The killing is irrespective of age and gender, unless specified beforehand. A man may keep a captured woman or child. Sometimes, in case of a shortage of women, abduction of women may be the sole objective of the raid. A young man who has cornered his victim may exclaim: 'Fathers, brothers, the women of our village never took any notice of me. I'll take this woman home', or, 'I want a dagger' (as proof of being a headhunter). As soon as a victim is overpowered, there is a wild outburst of joy ( $k$ us yetet); at the same time, this is a reaction to tense nerves. The victims are seized and generally ill-treated, their heads in particular being subject to torture: 'My head, my head won in the raid'. Except when raiders are in a hurry and the victims are killed on the spot and left there, the victims, dead or alive, are dragged to the canoes and placed in a sitting position on the bottom, their hands and chests 
hanging over a pole. They are beheaded by especially skilled men at the confluence of rivers or at river bends, places where living spirits are found. It is imperative to know the names of the victims. These are sometimes found out by tricks beforehand (Zegwaard 1959:1034-50). On the way home the bamboo horn is blown. On arrival there is the usual enquiry, as described under the heading simulation. People jump and howl. The adorned, excited women cheer and dance and praise the killers (Zegwaard 1959:1022).

Shortly before the raid, and on return, the warriors sing the song of clouds. This song is said to have first been performed by the ancestors of the Bismam villages when they rowed from the mountains to the coast. The song begins by enumerating the large number of insane, deformed, malevolent and aggressive anthropomorphic and zoomorphic beings in the upper world: the misers, the roughnecks, the lizards, the thunder-men, the ant-men, the gnat-men, the wasp-men, the praying-mantis-men, the worm-men, in short all those creatures who 'harm us' (mira fenaoa, Zegwaard 1959:1034). Zegwaard notes that there is a striking resemblance to the underworld spirits that embitter the lives of the Kamoro, against which a ritual war is waged at the end of Kaware, when the apoko dignitaries thrust their lances into the sands of the beach (see Chapter III). In various Kamoro narratives malevolent rain, thunder, and storm beings, and black-cloud men or women in the upper world, function as the counterparts of the benign heroes of the sun. The enumeration of malevolent beings in the song of clouds signifies the risks encountered en route by the ancestors, and at the present time by their warrior descendants. The song continues, enumerating scores of trees that grow on buttress roots, grasses and reeds. It lists the spirits hiding in these places, from where they attack humans, making them ill and weak. The third part of this cosmological 'symphony' represents the turning point: it addresses one by one, separately, the companions, the 'brothers' of man, namely various kinds of parrots, the tree-kangaroo, and different kinds of squirrels. The headhunters feel a relationship with these fruit-eating beings (Zegwaard 1959:1034), similar to Kamoro's concept of ipu enakoa. The song is a male prerogative: it is repeated many times and is sung softly, so that the women and children sleeping in the family houses cannot hear it.

The prelude to the raid and the raid itself in its ritual context clearly demonstrate that commemoration and revenge of the dead is an all-out affair involving all walks of life and the entire cosmos. Headhunting provides us with a classical example of Marcel Mauss's total social fact. Small wonder, then, that Asmat art is so graphically anthropocentric. The initiation of male adolescents represents a momentous aspect of the commemoration and revenge of the dead. 


\section{The initiation}

The initiation of male adolescents is the third stage in a series of transitions: from the invisible (nat) to the visible (moro) status of a 'soft' vulnerable human baby; from there to the status of a 'hard', less vulnerable, real human being (kawenak), a transition which takes six or seven years; and from there to puberty and adolescence. ${ }^{11}$ It seems warranted to relate the first two stages to the third one as female to male. The invisible, spiritual status reflects, and not merely anticipates, the human status. Zegwaard gives details of two cases that demonstrate my point. One is about a young man from the settlement of Ayam who had served some years with the police corps in Kaokonao. He explained to Zegwaard in 1954 why he never ate bananas:

Before I was born as a human baby, I was a spirit-child. I was living with my spirit-parents in the woods. We were embodied in iguanas. One day they left me alone in the house. I got hungry and, although I knew that I should not take a banana from the bunch stored by my mother without her permission, I could not resist the temptation and ate one. Almost immediately I realized that my mother would be very angry. I got afraid and looked for a hiding place. I could not find a safe one. When the sun was already low I panicked, and no longer knew where I was. I heard voices and walked in the direction where the voices were coming from. I saw a young woman who was chopping wood. She was not a spirit female but a human female. I followed her into her house and hid in an attic where she stored her skirts. After taking a bath in the river, she took the spare skirt in which I happened to be hiding. To prevent discovery I had no other way but to enter her womb. [...] My mother, concerned that I had not returned home, followed my scent-trail to the village of the humans. There she contacted a female medium and told her that her boy might have entered the womb of a human mother. She wanted me back. However, the medium took the human side [as they usually do]: the woman gave birth to a baby after some months. That was me. The medium told my human parents about the stolen banana: 'You must keep the boy away from iguanas and never permit him to eat bananas.'

In the second story, an adult spirit-man who was living under big trees in the woods ate the sago grubs his wife had stored for a grub ritual. She burst into a rage and even gave him a public thrashing. Embarrassed, he ran away and entered the womb of a human female. The medium explained to the human mother what had happened. Ever since then, her son shared the name of his spirit counterpart, a name that literally means Red Eyes. This name reflects his craving for sago grubs. After that he was excused for his passion for sago grubs.

These stories illustrate that the society of spirits is thought to be equal to

11 For a discussion of these stages, see Zegwaard 1989; see also Zegwaard n.y.f, from which I have selected my brief description. 
human society, except for its invisibility. It includes both children and adults. The reason for leaving this society is typical of mythical and human realms: antisocial behaviour drives them out. The liminal transition from the society of spirits to human society is guarded by a human, usually a female medium. Zegwaard specifies ten such mediums residing in Shuru (1954), two of them males. Most of them are of middle age. There is a connection between them and specified men's houses. Each men's house in Shuru has two or three mediums. Three out of ten mediums are prominent. They receive messages exclusively by hearing, not through trance, hence cannot be called shamans in the current use of the word. Their contact-spirits produce a whistling sound, almost identical to the sound of the wind, fa atakam, literally wind language. The spirits come very close to the houses their agents live in. They come at irregular intervals, mostly on short visits. They recognize their agents by their body smell. Some spirits speak clearly; others can hardly be understood (this difference may be one reason for the difference in status of the mediums). The mediums' knowledge is exclusive; nobody can check on the truth. Each medium has his or her own spirits that they listen to. Zegwaard specified the spirits for each medium in Shuru. The majority of them are spirits of culture heroes or lords of the land, but one of them was the spirit of a baby which the medium lost in a miscarriage. The emergence of the spirits entering a woman's womb tends to coincide with the first visible signs of pregnancy and the movement of the foetus. As soon as the condition of a newly born baby permits, it is taken to a medium of the men's house or to any other medium chosen by the parents. The medium examines the baby very carefully. For instance, in the first case reported she told the parents that the baby's skin and fingers looked remarkably similar to the skin and 'fingers' of an iguana. The medium tells the parents how and why the spirit-child left its own sphere. From her diagnosis she derives a set of preventive guidelines and taboos. In addition, she contributes to the child's health by giving it a spirit name, nat yuwus or namir yuwus, referring to features and qualities of the culture hero that the medium communicates with. This name is strictly taboo. It is only divulged to a small circle of the closest relatives. It is used exclusively in the daytime, and even then only if it cannot be avoided. At night it is replaced by the name of the child's father. It is strictly forbidden to mention the name of the culture hero to whom the name refers, or his place of origin, in the presence of the child. If the baby falls ill it is renamed. The spirit name is the most essential animating element of the body and is for humans only. During the period of having 'soft' bones the child might feel a need to go back to its spirit realm, hence it is dealt with gently and carefully until its transformation to kawenak, a really human child. Children are then given a human or real name (kawenak yuwus), usually associated with a father or grandfather. The male children's 'female' spirit status decreases over the years, but never ceases to exist. A boy 
only gradually advances to a male status, culminating in his initiation as an adolescent warrior.

A medium may give information about lost spirit-children, but may also receive and communicate messages about natural disasters, black magic practices, or the arrival of foreigners. In these respects a medium, though formally not having a high status, may yet have considerable informal power. Undoubtedly, the institution of spirit names highlights the position of the female gender. However, it operates in a socio-political context in which men have a big say. It is presumably no coincidence that two wives of Warsekomen, the powerful warlord of Shuru, were mediums. As Zegwaard puts it: 'Sjamanism and group politics are hand in glove'. ${ }^{12}$

The demarcation of the transition from the spirit world to the human world by a medium is not, or no longer, known among the Kamoro. There is a reminiscence of a medium's 'wind language' in the attempt of a male dignitary to get rid of the hovering scary spirit of a powerful man who was feared while alive. He is said to whistle while communicating with the spirit (see Chapter V). I also know of a male seer in West Mimika who was able to foretell the arrival of a feared pre-war police party by putting a maggot on his body near his heart, thus communicating with the spirit world. An acceleration of his heartbeat warned him of trouble.

\section{Identifying with the dead: the first stage of male initiation}

In Chapter III, I described how Kamoro initiates in the course of Kaware identify with the death and resurrection of the culture hero Mamirima (Asmat: Fumuripic). Asmat initiates do not; instead they identify with a slain enemy victim of headhunting - a conspicuous difference. Another telling difference is that for the Kamoro, initiation is the ceremonial duty of bride-receivers, whereas among the Asmat the initiate's mother's brother acts as the initiator. He immerses the decapitated head earmarked for the initiate in the river often after a brawl about suitable candidates that sometimes involves snatching the victim's body. He then takes the head to the men's house and pins it to the floor near the fireplace with a dagger, so that it will dry. He makes a mat and fills it with magical twigs (eram). The initiate walks out of the men's house, the mat under his arms, boards a canoe, places the mat in the bottom, and acts as if he is returning to the place where the victim comes from. He then changes his mind and returns to the men's house after some water has been poured over his head [thereby identifying with the submerged head 
of the victim]. He sits on the floor assuming the taboo pose of one who is ashamed: he lowers his head and does not look around. He perseveres in this pose for several days and takes no notice of the attempts of bystanders to divert his attention. Like newborn babies, he is subject to food taboos, such as not eating fish with bones in them. Meanwhile, his mother's oldest brother holds the decapitated head in the fire long enough to scorch part of the hair. In the afternoon or evening following the raid, he smears the ash of the victim's hair, mixed with the victim's blood, on the initiate's head, shoulders and body. In this way the initiate identifies with the victim. The initiate's body is painted with red ochre and his face with black and white stripes. His hair is lengthened with sago-leaf fibres. A piece of mother-of-pearl hangs on his forehead, and two tassels of cassowary feathers on the back of his head. A delicately open-worked pig bone is placed in his septum, and a triton shell on his abdomen. A crossed band is put across chest and shoulders, as in Mimika; bracelets woven of finely split rattan adorn his arms, wrists, calves, and ankles. A dagger is stuck into an armband, and a sago-fibre apron, otherwise worn only by married women, adorns his hips. A bamboo plate (owam), a sign of decapitation, dangles on his back.

Meanwhile, the mother's brother prepares the head. It is roasted and then kept in a loft during the night. The following morning the nose skin is taken off and the jaws are removed. The jawbone is thrown outside for anyone interested in using it as an ornament. The skin is torn off. The flames of a fire touch the temple and the back. A hole is cut into the head with an axe named after the victim. The brains are taken out and, mixed with sago, consumed about midnight, exclusively by the old men. Only the head is taken to the men's house. The flesh of the body has been distributed beforehand among relatives and friends. Even the women and children get their share; the initiate is absolutely excluded from the cannibalistic meal: he must not eat his alter ego. The inedible parts, such as eyeballs and genitals, are placed in the initiate's magic mat.

The head, painted and decorated with feathers and beads, is then laid between the spread legs of the initiate against his groin. He must look at it continuously. The head remains there for two or three days.

A few days afterwards everyone, dressed up, boards canoes. The initiate stands sullenly in a canoe, taking on the pose of a worn-out old man leaning heavily on a club-with-a-disc. His mother's brother supports him. The canoes, manned with drumming and singing villagers, move in the direction of the sea. The 'old man' becomes weaker and weaker and finally collapses. Together with the head, the initiate is immersed in the sea for a while; the victim with whom he is identified has then descended to the underworld of the dead. After the initiate has been hauled back from the sea, all his ornaments are removed and placed in his mat, never to be used again. The head is no longer 
placed near the initiate, marking the end of the identification with the dead. The ceremony has reached its turning point. The old Adam is gone; his namesake the initiate is reborn. Initially he acts like a child, does not know how to handle a paddle and has to learn the name of the river and its tributaries. His decapitation name (nao yuwus), transferred from the victim he replaces, is pronounced at every tributary.

\section{The ritual recognition of adolescence}

Back in the village, the initiate is decorated anew in the family house from head to toe; the bamboo plates covered with the dried nose skin of the victim, signifying a conquered head (there are three types of plates connoting a difference in ranking), switch from his back to his breast. All present sound a long drawn-out 'e-e-e-e-e-h'. Henceforth the initiate acts as a vigorous young man admired by all. After a few days of rest, the initiate's mother's brothers, in the presence of the whole community, assist in cutting down a sago palm and removing the bark. The initiate watches the scene together with the woman to whom he previously had handed the skull; she acts as a ritual mother. His mother's brothers plant a sago-leaf stalk near the middle of the trunk of the palm. By loosening the outer layer, except at the top and the bottom of the stalk, they can bend the middle part in such a way that an oblong hoop is formed. Then the ritual mother-with-the-skull swings a sago pounder through the hoop without touching the sago palm. She hands the sago pounder to her 'son', who repeats the act. The onlookers sing 'Sago pounder, sago pounder', followed by a song that was performed on the occasion of the preparation of the head. This ceremony re-enacts the following narrative told to Zegwaard (1959:1027-8) on another occasion: Biwiripic [again] goes with his wife and children to the mouth of the Fait River to pound sago. After felling a palm in full flower, he removes the bark from top to bottom. He orders his adolescent son to lie prostrate on the bare trunk. The father [or, according to some versions, the mother] swings a sago pounder and strikes the boy's neck. The boy's head, decorated with hair-lengthenings, lands upside-down in a tree. The father [or mother] strikes again and again, so that the blood and flesh of the son's smashed body entirely mix with the sago pith; the entrails splash high into the surrounding trees. Now the pith proves to be very easy to handle. The mother rejoices: 'Before, the sago was hard to knead and to wring out; now it is easy.' [Headhunting even literally permeates the sago.] The son's head begins to talk. He teaches his father the songs to be sung on the way from the raid, at the decapitation festivities, and so on. [Apparently, this is an alternative version of the myth which institutionalizes headhunting.]

After this ceremony everyone departs for pounding sago. The ritual mother and her 'son' exchange sago pith. The woman also prepares some sago in 
the shape of a stick and gives a few pieces to the initiate. Other pieces are put in the magic mat. The initiate's mother's brother then decorates him again. The following night there is drumming and dancing in the men's house till daybreak. In the morning the initiate's hair is lengthened with curled sago-leaf fibres. He and the skull are decorated for the final ceremony on the following night. The skull is suspended in the centre of the men's house. At night a big fire is built in front of the house; singers and dancers sit around it in solemn silence. Then the initiate comes out of the men's house carrying the magic mat under his arm and the richly decorated skull. The men carry shields and move them towards and away from them, while a song is intoned. The dance begins. The initiate joins the dancing men; from now on, he is accepted by them as an adult. The songs performed during the preparation of the head and the sago pounding are repeated again and again. The dance, lasting till dawn, completes the Nao Pokmbu, the headhunting and initiation rituals.

Strikingly, an important part of the initiation of adolescent men aims at identifying the initiate with the victim of a raid. The great attention paid to the victim is in keeping with a general tendency, among both Kamoro and Asmat (a tendency also noticed by Zegwaard) not only to commemorate the dead but also, even particularly, to placate the dead. This is believed to be vital for the well-being of the living. It applies all the more to anyone killed in action.

There is also a most remarkable strategic side to ritual identification with the victim: it proves to be very useful in interlocal communication. Zegwaard (1959:1027) notes that the relatives of the murdered person, whenever they meet his namesake in the attacking party, will always call him by his assumed name. They will treat him as a relative, dance and sing for him, and give him presents. It is strictly forbidden to kill people from other villages who, because of their ritual names, are related to ego's village. A namesake (by virtue of this ritual) is often chosen as a go-between. On his tours Zegwaard frequently hired such namesakes to be his guides on his visits to tribes hostile to their community. Killing such people, although it happens occasionally, is considered a serious breach of convention. This Asmat practice seems to me a most interesting alternative to a rule practised in many parts of New Guinea, namely to marry those you wage war with. Asmat interlocal marriages outside affiliated settlements are rare. These two practices keep interlocal rivalries in check and promote interlocal trade and travel.

Finally, initiation of adolescent men is not the main significance of headhunting, although it may contribute to it. It is merely one aspect of headhunting, which functions as a 'totalizer' of Asmat society and culture. 


\section{Chapter xiI \\ Conclusions}

'Similar yet different' is a recurrent phrase in my comparison of Kamoro and Asmat. How are we to account for this paradox? As suggested by Knauft (1993), we can resort to the dialectic between the existential and symbolic dimensions of Kamoro and Asmat social formations, including their structural history. Structural history, as I see it, 'happens' on the borderline between chance events and non-chance structure. Structural history is structure on the move; it is 'structuration', a process of articulation and signification, which in Durkheim's ${ }^{1}$ words is ceaselessly forming and breaking down.

Let us draw the threads together. The Kamoro (including Sempan) and the Asmat share as their habitat a vast, marshy coastal plain that widens, going from a small coastal zone and hinterland in the far northwest to a broad zone several hundreds of kilometres wide in the far southeast. This environment, in interaction with the activities of its inhabitants, gives rise to an ecological situation in which the carrying capacity of the land gradually increases from northwest to southeast. In keeping with this, the average size of settlements and their constituent groups, the Kamoro taparu and the Asmat yew, increases as we move from northwest to southeast. The largest settlements and groups are located about midway along the rivers east of Kaokonao, due to an optimal balance here between tidal and freshwater swamp. The settlements near the coast and those further upstream are somewhat smaller. These smaller Kamoro and Asmat settlements resemble each other, in that the number of their taparu and yew is considerably higher than that in the much larger settlements. Presumably the larger number of smaller social units is due to a larger dispersal of wild and semi-cultivated sago stands.

This ecological situation, which crosscuts ethnic boundaries, may be considered the common existential dimension of the Kamoro and Asmat social formations. It has important implications: the more manpower per settlement, the stronger their political and military potential. Consequently, it is no coincidence that in the larger Kamoro and Asmat settlements to the east, which tend to concentrate along the middle courses of rivers, competition for sago and 
fishing areas has resulted in more conflicts and warfare than in the smaller settlements further inland and near the coast.

So much for the similarities in the existential dimension of Kamoro and Asmat social formations. Their interaction with the symbolic dimension, however, shows a considerable difference in social formation and culture. Kamoro conflicts and wars lacked the virulence of Asmat warfare. Asmat warfare is inspired by a dominant orientation towards headhunting and an obsession with revenge. This is evident in the naming of all sorts of objects of daily use after victims of conflicts, as an incitement to take revenge. The tendency towards violence is also seen in the high rate of casualties and the large amount of settlements and groups wiped out, decimated, dispersed, or integrated elsewhere. I presume that the historical origins of headhunting must be sought east and southeast of the Asmat area. Take for instance the Yaqai of the Mappi area, described by Boelaars (1981). In Part Three of his monograph, which describes traditional headhunting practices, the author stresses the point that headhunting was a complex, highly differentiated phenomenon constituting the cultural focus of Yaqai society (Boelaars 1981:125-97).

The Kamoro, on the other hand, display an orientation towards the performance of an elaborate and sophisticated cycle of rituals. Headhunting has no place in this and has never been reported. It does not occur in myths either. Kamoro participants tend to engage in wars and conflicts by referring to the transgression of ritual secrets, even if the underlying cause may well be competition for sago and fishing areas. Violating ritual secrets is not reported as a cause of Asmat conflicts. However, it should be noted that a reported scarcity of sago groves may well function as social, emotional and symbolic, as well as economic causes of conflicts. Excessive ritual consumption of two crucial social goods, namely sago grubs and young sago-palm hearts, is a case in point. These delicacies are considered a source of spiritual power and fertility. Their production leads to massive felling of sago trees, and sometimes to overexploitation.

Most interestingly, in the far western part of Mimika a shortage of conventional natural resources, due to a limited hinterland and consequently limited manpower in small settlements, went together with strong and expansive political and military power. The lack of resources was made up for by exclusive access to and even a monopoly of Western and Indonesian commodities in high demand throughout Mimika. People from the east made risky journeys to Mimika in the far west to acquire iron tools, textile and ornaments. Here external history comes in. In the first quarter of the twentieth century there emerged in Kipia, West Mimika, a commercially-oriented Kamoro rajadom that participated in the slave trade (Pouwer 1955a:220-5); this rajadom was at least nominally Islamic. It affected, and in the long run might have changed, the traditional Kamoro cultural orientation, if not for the fact that 
the Mission and the Dutch colonial government overruled the rajadom. It may be concluded that similar existential dimensions in dialectic interplay with symbolic dimensions and history can result in different social formations and cultural configurations.

The Kamoro and Asmat are similar in their multiple manifestations of dual organization and bipartition, which operate in both the existential and symbolic dimensions. Although the Kamoro differ from the Asmat in that their taparu are not divided into residentially separate, exogamic, intermarrying moieties as are the Asmat yew, about half of the settlements do consist of two taparu. The remainder consist of parishes having two or more taparu (Sempan yahe se) that, like the Asmat yew halves, relate to each other as downstream to upstream. Marriage within the settlement is dominant. Taparu of limited size are exogamous, while larger taparu/yahe se, such as in the Wania and Sempan regions, are non-exogamous. Adjacent settlements tend to be organized in pairs. We may conclude that the differences in actual dual organization between Asmat and Kamoro are a matter of scale rather than of principle. Many taparu are simply too small to allow for exogamic, intermarrying moieties.

Nearly perennial warfare has decimated or wiped out a good number of Asmat settlements or yew (Zegwaard 1977:18-25) and was a constant danger affecting social stability. In order to survive, individual or group remainders of the ravages of warfare were often forced to join other, stronger settlements or groups. Zegwaard repeatedly found that seemingly genuine yew are in fact fused ones which have absorbed the remains of other yew that were forced by violence and killing to submit to a stronger unit for the sake of survival (Zegwaard 1977:22). Dual organization, since it overrides ties of kinship and descent, and often operates through the individual power of yew or moiety warlords, acquires extra emphasis in the Asmat political sphere as a flexible instrument of survival and power. In contrast, Kamoro dual organization and bipartition holds sway over the symbolic dimension, due to a central orientation towards the cycle of rituals. Bipartition in these rituals is of vital importance for Kamoro ritual, more so than for Asmat ritual.

Kinship and marriage obviously operate in both the existential and the symbolic dimensions. The Kamoro and Asmat types of kinship and descent are roughly similar in their emphasis on 'horizontal', generational ties - witness the Kamoro generational category of peraeko and the Asmat counterpart of afayis cokom in combination with the pivotal 'brothers', ofew. Consequently, the 'vertical' line of descent is shallow and not well known; it may be better described as cumulative filiation. A residential override in combination with interlocal and even local fragmentation, rather than segmentation of constituent units, renders thorough genealogical knowledge superfluous. It is likely that the Asmat trend towards patrifiliation is related to the central symbolic 
orientation towards warfare, headhunting and virility. The Kamoro tendency towards matrifiliation may be connected with a strong emphasis on (female) fertility in the symbolic dimension and on women's powerful position in the food quest, acknowledged by men. Kaware is a male stronghold vis-à-vis the power of women in everyday practice. Women as workforce and as the source of offspring and alliances are a highly valuable 'commodity'. Bride-receivers are therefore obliged to render a wide variety of economic and ritual services; matri-uxorilocal marriage fits in with this pattern. In their turn the preponderant position of Asmat 'brothers' corresponds with their living together around one 'door' in the men's house. Consequently, Asmat marriage tends towards patrilocality and virilocality. The subservient role of bride-receivers, though, is less pronounced. Kamoro women have a higher status and a more powerful position than their Asmat counterparts. Papish, Asmat ritual-ceremonial wife-swapping in situations of socio-political or cosmological danger, is not practised by the Kamoro. However, its Kamoro linguistic and cosmological equivalent kaypiri also denotes a situation of cosmological danger, such as travelling through unknown territory or being immersed in a foreign world as a contract labourer in the city. It is characteristic of the Asmat central orientation towards revenge and war that Asmat warlords use wife-swapping not only for counteracting cosmological danger, but also as a strategy for enlisting the support of or remunerating allies. They talk their wives into accepting this role. Wife-swapping as a strategy is not mentioned in the myth accounting for papish. (It should be noted that papish is strictly regulated. Transgression of the rules leads to conflicts and fights.)

Kamoro and Asmat cosmology is by and large similar. Humans live in a world in between the upper and the lower world. From this 'crossover', superhuman tricksters 'furnish' the earth with goodies acquired from above and below. The entrance to these abodes is paved by antisocial behaviour. Good and bad are complementary. Their human descendants likewise manipulate cosmological forces. There is a difference, though. I would venture the suggestion that such manipulation in cosmology-based ritual varies according to the main cultural orientation. For instance, in the course of Kamoro Mirimu Kame - the initiation of young people - as well as on other occasions, the names of the sago areas are recited one by one with a view to manipulation. The male sago dignitaries state that there is sago, not just that there should be sago: it is a coercive act. They also summon two female sago dignitaries and the sun: 'Sun, shine upon the mature sago palms [that is, fill them with pith], and let all areas [as specified] be replete with palms.' A reverent attitude of prayer is nonexistent. The male and the female sago dignitaries stride past the houses and shoot arrows made of sago ribs by way of symbolic exhortation to the sago spirits to do their job and fill the sago trees. Immediately prior to the nose-piercing ceremony, the specified course of the rising sun is recited in 
a series of ritual statements, accompanied by a staccato of striking gestures and passes by special dancers. This reaches its climax in shooting burning arrows in the direction of the sun to emphasize and support the sunrise. No mistake in the songs should be made, lest the sun not rise. The impressive sun ceremony is part of other rituals as well, such as the bat dance, as a highlight of Ema Kame. These and other ritual activities are meant to evoke the elements and forces of cosmology to promote fertility and growth. The Asmat attempt to ensure a successful raid by forcefully singing and repeating the cloud song. The malevolent beings of the upper world and of the earthly forest are exorcized by naming them one by one. The animal 'brothers' of man are similarly invoked.

Kamoro and Asmat narratives agree in locating the origin of Ema Kame/ Emak Cem in the hinterland. I venture the suggestion that in long-term history the present Kamoro, the Sempan, and the Nafuaripi had ancestors in common. Linguistic evidence seems to support this conjecture. Their main locations were upstream, in the hinterland. Ema Kame/Emak Cem is likely to have originated from them. In this respect it is noteworthy that the architecture of the Kamoro Ema Kame ceremonial house differs from all other ceremonial houses, including the Asmat ones. And it is perhaps no coincidence that in the Ema Kame/Kiawa of the Kamoro/Sempan a canoe as ceremonial object is absent, whereas it is a dominant, possibly pre-existent or coexistent, symbol in the Emak Cem of the Asmat.

Then, the more recent migrations of coastal-oriented communities from the far eastern part of Mimika, set in motion by attacks by peoples bordering on or living in the present Asmat territory, clashed with or merged with the preexisting, inland-oriented communities. These migrants gradually moved to the present Kamoro territory, where they settled as far as Etna Bay in the far western part of Mimika. They might have adopted Ema Kame from their inlandoriented predecessors. Ema Kame is universal in Mimika and was added to their coastal Kaware and nose-piercing rituals. The story of their migration has it that some migrants retraced their steps to collect the pin (amupao) for nose piercing in the far eastern Koperapoka coastal area, where they had left it behind when they panicked and fled. A myth about the introduction of nose piercing locates it in Mimika far to the east (Zegwaard 1952:47-8).

Descendants of the original inland-oriented people, who did not mix with the coastal invaders, retreated further inland, and are the present-day Nafuaripi. They do not celebrate Kaware, nor do the closely related Sempan. The inland- and upstream-oriented factions of Asmat, whose ancestors are believed to have migrated long ago from areas east and northeast of their present habitat, presumably also adopted Ema Kame/Emak Cem from these Nafuaripi. The latter retreated to the headwaters because of attacks by the far more powerful Asmat invaders. The coastal Asmat do not celebrate Emak 
Cem, but there has been some recent diffusion of it downstream.

In view of these intricate vagaries of history and migrations, it is all the more striking that all myths related to Ema Kame/Emak Cem, in spite of their diversity, are similar in eliciting the paradox of human genesis: born out of one, yet born from two. These myths also have in common that they ascribe physical genesis to the female gender and social genesis, the genesis of different groups, to the male gender.

Ema Kame/Emak Cem demarcates, at least among the Kamoro, the final stage and climax in a gradual, ritually demarcated process of commemoration of the dead. In the end, their bones are abandoned in the ceremonial house and left to decay. For both the Kamoro and the Asmat, Ema Kame/Emak Cem is a rite of passage from the living to the dead and vice versa, and from adolescence to maturity. The transition to adult status is marked literally by scarification. Ema Kame/Emak Cem celebrates and promotes fertility and growth, and is therefore classified as female, and as the source of physical reproduction.

There is a difference, though. Kamoro Ema Kame displays a plethora of rituals and ritual objects expressing a female-centred and matri-centred orientation. One of its highlights, if not the main one, is the simulation of birth from the vagina/navel of the ancestral mother, represented by a sacred board in the centre of the ceremonial house, one out of two (puru mane) symbolizing the ancestral couple. The very elaboration of a matri-centred complex of narratives and rituals points to Ema Kame as an age-old institution. One of my key informants even rated Ema Kame as the mother of all rituals. Asmat Emak Cem is less elaborate and a matri-centred complex is missing. The sacred boards are there, but they function merely as a deterrent. Emak Cem's central symbol is the spectacular spirit canoe (uramun or wuramun), which is similar in name to puru mane, yet quite different in substance and meaning. It is a magnificent piece of craftsmanship. Together with its associated ritual it is a perfect symbol of the life cycle: the honoured dead are invited to depart with the canoe to their abode in the underworld, while the initiates are marked as their successors by scarifications applied to shoulder, back and buttock. This happens in or in the vicinity of the ceremonial canoe. The marriageable ones among them are marked a second time by scarifications of the chest, which are applied in the same manner to the chests of their younger sisters. This scarification marks brother and sister as the basic pair for social exchange. So patrifiliation, patri-descent and marriage, the basic mechanisms of social continuity, are literally carved out in a 'female' ritual. The origin of Emak Cem is ascribed to two sisters who not only devise the ritual but also participate in it.

For the Asmat, canoes together with war shields (yamesh) are important components of their cultural complex of warfare, their 'male'-centred orientation. The making of war shields is even the subject of a special ritual. It is striking that for the Kamoro, shields are components of 'female' Ema Kame, 
but as strictly ceremonial objects (yamate) only, without a grip. Each of these shields represents a male or female person who has passed away and is honoured during the ritual. Special shields represent the ancestors and their peraeko descendants. Ceremonial shields are not a part of Asmat Emak Cem. So Ema Kame and Emak Cem are similar in some respects, yet the rituals differ in orientation.

Yipae, the fascinating 'female' Asmat masquerade impersonating and honouring selected dead persons, is strikingly similar in this respect to the Kamoro masquerade during the spirit platform ritual. However, the number of masked performers usually exceeds the two of the Kamoro masquerade. Seven have been reported in one case, but the number two does come in, since the dead to be honoured as well as their performers are chosen by the moieties. Of more importance is the difference in purpose. Yipae is meant not only to honour the dead but also to replace them. Relatives of the deceased adopt the performers of the masquerade and a good number of their relatives as well. The adoption is marked by the adoptees being provided with a bracelet. Scores of bracelets are involved. The adoptees identify with the deceased by adopting the name of the deceased. In this way, persons of different family groups are knitted together and the loss of relatives by death is made up for. Yipae has a strong socializing effect, comparable with the effect of Emak Cem ceremonies. It is enhanced by a massive exchange of food. Its intention is clearly revealed by the constituting narrative. An orphan who is not looked after very well helps himself to food by donning a fun mask to scare women and men returning from collecting sago and fish. Terrified, they leave the food behind. When the men find out, they not only decide to remedy the evil of neglect, but also are induced by the orphan's ruse to start the real masquerade, this time using sacred masks. During the ceremony a masquerade impersonating the orphan and bringing about a lot of commotion and fun precedes the masquerade impersonating the dead. Imu joking adds to a relaxed atmosphere. Making up for the dead is an important feature in view of the high rate of casualties through warfare and headhunting. It is absent in the Kamoro masquerade. Further, the Kamoro masks are donned by bride-receivers, not by relatives. This would be improper in the Asmat case: one should not mingle affines with kin by means of adoption. Although armbands are also donned in the course of the Kamoro masquerade, this is done by bride-receivers of the deceased. They collect food delicacies to give to close relatives of the deceased in order to alleviate their sorrow. Again, a difference in cultural orientation, in spite of superficial similarities, is associated with a difference in deeper meaning.

The complex relation of 'male' Kamoro Kaware to Asmat Yew Mbu/Tow $\mathrm{Mbu}$ rituals was discussed in detail in Chapter IX. Here it suffices to reiterate some conclusions. The rituals have two founding myths in common, though in varying versions. A third Kamoro myth, about the culture hero Nokoro, 
is not shared, but an important part of its subject matter, namely the sago grub ritual, is. However, the form and aims of these rituals vary. Interestingly, Nokoro's canoe, serving as a container for massive quantities of sago grubs, turns up among the Asmat in the form of four cylindrical logs, either interconnected with a mat or used separately. Both serve as containers of sago grubs coming down through a tube.

However, the orientation and focus of the rituals differ markedly. The concern of the Asmat ritual initiation of a new men's house is the promotion of communal strength and solidarity, explicitly including the relation between the sexes. Their chief culture hero is Yenip-from-above (the earth). His exploits are dramatized in the ritual. He is credited with the conversion of small dispersed and self-seeking bands into a large powerful community, enjoying access to abundant natural resources and the pleasure of a rich social and cultural life. Ritual collecting of large quantities of sago grubs and their distribution express and promote cross-gender strength. There is a mock enactment of warfare by males and females separately. The exploits of Fumuripic, the culture hero of resurrection, are not dramatized but are commemorated in song.

For the Kamoro, on the other hand, Kaware marks not the solidarity but the opposition between the sexes. Further, it is not the myth about the Kamoro version of Asmat Yenip that is depicted in the ritual, but rather the narrative about the culture hero of resurrection. Nokoro, the culture hero of the third myth, is also impersonated. He exhorts women not to neglect the men but to take good care of them. Finally, the violent death of the hero of resurrection is avenged in ritual by thrusting lances into the sand during the grandiose final act of Kaware, thereby crushing the evil spirits. Kaware is a male stronghold rather than an expression of cross-gender solidarity. Again, in spite of similarities, the difference in main orientation shows up.

Finally, the Asmat Mbish ritual, considered in the context of the ritual of warfare and headhunting that it was formerly part of, is the 'male' coastal counterpart of 'female' inland Emak Cem. Both rituals combine a commemoration of the dead embodied in a spirit pole and a spirit dugout - a vertical and a horizontal canoe, respectively - with initiation. Initiation in Emak Cem involves the recognition and participation of both males and females as adults in everyday social life, based on kinship, marriage and cumulative (patri)filiation. This aspect of social life relates as 'female' to the 'male' aspect of warfare and headhunting. The initiation and social acceptance of male adolescents in the 'male' sphere of social life is ritually demarcated by presenting the initiate with the skull of a slain enemy. The initiate is expected to identify with the victim; he even adopts his name. Nose piercing has no place in this. This initiation is explicitly associated with warfare and headhunting, and so is the spirit pole. The tree selected for making it is even attacked as if it were an enemy. Its transportation and arrival in the settlement are marked by a mock 
war between moieties and between all the men and the women. The women are assembled in the men's house: they function as the enemy. The blood of the victim or victims of headhunting is applied to the eyes, mouth and genitals of the carved figures. It is this act which vitalizes the carvings and gives them their power.

The 'female' side of the Kamoro initiation of young males as performed in Ema Kame is similar to the Asmat one, but more elaborate. It marks their passage to the social life of adults in terms of kinship, marriage and (matri) filiation in the same way. However, the 'male' aspect of initiation as apparent in nose piercing during Mirimu Kame differs from the Asmat one. It is connected not with warfare but rather with fertility and growth, with cosmology and its manipulation. Witness for instance the fact that it is performed on a sago scaffolding, a major symbol of growth. Also, the male aspect of initiation in Kaware is about ritual resurrection, not war.

Although the naming of Kamoro and Asmat spirit poles is identical and they both consist of three parts meant to commemorate the dead, there are significant differences in construction and meaning. The Kamoro tripartition of the mbitoro clearly corresponds with the tripartition of the cosmos. The central round or oval motif of the wing represents the may kame, literally 'father's house', the house of the sun hero. Zigzag openwork carvings between the sun motif and the junction with the wing denote clouds, the transition between the sky and the earth. Marks (otepe) of cult groups to which particular ritual sequences are assigned are also carved in openwork on the wing. Then follows the depiction of humans represented by the hollow carvings of a specified deceased man and woman. The inner body (ndata) departs from the human body, leaving only the outer covering (kao). The point at the bottom as well as the hole in which it is inserted are puri (taboo), as they represent the transition to the underworld. Just beneath the point of the pole, the spirits of honoured deceased, called up by the songs, watch the festive events. The tripartition of the Asmat mbish does not explicitly correspond with the tripartition of the cosmos. Its top is not the wing but consists of the carving of a deceased man from which the wing protrudes. The wing consists of openwork spirals that denote unspecified ancestors. Anthropomorphic carvings denoting deceased children are also part of the wing (similar to Kamoro carvings of faces denoting children). The abode of the sun is not indicated. The carvings of the middle portion of the mbish correspond with those of the middle part of the mbitoro, but the bodies are not hollow and the arms, unlike the drawn-up ones on the mbitoro, hang down and point to the crotch, thereby referring to the scalp of a slain man placed between the knees of an initiate (Gerbrands 1967:310-1). The bottom part of the mbish is not inserted in the earth. It often ends in a reduced version of the spirit canoe or in an open niche in which other male but especially female ancestors are depicted with Kamoro-like bent knees. Asmat and 
Kamoro have in common that the oval icons of living/moving, respectively bianam and mopere, are applied to the limbs. In Asmat carvings, however, scarifications of the limbs indicating muscles, which connote physical power, are predominant.

So our conclusion with respect to anthropomorphic carving is, again, that they are similar yet different. The Kamoro deeper meaning of tripartition of the spirit pole clearly reflects cosmology. The Asmat tripartition reflects ancestry.

Both Kamoro and Asmat culture agree in a strong predisposition towards, if not preoccupation with, a cult of the dead. The Kamoro take leave of the dead in a gradual series of eight stages, including the final stage of Ema Kame. This takes several years. Unfortunately, our knowledge of the Asmat stages of farewell from the dead is incomplete. However, it is quite clear that the Kamoro and the Asmat share a deep concern with the dead, since they believe that caring for the dead is essential for living, for survival. At the same time, their attitude towards the dead is deeply ambivalent. The dead are a basic component of everyday life. They are honoured and deeply respected, but also feared. The living constantly feel the need to remind the dead that they can handle life without them: 'You were a good hunter, provider, fisherman, drummer, singer or storyteller, but we can manage perfectly well without you, thank you. Now please move on and leave us alone.' 


\section{Chapter xili}

\section{Epilogue}

\section{Continuity in discontinuity: the current situation}

It is not a pleasant sight - a people totally indifferent to your presence; people educated but without a place in their own society. Mimika strikes a person as a dead area filled with zombies. There is no work and no interest in work. Religion of the past is no longer celebrated and the Christian religion means nothing to the people. The past is gone forever. The future holds no hope. ${ }^{1}$

This harsh, sad judgement by a progressive American OSC missionary in Asmat, a man with some anthropological training, calls to mind the atmosphere of cultural malaise I sensed during my visit to Etna Bay in 1952. To the American Crosiers and other missionaries in the Asmat territory 'the Kamoro were a beaten down and lost people, somehow ruined by the intolerant and judgmental Dutch missionaries and Kei Islander catechists and teachers who converted them in the 1920s and 1930s' (Pickell 2002:xviii). For this new generation of Catholic missionaries, the Kamoro stand out as a glaring example of what not to do in dealings with the more recently proselytized Asmat. However, this negative assessment is belied by the vitality radiating from the vivid, magnificent photographs of Kamoro cultural happenings and of everyday life made in the 1990s by Dr Kal Muller, the popular and respected 'liaison officer' of the Freeport Mine. His photographs sparked off a factfinding tour of several months in 1997 by him and David Pickell, an experienced American writer familiar with Indonesia. The journey took them from Timika, the downstream centre of Freeport Mine in the east, to Etna Bay in the far western part of Mimika. Pickell's independent, lively, sympathetic and reliable travelogue of 2002, illustrated with Muller's revealing and natural photographs, bears witness to their open minds and excellent rapport with the people on one hand, and the unmistakable cultural and personal vitality of the Kamoro on the other. How are we to account for these contrasting observations from the 1970s and 1990s? Is it a matter of different eras, or of 
disparity in the eyes of the beholder? I think it is both.

What was the situation before the 1970s? Part One makes it clear that the nearly universal celebration of Karapao, of parts of Kaware, Ema Kame, of various rituals marking death, some other rituals, and the horseplay (imu) between the sexes, were in evidence in the 1950s. They were also reported in the 1960s. Moreover, in spite of considerable time lapses in the actual celebration of rituals, the detailed knowledge and enthusiasm about them were remarkable. The memory of rituals and of the dozens of individual hereditary ritual functions was by no means dead. One could even speak of a revival. In the early 1950s the celebration of extensive ceremonies required the consent of the colonial government. In the second half of the 1950s and in the early 1960s rituals were condoned without explicit consent. These decades clearly witnessed a far more liberal attitude on the part of the colonial government and the Mission. My fieldwork, Father Zegwaard's and my interest in ritual and myth, and the explicit attempt of the Catholic Mission to integrate some ceremonies and carvings into its ecclesiastic practice no doubt played their part. Pickell's (2002:111-2) remark that in the late 1950s the colonial government did its best to ban native ceremonies outright, as part of its efforts to govern its last East Indies colony, is not correct, at least as far as Mimika is concerned. Moreover, the brief interim period in 1962 of administration by the UN, before political control was handed over to the Indonesian authorities, offered some breathing space: there was nobody to stop the Kamoro from celebrating rituals, and they did. ${ }^{2}$ The last Kaware that Pickell's Kamoro assistant Alo saw was the one celebrated in Ipiri, west of Kaokonao, in 1968: 'That same year [...] the Indonesian government, police and military began cracking down in earnest on traditional ceremonies [...] a village could no longer openly build a karapao or erect a mbitoro' (Pickell 2002:112). This was ironical, since from 1971 onwards imitations of the Karapao ceremonial house appeared in almost every village, but they were small 'secular' ones with a single mbitoro and only one door. They were used as a backdrop for political speeches during national elections favouring the government-dominated Golkar party. This party was the only one allowed to organize meetings below the regency level. A Golkar logo decorated the building. Golkar T-shirts were a common sight. Some Kamoro even elevated these to body decorations by burning a pattern of holes into them and by cutting the sleeves into neat strips, an inventive way to conceal wear and tear (Pickell 2002:172). The colonial government required people to focus on government programmes and kept them busy with collective duties for the maintenance of the village: ${ }^{3}$

2 Information from Alo, a knowledgeable Kamoro informant Pickell consulted, see Pickell 2002:112.

3 Apollo, Pickell's Kamoro assistant, Pickell 2002:111. 


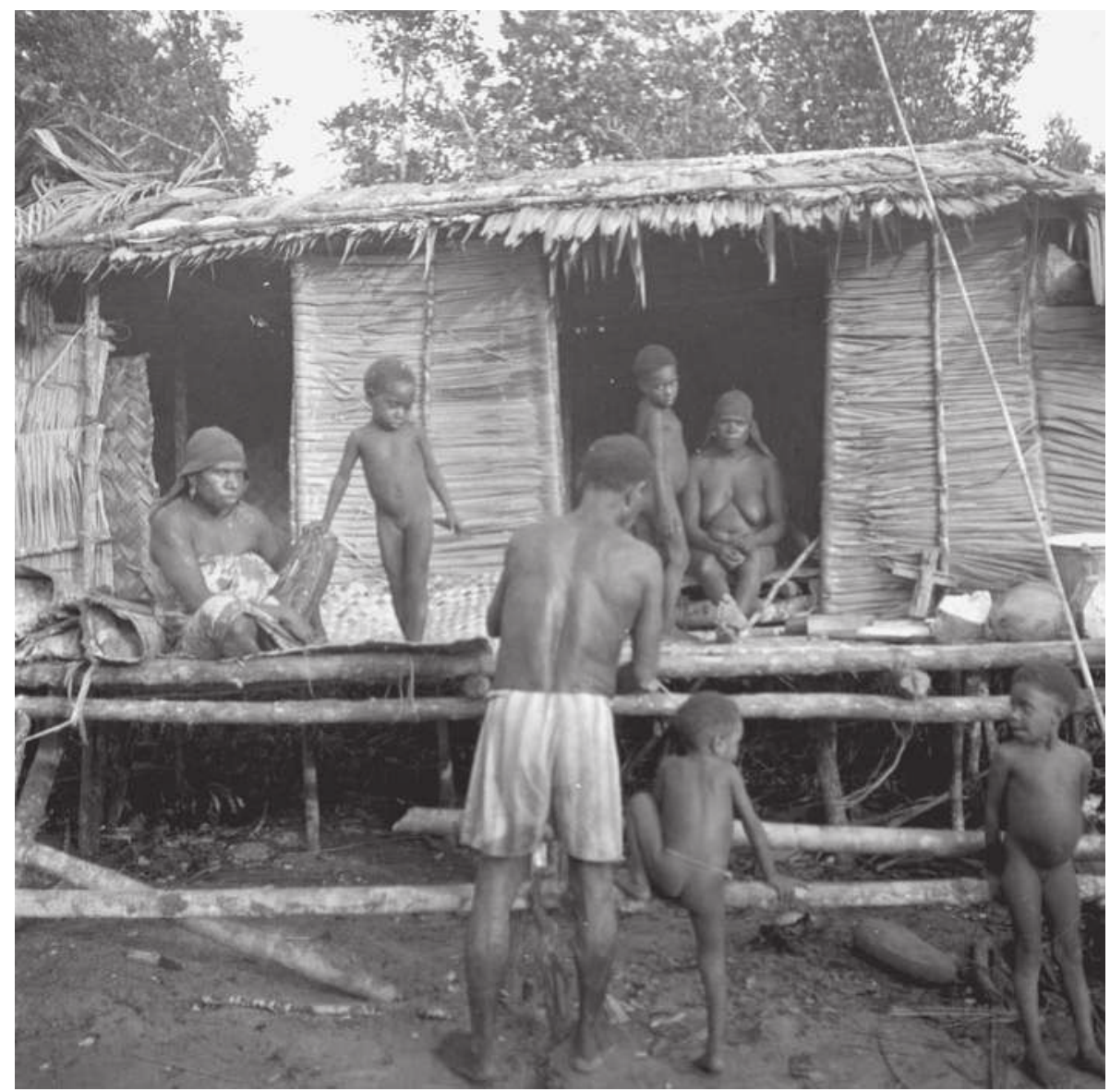

Family compartment in temporary longhouse near sago groves. Ipiri River, February 1954. RMV: NG-54-55. Photograph by Jan Pouwer.

They say that the adat is not any good but the real reason is that the government and the Catholic Church are afraid of the traditional ceremonies. They are afraid of two things: the first is sex; a woman may go off with a man who is not her husband. The second is that the people will stop believing in God and revert to animism. ${ }^{4}$

In the absence of ceremonies tying the people to the village, the people carried on as much as possible with their semi-nomadic life, travelling up and down the river to collect sago and fish and occasionally to work in makeshift 


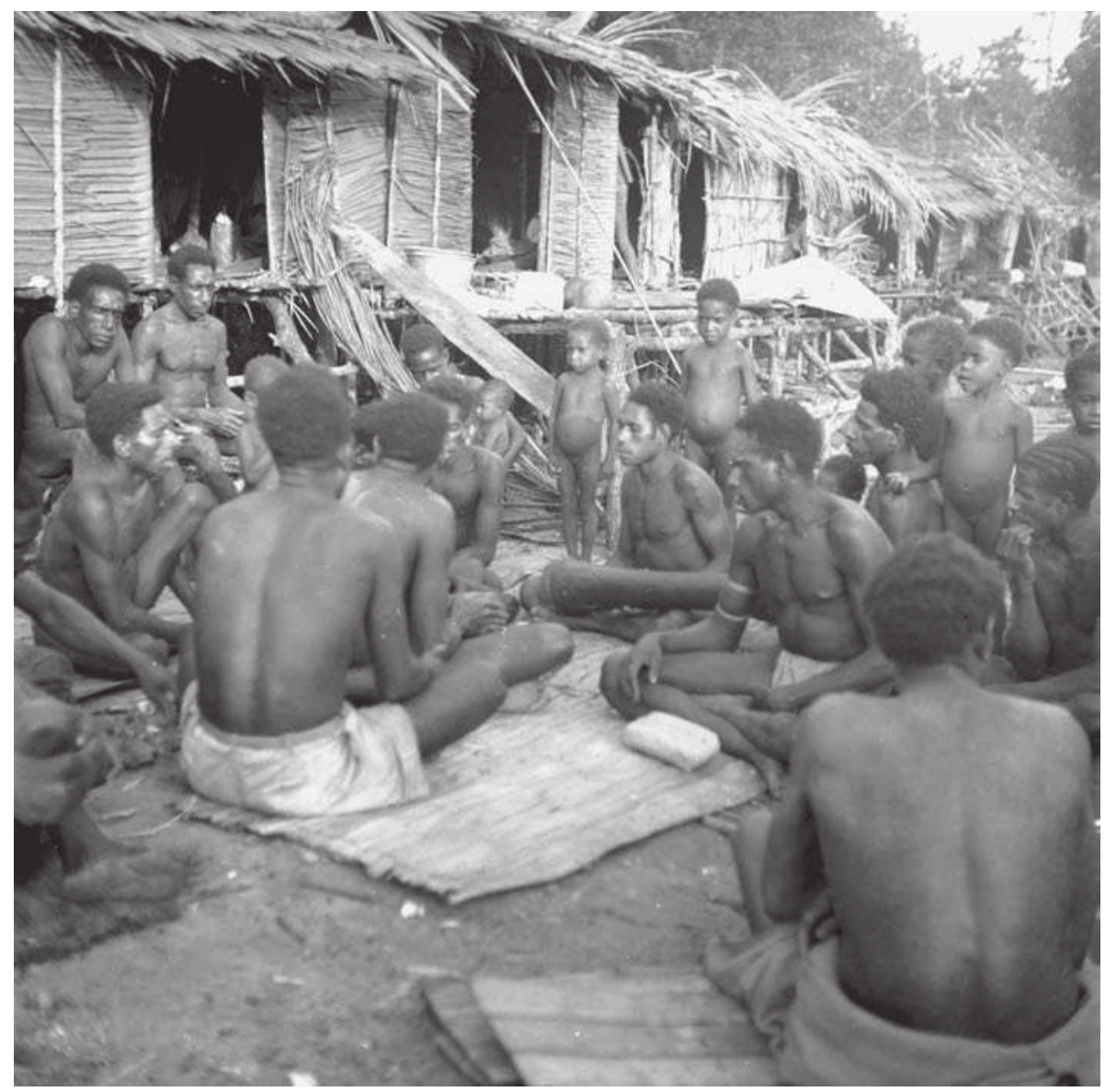

After a full day's arduous work in the sago groves nearby, people sit close to each other, relaxing in front of their temporary longhouse and enjoying listening to drumming and casual songs. Paripia River, Ipiri, Mimika, 1954. RMV: 10809-54-50. Photograph by Jan Pouwer.

gardens, not simply to make a living but also because they love it. Why toil in a garden when one can enjoy a less demanding, more relaxed way of life hunting and gathering? During my fieldwork in the 1950s I joined them in their travels and work, and I noticed how much they enjoyed themselves. The atmosphere was much more relaxed in their temporary shelters than in the government-style houses in the village. At night when the work was done - and the pace of work was high, not allowing for any laziness - men and women sat around their fires in or outside the shelters. Children played 
on moonlit nights. People chatted, laughed and listened to the drumming and songs relating everyday happenings and gossip. In their shelters they escaped from government pressures and the duties imposed by local Kei schoolteachers. Foreigners as a rule do not participate in this lifestyle, which to them is invisible. What they do witness is the dreariness of life in the government-style villages. Often houses are deserted, except for some old people and children who stay behind. When Pickell and Muller, on their way back from Etna Bay, arrived in Ararao (official name Umar), one of the largest Kamoro villages (population of 480), they saw no more than a few dozen people (Pickell 2002:177). The rest were staying in shelters on the eastern shore of the Umari River for fishing, gathering oysters, and hunting pigs. On this shore the entire village of Poraoko, almost 50 kilometres to the west, also lived in an encampment. These people had already been there for two months. On the western shore the visitors found the people of Ayndua, some two hours' travel from their village. From Pickell's (2002:145) description it is clear that all these people were enjoying themselves immensely:

To settled [Kamoro] urbanites like Alo and Apollo, this scene brought on a wave of contentment, a feeling that seemed to combine nostalgic memories [...] and a sense of pride in the irrepressibility of the nomadic spirit that continues despite 80 years of the best efforts of two governments to get them to stay put.

And to turn them into horticulturalists, one might add. Conventional wisdom has it that 'civilization' begins with farming, in spite of convincing anthropological evidence to the contrary. As Pickell (2002:82) argues, 'the world has seen far too many complex, highly developed nomadic societies to suggest that farmers have an advantage in terms of cultural sophistication $^{5}$ (or, one might add, economic surplus). The Indonesian government, represented by people who come from a tradition of the labour-intensive cultivation of irrigated rice, is having at least as much trouble as the Dutch had in understanding a semi-nomadic hunting and gathering society like the Kamoro (Pickell 2002:82). Moreover, hunting and gathering were part of a ritual cycle, the focus of culture and art. On their way back from West Mimika Pickell and Muller had a revealing conversation in Kaokonao with a former Kamoro school principal who wanted to discuss something very important with them. They were barely seated in his house when he raised the subject of the decline in art and woodcarving. His lips quivering with anger, he said: 'All of Kamoro tradition has ended because the Church objected to two small parts of Kaware: nose piercing and free sex. What do these have to do

5 Pickell refers here to the British anthropologist Bruce Chatwin, whose elegant travel writings continually poked fun at the conventional wisdom of the advanced farmer versus backward hunter-gatherer distinction. 
with woodcarving, or the important parts of Kaware?' By Kaware he meant the overall cycle of Kamoro ritual life, including Karapao and all the other rituals. He apparently considered Kaware to be the most basic ceremony, whereby Kaware as the 'father' compares to Ema Kame as the 'mother' of all ceremonies. For him, the end of Kaware meant the decline of all other forms of Kamoro culture. Together with two partners, carvers like him, he started an organization to promote a renaissance of Kamoro art and culture. Referring metaphorically to the wing of a spirit pole (in fact the root of a tree), he said his organization wanted to start with the root, in this case a synopsis of the various narratives from the different villages (Pickell 2002:244). Almost sixty years after my fieldwork, this participant's view strikingly strengthens my conviction that the ritual cycle constitutes the focus of Kamoro culture. Work derives its impetus (or lack of it) from this central orientation.

Thirty years after Trenkenschuh's assessment, things have changed due to increasingly tolerant and understanding attitudes of at least the new generation of leading government and military figures and of progressive missionaries. This change cannot be attributed to a single event. ${ }^{6}$ Missionaries and foreign visitors occasionally report misbehaviour by local administrative or military satraps. In the perception of these people the Papuan hunters and gatherers are lazy, inferior to Indonesian horticulturalists, and they perform outmoded ritual instead of engaging in 'progress'.

In Asmat, Indonesian government policy proceeded along similar lines, but initially in a more aggressive form. At an impasse on how to stop current raids, in May 1964 the civil administrator abolished yew, burning them to the ground. All feasting and carving were prohibited. He did this under the mistaken supposition that these institutions were responsible for the people engaging in raids. His successor in October 1964 likewise set fire to new men's houses, including houses which had replaced the ones destroyed. He went so far as to force men and women to stand in the glaring sun for hours, even to the point of fainting (Sowada 2002:53-4). Father Sowada, then Superior of the Asmat Crosiers missionaries, fearing a damaging void that would soon spell the disintegration of Asmat culture, attempted to counteract the destructive Indonesian policy by having buildings constructed in various villages. The buildings were meant to serve as social and cultural centres replacing the prohibited ones. However, they did not resemble the men's houses, were not consecrated by ritual, and consequently failed to function as traditional social and ritual centres. Instead, young men used them as meeting points to play guitars, cards, and other games (Sowada 2002:54). In September 1965 Indonesia rejoined the United Nations and consequently reactivated 
the United Nations development programme for West Irian (FUNDWI). Sowada succeeded in mobilizing funds and personnel for initiating an Asmat Art project, after the UN representatives realized that there was a real and even booming international market for traditional Asmat carvings, as well as for innovative woodwork, mostly in ironwood and reduced to a manageable size. In December the Dutch art collector and Asmat art expert Jacques Hoogerbrugge arrived in Asmat to initiate the project with the Mission's full support (Sowada 2002:55). In the course of 1969, when Sowada was appointed bishop of the new Diocese of Agats and got full ecclesiastical support for his cultural policy, he launched the idea of establishing a separate cultural centre for the preservation and promotion of Asmat art. Missionaries purchased and collected numerous fine objects. The idea was then born to establish an Asmat Museum of Culture and Progress for local and international display and as a sales outlet. The Indonesian government realized that Asmat art was in high international demand and began to disregard its own injunction against ritual, men's houses, and carvings. In July 1971 the regional administrator in Merauke permitted the Mission to build a museum. Quite remarkably, he requested that a ceremony to celebrate the placement of the museum's foundation stone be held on 17 August, Indonesian Independence Day (Sowada 2002:56). The administrator even asked local people to carve a number of mbish to decorate government buildings in Merauke. Consequently the Bismam villages, noted for their spirit poles, immediately arranged for fitting ceremonies. When stopped by local officials, they were unable to understand that the government had ordered ancestor poles yet forbade the ceremony, Mbish Pokmbu, required for carving them. They were then permitted to celebrate (Sowada 2002:56). A similar incongruence concerned the request by the Merauke chief of police for war shields. When the local administrator noticed people carving these shields, he presumed that they were preparing for warfare and destroyed the men's house (Sowada 2002:57). Sowada reports various other examples of irrational behaviour by local administrators. He also brought to the attention of regional administrators and the national press claims that some Indonesian merchants, in cooperation with bribed local administrators and army commanders, underpaid logging, delayed payment, or even failed to pay at all. The demand for logging also interfered with carving and seriously disrupted village life. A wave of anger swept through Asmat. It sparked off an anti-Indonesian messianic movement and cargo cult in the large village of Ayam in 1975 and 1977 (Sowada 2002:57). It also led to a sharp conflict between the Mission and some of the government officials involved (Sowada 2002:58). The missionaries successfully took the side of the people. In 1978 and 1979 rituals revived. Sowada lists ceremonies for an ancestor pole, a war shield, an initiation (Emak Cem), new men's houses, and a sago grub feast in various downstream and upstream villages of Central 
Asmat. The initiation involved some 100 young adults (Sowada 2002:57).

The Diocese of Agats officially opened the museum on 11 August 1973. It arranged for the overseas training of successive Papuan curators, including an Asmat one. The acquisition, display and adequate storage of a rapidly growing and representative collection were greatly assisted by the employment of Gunter and Ursula Konrad and Tobias Schneebaum, art collectors of note. The building consists of a display section, an educational and library section, and a wing for storage. A separate wing contains prize-winning innovative artefacts from a contest for individual carvers, held every year since 1981. The contest subsequently turned into an arts festival, also serving as a sales outlet for commercial and individual collectors. The Freeport Mine sponsors the festival and has contributed financially to remodelling and expanding the museum.

Since 'traditional artefacts [closely connected with rituals] began to lose meaning and value, the master carvers were clever to maintain the medium of wood, not to bring the spirits to the people but to bring their personal spirits to the world'. Yet the modern, marketed carvings continue to be spirit-imbued (Sowada 2002:63-4). When Sowada asked highschool children boarding in Agats to use broken pieces of modern carvings for firewood, they would not do so for fear of offending the spirits (Sowada 2002:64). The spirits of the deceased,

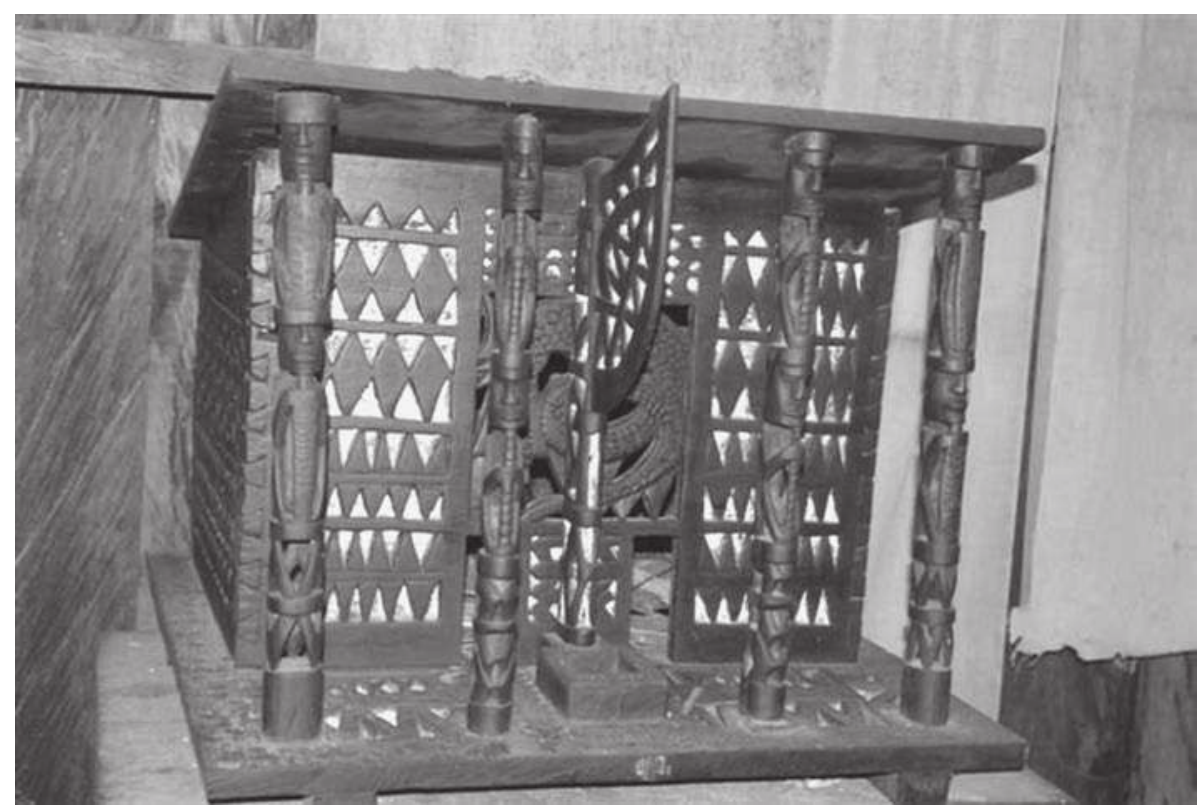

Model of a Karapao ceremonial house in the Roman Catholic church of Poraoka, Mimika, 6 November 2006. Photograph by Kal Muller. 


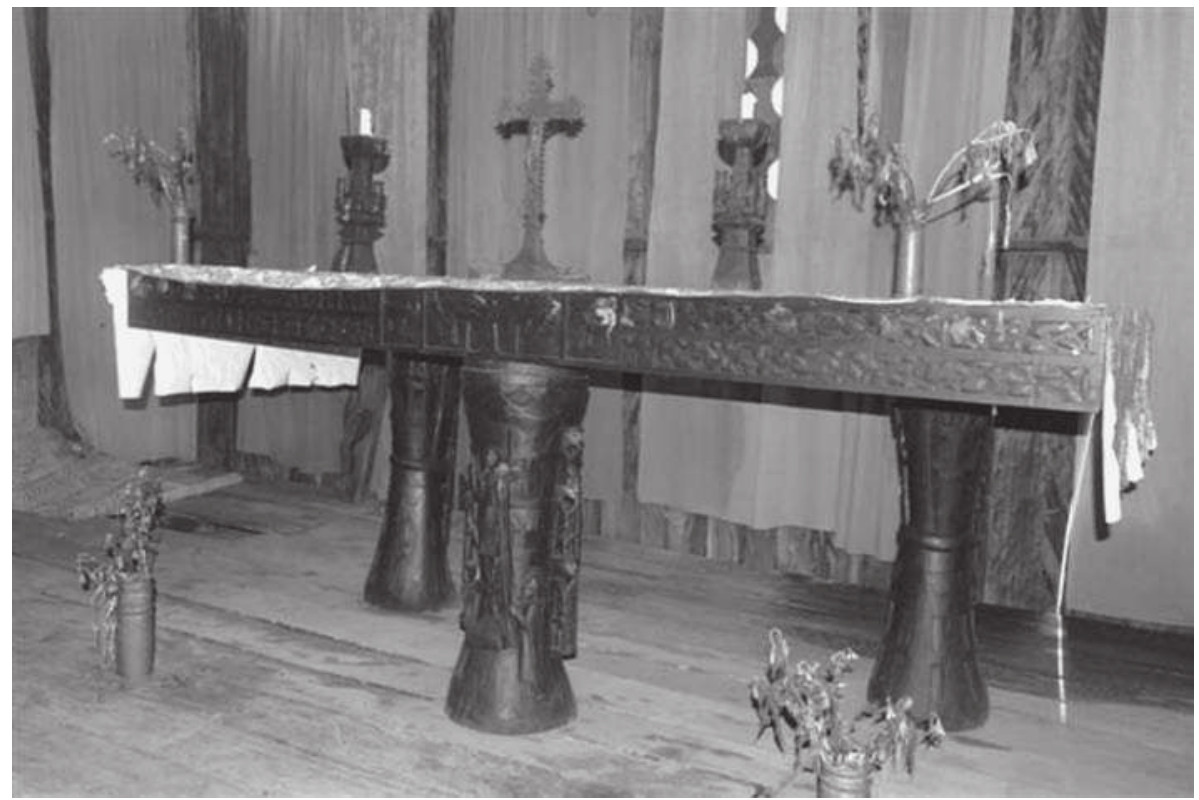

Altar of Roman Catholic church of Poraoka, Mimika, 6 November 2006. The drums signify communication with the supernatural. Photograph by Kal Muller.

be they Asmat or Kamoro, are also experienced as omnipresent. A team of Kamoro woodcarvers, invited to demonstrate their art during a Kamoro exhibition at the National Museum of Ethnology in Leiden in 2002, addressed their ancestors at the very moment of their arrival on the premises. They requested their permission to display their craftsmanship and made offerings to them.

Obviously Asmat and Kamoro carvings, be they traditional or modern, convey their cultural and personal identity, as promoted by the Crosiers. However, this does not detract in the least from their traditional spiritual significance.

There is also a political aspect to this matter, due to the promotion of ceremonies and carvings by the government and Freeport Mine. One could term this 'cultural diplomacy', a catch-phrase launched by an Indonesian foreign minister, when the downturn in oil revenues in the 1980s prompted the government to give international tourism a greater role (Jacobs 2003a:130). She notes that cultural diplomacy occurred on a large scale when Indonesia promoted itself in the United States with a festival in 1990-1991 consisting of 700 cultural events in some 50 cities. Part of the promotion was a fourweek tour funded by the Freeport Mine in which Asmat and Dani groups 
performed in four museums. Under the New Order, regional cultures were considered to constitute the national culture, rather than a national culture replacing the regional ones. However, regional cultures had to fit into the national ideological framework and consequently were supervised by the government, in this case the Department of Education and Culture (Jacobs 2003a:97). Jacobs outlines two effects of this policy: a state-controlled reification of culture which does not allow for regional political expression, and a reduction in ethnic diversity to the provincial level (Jacobs 2003a:97-102). In a state-sponsored theme park in Jakarta the building for Papuan artefacts was filled with objects without any reference to their origin and mainly consisting of unnamed Asmat objects (Jacobs 2003a:94). Asmat became the 'culture' of the entire province of West Irian, of Papua. Asmat motifs were appropriated by outsiders without compensation. Examples are Asmat-style lampposts in the streets of Jayapura made by Buginese craftsmen, Asmat motifs in Javanese jewellery, a new line of cosmetic make-up called Asmat, and fashion inspired by Asmat and Dani costumes, even to the point that some Asmat and Dani were flown in for the occasion. Papuan 'backwardness' and headhunting were even turned into an asset for promoting Indonesian tourism (Jacobs 2003a:101). In short, Asmat 'culture', an artistic and artificial reification, was Indonesianized and commercialized. The less well-known Kamoro culture jumped on the Asmat bandwagon. Although reification of culture has been regularly criticized by anthropologists, it should be borne in mind that indigenous people often adapted to it. ${ }^{7}$ Jacobs (2003a:123) notes that most of the Kamoro people had chosen to be involved: 'They felt they were representing a larger Kamoro community and perceived this as a responsibility, which led equally to personal advantage and profit.'

What is the relation of the Freeport Mine to the government and to the local populace? To answer this question I draw mainly on Jacobs's clear and concise $\mathrm{PhD}$ thesis (2003a:102-56), in conjunction with a seminar paper written by Ballard (1997) as an independent consultant, and a paper by Muller (2000). For further details the interested reader may consult Ballard et al. (2006). Ballard (1997:2) writes:

Freeport's Irian Jaya operation is almost certainly the world's single richest mining complex. The latest estimates suggest that the mine has both the third largest reserves of copper and the second largest reserves of gold, in the world; with much of the necessary infrastructure in place, production costs are also unusually low. Add to this the unknown potential of the largest ore body, the Grasberg, where the base of the ore deposit has yet to be identified, and the result is a mine complex of staggering wealth. 
Following the accession to power of Suharto's New Order regime, Freeport was awarded the first mining COW. Development - on-site - began almost immediately, and production commenced in 1972. Under the contract, Freeport was given mining rights for 30 years within a 100-square-kilometre concession. Neither the opinion nor the consent of the local people involved was sought. Since Freeport had viewed the exploitation of Ertsberg as a short-term project of about 20 years, the company did not consider compensating the local people either and left this to the government. The ore works are located on the land of the highland Amungme people, while coastal Freeport constructions are situated on Kamoro land. Since the Indonesian government had been slow to provide basic utilities, infrastructure, health and education, Freeport assumed responsibility for almost all these services. These included the construction of a 101-kilometre road - a titanic job in the swamps and the rainforest - and of a town, Tembagapura (Copper City), to house Freeport staff. A seaport and an airport were constructed on the Kamoro coast. The strong link between Freeport and the Indonesian government was clearly expressed at the mine's inauguration by Suharto himself. On this occasion he even renamed West Irian as Irian Jaya (Victorious Irian). He put Freeport to good political use and declared the mine to be one of ten national assets. Freeport has been obliged to house, supply and transport any government officials, including security forces (in 1997 there were 1,800 soldiers in the COW area). After the discovery of immense copper-gold ores in Grasberg, a second COW (COWB) was signed in 1991 allowing 30-year access with a ten-year extension to an area of 4,800,000 acres (the first concession covers a mere 24,700 acres). A table on the daily production rate shows an almost exponential increase in mill throughput from 7,500 metric tonnes in 1972 to 230,000 in 2002 (as anticipated in 1997), and a possible maximum of 300,000 kilotons per day. Compare this with the adjacent copper-gold mine output of 8,500 tonnes in the Tedi River area of Papua New Guinea (Ballard 1997:3). The rapid growth in tonnes gave rise to a lowlands boomtown, Timika. Its core consists of three resettlement locations, a Kamoro one (in particular Koperapoka), a West Sempan one, and a highland (especially Amungme) one. More and more highlanders from different tribes moved to Timika. Later Timika was expanded when the Indonesian government launched a transmigration programme. The first settlement of Indonesians was opened in 1985, and ten more followed in succeeding years, amounting to some 20,000 people. These include about 1,000 Kamoro, but only a handful of them turned to agriculture (Muller 2000:10). This transmigration is considered a success. The farmers mostly grow vegetables rather than rice. Their products find a ready market in the rapidly growing suburbs of Timika (Pickell 2002:231). Overseas Freeport employees in Timika have acquired their own luxurious living centre in Kuala Kencana. Jacobs (2003a:106): 
'Today Timika supports a cosmopolitan and multicultural population drawn from all areas of Indonesia, an airport and a four-star Sheraton Hotel.' The town has grown rapidly to its present size of 40,000 to 50,000 inhabitants, spread out over various, mainly ethnically separate locations. The highland Amungme and the lowland Kamoro, as the traditional inhabitants, are outnumbered by other Papuans; the Papuans in their turn are outnumbered by other Indonesians - all drawn by the magnet of employment opportunities (Jacobs 2003a:106). The rapid development had a huge impact on the region that was recognized only slowly by the government and the Freeport Mine, which initially left any action to the authorities. In 1990 the Freeport Irian Jaya Foundation was established. It was initiated by a mining engineer who persuaded the mine's manager of community services cum director of the foundation to radically change the mine's policy of non-commitment with regard to Kamoro and Amungme. Five key areas were emphasized: education, health, cultural preservation, small-scale economic development and infrastructure (Jacobs 2003a:110-1). Kamoro cultural preservation focused on woodcarving. ${ }^{8}$ As in the Asmat case, the woodcarving project was instigated by the Indonesian Department of Industry, as an opportunity for small-scale economic development. In its search for a sponsor it approached Freeport. The latter exceeded the role of sponsor and officially propagated itself as Bapak Angkat, or 'Foster Father', of Kamoro arts and culture. Dance groups were encouraged to perform for tourists from cruise ships. This also offered an opportunity for woodcarvers to sell. In 1993 Foster Father created the Kamoro Arts Building in Timika. This was modelled on a Karapao ceremonial house. Carvers from the whole region covered the walls, the doors, and the supporting poles with motifs depicting daily life activities taken from carvings on yamate and spirit poles. Carvers could be seen at work. They were also trained in market development skills. The building soon became known as a place where artefacts could not only be bought but also be commissioned. Buyers were mainly Freeport staff. The house provided some carvers with cash income but the market was restricted, with no potential for growth. This situation changed when the Foster Father project evolved from sponsorship to art patronage, with considerable influence from the patron. The Sheraton Hotel and the public buildings of Kuala Kencana, the town of Freeport employees, were embellished with monumental Kamoro anthropomorphic figures (we mawe) and open-worked panels. Asmat carvings such as a spirit canoe and carvings representing crocodiles were also put on display in the hotel. There were two outlets for selling artefacts, one at the Sheraton Hotel and one in town. The project resulted in the creation of what Jacobs 
calls 'public culture'. Kamoro carvings were further displayed at two exhibitions in Jakarta. One was mounted in the Spanish Embassy. A combined Asmat-Kamoro exhibition was timed to coincide with a conference of the APEC (Asia-Pacific Economic Cooperation). These two exhibitions are clear examples of cultural diplomacy. The Crosier Asmat project, the Kamoro State and Freeport Corporate projects converge in the reification of 'culture', limited to art. These exhibitions were meant to improve the tarnished image of Freeport Mine and to encourage socio-economic development. This reification dissociates carving, dance and ceremonies from their ritual and mythical moorings. The Foster Father project ended in 1996 when violent riots forced Freeport to close the mine for several days. The company then decided to transfer more responsibility to the government. The foundation was abandoned in favour of the Freeport Fund for Irian Jaya Development. This Fund supports the government's Integrated Timika Development Programme by making one per cent of Freeport's gross revenues available. The Fund was to be used for community development of displaced highland and coastal populations, through activities such as relocation, housing, the building of wells and infrastructure, and promoting health and education. The job of managing and disbursing the funds fell to this Development Programme. The provincial planning department in Jakarta, in conjunction with Freeport, urged members of seven ethnic coastal and highland groups involved to form non-profit development foundations through which the Fund's donations were to be channelled. In the first year the Fund disbursed AU\$ $10,000,000$ to these brand-new foundations, which however were not sufficiently equipped for this huge task (Pickell 2002:232-3). Millions of dollars were spent on housing. For the Kamoro the primary request was for ironwood and concrete housing. Pickell found out that the real reason for requesting the new houses had nothing to do with their superiority as places to live; it was a matter of 'keeping up with the Joneses', that is to say, with relocated highland people (Pickell 2002:235). There was also a campaign resulting in a drastic reduction in malaria in the lowland area adjacent to the Freeport concession. In the 1960s about 2,000 Amungme, spurred by a Catholic-oriented religious movement, left the highlands and settled in Akimuga in the eastern lowlands of Mimika. Hundreds of these migrants then succumbed to malaria, as they had no resistance to it. The high mortality rate was exacerbated by the virtual abandonment of the project by the new Indonesian government. Akimuga then became the breeding ground for the generation of Amungme that rose in rebellion in 1977 (Ballard 1997:4-5). The history of communication by the Freeport Mine and the government with the Amungme, to whom the excavation sites are the very focal points of their cosmology, is beyond the scope of my study. Suffice it to say that it is a story of failed relations, though Freeport's efforts since the mid-1990s to rem- 


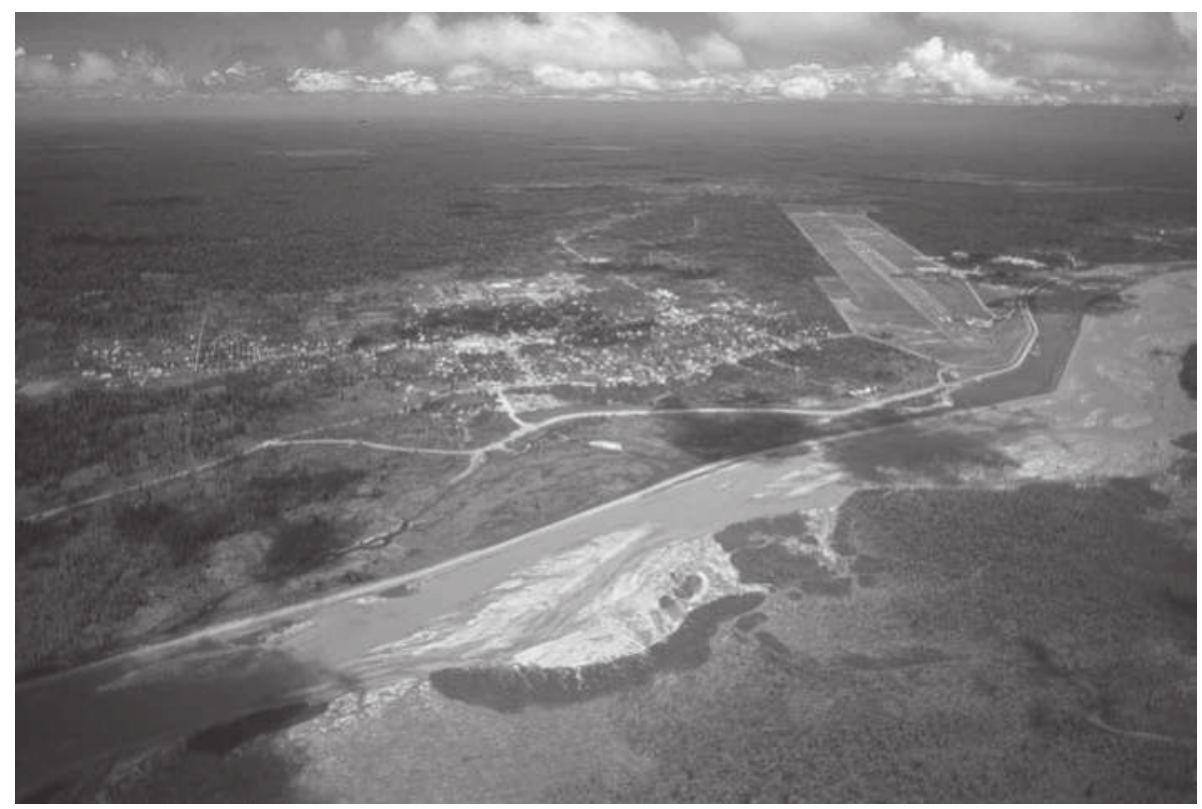

Timika. In the foreground is the Aikwa River, now bordered by levees to create a place to dump the tailings from the mine. Mimika, 1997. From: Pickell 2002:81. Photograph by Kal Muller.

edy its mistakes must be acknowledged. The Amungme saw the Freeport activities as a constant encroachment on their land without either consultation or adequate compensation. This led to numerous riots quelled by brutal force and the infringement of human rights by Indonesian military forces. It also worsened Freeport's bad reputation, as the security forces were considered an extension of the mine. The already tense situation was compounded by real and presumed actions of OPM, the Papuan liberation movement, which attacked Freeport facilities. ${ }^{9}$

I agree with Jacobs's assessment that, in general, the Kamoro are less confrontational and intense in their opinion about Freeport than the Amungme. Kamoro participation in riots was limited. Since they are more widely distributed than the Amungme, not all Kamoro communities (especially in West Mimika) are severely impacted by Freeport's activities (Jacobs 2003a:106). Freeport's expansion after the discovery of Grasberg necessitated the creation of a waste deposit area affecting the lowland rainforest. The dumping 
of 'tailings', the silty residue from the ore crushing operations near the mine, caused a freak flood downstream in the Aikwa River in 1990. The adjacent ground turned into a sheet of viscous mud flowing some four kilometres to the east. About 30 square kilometres of lowland forest, including sago areas, was covered in a thick layer of mud (Pickell 2002:83). This led to Freeport constructing a levee to protect Timika. A second eastern levee was constructed in about 1995, creating a flood plain, the Aikwa Deposit Area. The Tipuka and Nawaripi people living along this river were compensated by assisted resettlement in other areas in houses built by Freeport. However, they felt unhappy with this compensation and sent a letter of protest on behalf of 300 affected people. Freeport then invited and financed an Indonesian non-governmental organization and hired the American anthropologist Todd Harple to assess the environmental damage, including damage done to the sago groves. In November 1997 this resulted in a five-year recovery programme for the benefit of traditional landowners of five affected villages. ${ }^{10}$ An ongoing experimental reclamation will eventually turn the floodplain into valuable land for farming, fish farming, silviculture and forestry. In the end the recovered area will be about 233 square kilometers, out of a total area of 14,364 square kilometres of Kamoro land (Muller 2000:7). One wonders, though, if and how the affected Kamoro communities will avail themselves of these opportunities. According to Muller, over-logging and over-fishing by Indonesian entrepreneurs, and the permanent loss of land and natural resources to Indonesian settlers, to highland migrants, and to urbanization without reasonable compensation, constitute a bigger challenge for the Kamoro than the effects of Freeport tailings (Muller 2000:3-4).

The number of Kamoro employed by Indonesian contractors who supply the bulk of the Freeport 17,000 workforce is small, compared to the number of highland workers. Even so, although statistics from contractors are hard to come by, it is fair to say that most of them hire Papuans only as menial day labourers. As for direct employment by Freeport, company statistics from 1997 show a total of merely 73 Kamoro employees, 31 of whom are day labourers. Twenty-four Kamoro have graduated from a Freeport basic skills programme (Pickell 2002:78). By the end of 1999 Freeport directly employed 6,357 people, including 1,244 Papuans. ${ }^{11}$ Kamoro living in the Freeport area (or in villages connected to it by footpaths) do sell fresh fish and vegetables directly or indirectly to markets in Timika. These markets, however, are dominated by Buginese traders. Relations between the Kamoro and the Buginese shopkeepers are distrustful at best and outright hostile at worst (Pickell 2002:227). 
Whenever possible, the Kamoro make their purchases at Chinese shops, as the Chinese are said to give them a fair deal (Pickell 2002:228). The bulk of fish is imported from Surabaya, which is a classical case of 'coals to Newcastle' (Muller n.y.:2). Muller points to the paradox that animal protein is imported to Timika while the Arafura Sea and the fresh and brackish waters inland are teeming with fish. Meanwhile, efforts are made to turn the Kamoro into farmers (Muller n.y.:2), with no success whatsoever. The most logical solution, namely to have a boat with ice-storage containers ply Kamoro villages in order to purchase fish and shellfish, has been proposed, but Freeport managers have not seen fit to implement it. By and large, the Kamoro tend to be disinclined to work for Freeport as labourers, and this is understandable in view of their predilection for fishing, hunting and collecting in the context of ceremonies cut to contemporary size. Why not make use of their abilities by organizing modern fisheries? This industry, however, is capital-intensive. Also, why not involve them in the processing of sago?

Kamoro enterprise, shops, cooperatives or other forms of economic cooperation to take products to markets in Timika, are rare and not very successful. ${ }^{12}$ Development professionals find the Kamoro a frustrating group to work with. ${ }^{13}$

\section{Contemporary Kamoro ceremonies}

Let me conclude with a discussion of three Kamoro ceremonies Kal Muller was invited to attend in 2002 and 2003. ${ }^{14}$ The first one is part of Karapao and was held in upstream Iwaka near the Freeport concession area and connected to it by a rough track. Iwaka ceded the use of considerable tracts of land for the construction of the township of Kuala Kencana. The village was compensated by the construction of ironwood houses.

The preparation and celebration of Karapao was spread over about six months of 2002. In February a very unusual mbitoro was erected in front of the emerging ceremonial house. Muller took a close look at its construction on two occasions. The carving was done by two specialists, an old man and a younger one. The carvings commemorated the death of an unusually high number of 49 persons, instead of the usual three to five, each with their own standardized carving: six adult men, three adult women, twenty boys, and twenty girls. The large number of children bears testimony to the high infant mortality rate. Muller took down the full names of all individuals and the ages

12 For examples, see Muller n.y.:1-3.

13 For a critical assessment of their opinion, see Pickell 2002:239-40.

14 Muller generously made his field notes available to me (2002, 2003a, 2003b, 2006). 


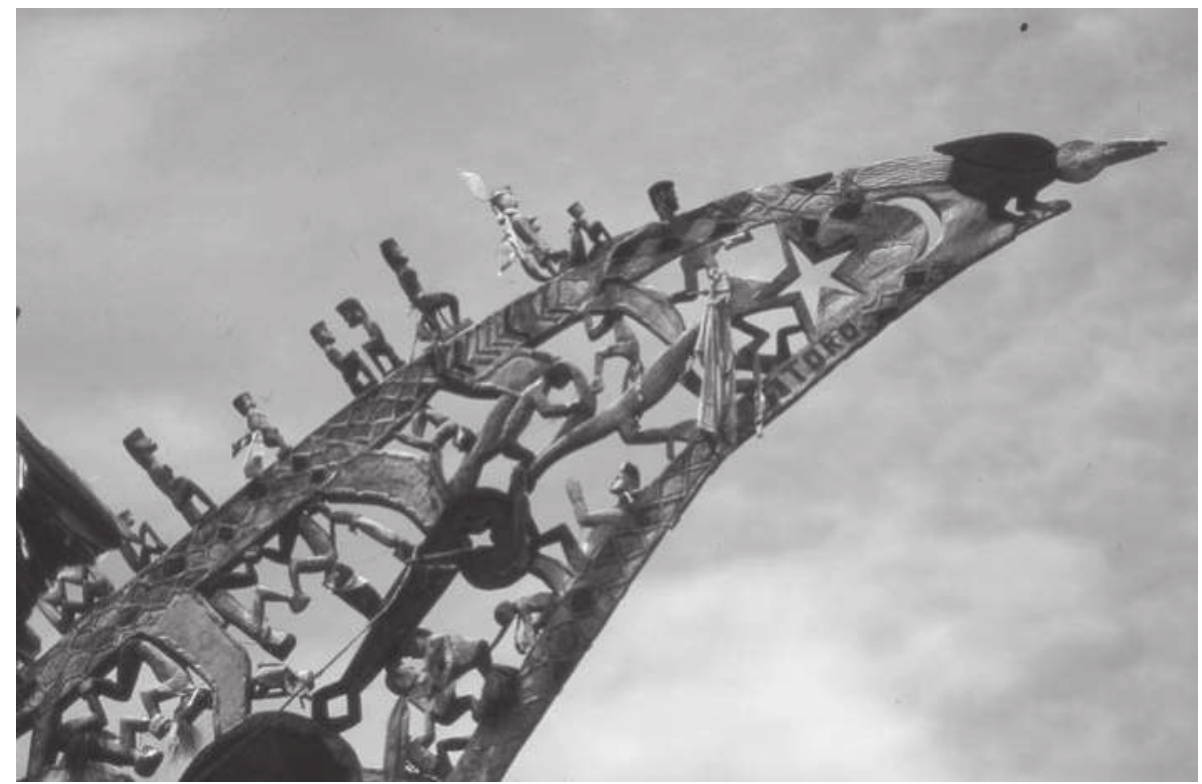

'Wing' of spirit pole at the Karapao ceremonial house of Iwaka, Mimika, July 2002. Note the mini-figures on the edge of the wing. Photograph by Kal Muller.

of the children, which varied from one to eight years old. He recorded the number of each individual on a photo of the mbitoro; the pole was donated to the Leiden Museum of Ethnology. The mbitoro as a whole was dedicated to the strongman and head of the village, who had died two years previously. The three figures on the main pole and the two on the wing are all men. Due to lack of space on the pole, about a dozen separately carved mini-figures were attached to the wing with a nail or slotted into it, an innovation. Except for the persons on the pole, all others commemorated are depicted with a few carved, often facial lines. The mbitoro covered with carvings makes a baroque impression. When asked why so many persons were commemorated, the two carvers said that they wanted to show all the recently deceased people. There was also a comment that many children and other less important people till then had never had their own mbitoro. Their relatives wanted to do something about this. This justification, however, is not sufficient as an explanation. Why now, and not earlier? My guess is that increased prosperity due to the Freeport Mine enabled more people to remunerate the carvers and their assistants. Strong emotional feelings, especially about the loss of children, could thus be made visible. 
In August, when Muller revisited Iwaka to attend a following stage of Karapao, a price tag of Rp. 100,000,000 (about US\$ 11,000) had been nailed to the mbitoro, though it was open to negotiation. Some men said that they would be proud to have the statue displayed in the Netherlands. In the course of the day two hunting parties arrived, effusively greeted, as usual, by greedy women. Chunks of meat from 11 wild pigs, a cassowary, and a crocodile were taken to the ceremonial house, accompanied by eight drummers and singers. The meat was distributed among the men and women and mainly taken home. During the day the women participated in joking (akapa): one or two women chased the other women with all sorts of objects, including banana stems and peels, and a dead snake. In the afternoon a group of drum-beating and chanting men walked slowly in a tight procession back and forth past the Karapao house very close to a statue (we mawe) covered with lime, about a metre high, placed in front of the house. It represented the grandfather of its carver, who had died some 50 years earlier. He was honoured by the procession and by dancing women. The statue was equipped with a paddle, and a bow and arrows. This implies that the spirit of the deceased is expected to depart upstream for the abode of the spirits. The dancing and chanting of men and women throughout the night was disrupted by many of the men getting very drunk, a contemporary as well as a precolonial feature.

In November Muller attended the initiation ceremony, which lasted two days. By and large it followed the pattern described in Chapter IV. On the first day, parties of pig hunters brought down 11 slaughtered pigs. They were, again, boisterously welcomed by dancing women. Muller does not mention whether the sago, pig and lizard rituals to ensure a good supply had been performed beforehand. Chunks of meat were distributed. The pig dignitaries also hung long strips of pork from the rafters of the central part of the ceremonial house, as I have described. There was drumming and singing throughout the day. Men engaged in lots of horseplay, grabbing each other's back sides and occasionally pretending to engage in sodomy. Again, women engaged in a mock fight. Muller noticed some women trying to stick a piece of wood alluding to a penis under another woman's skirt. In the afternoon the boys who were to be initiated lined up in two rows parallel to the ceremonial house. Each boy was given one or two chunks of pork. According to Muller's informants this was the upstream version of the coastal shellfish ceremony (see Chapter IV). I presume that this pork was also distributed among the initiates' mothers and sisters, but Muller does not mention it. The initiation on the second day was preceded by the traditional full-night sun dance, which ended with the shooting of two arrows with smouldering tips, to assist the sunrise. This act was preceded by men and women lining up in two rows facing the ceremonial house and jumping over a fire between them. Early in the morning the pig dignitaries ran to the river with some chunks of raw meat, moistened 


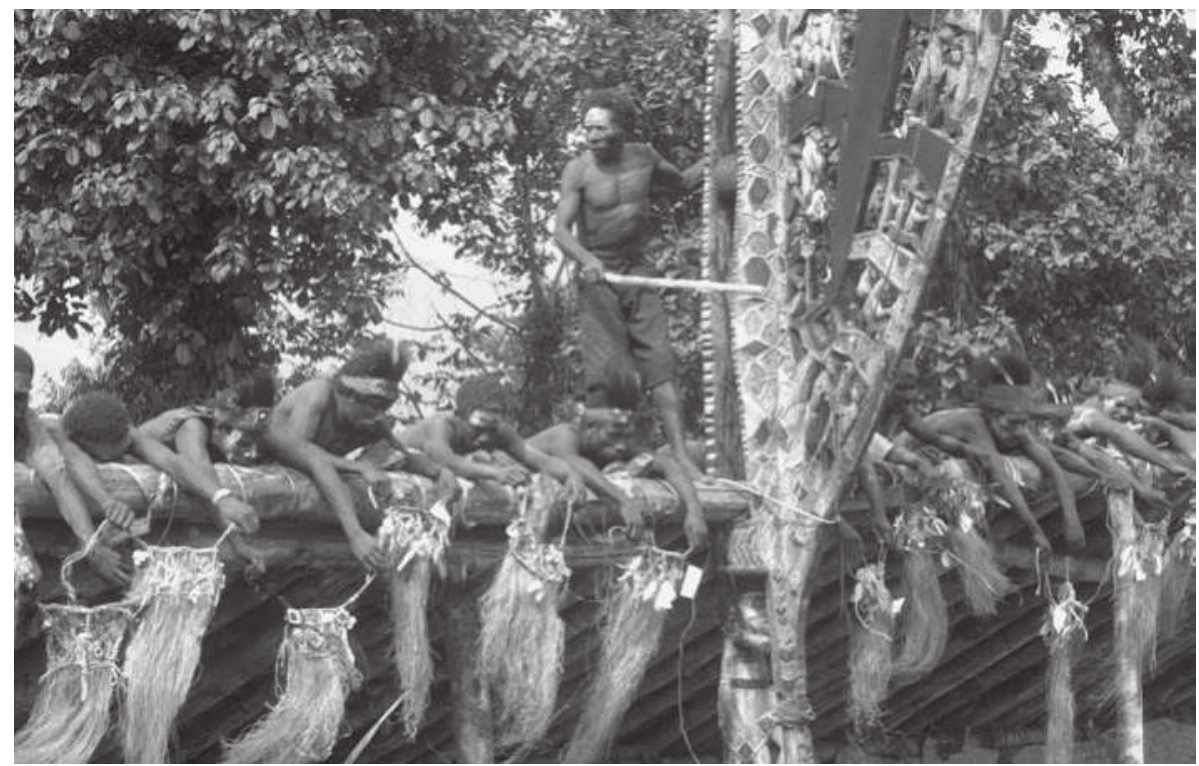

Sponsors of the initiates lie down in a long row on top of the roof of Karapao ceremonial house, Iwaka, Mimika, July 2002. They hold the 'female' tawri skirts of the initiates, to be abandoned at their passage to 'male' adulthood. Photographer: Kal Muller. Photograph also published in Smidt 2003:38.

these, then backed up and touched each initiate's back with these chunks. This is a fertility act comparable to the coastal act of knocking the content of two onaki mussels over the initiate's head. Men also formed a procession passing around another we mawe statue representing the strongman already depicted on the mbitoro. His outfit for the journey upstream to join his co-spirits consisted of two paddles, two bows and arrows, a small spear, and a digging stick, the tip of which could also be used as a spear. One elaborately carved paddle had a human figure on top representing the strongman. The double set of equipment reflects the dual division of the community. The group was led by two men wearing a mamokoro mask. (Muller bought these masks, as well as two more, leaving at least five behind.)

Around noon the boys to be initiated, ranging in age from about eight to fourteen, were brought to the ceremonial house by their mothers and female relatives and handed over to their fathers. Mats were put up at each of the dozen or so entrances.

Inside, the initiates were painted and fitted with decorations. Around 2 p.m. the drumming inside increased, and the women danced with renewed 
vigour. The mats blocking the entrances were removed and the women driven back a few metres. In each doorway an initiate was sitting on the shoulders of a squatting bride-taker. In this position they came outside and formed several rows parallel to the ceremonial house. The women were kissing the boys and making a great deal of fuss over them. Then the boys lined up facing the Karapao house, each with the man who carried them standing behind them (a ceremony similar to nose piercing, see Chapter IV). Meanwhile, some men were secretly lying on the roof of the ceremonial house. Each of them held a colourful tawri skirt. The man in charge climbed onto the roof via the mbitoro and performed a dance amid loud drum playing and women dancing below. After a while, each of the men on the roof dropped the grass-skirt, which was caught by one of the women below. In this spectacular way the conspicuous role of males and the transformation of the initiates from the female to the male domain were highlighted. The (female) tawri skirts and the (male) belts were then put on each of the boys by their bride-receivers. The lower part of the grass skirts was cut off and burned in front of each boy: he was passing from the female to the male sphere. The 'female' ashes were rubbed into the initiates' belly buttons 'so that they will become "responsible" [take on their male adult role] faster'. The boys were then placed on the men's shoulders and carried off in two rows to their houses (similar to the final act of nose piercing).

In the course of the ceremonies, drumming and chanting by about a dozen men went on non-stop. This was a crucial part of the ritual. Drummers took turns. Pickell and Muller, witnessing Karapao in Keawkwa in 1997, report that between drumming sessions men played cassette tapes featuring the Rolling Stones and Creedence Clearwater Revival (Pickell 2002:60). At some sessions in Iwaka, hidden rattles (minikwaro) imitating the muffled nasal voices of attending spirits were heard.

For two days in September 2003 Muller attended a breadfruit ceremony, Opako Kata, in Mioko, upstream on the Kamora River. This ceremony is known in virtually all Kamoro upstream villages, including Iwaka, Pigapu, Mware, Koperapoka, and the Sempan villages. The breadfruit tree only grows upstream. The initial part of the ceremony is not reported by Muller, probably because it is taboo. Coenen (1963:59) describes and presumably witnessed it. Long before the ceremony a prohibition on collecting the fruits is announced to ensure that they stay on the tree and ripen. When the fruits are deemed mature, some dignitaries of the breadfruit secret inspect them, and then take them home and show them to the people. Presumably on the afternoon of the first day of Muller's visit, the owner of the secret and two assistants, who related to him as ipere to mapere, entered a makeshift ceremonial hut, shielded from women and children. They lay down on the floor in a formation imitating the tree, the owner at the bottom and his assistants from bottom to top. 
This position is similar to that used for the female Tama, and male drum (eme) tree, rattan, and python-tree rituals (see Chapter II). By so doing the dignitaries identify with the soul of the trees (ipu enakoa). The breadfruit tree is represented by two bamboo poles. The breadfruit collected was tied to the top of the poles that projected outside the ceremonial hut but were covered by leaves, hence out of sight of the women. The dignitaries were covered likewise. Then the young men were initiated into the secret. They uncovered the fruit and the dignitaries; the ritual was explained to them (this is similar to the initiation into the python-tree secret, see Chapter II). Needless to say, all the dignitaries and young men were dressed up and painted. Then - here Muller comes in - the young men in their turn lay down and wrapped themselves around each pole. At a signal, breadfruit peelings were thrown at the women dancing nearby; the barrier to the hut was taken down. The bamboo poles moved forward quite slowly, as so many young men were clinging to them. When the poles were outside the hut, the young men let go and the two poles were erected. They were then shaken forcefully until all the breadfruit tied to the top fell off. Thus ended the first day's activities.

The following morning the villagers went to the woods to gather breadfruit. On their return, several breadfruit were placed on open fires. Drumming and chanting lasted from morning until afternoon. Then about 15 teenagers and men, who were to perform as breadfruit spirits (mbi opako) in the final act, left quietly. They were wrapped in large leaves some 3 to 5 metres high. Only feet and an occasional arm protruded from the tightly wrapped figures. They were armed with a short spear. Prior to their swaying appearance from the vicinity of the village cemetery, women and children were sent to the far side of the river, where, using breadfruit leaves, they splashed water from the canoes lined up along the bank. As soon as the spirits made their appearance in the village, they were pelted with chunks of cooked breadfruit. Occasionally some of the spirits made a concerted dash towards the men following them. Sometimes they threw the chunks back. Two of them had bows and arrows, but these were not used. The spirits were 'driven' into the woods, but before they disappeared, they shouted that they would not bother the village again and would ensure a good harvest of breadfruit. Apparently the attitude towards the spirits oscillated between awe and aggression. There is a striking similarity in this respect with the spirit platform ritual, which marks the farewell to the masked spirits of the dead (Chapter V), and with the appearance of the masked spirit of the mythical orphan during the celebration of its Asmat counterpart Yipae (Chapter VIII). The latter is also pelted.

In August 2006 Muller informed me that the people of Iwaka had announced a Women's Festival. Apparently this term refers to the Kamoro Kakuru Festival that Muller has organized almost every year since 1998, though (for 
political reasons) not in 2006. In the course of this year he travelled to most of the Kamoro villages in order to buy carvings directly because it was not possible to put them up for auction at the Festival. He promised the Iwaka people that he would buy carvings after attending the ceremonies. The use of the term Women's Festival might also be taken as a counterpart of the maledominated Kamoro Festival. Beforehand, I intimated to Muller that the term Women's Festival possibly referred to the women's secret of Tama, during which women identify with the 'soul' of a pandanus tree, the fibres of which are used to stitch together atap leaves for roofing the Ema Kame ceremonial house (see Chapter II). My guess was right. It was indeed celebrated and, quite interestingly, without its male counterpart of Ore, the ceremonial collecting of atap fronds for thatching the roof of the ceremonial house. The latter was neither really nor symbolically erected on this occasion. The Tama ritual was clearly a show of female power and was used to initiate young females into the secret to ensure its continuity. By performing this ritual they honoured a woman who had died two months before, so that her spirit would not bother the living. Evidently Muller was not invited to witness the ceremonial cutting down of the tree in the woods, but his female Indonesian assistant was. Even so, the ritual of addressing the tree, performing a dance, and the identification with its spirit by three or more female dignitaries lying naked next to the tree, presumably had been performed beforehand, without her knowing it. This was done by a group of women-in-the-know who entered the woods before the uninitiated women. The assistant's report mentions that no information was disclosed about what really happened, lest the ancestral spirits cause a calamity. Compare this with the breadfruit-tree ritual, to which Muller was also not invited. What the assistant, like Muller, did witness was the inauguration of the young women: they lay down next to the pandanus tree with their upper lips tied back, thus representing the spirits believed to be in attendance. They were covered with leaves while other women sang and danced. The latter then removed the leaves according to the usual procedure of being initiated into a secret. The pandanus tree was then cut down. Stave-like sticks were carved out of the trunk. The women returned to the village while chanting the narrative of the two men who were killed because they spied on women performing the Tama ritual (see Chapter II). They then engaged in a victory dance usually performed by men after they have killed a cassowary. By doing so they display their power and courage. Their recital justified the killing: 'You men, you cannot take us for enemies because the killing of the two men was due to their own misbehaviour'. The women did not engage in the usual mock war with the men. Instead, the men joined them in a procession, while the women chanted about the killing. Presumably in order to save time, this meeting coincided with the first stage of a performance of male rituals which in their turn are taboo for women. It is telling for 
the position of women that this performance was not announced separately, but went under the label of Women's Festival. The men called the spirits of their ancestors, who advised people not to eat several kinds of food lest they be cursed. The taboo, lasting for two months, was on five varieties of fish, one kind of freshwater shrimp, sago grubs, one kind of crab, pregnant pigs, any kind of eggs, and any kind of canned food. Thus ended the first day.

At 6.30 a.m. on the second day, women ceremonially restored peace with men by breaking two staves fashioned from the trunk of the pandanus tree; such staves are used to beat up men during a mock war. The first part of the men's Te Kata or 'mud secret' ritual, the exclusively male digging-stick ritual, which is named Poraoko (digging stick), began in the afternoon of the first day. However, it was interrupted and repeated on the afternoon of the second day because of a fight between an intoxicated younger brother who contested his brother's right to participate in the ritual. The spirits might take offence, hence the repeat. As on the first day, men and women formed two long groups moving on either side of the village road, preceded by two pairs of drummers and two men who chanted and gesticulated while moving forwards and backwards. As on the first day, the ceremony concluded with a woman pouring water on the ground from a plastic container. However, whereas pouring water on the first day was said to symbolize the Kamora River flowing into a channel dug by the ancestors, the same act on the second day symbolized the coming together of the Iwaka and Kamora Rivers at their junction. There seems to have been a mix-up, either by the informants or by the interviewers. Neither during the interrupted ceremony on the first day nor at its repetition on the second day was there any evidence of digging sticks. I take it that the ceremony on both days constituted the final phase of the digging-stick ceremony and the python ceremony, dealing with the shaping of the Kamora River and the Iwaka River respectively. The mud secret ritual was attended by both men and women.

I witnessed the initial phase of the mud secret ritual in Iwaka on 15 September 1952; the digging-stick ritual was performed by the Iwaka and Temare people who at that time lived together in separate quarters. A lengthy, fairly narrow platform was built on either side of the road, one for the Iwaka men and the other for the Timare men. Each taparu constructed its own section of the platforms. These were hidden from women's sight by foliage tied to the platforms. Old ants' nests were suspended on the inside of each platform in order to give outsiders the impression that the initiates of marriageable age (koapoka) lying on the ground next to the platforms were being attacked by ants. Each of them had in his hand a makeshift digging stick with a flattened lower end. After some instruction from old people and some exercise, the sticks of the squat- 
ting initiates hit the ground in a uniform rhythm, accompanied by chanting drummers. The sounds of rattles, bullroarers and flutes, impersonating spirits, were also heard. The ceremony dramatizes the story of the ancestors who dug the Kamora River. This river is said to differ from the winding Iwaka River in that it follows a straight course. At the end, water pouring from a container depicted the filling of the channel. The digging-stick ceremony of the first phase of the mud secret ritual that I witnessed was apparently merely alluded to in the second phase, which Muller attended in 2006. Probably two phases were combined in order to save time. During the night of the first day the men dug a large hole, 4 to 5 metres long, 3 to 4 metres wide, and 1.6 metres deep. This hole was covered with wooden boards, topped by soil and some vegetation, so as to be invisible. There was a chute-like passage into the hole at either end. Muller was asked to enter the area through a small opening between two heavy tarpaulins which screened off the area from women's sight. Some 40 to 50 men were present, completely covered with mud and dancing to the beat of several drums. A man was sitting at the far end of the area near one of the chute-like passages into the hole. He was shown a long, thin rattan. A carver fashioned a very crude head of a snake at one end of the rattan. The dancing sometimes had the men aligned in two rows facing each other, about 2 metres apart, each man with a wooden stave in his hand: the digging stick. Apparently the digging-stick ritual was being alluded to. Then to the beat of the drums some 20 men slid into the far end of the holes. Two small openings were made to allow air and light to come into the pit. Soon drumming and singing was heard from underground. The underground pit was said to be the lair of a marsupial. After some time the snake was introduced into the hole, head first. It was said to represent the python (miroko) who, while wriggling, had dug the channel of the Iwaka River, thus producing the bends in the river. A piece of plywood with a small opening chipped out was placed over the chute passage on the other end of the hole, facing the centre of the area. Soon the head of the snake peeped through the opening. The men on the outside tried to grab the head, but it was quickly pulled back After a while the head of the snake was captured and its body slowly pulled out, along with the men who were hanging onto it. As these men came out, they lay on the ground still clutching the body of the snake, pretending to be spirits of the dead. Then the tarpaulins were taken down and the women were invited to enter the ritual area. They came, and then danced a bit while crying for the dead men. Some women even lay down next to a man, crying and caressing his body. Then, at a signal, the drumming intensified and the men lying down on the ground rose from the dead as if in trance, but soon joined the dancers. Then the body of the snake was cut into small, neatly aligned pieces. About one metre of the body was left with the head and taken by several dancers to Muller. A woman 
offered the snake's head to him, with a short speech in the native language. She was probably the widow of the highly respected headman who had died two years ago and to whose memory this the mud secret ceremony was dedicated. This concluded the Pako phase. At the conclusion of Tama and of the interrupted ritual, Muller was offered a carving, namely a walking stick and a shield, both tourist items made of ironwood, presumably by the same woman. In her speech on the occasion of handing over the shield, translated by one of the men, she said that it was given as a tribute to Muller because he had been the main person to encourage their culture. She reminded him to remember Iwaka, in the hope that he and Iwaka would be appreciated by the outside world. At the end of the ceremonies Muller bought two mbi kao masks, Iwaka being the only village that continuously produces good ones. He selected half a dozen carvings out of the 80 to 100 taken to the ceremony; their quality was low compared with the carvings of some other villages.

So, a common socio-commercial setting marks the performance of Karapao, the breadfruit ritual, and the various stages of the mud secret ritual as cultural diplomacy on the part of the Kamoro participants themselves. At the same time these performances serve to promote cultural revival and cultural continuity. Ceremonial and non-ceremonial carvings and other objects, such as masks forbidden to women, are also subject to commodification. The public cutting up of the rattan, depicting the python ritual secret, in the presence of women, and even more the presentation of the python head to a foreigner by a woman is highly unusual, and could even be said to be an innovation. The usual practice with regard to ritual objects in ceremonies performed by males is that these are buried, destroyed, incinerated or hidden, or in any case kept from the view of women, children and non-initiates. To some extent Muller was considered as a participating initiate: they covered his body with lime on these occasions.

Te Kata is associated with Tiri Kata (sand secret), which is or was celebrated throughout Mimika. I happened to attend the sand secret ritual in the very same village of Iwaka in 1952, where it was combined with the digging-stick ritual. The sand secret ritual is a dramatization of the universal myth of the culture hero Mapurupiu originating from Moare, an important midstream Wania settlement. It is to his exploits that man owes mortality. Some of my informants therefore called him the Papuan Adam. An old man of Moare, cited by Coenen, takes it further: '[T]he God of the Pastor [he means Zegwaard] is of a later date. Mapurupiu is the real God, the God that reigned over the people before Adam and Eve; they are his descendants. He took the soul of his daughter and gave her the name of his wife Maimari; she was the Virgin Mary. ${ }^{\prime 15} \mathrm{He}$ is credited with the secret of eternal affluence, more specifi- 
cally with the secret of Western wealth. As noted, kata stands for ritual secret and for (Western) commodities. According to the myth, ${ }^{16}$ he is the first man to die after eating a watare, a delicious kind of yellowish eel, ${ }^{17}$ taboo during the mud secret ritual. For transgressing this taboo he is punished: he is attacked by wasps when he fails to notice their nest hanging in a sago tree cut down by him. His soul travels up the Wania River towards the mountains, as souls do after parting from the body. He calls his soul-mates wherever he goes, but there is no reply. The myth implies that there were no souls, since he was the first (super)man to die. Disappointed, he retraces his steps until frogs and snakes answer his call. He provides them with an axe and tells them to make a canoe. He then sets out for the sea accompanied by a miroko, probably an allusion to the python who shaped the Iwaka River. In the vicinity of his villages he meets up with his wife, who already - far too soon - has remarried and is married to his younger brother. He sees them having sex; he kills her and his children. Their souls join him; their bodies stay behind in the village and disintegrate. He and the newly acquired fellow souls travel upstream again, but then follow the Kamoro River. The python stays behind. Mapurupiu then meets up with two sisters, women from Mioko, at the Kamoro River, ${ }^{18}$ whom he wishes to marry. He has sex with them. Their relatives are busy digging the upper reaches of the Kamoro River. When the two women come to bring him sago, they smell the scent of a corpse and notice maggots in Mapurupiu's nose. They are frightened; they and their relatives take to their heels and travel upstream on the Kamoro River. Where are they to go? The soul of a child, said to be a son of Mapurupiu and the younger Mioko woman, ${ }^{19}$ who died in their camp, takes them to a waringin tree [a well-known abode of souls], removes its roots, and shows them the way to the brilliant underworld replete with houses and people. The child wears the jacket and trousers of the foreigners [uniform of a District Officer] as evidence of his story. They descend into the underworld and become the Surabaya people of Indonesia [named after the 'Surabaya', the ship of a Dutch expedition]. Mapurupiu finds out. He reprimands his [soul] son for removing the tree, ${ }^{20}$ which implies that the foreigners [District Officers?] are subordinate to Mapurupiu. He also descends into the underworld, but leaves them behind; he travels on further to the west. The Dutch, Americans and English are his descendants.

During the sand secret ritual, an impersonation of Mapurupiu instead of the python emerges from the hole. While doing so, a dignitary behind him

16 For the full story, see Offenberg and Pouwer 2002:162-8.

17 Information from Kal Muller, 19-6-2007.

18 Information from Kal Muller, 19-6-2007.

19 Information from Kal Muller, 19-6-2007.

20 Information from Kal Muller, 19-6-2007. 
ritually stabs him with a harpoon. Mapurupiu staggers from left to right along the platforms, past the frightened young men (koapoka) lined up at the platforms. He convincingly mimics dying. He and the man who stabbed him return to the hole, chased by the young men. The young men end up lying down near the platforms, where they are covered with leaves. The adolescent boys are then invited to enter the scene. They remove the leaves, that is, they are initiated into the Mapurupiu secret of life and death. Women are strictly taboo. The paraphernalia of the ritual are buried, burned or hidden. The ritual, as I saw it, ends with men improvising the erection of the front of the Ema Kame ceremonial house. From there, the leaders of 'right' and 'left' solemnly announce the food taboos I mentioned earlier.

Not surprisingly, the wealth of the Freeport Mine is attributed to Mapurupiu. In a contemporary version of the story told ${ }^{21}$ by the vice-president of LEMASKO (Lembaga Masyarakat Adat Kamoro, Indonesian: Kamoro Adat Council), referred to earlier in this chapter as a non-profit development foundation, Mapurupiu's soul travels in a 'Johnson canoe' with outboard motor made by frogs (Harple 2000:253) as far as Tembagapura in his search for the python who suggested that he eat the forbidden fish that caused his death. [Mapurupiu's transgression of the food taboo and his search for fellow souls are left out in this version.] Angry with the python he cannot find, he throws a shower of lime [the mist covering the mountains] and greenish bile [the greenish-blue colour of the mountains]. By so doing he locates the gold for his descendants, according to a version told to Harple (Harple 2000:253). The gold in the mine is a direct result of Mapurupiu's activities. The villagers entering the hole underneath the waringin tree spot a magnificent town with high apartment buildings [Kuala Kencana] and intricate technology [Tembagapura]. Consequently, the Freeport Mine, because of its failure to consult the Kamoro about acquiring its concession and mining the gold, is called a thief, otomo we. Freeport disobeyed the golden rule of reciprocity, aopao (Harple 2000:254). This passage is reported by Harple but is significantly absent in the 2006 version, published in Radar Timika, a paper supported by Freeport. What it does say is that Mapurupiu is a reformer. He curses the villagers for allowing his wife to remarry too soon and for not accepting his presence. Mapurupiu calls for tolerating other people if they wish to share in their wealth. By 'other people' the storyteller means strangers, foreigners. Mapurupiu is said to encourage the villagers not just to watch the foreigners from a distance, but to accept them in their midst. Here the contemporary context shows up loud and clear: the Kamoro are a minority in their own land. If they wish to share in 'progress', reported by the local paper Radar Timika of 20-11-2006 ('Reformator suku Kamoro dan petuah ular piton'). 


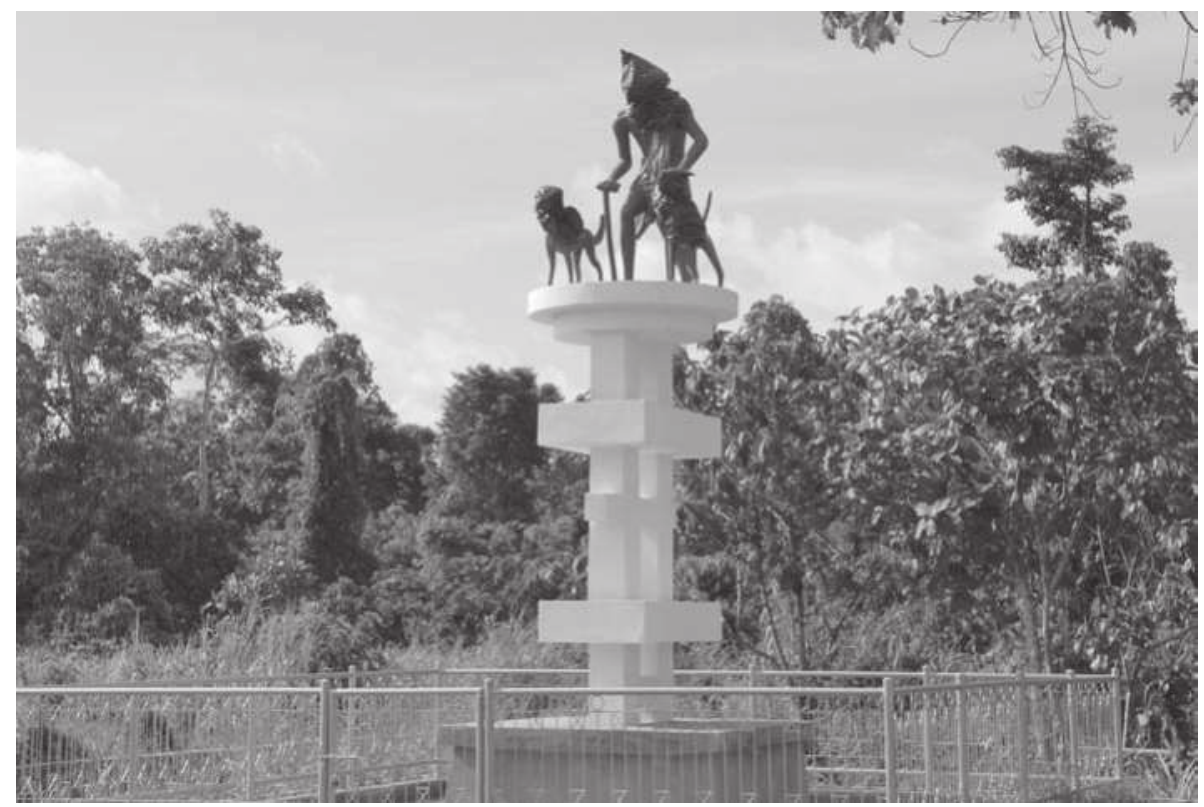

Monument of culture hero Mapurupiu with his dogs. Moare, Mimika, 13 February 2007. Erected on the initiative of the LEMASKO (Kamoro Adat Council), financed by Freeport Mine. Until the start of the inauguration ceremony, the faces are covered with plastic bags. Photograph by Kal Muller.

they must accept the foreigners. Mapurupiu, the culture hero, the first man to die and consequently imbued with knowledge of and power over the paradisal underworld, and depicted here as the great reformer, explicitly says so. In Moare a monument has been erected for Mapurupiu by the Kamoro Adat Council, sponsored by the Freeport Mine. The Wania Indonesian sub-district has been officially named after him: Mapurujaya (Victorious Mapurupiu, see Harple 2000:248). The idea for the monument came from Chris Mapeko of Moare-Hiripau, said to be a descendant of Mapurupiu. He is the executive director of LEMASKO. According to an article in Radar Timika of 7 June 2007, the Wania settlements Moare and Wanihiripao have asked for an additional monument depicting the forbidden eel, and the frog and snake or lizard who built the canoe on Mapurupiu's orders. There are proposals to turn the area around the monuments into a recreational area. ${ }^{22}$ LEMASKO has agreed to 


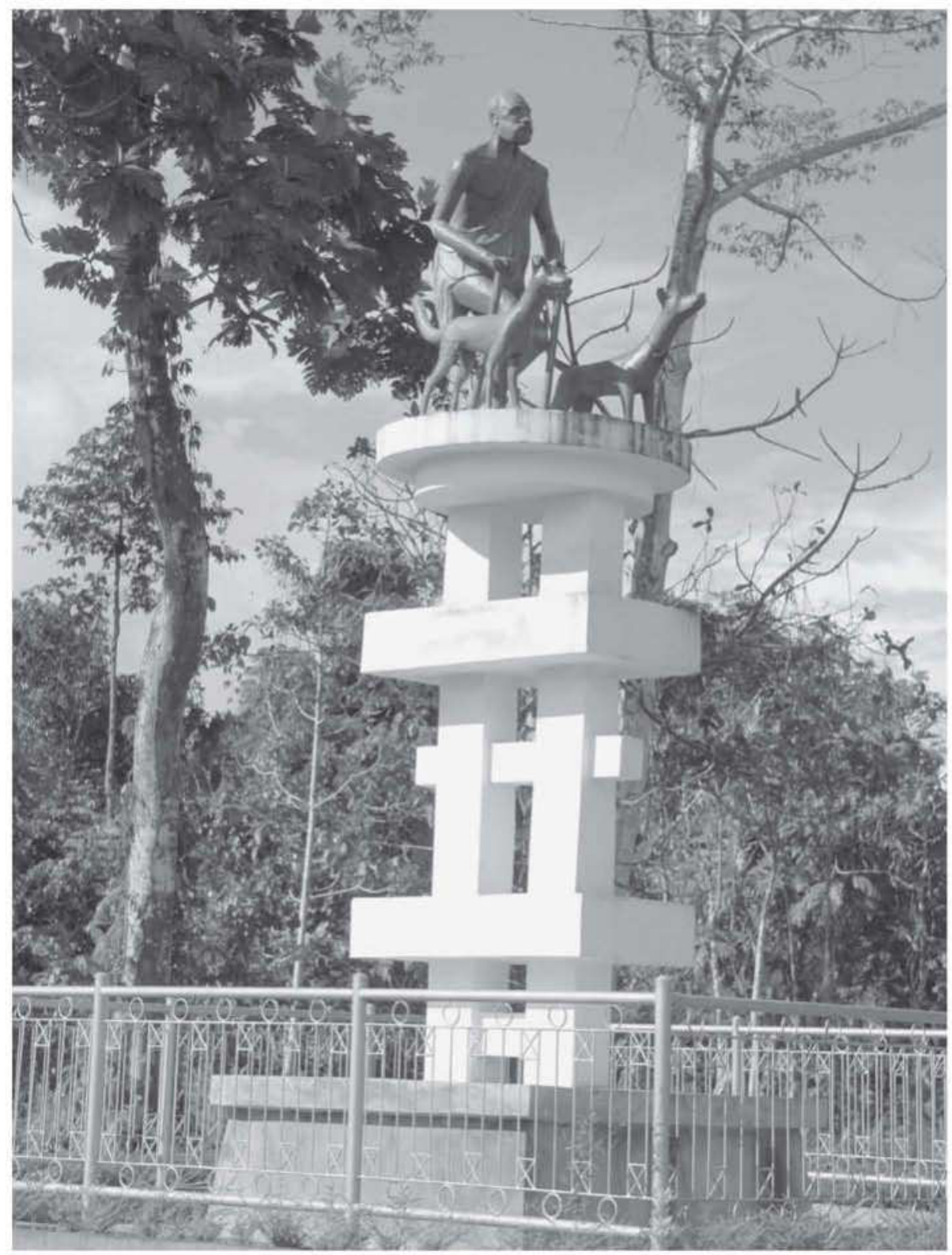

Monument of culture hero Mapurupiu with his dogs. Moare, Mimika, 18 August 2007. The plastic bags, tattered by gusts of wind, have been removed by LEMASKO staff. There has been no inauguration yet, pending deliberations about extension of the monument. Photograph by Kal Muller. 
this request. The additional project awaits the 2008 budget. ${ }^{23}$ Pending the realization of this project, which involves internal strife and politicking of communities and personal gain of key persons concerned, the official inauguration of the Mapurupiu monument was delayed. This explains the plastic bags covering the faces of the culture hero and his dogs. However, gusts of wind thereafter blew the bags to tatters. Presumably the LEMASKO staff then removed the remains. ${ }^{24}$ The monument is still awaiting the addition of a canoebuilding frog and other attributes of the culture hero to complete it before being inaugurated. However, at present other matters have a higher priority and one may wonder whether realization of these plans and an official inauguration will ever happen. ${ }^{25}$ 


\section{Glossary}

$\mathrm{A}=$ Asmat; I=Indonesian; not marked=Kamoro;

$\mathrm{c}$ is pronounced as tsj; $\mathrm{j}$ at the beginning of a word is pronounced as $\mathrm{y}$.

$\operatorname{acir}(\mathrm{A})$

afayis cokom (A)

akap, akapès (A)

akapa (K)

amaa $(\mathrm{K})$

amaa kèmè $(\mathrm{K})$

amaa mbi (K)

amaa òtò $(\mathrm{K})$

amaa pokà $(\mathrm{K})$

amakò (K)

ambirak (A)

amer (A)

amer nak (A)

amòkò kaoka (K)

amòkò wé (K)

amon, amun (A)

amota pareta $(\mathrm{K})$

amupao (K)

anaipo

aopao $(\mathrm{K})$

àpokò $(\mathrm{K})$

$\operatorname{ar}(\mathrm{A})$

ar arat ow (A)

ashu mapom cemès $(\mathrm{A})$

Asmat capinmi (K) tube

lit. grandfather one; those who have a father's father in common

the Asmat counterpart of Kamoro akapa

joking and laughter; mock attacks

sago

lit. sago rattan; involves sago dignitaries dressed up as parrots, to promote growth and abundance of sago pith sago spirit

sago (magical) medicine, to ensure full containers of sago during initiation of male adolescents

magical medicine to promote the growth and abun-

dance of sago

claimant of right; dignitary

creatures of tidal forest (associated with death)

kind of snake

black snake, 'the true one'

culture hero women; superwomen who wage war with men

culture heroes 'in the beginning'; remote male and female ancestors

to call

semi-cultivated sago

sharp pins of palm wood, used for nose piercing

(game of) frightening noises

counter-service, counter-action, counter-gift, exchange

or barter, response, revenge and retaliation

kind of snake; the name of a ceremony in which this

snake plays a ceremonial role; (ceremonial) lance

sawfish

owners of sago areas or fishing grounds

formal meeting (during Yipae)

Asmat territory 


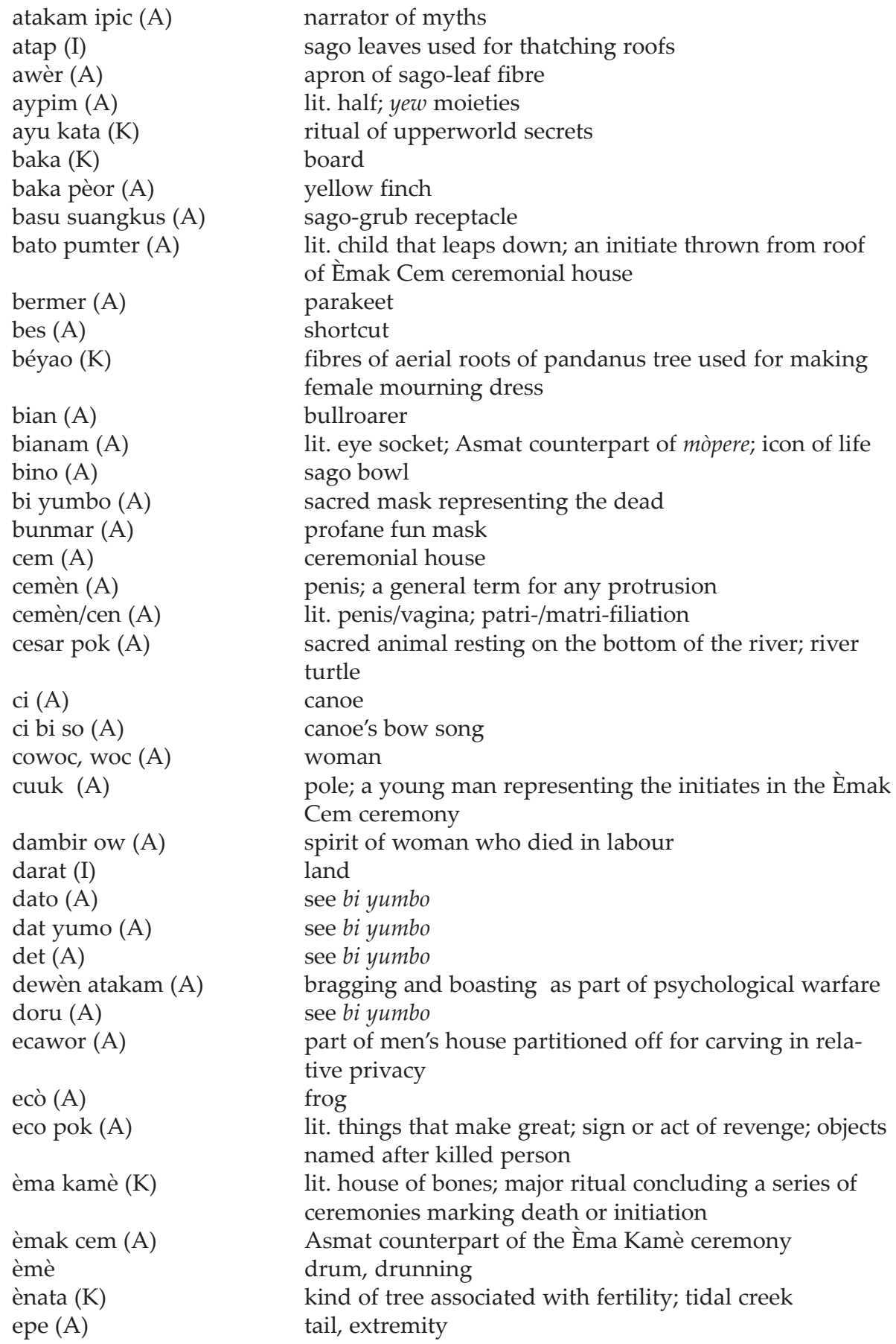




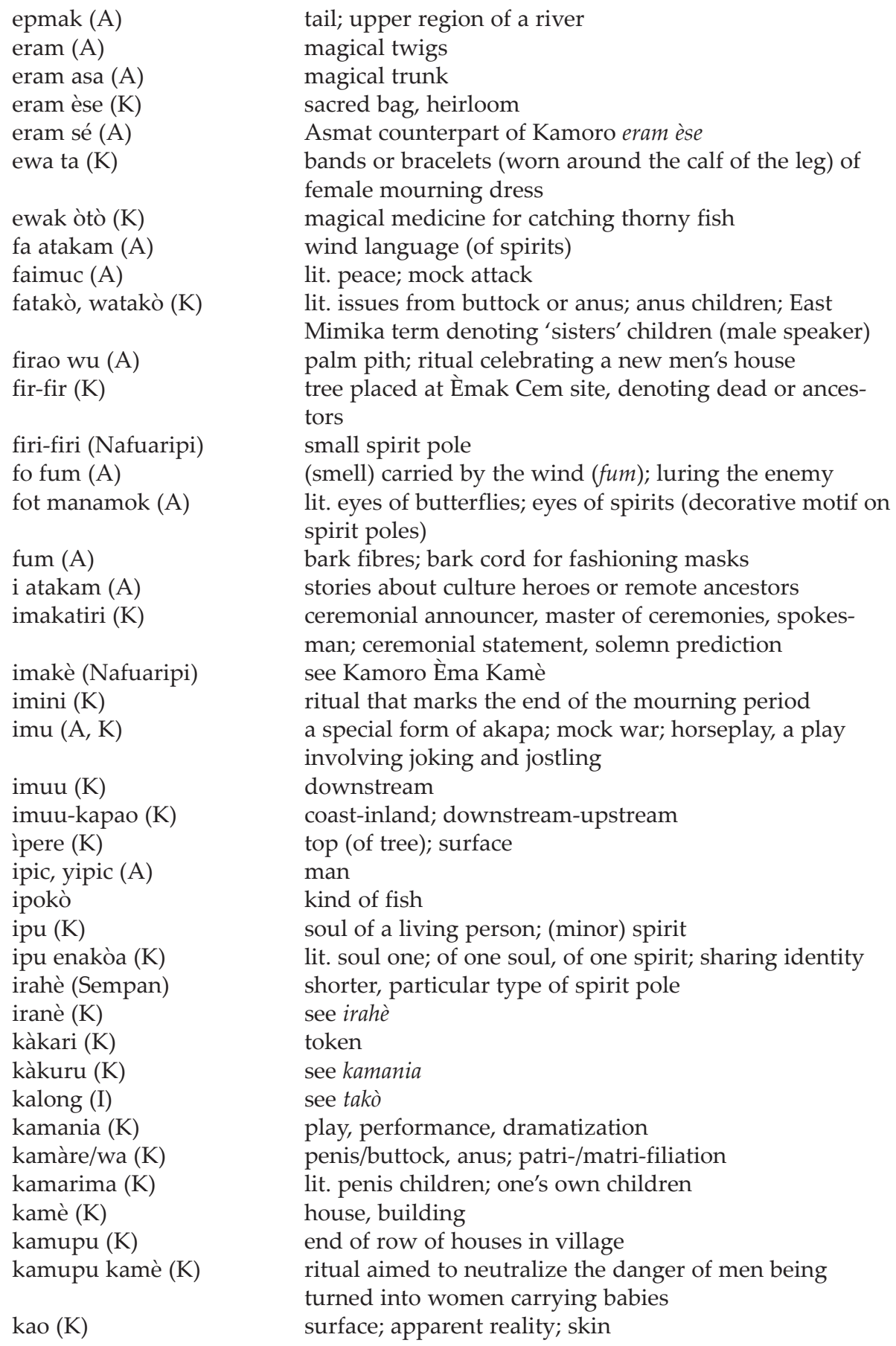




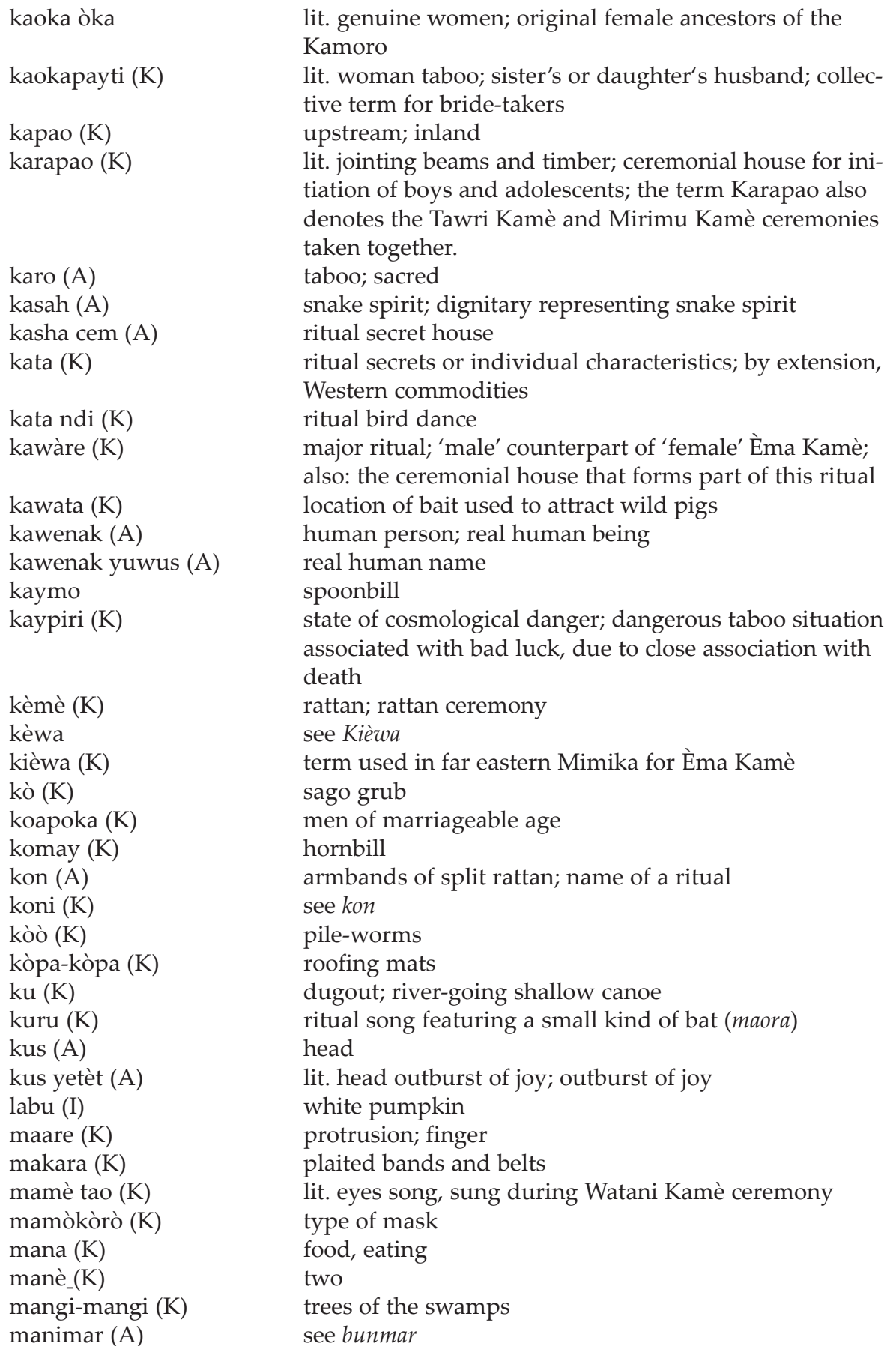




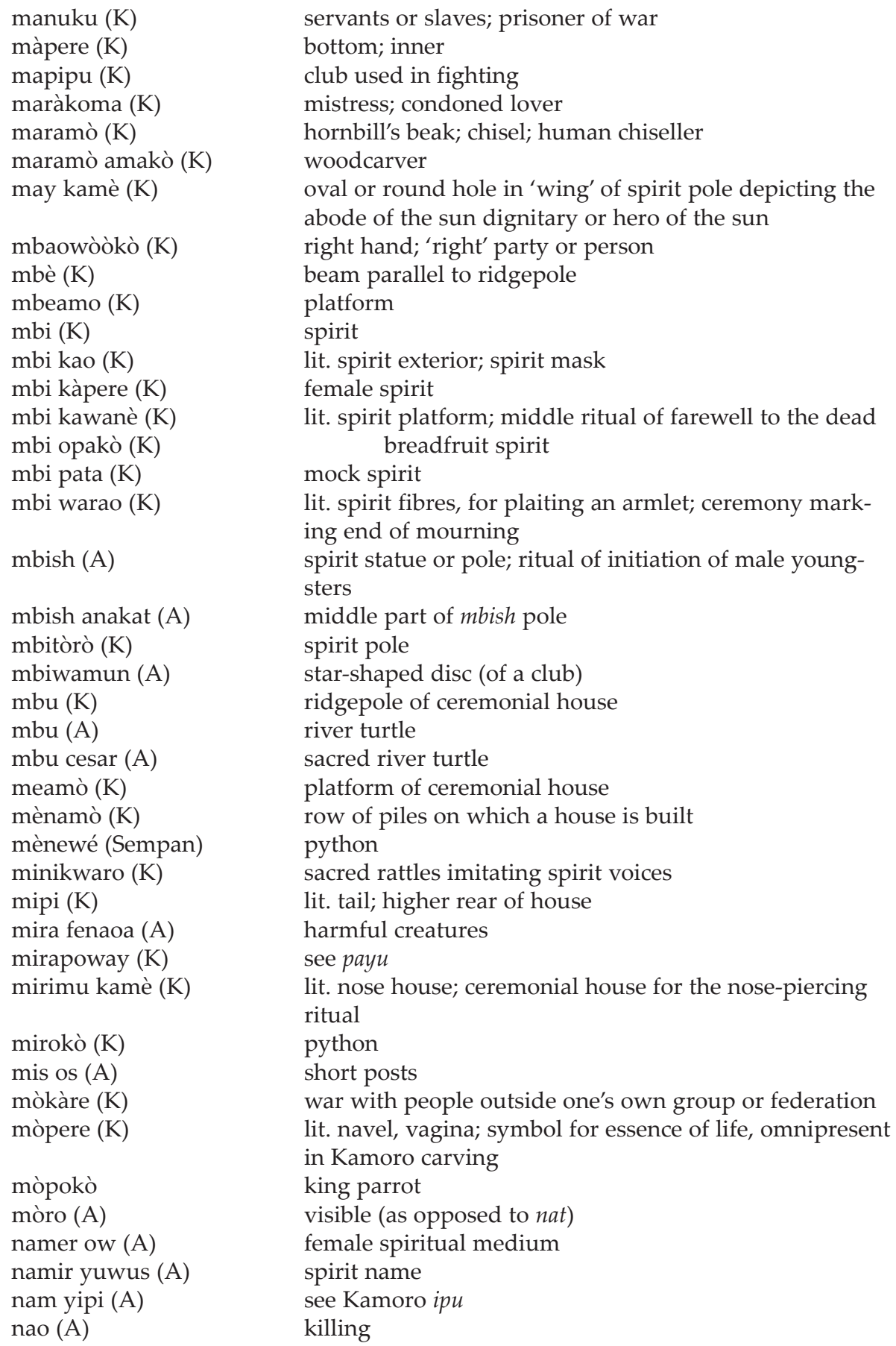


naoka-bikipa (K)

nao onak (A)

nao piri (A)

nao pokmbu (A)

naowam (A)

nao yuwus (A)

nas minu (A)

nat $(\mathrm{A})$

ndamin (A)

ndao mber (A)

ndata $(\mathrm{K})$

ndi (K)

nipah (I)

nòkòrò kao (K)

noma (K)

nòòpa $(\mathrm{K})$

ofa (A)

ofew (A)

òkom (A)

òkò òtò $(\mathrm{K})$

òokore (K)

ò mbi

omer pok (A)

ò mipi (K)

onaki (K)

onam sò $(\mathrm{A})$

ònati $(\mathrm{K})$

oo kamè $(\mathrm{K})$

ò òtò $(\mathrm{K})$

opakò kata (K)

òpò kata $(\mathrm{K})$

ore $(\mathrm{K})$

os eyok (A)

otèmakò $(\mathrm{K})$

òtènaputayoro $(\mathrm{K})$

òtepé (K)

òtò $(\mathrm{K})$

òtòmò wé $(\mathrm{K})$

owam (A)

ò wé

owen (A)

pakàre $(\mathrm{K})$ lit. younger and older brothers; sibling bonds; kin in general

lit. killing stick, club

spreading lies as part of psychological warfare

headhunting/initiation ritual

frond made from pieces of bamboo worn by the woman who severs the head of the victim during headhunting

feast

decapitation name transferred from the victim

a man without spirit or courage

the invisible; spirit (as opposed to moro)

whale

Asmat counterpart of Kamoro mòkàre

inner, real body as opposed to kao; leaves the body

together with ipu at death

(ritual) dance

kind of palm tree

lit. outer cover of Nòkòrò; outside of canoe of culture

hero Nòkòrò; ceremonial object used in Kawàre

kind of watersnake

grandfather (term of address)

wavey scarification

brothers; kin in general

sea monster

magical medicine used to catch lizards (òkò)

stealing; bride-stealing against her will

pig spirit

things to frighten people

lit. pig tails; leaves imitating pig tails to evoke a success-

ful pig hunt

mussel

lit. song of clouds, sung during headhunting raid

see ènata

pig house ritual

magical medicine used to catch pigs

breadfruit ceremony

see ayu kata

see atap

name of tree; comparable to Kamoro spirit pole

owner of the secret

magical medicine to catch pigs

secret; mark denoting a secret

(magical) medicine

thief

bamboo plate signifying act of decapitation

pig people/dignitaries

Asmat counterpart of Kamoro wiko

left hand; left party or person 
papish (A)

papita (K)

paturu wé (K)

payti (K)

payu (K)

peraekò (K)

pic (A)

pinamò (K)

pit (A)

pokay (K)

pòraokò

pòtakò paata $(\mathrm{K})$

pòtakò paata

puri (K)

puru (K)

puru kani (K)

puru manè $(\mathrm{K})$

safan (A)

samu mini (A)

sawar (A)

senap (A)

so (A)

surga (I)

takò (K)

takò wé (K)

tama $(\mathrm{K})$

tami (K)

tao $(\mathrm{K})$

tapar amakò $(\mathrm{K})$

taparè $(\mathrm{K})$

taparu (K)

tapèna wé (K)

$\operatorname{tar}(\mathrm{A})$

tarai atakam (A)

tawri (K)

tawri kamè (K)

tem as (A)

tesmaypic (A) regulated ritual promiscuity; ritual-ceremonial wifeswapping in situations of socio-political or cosmological danger

jacket of female mourning dress

lit. bird people; Èma Kamè initiates

state of ashamedness; compare with malu (I)

bullroarer

lit. vagina share one; matrilineal descendants in three generations from a specified woman; in particular descendants of ego's generation

male person

lit. buttress root; protruding 'wing' of spirit pole

python

ceremonial staff or lance used in Èma Kamè ritual; ceremonial pole

digging stick

lit. mock spears

mock lances

see puru

sacred; taboo

special horizontal ceremonial board decorated with carvings; male part of puru manè

lit. sacred two; two carved boards representing ancestors; centrepieces of Èma Kamè

abode of the dead in the underworld (heaven)

spirit of a decapitated member of one's own yew

kind of fish; carved board representing this fish

kind of forest fruit

song; Asmat counterpart of Kamoro tao

heaven

large variety of bat; flying fox

bat people; name for the people who celebrate and attend Ema Kamè

pandanus fibre strips; name of ritual of women's secrets clouds

song

lord of the land

territory of a localized descent group or extended family localized matri-oriented descent group

lit. armband people; initiates

flying fox; Kamoro takò

stories about ancestors

sago leaves; sago-leaf aprons; hair extensions

lit. apron house; 'skirt-tying ceremony', initiation of boys to adolescence

large statue made of rattan and representing a spirit who guards the interior of the Èmak Cem ceremonial house

big man; leader 


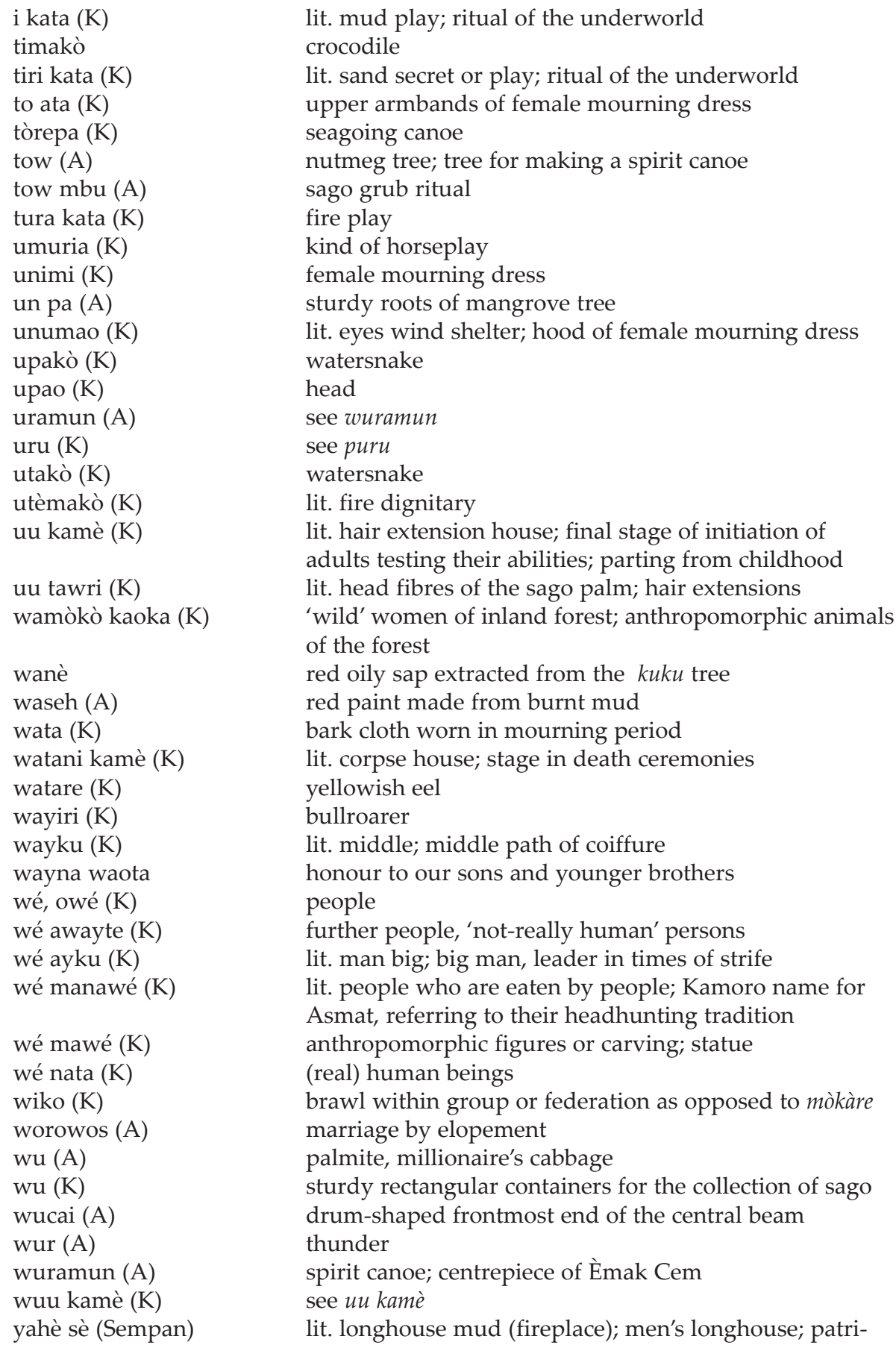


yamaté $(\mathrm{K})$

yamesh (A)

yao (K)

yao amako (K)

yaomakò, yawmakò $(\mathrm{K})$

yao ndi (K)

yao wé $(\mathrm{K})$

yatari $(\mathrm{K})$

yati $(\mathrm{K})$

yeer $(\mathrm{A})$

yeere $(A)$

yew (A)

yew mbu (A)

yew mopan (A)

yew sè $(A)$

yi muc $(\mathrm{A})$

yinic (A)

yipae (K)

yipic-cowoc (A)

yipic os (A)

yirai $(A)$

yis $(A)$

yi ti (A)

yi wawoka (A)

yok (A)

yuerfepin (A)

yunum (A)

yunum eperak (A)

yus (A)

yuwur (A) oriented localized descent group

ceremonial shield representing a deceased member of the community

warrior shield

sun

owner of the sun secret; sun dignitary

bird of paradise

lit. sun dance

sun people

kind of tree used for fashioning spirit poles

two-pronged wooden fork for erecting spirit pole

central beam; ridgepole

cries of terror of young initiates

men's house; localized patri-oriented descent group

inauguration of men's house

men's house

Asmat counterpart of Sempan yahè sè

sacred 'in the beginning' songs

mask (of spirits)

masquerade for commemoration of the dead

man-woman

long post

kind of fish; carved board representing this fish

watersnake; watersnake woman

lit. spirit child; name for the Yipae ritual in Pupis

lit. spirit female; attire of impersonator of mythological old woman during Yipae

monitor lizard

muscles

hair extensions; compare Kamoro tawri

person wearing spirit costume

see yis

tree used for making canoes 



\section{Bibliography}

Algemene Politie Onderafdeling Mimika

1961 'Het “dodenfeest” bij de Nafaripis'. [Typescript, 2 pp.]

Amelsvoort, Vincentius F.P.M. van

$1964 \quad$ Culture, Stone Age and modern medicine; The early introduction of integrated rural health in a non-literate society; A New-Guinea case study in medical anthropology. Assen: Van Gorcum. [Samenlevingen Buiten Europa/NonEuropean Societies 3.]

Baal, Jan van

1966 Dema; Description and analysis of Marind-Anim culture (South New Guinea). With the collaboration of J. Verschueren. The Hague: Nijhoff. [KITLV, Translation Series 9.]

Ballard, Chris

1997 'Engaging Freeport; Land rights, human rights and the ethics of consulting in Irian Jaya'. Paper, seminar at Australian National University. [17 pp.]

Ballard, Chris and Glenn Banks

2007 'Between a rock and a hard place; Corporate strategy at the Freeport Mine in Papua, 2001-2006'. Paper, seminar at Australian National University. [32 pp.]

Ballard, Chris, Glenn Banks, David Gillieson and David Paull

2006 'Monitoring the environment of mining in remote locations through remotely sensed data', Geocarto International 21-1:33-42.

Bateson, Gregory

1972 Steps to an ecology of mind; Collected essays in anthropology, psychiatry, evolution and epistemology. San Francisco: Chandler.

Baudhuin, Robert and Kayus Capu

1996 The story and the songs of the Bis feast; Ewer, the Piri Yaman dialect of Asmat. Sentani: Centre for Studies of Asmat Culture and Development, Diocese of Agats, Metropolitan Archdiocese Sentani, Irian Jaya.

Baudhuin, Robert, Bonifacius Firkoman and Kayas Capu

1996 Myths, stories and language lessons from the Piri Yaman dialect of the Asmat language, Ewer. Agats: Center for Asmat Culture and Development.

Baudhuin, Robert and S. Salama

1997

Stories, myths and language lessons from the village of As-atat; The Joerat dialect of the Asmat language. Agats: Center for Asmat Culture and Progress. 
Boelaars, J.H.M.C.

1981 Head-hunters about themselves; An ethnographic report from Irian Jaya, Indonesia. Foreword by Jan van Baal. The Hague: Nijhoff. [KITLV,

Coenen, Julianus Verhandelingen 92.]

1956 'Enige opmerkingen over de gods-dienstige toestand in de onderafdeling Mimika, speciaal Oost-Mimika'. Kaokonao: OFM Mission. [Typescript, 14 pp.]

1963 'Enkele facetten van de geestelijke cultuur van de Mimika'. Omawka: OFM Mission. [Typescript, 177 pp.]

Concise Oxford dictionary

$2008 \quad$ Concise Oxford English dictionary. Oxford: Oxford University Press.

Drabbe, Petrus

1937 Woordenboek der Kamoro-taal. Uta, West Mimika: MSC Mission.

1947-50 'Folk-tales from Netherlands New-Guinea', Oceania 18-2:157-75, 183:248-70, 19-1:75-90, 20-1:66-79, 20-3:224-40.

1953 Spraakkunst van de Kamoro-taal. 's-Gravenhage: Nijhoff. [KITLV.]

Durkheim, Émile

1900 'La sociologica e il suo dominio scientifico', Rivista Italiana di Sociologica 4:127-48.

1953 'La sociologie et son domaine scientifique', in: Armand Cuvillier, Où va la sociologie française? Avec une étude d'Émile Durkheim sur la sociologie formaliste, pp. 177-208. Paris: Rivière. [French translation of Durkheim 1900.]

1960 'Sociology and its scientific field' in: Kurt H. Wolff (ed.), Essays on sociology and philosophy, pp. 354-75. New York: Harper Torchbooks. [English translation of Durkheim 1900.]

Eyde, David Bruener

1967 Cultural correlates of warfare among the Asmat of south-west New Guinea. $\mathrm{PhD}$ thesis, Yale University, New Haven.

Feil, Daryl Keith

1987 The evolution of highland Papua New Guinea societies. Cambridge: Cambridge University Press.

Fleischhacker, John and Tobias Schneebaum

1977 'Woramon initiation feast in Jamasj', Asmat sketch book 6:94-9.

Gerbrands, Adriaan A.

1967 Wow-ipits; Eight Asmat woodcarvers of New Guinea. The Hague: Mouton. Harple, Todd S.

$2000 \quad$ Controlling the dragon; An ethno-historical analysis of social engagement among the Kamoro of South-West New Guinea (Indonesian Papua/Irian Jaya). PhD thesis, Australian National University, Canberra.

2002 'Prologue', in: G.A.M. Offenberg and Jan Pouwer (eds), Amoko in the beginning; Myths and legends of the Asmat and Mimika Papuans, pp. xxii-xxvi. Adelaide: Crawford House Publishing.

Herdt, Gilbert H. (ed.)

$1984 \quad$ Ritualized homosexuality in Melanesia. Berkeley: University of California Press. 
Jacobs, Karen

2003a Collecting Kamoro; Objects, encounters and representation in Papua/West New Guinea. PhD thesis, University of East Anglia, Norwich.

2003b 'Kamoro Arts Festival', in: Dirk Smidt (ed.), Kamoro art; Tradition and innovation in a New Guinea culture, pp. 67-71. Amsterdam: KIT Publishers, Leiden: Rijksmuseum voor Volkenkunde.

Kamoro baseline study

$1998 \quad$ Kamoro baseline study; Final report. Jayapura and Canberra: Universitas Cenderawasih and Australian National University. [UABS Report 7.]

Kessel, C.H. van

1961 'De Casuarinenkust', Nieuw Guinea Studiën 5-4:277-300.

1962 'Enige losse notities over rituelen en gebruiken in het Asmatgebied aan de Casuarinenkust'. Zegwaard Archives, KDC, File 5. [Cyclostyled, 16 pp.]

Knauft, Bruce M.

1993 South Coast New Guinea cultures; History, comparison, dialectic. Cambridge: Cambridge University Press.

Konrad, Gunter

1976 'Von den Asmat', in: Heinrich Harrer (ed.), Unter Papuas; Mensch und Kultur seit ihrer Steinzeit, pp. 78-80. Innsbruck: Pinguin-Verlag.

Konrad, Gunter, Ursula Konrad and Yufentias Biakai

1987 Zur Kultur der Asmat; Mythos und Wirklichkeit. Frankfurt am Main: Museum für Völkerkunde.

1995 'Emakcem - Mythe und Ritual', in: Gunter Konrad and Ursula Konrad (eds), Asmat; Mythen und rituale Inspiration der Kunst, pp. 227-63. Venezia:

Erizzo Editrice. [Expanded edition of Konrad, Konrad and Biakai 1987.]

Konrad, Gunter, Ursula Konrad and Tobias Schneebaum

1981 Asmat; Leben mit den Ahnen; Steinzeitliche Holzschnitzer unserer Zeit. Glashütten: Brückner. [Includes translation in English: Asmat; Life with the ancestors; Stone Age woodcarvers in our time.]

Konrad, Ursula, Alphonse Sowada and Gunter Konrad (eds)

2002 Asmat; Perception of life in art; The collection of the Asmat Museum of Culture and Progress. Mönchengladbach: Kühlen.

Kooijman, Simon

1984 Art, art objects, and ritual in the Mimika culture. Leiden: Brill. [Rijksmuseum voor Volkenkunde, Mededelingen 24.]

Kuruwaip, Abraham

1974 'The Asmat Bis pole; Its background and meaning', Asmat sketch book 4:5-39.

Lagerberg, S.C.I.J.

1956 Proeve ener beschrijving van varkensfeesten in Mimika. Hollandia: Kantoor voor Bevolkingszaken, Gouvernement van Nederlands Nieuw Guinea. [Kantoor voor Bevolkingszaken, Rapport 70.]

Lévi-Strauss, Claude

$1960 \quad$ Le champ de l'anthropologie; Leçon inaugurale de la chaire d'anthropologie sociale faite au Collège de France le Mardi 5 Janvier 1960. Paris: Collège de 
France. [Reprinted in: C. Lévi-Strauss, Anthropologie structurale, 1973, Vol. 2, Paris: Plon, pp. 11-44.]

1968 'The structural study of myth', in: Claude Lévi-Strauss, Structural anthropology, pp. 206-31. London: Allen Lane.

1977 'The scope of anthropology', in: Claude Lévi-Strauss, Structural anthropology, Vol. 2, pp. 3-32. London: Allen Lane. [Reprinted Harmondsworth: Peregrine Books, 1978.]

Mamapuku, Methodius and Todd S. Harple

2003 'Ancestral heritage and the essence of life', in: Dirk Smidt (ed.), Kamoro art; Tradition and innovation in a New Guinea culture, pp. 22-3. Amsterdam: KIT Publishers, Leiden: Rijksmuseum voor Volkenkunde.

Mampioper, A.

1961 'Memorie van overgave van de onderafdeling Mimika'. Kaokonao: Bestuur Nederlands Nieuw Guinea.

Muller, Kal

no year 'Easing into a money economy; An Irianese village called Kekwa struggles with the mixed blessings of cash'. [Field notes, 3 pp.]

2000 'Risk assessment of the Kamoro life-style; Introduction to the Kamoro natural resources utilization study'. [Field notes, 12 pp.]

$2002 \quad$ 'All Iwaka notes regarding Karapao'. [Field notes, 12 pp.]

2003a 'Iwaka Bitoro (Re. Karapao)'. [Field notes, 2 pp.]

2003b 'Opako Kakuru; The Kamoro breadfruit festival'. [Field notes, 2 pp.]

2006 'Iwaka village, two-day ritual cycle on 20 and 21 August 2006'. [Field notes, 4 pp.]

Offenberg, Gertrudis A.M. and Jan Pouwer (eds)

2002 Amoko in the beginning; Myths and legends of the Asmat and Mimika Papuans. Adelaide: Crawford House Publishing.

Pickell, David

2002 Between the tides; A fascinating journey among the Kamoro of New Guinea. Photography by Kal Muller. Hongkong: Periplus. [First published in 2001 by Aopao Productions as Kamoro; Between the tides in Irian Jaya.]

Pouwer, Jan

1953a 'Geschiedsbeschouwing van de bewoners der Kamoro-vlakte, onderafdeling Mimika'. Hollandia: Kantoor voor Bevolkingszaken. [Cyclostyled. 42 pp, with 27 pp. appendices.]

1953b 'Kroniek der aanrakingen met en vestigingen in de onderafdeling Mimika'. Hollandia: Kantoor voor Bevolkingszaken. [Cyclostyled, 47 pp.]

1954 'De sociale en rituele markering van de dood in de onderafdeling Mimika'. [Cyclostyled, 79 pp.]

1955a Enkele aspecten van de Mimika-cultuur (Nederlands Zuidwest Nieuw Guinea). 's Gravenhage: Staatsdrukkerij- en Uitgeversbedrijf. [PhD thesis, Leiden University, Leiden.]

1955b 'Rechten op de grond in Mimika', Adatrechtbundel 45, pp. 381-411. 's-Gravenhage: Nijhoff. [Published in English translation as Pouwer 1970.]

'A masquerade in Mimika', Antiquity and Survival 5:373-86. 
'Radcliffe-Brown's ideas on joking relationships tested by Mimika data', Nieuw-Guinea Studiën 2:11-28. [Republished as Pouwer 1964.]

1964 'Radcliffe-Brown's ideas on joking relationships tested by Mimika data', International Archives of Ethnography 1:18-30. [Earlier published as Pouwer 1958.]

1966 'Towards a configurational approach to society and culture in New Guinea', Journal of the Polynesian Society 75-3:267-86.

1970 'Mimika land tenure', in: 'Land Tenure in West Irian', New Guinea Research Bulletin 38:24-33. [Canberra, Australian National University, Research School of Pacific Studies, New Guinea Research Unit Committee. Earlier published in Dutch as Pouwer 1955b.]

1973 'Signification and fieldwork', Journal of Symbolic Anthropology 1:1-13.

1974

1975 'The structural configurational approach; A methodological outline', in: Ino Rossi (ed.), The unconscious in culture; The structuralism of Lévi-Strauss in perspective, pp. 238-55. New York: Dutton.

'Structural history; A New Guinea case study', in: W.E.A. van Beek and J.H. Scherer (eds), Explorations in the anthropology of religion; Essays in honour of Jan van Baal, pp. 80-111. The Hague: Nijhoff. [KITLV, Verhandelingen 74.]

1984 'Geslachtelijkheid en ideologie, toegelicht aan een samenleving van Irian Jaya', in: Ton Lemaire (ed.), Antropologie en ideologie, pp. 127-66. Groningen: Konstapel.

1987 'Gender in Mimika; Its articulation, dialectic and its connection with ideology'. Paper, International New Guinea Workshop, Catholic University of Nijmegen, February 24-26. [55 pp.]

1988 'The presentation of art; A museologist's dilemma', Bijdragen tot de Taal-, Land- en Volkenkunde 144:557-64. [Review article of Simon Kooijman, Art, art objects, and ritual in the Mimika culture, Leiden: Brill, 1984.]

1991 'Mimika', in: Terence E. Hays (ed.), Encyclopedia of world cultures. Vol. 2: Oceania, pp. 206-8. Boston: Hall.

1999 'The enigma of the unfinished male; An entry to east Bird's Head mythologics, Irian Jaya', Anthropos 94:467-86.

2002 "'We-humans" betwixt and between; A stories' guide', in: G.A.M. Offenberg and Jan Pouwer (eds), Amoko in the beginning; Myths and legends of the Asmat and Mimika Papuans, pp. 22-34. Adelaide: Crawford House Publishing.

2003 'Kamoro life and ritual', in: Dirk Smidt (ed.), Kamoro art; Tradition and innovation in a New Guinea culture, pp. 24-57. Amsterdam: KIT Publishers, Leiden: Rijksmuseum voor Volkenkunde.

Rawlings, Cecil G.

$1913 \quad$ The land of the New Guinea pygmies; An account of the story of a pioneer journey of exploration into the heart of New Guinea. London: Seeley and Service.

Renselaar, Herman C. van

1956

Asmat; Zuidwest Nieuw Guinea. Amsterdam: Koninklijk Instituut voor de Tropen. [Mededeling van het Koninklijk Instituut voor de Tropen 121, Mededeling van de Afdeling Culturele en Physische Antropologie 55.] 
Sahlins, Marshall

1999 'Two or three things I know about culture', Journal of the Royal Anthropological Institute 5-3:399-421.

Sanday, Peggy Reeves

$1981 \quad$ Female power and male dominance; On the origins of sexual inequality. Cambridge: Cambridge University Press.

Schneebaum, Tobias

1985 Asmat images; From the collection of the Asmat Museum of Culture and Progress. Agats: Asmat Museum of Culture and Progress, New York: Pendragon Press.

Schoot, Hein A. van der

1969 Het Mimika- en Asmatgebied (West Irian) voor en na de openlegging; Beleidsaspekten van een overgangssituatie. Tilburg: Gianotten. [PhD thesis, Katholieke Hogeschool, Tilburg.]

Smidt, Dirk (ed.)

2003 Kamoro art; Tradition and innovation in a New Guinea culture. Amsterdam: KIT Publishers, Leiden: Rijksmuseum voor Volkenkunde.

Sowada, Alphonse A.

no year 'The Pokomban'. Zegwaard Archives, KDC, File 11. [14 pp.]

1961 'Socio-economic survey of the Asmat people of southwestern New Guinea'. MA thesis, Catholic University of America, Washington.

$1970 \quad$ 'Feasts in Asmat', Asmat sketch book 1:35-8.

1979 'Waar vliegende honden vandaan komen'. Zegwaard Archives, KDC, File 70.

1980a 'Bisere and the flying foxes, related by Kunep (age 60+)', Asmat sketch book 7:71-3.

1980b 'The epic of Beorpitsj, narrated by Pirimbu of Biwar (age 65), 1979', Asmat sketch book 7:57-9.

1980c 'The saga of Tjawotsj-Biwar, narrated by Pirimbu (age 65)', Asmat sketch book 7:67-9.

1995a 'Bi Pokomban', in: Gunter Konrad and Ursula Konrad (eds), Asmat; Mythen und rituale Inspiration der Kunst, pp. 215-25. Venezia: Erizzo Editrice. [German translation of Sowada no year.]

1995b 'Religiöse und philosophische Grundkonzepte der Asmat', in: Gunter Konrad and Ursula Konrad (eds), Asmat; Mythen und rituale Inspiration der Kunst, pp. 65-72. Venezia: Erizzo Editrice.

2002 'The decline, suppression and rejuvenation of Asmat culture and art; A historical approach', in: Ursula Konrad, Alphonse Sowada and Gunter Konrad (eds), Asmat; Perception of life in art, pp. 47-65. Mönchengladbach: Kühlen.

Trenkenschuh, Frank A.

1970a 'Case for orphans', in: 'Some stories from Asmat collected by Crosier missionaries', Asmat sketch book 1:71.

1970b 'Neighbors of Asmat, border areas of Asmat; The Mimika', Asmat sketch book 2:77-82.

1970c 'Some additional notes on Zegwaard (Social structure of Asmat) from a 1970 vantage', Asmat sketch book 1:31-8. 
Trenkenschuh, Frank A. (ed.)

1970-81 Asmat sketch book; A series on the Asmat people. Agats: Asmat Museum of Culture and Progress, Hastings, Nebr.: Crosier Missions. Eight vols. [Vol. 1, 1970; Vol. 2, 1970; Vol. 3, 1971; Vol. 4, 1974; Vol. 5A-B, 1975; Vol. 6, 1977; Vol. 7, 1980; Vol. 8, 1981. Republished in 1982; reprinted in 1988 by Grove Press, New York.]

Van Arsdale, Peter W.

no year 'The Asmat tribesmen and their struggle for life'. Zegwaard Archives, KDC, File 240. [Typescript, 15 pp. Probably completed in 1970.]

1975 'Perspectives on development in Asmat', Asmat sketch book 5A:1-129.

1993 The Asmat, an ethnography and film guide. Englewood, Colorado: Center for Cultural Dynamics. [37 pp.]

Van Arsdale, Peter W. and Kathleen O. van Arsdale

1991 'Asmat', in: Terence E. Hays (ed.), Encyclopedia of world cultures. Vol. 2: Oceania, pp. 19-21. Boston: Hall.

Voorhoeve, Clemens Lambertus

1965 The Flamingo Bay dialect of the Asmat language. 's-Gravenhage: Nijhoff. [KITLV, Verhandelingen 46.]

Wollaston, Alexander F.R.

1912 Pygmies and Papuans; The Stone Age to-day in Dutch New Guinea. London: Smith and Elder.

Yokapem

1981

'Report about Asmat shields ceremony', in: Gunter Konrad, Ursula Konrad and Tobias Schneebaum, Asmat; Leben mit den Ahnen; Steinzeitliche Holzschnitzer unserer Zeit, pp. 44-6. Glashütten: Brückner. [Includes translation in English: Asmat; Life with the ancestors; Stone Age woodcarvers in our time.]

Zee, Pauline van der

$2005 \quad$ Kunst als contact met de voorouders; De plastische kunst van de Kamoro en de Asmat van West Papua. PhD thesis, University of Gent, Gent.

Zegwaard, Gerard A.

no year a 'Comment on an Asmat myth collected by Sowada 1979'. Zegwaard Archives, KDC, File 70.

no year $b$ 'Notities in verband met kosmologische interpretaties'. Zegwaard Archives, KDC, File 34. [With notes.]

no year c 'Notities over gebruiken bij het denken van de Papoea's'. Zegwaard Archives, KDC, File 204. [Typescript.]

no year d 'Notities over taal, gebruiken en levenswijze van de Asmat bevolking'. Zegwaard Archives, KDC, File 202. [Typescript.]

no year e 'Rituelen'. Zegwaard Archives, KDC, File 2. [Typescript, 75 pp.]

no year f 'Verhandeling "De Namer O" (De geestenwereld)'. Zegwaard Archives, KDC, File 39.

no year g 'Verhandeling "Het Schildenfeest in het dorp Ac 1978"'. Zegwaard Archives, KDC, File 3.

1952 'Mythologische- en voorouderverhalen van de Kamoro'. Zegwaard Archives, KDC, File 226. [Mimeographed, 112 pp.]

$1953 a$

'Losse notities'. Zegwaard Archives, KDC, File 209. 
1953b 'To-mbu en Jo-mbu te Kapi'. Zegwaard Archives, KDC, File 7.

1953-56 Papers compiled by A.A. Gerbrands. Available in the Library of the Rijksmuseum voor Volkenkunde Leiden. Two vols. [Cyclostyled, 241 pp. Kewa refers to Zegwaard's account of the Ema Kame ritual.]

1955

'Bevolkingsgegevens van de Asmatters (1953)', Adatrechtbundel 45, pp. 238-43. 's-Gravenhage: Nijhoff. [Published in English translation as Zegwaard 1977.]

1959 'Headhunting practices of the Asmat of Netherlands New Guinea', American Anthropologist 61-6:1020-41.

1977 'Data on Asmat', Asmat sketch book 6:15-32. [Originally published in Dutch as Zegwaard 1955.]

1988a 'Fira-Wu en Fo-Fum ritueel'. Zegwaard Archives, KDC, File 116.

1988b 'Tow Bu/Yew Bu Basu Suangkus'. Comment on Schneebaum 1985:105. Zegwaard Archives, KDC, File 245. [Typescript; 2 pp.]

1989 'Spirit-children and sjamanism'. Zegwaard Archives, KDC, File 27 and File 236.

1991 'Notes on the Yipae ritual'. Archives Jan Pouwer. Not available in Zegwaard Archives, KDC. [Typescript, 6 pp.]

1995 'The induction ritual and body decoration of recently initiated young men in the Mimika region', in: Dirk A.M. Smidt, Pieter ter Keurs, and Albert Trouwborst (eds), Pacific material culture; Essays in honour of Dr. Simon Kooijman on the occasion of his 80th birthday, pp. 308-23. Leiden: Rijksmuseum voor Volkenkunde. [Mededelingen van het Rijksmuseum voor Volkenkunde, Leiden 28.]

Zegwaard, Gerard A. and Jan H.M.C. Boelaars

1955 'De sociale structuur van de Asmat-stam', Adatrechtbundel 45, pp. 244301. The Hague: Nijhoff. [Annotated and published in English translation as Zegwaard and Boelaars 1970.]

1970 'An annotated translation of De sociale structuur van de Asmatbevolking', Asmat sketch book 1:13-29. [Annotations and translation by Frank Trenkenschuh and Jac Hoogerbrugge.]

Zöllner, Siegfried

1988 The religion of the Yali in the highlands of Irian Jaya. Goroka: Melanesian Institute. [Originally published in 1977 as Lebensbaum und Schweinekult; Die Religion der Jali im Bergland von Irian-Jaya (West New-Guinea), Wuppertal: Theologischer Verlag Brockhaus. Translation and synopsis by Jan A. Godschalk.] 


\section{Index}

A= Asmat; not named $=$ Kamoro

For rituals and ceremonies that are part of Ema Kame and Kaware please consult the Table of Contents (Chapters II and III).

Ac River 210

Ac village 110, 167, 173, 176, 194, 210-1

Adam 140, 229, 265

administration, government 5, 9, 11, 20,

$50,61,83,85,108-9,148,158,169-70$,

$181,184,225,227,232,242-6,250,252$, 254, 266

afayis cokom see kinship

Agats 145, 194, 247-8

Aikwa River 14, 254-5

Akimuga village 253

Akimuka River 19, 214

Alo 242-3, 245

Althusser, L. 100

Amamapere Portsite 184

Aman village 110

Amanamkai village 194

Amberep village 218-9

ambivalence $8,31,83,91,122,126,140$,

$151,176,202,213-4,240$

Amborep village 122, 188

Amnes (Taray) village 185, 187-9

Amonus, A. 145

Amungme tribal group 5, 251-4

ancestor(s) 13, 15, 99, 105, 107, 128, 135, 137, 147-9, 158, 160, 195-6, 198-9, 203, 216, 224, 235-6, 239, 263

- Mapurupiu (Papuan Adam) 266-7, see also culture heroes

- Naneu 213

ancestral pole 221, 247

ancestress ritual 34-5

ancestress(es) (kaoka oko, 'genuine

women') 23, 32-5, 37, 65, 122, 151,
155, 159, 161-2, 199-200, 239

- Cowow-Biwir 207, 210-1, 213-4

- Kane 137

- Miroko 23

- Tjawotsj-Biwar 212-3

animism 243

anus children 34

Ao (Marpac) village 142

aораo (reciprocity, revenge) 5, 13, 17, 27,

37, 85, 91, 106, 11 (A), 120, 123, 125,

128, 151, 171, 176, 204, 209-10, 222,

267

apoko see lance

Apollo 242, 245

Arafura Sea 104, 256

Ararao village see Umar village

Arguni Bay 117

armbands

- donning the armbands 56, 83, 237

- donning the armbands (kon, (A))

176-8, 237

Arsdale, Peter van 105

As village 144

Asewec River 132, 142, 210

ashamedness (pajti) 48, 88, 130, 228

Asia-Pacific Economic Cooperation 253

Asmat Arts Festival 248

Asmat Museum for Culture and

Progress 145, 194, 247-8

Asmat

- Bismam 110-1, 114, 126, 193, 213-4,

224, 247

- Central Asmat 104, 109, 111, 119,

$121,142,158,181-2,193,248$ 
- Citak 110

- Kawenak 109, 181

- Keenakap 109, 190, 204

- Keenok 109, 181

- Manawe 214

- Minar 135

- Northwest Asmat 142, 147-8, 157-8, $165,168-9,181,183,185$

Atat village $142,144,187-8$

Atuka village 29, 37, 39, 50, 76, 116, 119, 184

Ayam village 19, 129, 188, 225, 247

Ayip River 130-1, 138

Ayiw village 195

Ayndua villages 12, 118, 245

- Yapakopa village 12

Ayrat 168

Ba River 110-1

Bai 194

Bapak Angkat ('Foster Father') Project 252-3

Basim village 218, 220-1, 223

bat ritual (Meamo, Ireku Nao, Emakasja (S)) 29, 38-40, 43, 163

Bayir River 211

Bayit village 111

Bec River 130-1, 139, 194, 210-1

Biakai, Y. 145, 148

big men (we ayku, tesmaypic (A)) 11, 88, 110, 115, 118, 218, 122

Binar River 210

Bini, L. 145

bird dance ritual (Kata Ndi) 25

Bird's Head 99, 119, 129

birth 15, 23, 30, 35, 61

Biwar village 207, 210, 213-4, 219

Biwar-on-land village 210

Biwar-on-sea village 210-3

board see ceremonial board and sacred board

Boelaars, J. 232

Bow River 110

brawl, conflict within a group 116, 170, $185,204,212,227$

breadfruit $15,44,48,51,180,260-1$

breadfruit ceremony (Opako Kata) 15, 17,
260,262

bride-giver $11,13,23-4,46,74,106,124-5$ bride-receiver (kaokapayti) 11, 23-4, 26-7, 30-1, 35-6, 40, 42, 44-6, 48, 52-3, 65, 67, 72, 74-5, 78-83, 85-6, 91, 93, 106, 108, $113,121,124-5,171,176,187-8,215$, $218,237,260$

Buka village 116

bullroarer see sacred rattle

cannibalism 11, 99, 113, 169, 209, 214, 216, 228

Cape Steenboom 27

cargo cult 47, 184, 247

carrying capacity see ecology

Carstensz mountain range 9

carver(s) (maramo amako) 7, 24, 26, 31-2, $36,54,65,144-5,195,198,248-9$, 252, 256-7, 264

carving(s) 20-1, 26, 31-4, 36, 65, 106, 121, $131,143,145,151-2,157,162,164,180-$ 1, 195, 197, 199-201, 203-4, 220, 239-40, $242,245-9,252-3,256-7,262,264-5$

Casuarinen Coast 102, 109, 112, 126, 139, $169,193,203,210-1,222$

Catholic Documentation Centre 102 ceremonial announcer/announcement (imakatiri) 26, 36, 44, 65, 133, 135, 184 ceremonial board 36, 148-50, 162

ceremonial shield commemorating the dead (yamate) 27-8, 31-6, 163-4, 167, 237, 252

Chatwin, B. 245

$\mathrm{Ci} \mathrm{Mbu}$ see construction, making

Citak Sub-district 110

cloud (tami) 125, 127, 239

- cloud of ashes 222

- cloud of lime powder 25, 91, 125,

152, 175, 203

- cloud of mosquitoes 74

- cloud people 224

- cloud song (Onam So) 125-8, 218, 224, 235

Coenen, J. 7, 20, 29, 32-5, 37, 39, 68, 125, 199, 260

configuration(s) 7-8, 47, 100-2, 112, 119, 178,233 
construction, making

- Ci Mbu (A) (ritual making of canoes

and shields) 167

- Firao Wu (A) (ritual opening con-

struction of new men's house) 114-5, $183,217-8$

- Yew Mbu (A) (ritual construction

and inauguration of men's house)

167, 173, 179, 182-3, 186-7, 190-2, 204,

237, 247, see also Tow Mbu

- Yimis Pokmbu (A) (ritual construc-

tion of shields) 167

cosmology 11, 13, 29, 47, 51, 66-7, 98,

124-8, 203, 210, 224, 234, 239

- ipu enakoa (cosmological unity, 'of one soul') 29, 38, 66, 124, 185, 203,

224, 261

- kaypiri (cosmological danger, bad

luck, death) 85-6, 221, 234

counter gift see gift

Creedence Clearwater Revival 260

crocodile (timako) 9, 20, 26-7, 43, 50, 132 ,

134-5, 143-5, 148, 158, 212, 252, 258

culture heroes and other mythical char-

acters $5,13,30,52,121,126-8,137$,

$141,160,216,226$

- Acakap 210-1

- Aman Yenip 186

- Anemar Ipic 125

- Aowameyao 51

- Aoweyao 13, 62, 75, 91, 128, 214-5

- Baiku 210

- Bayndosopic 139

- Beworipic 110, 197

- Beworpic 194-8, 207-9

- Biwiripic 197, 221-2, 229

- Biwirpic 163

- Buciwu 213

- Cic 131-2, 134

- Dafarawoc 130-1

- Dariw 195-6

- Darkau 213

- Desoipic 197, 207

- Desopic 110

- Ewer 127, 213

- Fayit 222

- Fumarewa 53
- Fumuripic (A) 49, 53, 59, 159, 179,

181-3, 191-2, 227, 238

- Juak 175

- Kaimes 127

- Kamirima 179, 191-2

- Kankani 221-2

- Kayir 127

- Kumurupi 125

- Kur 142, 144, 159

- Kurap 120, 130-1, 138-9, 143, 173, 183

- Maimari (Virgin Mary) 265

- Mamirima (Japako) 37, 49, 53, 59,

181-2, 192, 199, 227

- Manawe 214

- Manifuk 127

- Manimar ('orphan boy') 126, 168, 175

- Manma-tiw-nakap ('orphan boy'

(A)) 125-6

- Mapurupiu 17, 265-70, see also

ancestor(s)

- Mberen 142

- Mbiminareyao 13, 62, 75, 91, 128,

214-5

- Mbish 195-199, 208

- Mbuper 142

- Minare 214-6

- Mirokoata 134, 136

- Mirokoatayao 23, 132, 134-6, 140,

181-2

- Muanuru 48, 179-80, 191-2, 204

- Mumuripic 142

- Murupiuta 45

- Muyaropo-ayti 136

- Muyaruru 136

- Naakawe 133

- Nokoro (Kinako) 49, 55, 131, 138,

182-5, 190-2, 204, 237-8

- Omarawoc 130-1, 138

- Owus 127

- Paotaru 125

- Pipiripic 143

- Pupuripic ('hornblower') 196-7,

198-9

- Sarawap 120, 130-1, 138-9, 173, 183

- Sawar 142-4, 159 
- Seitakap 194-5, 197

- Seos 138-9

- Siwet 208, 210

- Sunu 127

- Tewer 194

- Tewerawoc 131, 163, 194, 196

- Tewerowoc 198, 207, 209-10

- Ton Yenip 48, 180, 186, 191

- Totepere 132-3, 148

- Totepereyao 133

- Ufiripic 129-31, 133, 137-9, 148, 151,

163, 183, 197

- Waise 196

- Yaun 127

- Yenip 179-80, 188-9, 191, 204, 238

- Yepem 127

- Yisbermerat 138, 147, 155

- Yuwus 213

Dani (Yali) tribal group 127, 249-50

death (ambirak) 3, 13, 15, 39, 44, 48, 51-3, 79, 83-4, 86-8, 92, 94, 106, 122-3, 130, $133,135,143,168-9,179-80,182,192$, 198, 215, 221-3, 227, 237-8, 242, 256, 267

death rituals Chapter V (79-94), Chapter X (193-205), see also spirit poles (making and erecting)

- Imini (end of mourning ceremony) 81, 86, 93

- Mbi Kawane ('spirit platform') 89-93, 118, 167, 171, 176, 237, 261 - Mbi Warao ('spirit fibres') 83-4 - Watani Kame ('corpse house') 85-8

death, ritual cleansing associated with death 84-5

- Kamupu Kame, on the occasion of a woman who dies in labour (kamupu kaoka) 17, 37

dialectic(s) 97, 100-2, 104, 113, 163, 231, 233

digging stick ritual (Poraoko, 'digging stick') 263-5

Drabbe, P. 9

dual division, duality $11,15,47,98,105$, 109-10, 119-24, 128, 185, 207, 233

- downstream (imuu)-upstream (kapa)
$19,108-9,173,185,189$

- federations 110, 115, 118

- male-female $3,13,15,17,19,28-31$,

36-8, 47, 75, 120-4, 142, 151, 159-60,

164, 167 (A), 172-3, 183 (A), 188 (A), 190-3, 199, 212-4 (A), 226 (A), 236-7,

238-9, 242

- moieties (aypim) 108-11, 115, 170,

$174,233,239$

- right (mbaowooka)-left (pakare) 11,

13, 23, 25-7, 31, 35-6, 41, 47, 51-5, 58-9, 65, 67, 70-1, 73, 120-1, 204, 212, 215,

267

- surface-root, outer-inner, top-

bottom (ipere-mapere) 13, 24, 29, 65,

89,204

- upper world-underworld (safan (A))

15, 124-6, 128, 153, 173, 194, 204

- village halves 23, 25, 32, 91

Durkheim, E. 102

ecology 103-4, 109, 112, 173, 231

- carrying capacity 103-4, 112-4, 118, 231

Elema tribal group 99, 101

Ema Kame (major 'female' ritual honouring the dead and promoting fertility, 'bone house') 15, 17, Chapter II (1946), 50, 52-3, 62, 83, 87, 93, 99, 118, $121,129,132,134-5,140,142-3,148$, 151, 167, 172-3, 176, 183, 199, 204, 222, 235-7, 239-40, 242, 246, 262, 267 - comparison with Emak Cem 157-65

Emak Cem, Embakter, Yamas (A) 19, 21, 120, 129, 131-2, 137-42, 144-5, 147-57, $167,173,176,182,186,193,197,235-8$, 247

- comparison with Ema Kame 157-65

Emo village 110

Epepea 214

Erema village 21

Erma (Soma) village 110, 169-73, 176

Ertsberg (mountain) 184, 251

Esamu village see Safan village

Espeno village 110

Etna Bay 3, 9-10, 20, 46, 102-3, 112, 1189, 134, 199, 241, 245 
Eve 140, 265

Ewec River 132

Ewer village 19, 110-1, 113, 129, 133, $163,181,195-6,198$

Ewerif River 139

Ewerpic 195

Ewta River 193

Eyde, D. 102, 105, 108, 126, 173-4, 185

Fai River 181, 210

Fait River 229

Faramap River 111

Faya, D. 145

Feil, D. 120

female ancestor see ancestress

Firao Wu see construction, making

Flamingo Bay 103, 109-10, 113, 126, 163, 169, 181, 193

Fleischhacker, J. 145, 198

foreign commodities and wealth 13, 17, $23,118-9,126,136,139-40,160-1,182-$ $3,222,232,266-7$

foreign(ers) 5, 9, 23, 45, 49, 122, 136 139-

41, 159, 161, 171, 181-2, 199-200, 220-2, $227,245,266-7$

- American 9, 241, 266

- Chinese 3, 9, 46, 119, 181, 256

- Dutch 9, 45, 91, 139, 184, 217, 233,

241-2, 245, 247, 266

- European 3, 13

- Indonesian 3, 5, 9, 28, 148, 169, 232,

241-2, 245-7, 249-53, 254-5, 262, 268

- Japanese 113

- Western 13, 17, 23, 62, 97, 113, 118-

9, 126, 136, 139, 160, 183, 232, 266

Fos village 193

Freeport Contract of Work (COW) 5, 251

Freeport Fund for Irian Jaya

Development 253

Freeport Irian Jaya Foundation 252

Freeport Mining Company 5, 7, 9, 183-4, 241, 248-57, 267-8

Freeport Portsite 184

Freeport Second Contract of Work (COWB) 251

gender see dual division (male-female) gift $13,27,29,71-2,80,84,121,133,135$, $142,159,163,171,173-4,176-7$

Golkar party 242

Gooszen, A.J. 22

government see administration

Grasberg (mountain) 250-1, 254

Gulf District 3

Harple, T. 5, 7, 184, 255

headhunting (A) 99, 110, 113, 115, 122, 126-7, 155, 165, 168-9, 173, 180, 188-91, 193-7, 201, 204-5, Chapter XI (207-30), $232,238-9,250$

- headhunting initiation ritual see initiation (Nao Pokmbu)

- headhunting prelude ritual 217-23

- headhunting raid 217-8, 223-5, 228, 235

Herdt, G. 120

Hiripao village 64,66

Hoogerbrugge 247

hornbill (komay, king parrot) 26, 32, 37, $42-3,77-8,161,164$

hornbill ceremony 41-4, 93, 164

horse play, horse battle see joking

Ibo village 165

illness 13, 15, 47, 79-80, 130, 172, 194, 222,224

- malaria 253

imakatiri see ceremonial announcer/ announcement

Imake (N) (Ema Kame, Emac Cem (A)) 129

Inawka village $26,32,35,47,53$

incest 38-9, 128, 133, 135-7, 141-2, 159, 179,208

Indonesia 5, 9, 28, 246, 249, 252

Ingarti, L. 270

initiation, testing - initiation of boys, skirt-tying ceremony (Tawri Kame, 'apron house') 15, $38,41,61-2,75-6,83,134,259-60$ - initiation of boys and male adolescents (house) (Karapao) 15, 52, 61-3, $66,68-72,76,122,242,246,248,256-$ 60,265 
- initiation of male adolescents, nosepiercing ceremony (Mirimu Kame, 'nose house') 15, 61-76, 83, 134, 202, 234-5, 238, 245, 260

- initiation of male adolescents (A) (Mbish) 167, 183, 193-4, 196-7, 200-3, 238 , see also spirit poles (making and erecting)

- initiation of male adolescents (A)

(Nao Pokmbu) 194, 225-30, 247

- testing of male adolescents (Kata

Kame, 'ritual secret house') (Kasha Cem

(A)) 153, 155, 163

- testing of male adults ( $U$ u Kame,

'hair-extension house') 61, 76-8, 83

Ipiri River 8, 10, 243-4

Ipiri village 6, 50, 83, 85-6, 116-8, 242

ipu enakoa see cosmology

Islam 9, 119, 232

Iwaka River 263-4, 266

Iwaka village $32,38,214,216-7,256-60$, 262-3, 265

Jacobs, K. 250-5

Jakarta 250, 253

Jayapura 250

Jeraja village 23

joking (akapa, akapes (A)) 13, 25, 29-31, 35-7, 40, 45, 52-3, 55-6, 66, 75, 124, 151, 163, 168, 172-3, 176, 188-9, 200, 204, $219,237-9,242,258,262-3$

Kaimana 119, 181, 199

Kaimes village 113

Kaimo village 190

Kakay 187

Kamora River 17, 19, 38, 44, 70, 99, 1167, 143, 165, 214, 260, 263-4

Kamoro Arts Building 252

Kamoro Arts Festival 7

Kamoro Kakuru Festival (Women's Festival) 261-3

Kamoro River 23, 26, 266

Kamtar 185, 188

Kamupu Kame see cleansing ritual

Kaokonao villages 20, 41, 45, 50, 68, 71, 73, 76, 78, 82, 89, 93, 103, 107, 118-9,
181, 199, 225, 231, 242, 245

- Mikiwia village 27, 89-90, 92, 94, 134

Kapauko tribal group 9

Kapi (Kapono) village 120, 142, 144-5, 147, 167-9, 173, 176, 185-9

Kapom village 188-9

Kapu village 187

Karapao see initiation

Kata Ndi see bird dance ritual

Kaware (major 'male' ritual concerning communication with under/upper world, ceremonial house) 15, 19, 37, Chapter III (47-59), 62, 65, 114, 116, $118,131,133,157-9,162,173,178-80$, 182-5, 188, 190, 192, 199, 202, 204-5, $218,224,227,234-5,237-9,242,245-6$

Kawkapu village 26-7, 32, 44

Kaye village 110

Kaymo village 195

kaypiri see cosmology

Keawkwa village 62, 135, 199

Kepi (Kopa) 211

Kiewa (S) (Ema Kame) 19, 22, 27, 32, 38-9, 42, 132, 161, 163-4, 203, 235

kinship

- ambilineal descent 214

- conical kindred 105, 174

- descent 11, 37, 98, 105-6, 111, 113,

137, 140, 161, 212, 233, 236, 266

- filiation 105-6, 110-1, 161, 233, 236

- localized patrilineal descent group

(A) (yew) 107-113, 115, 126-7, 145,

$162,170-1,179,181,185-7,189,198$,

231, 233, 246

- localized patrilineal descent group

(taparu) 11, 13, 23-4, 32, 35-6, 86, 91, $107-9,161,231,233,263$

- localized matrilineal or matrilateral subgroup (peraeko) 32, 34-5, 83, 107-8, 123, 161, 233

- mother's brother 56, 88, 126, 227-30

- patrilineal kindred (A) (afayis cokom)

106, 233

- siblings 57, 105

- sister's son 34,126

Kipia village 118-9, 232 
Kiwai tribal group 99, 101

Knauft, B. 3, 97-102, 113, 120, 231

Kolopom tribal group 99, 101

Konrad, G. 248

Konrad, U. 248

Koperapoka River 116-7, 216

Koperapoka villages $17,29,47,50,62$, $102,119,132,148,158,235,251,260$

Kuala Kencana 251-2, 256, 267

Kuruwaip, A. 194

lance 49, 133, 136, 182, 192, 205, 215, 238 - apoko (kind of snake, ceremonial lance, lance for hunting pigs) 37, 54-9, 92, 224

- pokay (ya mate, ceremonial lance, staff or pole) $44,67,91$

Leiden 7, 22, 118, 249, 257

Lembaga Masyarakat Adat Kamoro (LEMASKO, Kamoro Adat Council) 267-70

Lévi-Strauss, C. 101, 129

lime (powder) 23-6, 31, 36-7, 39, 45, 51, $58,68,74,76,91,143-4,148,152,175$, 194, 201, 209, 218, 220, 258, 265, 267

lord of the land (tapar amako) 23, 27, 160, 213, 226

Lorentz River 19

magic 38-9, 132, 138, 140-2, 197, 219, $227-8$

- sago magic 67

- sago magic ritual (Amaa Oto) 72

Mamapuku, M. 7

Mamoare village 83

Mani River 110

Mapar village 133

Maparpe village 118

Mappi District 211, 232

Marind tribal group 99, 101, 222

marriage $3,61,78,101,105-8,115,121-2$, 124, 129-30, 134-5, 137, 157, 159, 161,

$170,195,230,233,236,239,263$

- brideprice 11, 121

- bride-stealing 122

- elopement (worowos (A)) 121, 215

- polygyny 122
- sister exchange 3,11, 39, 79, 121, 147

Marx, K.

- concepts 100, see also dialectic(s)

masks 50-2, 55-6, 91, 106, 149, 167, 169,

171-3, 176, 205, 261

- manimar ('orphan') mock spirit

(mask) of Yipae (A) 169, 171, 174-5,

237, 261

- mamokoro mask 50, 56, 59, 259

- play mask 55

- sacred spirit (bi yumo, dat yumo, det, datu) mask representing the dead of

Yipae (A) 167-9, 175-6, 181

- mbi kao (type of mamokoro) mask 50,

$57,88,265$

- yinic mask 173-4

masquerade commemorating the dead (A) (Yipae, Yiti, Nat Pokmbu,

Pokomban) Chapter VIII (169-78), 179, 183, 186, 192, 261

Matoapoka River 104

Mauria, G. 58

Mauss, M. 113, 224

- total social fact 3, 113, 224

Mbi Kawane see death rituals

Mbi Warao see death rituals

Mbish see initiation, testing

mbitoro see spirit poles

Meamo see bat ritual

medicine 180

- medicinal bark 46

- pig medicine (o oto) 68

- sago medicine (amaa oto) 67

- tree lizard medicine (oko oto) 70

Mepe 132

migration 5, 47, 75, 91, 103, 110-1, 114, $119,141,158,162,235,251,253$

Mikiwia village 26

Mikiwia village see Kaokona agglomeration

Military Exploration 113

Mimika (Wakatimi) village 61, 78, 116

Mimika Coast 126

Mimika River 9, 165

Mimika

- Central Mimika 9-10, 29, 35, 38, 45, 47-8, 66, 103-4, 118-9, 134-5, 139, 143, 
158, 214, 247

- East Mimika 11, 17, 19, 21, 29, 32, $35,38,47,49,55,62,84,104,108-9$, $114-6,119,125,132,140,148,183,199$, 235

- West Mimika 3, 10, 20-1, 23, 27, 29, 35-6, 49-50, 55, 58, 78, 83, 99, 104, 108, $119,121-2,125,139,141,148,158,165$, $173,181,199,216,227,232,245$

Minaki Tiri ('gun beach') 118

Minar River 214

Mioko village 17, 23, 44-5, 70, 260, 266

Mirimu Kame see initiation

mission(ary), church 7, 11, 39, 108, 222, $232,245-7$

- Ordo Sanctae Crucis, OCS 7, 32, 145, 241, 246, 249, 253

- Ordo Fratrum Minorum, MSC 7, 9

- Protestant Mission/Church 20

- Roman Catholic Mission/Church 9, $50,61,85,119,241-3,248-9$

Miwar River 214

Moare village 265, 268-9

mock fight, mock battle see joking

Moluccan islands 119

- Kei 241

- Seram 9, 119

Momac (Le Cocq d'Armanville) River 103, 111, 142

monitor lizard (yok) 23, 43, 133-4, 138, 140,182 , see also crocodile

moon 13, 125-6, 133, 179, 245

- moon hero 125

- moon myth 126

mopere (inner/root reality, 'navel/vagina') 32-3, 35, 37-8, 162, 165, 204, 236, 240

mourning 36, 41, 79-81, 83-6, 91, 93-4, 130, 148, 182, 198, 202, 215

mud ritual (Te Kata, 'mud play'), display of sacred python from underworld $15,17,143,263-6$

Mukumuga River 27, 102, 104

Muller, K. 7, 241, 245, 256, 258, 260-2, 264-5

Mware village 38, 260

myth(s) 5, 13, 17, 30, 37-8, 43, 47, 51-2, $54-5,62,75,98-9,101,107,110,119$,
121-2, 126-7, 129, 145-9, 152, 155, 157, 159-61, 163, 167-8, 173, 175, 179-85, 190-5, 199, 207-17, 224, 232, 234-8, 246, $253,261-2,266$, see also culture heroes - M1 129-31, 133, 137, 141-2, 158, 163, $179,182,186$

- M2 131-2, 134, 141-2, 158, 179-80

- M3 132-4, 141-2, 148, 183

- M4 132-6, 139-42, 157

- M5 135-7, 141, 158

- M6 137-9, 141-2, 158

- M7 139-44, 157, 163

- Myth 1 48-9

- Myth 249

- Myth 3 49-50, 131

Nafuaripi (Sirao, Naeweripi) tribal group 19, 62, 102-3, 129, 158, 162, 183,235

Nakay village 110, 144

Namatote village 119

Namkai village 110

Nao Nokor Island 184

Naowa 118-9

Naowapinera tribal group 216

narrative(s) see myths

National Museum of Ethnology 7, 22, $118,249,257$

Nawaripi village 14, 255

Naygeripi village 32,36

Netherlands 258

New Guinea 3, 7, 22, 97-9, 101, 230

Netherlands New Guinea 5, 9

Nimae see Timika

Nokoryao, N. 184

Northwest River 21

nose piercing ceremony see initiation

Nijmegen 102

Oap River 210

Ocenep village 193, 223

Omanesep village 194

Omawka village 38,47

Omosmos River 210-1, 213

Onin Peninsula 119

Oo Kame see pig ritual

Opa village 47, 140 
Opako Kata see breadfruit ceremony

Opo Kata see upper world play

Ore Tao see sago leaves

Organisasi Papua Merdeka (OPM) 254

Orokolo 3

Otakwa River 9, 102, 161

Otakwa village 22, 31, 47, 84, 185

Owap River 182

Owus village 110

pandanus stitching strips (tama), ceremonial fabrication of tama (Tama Ore) for roofing ceremonial house 28-31, 66, $164,172,261-2,265$

papish see sexuality

Papua New Guinea 3, 251

Papuans 159, 170, 248, 252, 255

Parimau village 165

Paripia River 244

Paripia village $4,16,58$

penis children 34

Per village 110

peraeko see kinship

Pickell, D. 241-2, 245

pig ritual (Oo Kame, 'pig house') 15, 68-70, 134, 202, 207, 258

pig(s) 15, 26, 54, 66, 68-9, 76, 79, 91-2, 125-6, 130, 145, 162, 174, 202, 207-9,

$212,217-8,222,228,258,263$

- Baicep (ancestor of pigs) 213-4, 219

- Baitshep (ancestor of pigs) 127

Pigapu village 260

Pirimbu 207-8, 210

Pisan Bay 182

play (kakuru, kamania) 15, 20, 22-3, 25, 28, 40, 44-6, 50-3, 62, 70, 118, 124, 130, 132, $172-3,176,187-8,192,219,244$

- Ayu Kata, Opa Kata ('upper world secret') 44-6

- Tura Kata (fire play) 46

pokay see lance

Pomac River 145, 210

Poraoka 248-9

Poraoko village $117-8,245$

Potoway village 29, 43, 46, 134, 176

Pouwer, J. 3, 7, 33, 39, 45, 101, 129, 199, 214, 217, 242, 244, 264
Powec River 210

Pupis village 169

Pura Beach 134

Puriri Island 182

python (miroko, menewe (S), pit (A)) 22-4, 26, 32, 55, 134, 136-7, 141, 264, 267

python ceremony (Miroko Kata) 22-5, 26-7, 46, 201, 261, 263, 265

\section{Radar Timika 267}

rattan ceremony 26-8, 164, 176

Rawlings, C. 165

reciprocity $3,5,11,13,17,71-3,85,91$, $128,139,151,171,177-8,189,267$, see also aopao

revenge $13,37,49,75,106,111,123,134$, 151, 162, 182, 187, 192, 204, 209-10, 220, 222-4, 232, 234, see also aopao

Rolling Stones 260

sacred $34,45,65,118,125,127,131,161$, $163,168-9,173,180,182-3,185-6,195-$

$6,212-3$

- sacred board(s) (puru mane, puru kani) 21-2, 32-4, 37, 148-9, 151, 157, $161-2,165,204$

- sacred rattle (minikwaro), bullroarer (wayiri, payu, mirapo-way, bian (A)) 34-7, 54, 70, 145, 162, 175, 260, 264 safan see dual division (upper worldunderworld)

Safan (Esamu) village 138-9, 169, 211 sago grubs ( $k o$, capricorn beetle larvae) 30, 49-50, 54-5, 73, 93, 113-6, 151, 157, $175,179,185-9,191-2,195,200-2,204$, 217, 219-20, 225, 232, 238, 263

sago grub containers (nokoro kao,

'Nokoro's shell') (samu mini, 'spirit of a decapitated member of one's own yew' $^{\prime}$ (A)) 114, 187-8, 190, 204, 220-1, 238

sago grubs, cultivating and collecting to fill containers 185-9

sago grub ritual (A) (Tow Mbu) 55-6, 84, $115,133,145,173,183,185-6,191-2$, 204, 220, 225, 237-8, 247, see also Yew $\mathrm{Mbu}$ 
sago leaves (ore, atap (I))

- ceremonial burning of sago leaves

57-8

- ceremonial collecting of sago leaves

for roof of ceremonial house (Ore Tao)

28-31, 53-4, 66-7, 262

- using sago leaves for covering bod-

ies of spirit impersonators 171

- using sago leaves for covering carv-

ings of spirits 152

- using sago leaves for covering door-

ways of men's house 145

- using sago leaves for decorating

new canoe 57

- using sago leaves for covering sides

of ceremonial house 76-7, 86

- using sago leaves for covering spirit

canoe 146

- using sago leaves for decorating

spirit platform 91

- using sago leaves for decorating

spirit pole 200

- using sago leaves for covering

young women at their inauguration 262

sago-leaf fibres

- aprons of sago-leaf fibres (tawri) 41

- hair extensions of sago-leaf fibres (un tawri) 43

Sakarpic 195

sand ritual (Tiri Kata, 'sand play'), display of underworld culture hero 15 , 17,265

Sanday, P. 120

Saowa village 110

Sarew village 197

scarification, frightening, terrifying 27 ,

$37,53-5,58,91,143-5,147-9,151,155$,

$157,163-5,168,173,221,236-7$

Schneebaum, T. 102, 145, 190, 198, 248

Sempan tribal group 19, 22-3, 26, 35, $38,47,53,102-3,105-9,114-5$, 119-20, $129,158,161,182-3,185,231,233,235$, 251, 260

Seper River 218

Seper village 110

sexuality, eroticism 19, 30-1, 37, 39-40,
$43,48-9,68,75,78,120-1,130,132-3$, $135-7,140,142,159-60,163,172,179$, 202, 210, 243, 245, 266

- heterosexuality 99, 222

- homosexuality 3, 30, 99, 258

- promiscuity 38-40, 43, 121, 163, 222

- wife swapping (papish (A)) 39, 115, $123,172,188,221-2$

shamanism 115, 220, 227

Sheraton Hotel 252

Shuru village $19,108,110-1,113-5,121$, $129,132,147,167-9,171-2,177,181$, $185,188,207,222-3,226-7$

Sirec (Island) River 127-8, 137, 152, 182, 187, 190, 192-6, 204, 207, 209-10

Sitam River 198

Sitan (Brazza) River 194, 196, 207, 210

Smidt, D. 7

Sogoni village 211

Sor River 210-1

sorcery 124, 220

Sorong 77

Sowada, A. 102, 114, 207, 212, 246-8

Spanish Embassy 253

spirit canoe (A) (wuramun, uramun) 22, 35, 120, 142-3, 145-8, 151-3, 155, 157-8, 160-2, 164, 193, 203, 205, 236, 239, 252 spirit pole(s) (mbitoro, mbish (A)) 22, 25, 48-50, 53-4, 64-7, 70, 78, 118, 121, 125, $146,158,179,182,192,239-40,246-7$, $252,257-8,260$

- making and erecting spirit poles (commemorating the dead) 54, 64-7, Chapter X (193-205), 238, see also initiation (Mbish)

- Nao Pokmbu see initiation

structural history 101, 231

structure 100-2

sun $13,45,67-8,73,125-7,133,139,179$, $186,189,203,234-5,239,258$

- sun dance (Yao Ndi) 73-4, 125, 258

- sun hero 85, 125, 127, 139, 224, 239

- sun people (yao we) 68, 125

Surabaya 256, 266

Surabaya ship 266

Tama Tao ceremony see pandanus stitch- 
ing strips

Taniyu, P. 69

taparu (localized matrilineal descent group) see kinship

Taray village 187-9

Tarya We federation 118-9, 216

Tawri Kame see initiation

Tay 135, 214, 216

Te Kata see mud ritual

Tedi River 251

Temare village 263

Tembagapura (Copper City) 251, 267

Ternate 9

Tidore 9

Tilburg 33

Timare village 26

Timika 5, 20, 29, 184, 241, 251-2, 254-6

Timika Pantai village 63, 69

Timuka village 5, 26, 29, 35, 116, 184, 255

Tipuka River 48, 119, 184

Tipuka village 49-50, 52-3, 115-8, 182

Tiri Kata see sand ritual

totalizer 113-4, 118, 120, 230

totemism 107

tourism 78, 169, 249-50, 252, 265

Tow Mbu see sago grub ritual

Trans-Fly 101

transmigration see migration

tree lizard ritual 70-1, 258

Trenkenshuh, F. 102, 246

trickster 49, 126, 234

Umar (Ararao) village 20, 27, 36, 41, 118, 176, 245

Umari River 245

Umari village 49

Undir River 210

Unir River 193

United Nations 242, 246-7

United States of America 249

upper world play (Opo Kata), climbing a rope $44-5$

Upuye village 138-9

Uta village 119

Utukae village 62,75

Utumbuwe River 187
Uu Kame see initiation

Virgin Mary 265

Vitalis 87

Voorhoeve, B. 126

Wakatimi village 45, 165

Wanati Kame see death rituals

Wania River 26, 32, 104, 115, 116-7, 265-6

Wania Sub-district (Mapurujaya,

'Victorious Mapurupiu') 48-50, 55, 108, 116-7, 119, 233

Wanihiripao village 31-2, 268

Waoneripi village 32,39

warfare 29-30, 50, 62, 106, 110, 112-4,

$115-9,121,125,161-2,165,180,182$,

185, 191, 204, 207, 209, 212, 214-5, 220,

$222,232-3,236,238$

- prisoners of war, slaves (manuku) 9, $19,51,119$

- war shields (yamesh (A)) 162-4, 167, 180, 236, 247

- warlords and war leaders 13,62 ,

$75,83,89,207,111,115,118,125,128$,

131, 191, 198, 200-1, 207, 217-8, 220, 222, 227, 234

Warsekomen 115, 131, 207-8, 222, 227

Wasar River 169

Watiwamen (Wildeman) River 211

Wauco village 111

West Papua (Papua, West Irian, Irian

Jaya) 3, 5, 222, 247, 250-1

wife swapping see sexuality

Wollaston Expedition 20, 82, 165

Wollaston, A. 26, 32-3, 35, 165

Wumuka village 118

yahe se (men's house, 'longhouse mud'

(S)) 107

Yakafa, D. 185

Yakopeyauta, G. 82

Yamas village 110, 129, 137, 145, 147

yamate see ceremonial shield

Yao (Sokor) village 190, 193

Yaqai tribal group 232

Yaraya village 50-1, 55, 83, 118

Yaun village 110 
Yec River 210

Yokapem 167

Yeni village 110, 150, 152-4, 155, 187-8

Yoni village 216

Yepem village 110

yew (kindred) see kinship

yew (se) (men's house, 'longhouse mud'

(A)) 107, 198-9, 201-2

Yufri village 110

Yew Mbu see construction, making

Yic River (Bloemen River) 168

Yimis Pokmbu see construction, making

Zegwaard, G. 5, 19-20, 29, 31-3, 38, 68, $102,110,113-4,145,170,185,190$, 198-9, 207, 214, 216, 218, 225-7, 229-30, 242,265

Yipae see masquerade representing the dead 